Prepared for the U.S. Department of Energy under Contract DE-AC05-76RL01830

\title{
Energy Savings Modeling of Standard Commercial Building Re- tuning Measures: Large Office Buildings
}

N Fernandez

S Katipamula

W Wang

Y Huang

G Liu

June 2012

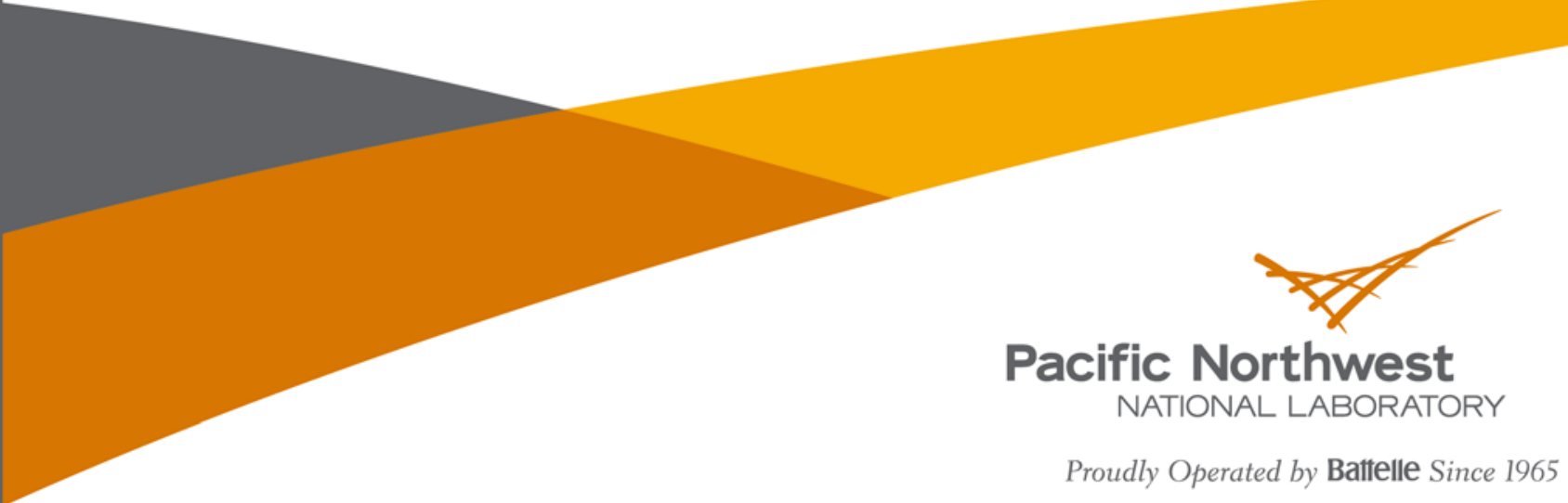


PNNL- 21569

\title{
Energy Savings Modeling of Standard Commercial Building Re-tuning Measures: Large Office Buildings
}

\author{
N Fernandez \\ S Katipamula \\ W Wang \\ Y Huang \\ G Liu
}

June 2012

Prepared for

U.S. Department of Energy

under Contract DE-AC05-76RL01830

Pacific Northwest National Laboratory

Richland, Washington 99352 


\begin{abstract}
Today, many large commercial buildings use sophisticated building automation systems (BASs) to manage a wide range of building equipment. While the capabilities of BASs have increased over time, many buildings still do not fully use the BAS's capabilities and the BASs are not properly commissioned, operated or maintained, which leads to inefficient operation, increased energy use, and reduced lifetimes of the equipment. This report investigates the energy savings potential of several common heating, ventilation and air-conditioning (HVAC) system re-tuning measures on a typical large office building prototype model, using the Department of Energy's building energy modeling software, EnergyPlus.
\end{abstract}

The baseline prototype model uses roughly as much energy as an average large office building in the existing building stock, but does not utilize any re-tuning measures. Individual re-tuning measures simulated against this baseline include automatic schedule adjustments, damper minimum flow adjustments, thermostat adjustments, as well as dynamic resets (set points that change continuously with building and/or outdoor conditions) to static pressure, supply air temperature, condenser water temperature, chilled and hot water temperature, and chilled and hot water differential pressure set points. Six combinations of these individual measures have been formulated - each designed to conform to limitations to implementation of certain individual measures that might exist in typical buildings. All of these measures and combinations were simulated in 16 cities representative of specific U.S. climate zones.

The modeling results suggest that the most effective energy savings measures are those that affect the demand-side of the building (air-systems and schedules). Many of the demand-side individual measures were capable of reducing annual HVAC system energy consumption by over $20 \%$ in most cities that were modeled. Supply-side measures (chiller, cooling tower and pump measures) affecting HVAC plant conditions were only modestly successful (less than $5 \%$ annual HVAC energy savings for most cities for all measures). Combining many of the re-tuning measures revealed deep savings potential. Some of the more aggressive combinations revealed between $35 \%$ and $75 \%$ reductions in annual HVAC energy consumption, depending on climate and building vintage. 


\section{Executive Summary}

Today, many large (>100,000 sf) commercial buildings use sophisticated building automation systems (BASs) to manage a wide range of building equipment. While the capabilities of BASs have increased over time, many buildings still do not fully use the BAS's capabilities and are not properly commissioned, operated or maintained, which leads to inefficient operation, increased energy use, and reduced lifetimes of the equipment.

Periodic re-tuning of building controls and heating, ventilation and air conditioning (HVAC) systems helps to reduce inefficient and faulty operations and improve building efficiency. Re-tuning is a systematic, semi-automated process of detecting, diagnosing and correcting operational problems with building systems and their controls. The focus of this process is to identify and correct building operational problems at little cost that lead to energy waste; it might be thought of as a scaled-down retro-commissioning $(\mathrm{RCx})$ process. The process has been shown to identify operational problems that can be corrected with low- or no-cost - and the impact is immediate. Unlike the traditional RCx approach, which has a broader scope, re-tuning primarily targets HVAC systems and their controls (Katipamula and Brambley 2008; Brambley and Katipamula 2009; Brambley et al. 2009).

Pacific Northwest National Laboratory (PNNL), with funding from the U.S. Department of Energy's (DOE's) Building Technologies Program (BTP), conducted a study to estimate, through simulation, energy savings for common re-tuning/RCx measures. This report documents the results from that study.

\section{Approach}

This study investigates and documents savings from a set of re-tuning measures that improves the operating efficiency of large office buildings. The re-tuning measures are associated with both air- and water-side HVAC systems. The re-tuning measures covered in this study are primarily associated with HVAC systems in large office (>100,000 sf). The scope of this report is limited, and focuses on two typical 200,000 sf, large office buildings; one with a vintage prior to 1980 (referred to as pre-1980 building) and one with a vintage after 1980 (referred to as post-1980 building).

Buildings with individual re-tuning measures and with packages of measures are modeled using DOE's EnergyPlus (U.S. Department of Energy, 2012) building energy modeling software and compared to a respective baseline building without these measures implemented. Each of the two prototype buildings are simulated in 16 U.S. cities, each representing a unique climate zone (as defined in ASHRAE 2010). The buildings' internal characteristics are identical from location to location; however the envelope characteristics vary according to DOE reference buildings (Deru et al. 2011). The building modeled for this study is the same as the building model used in the Advanced Energy Retrofit Guide (Deru et al. 2011), except that the chilled-water and hot water pumping configuration is changed from constant primary to constant primary and variable secondary. 


\section{Individual Re-tuning Measures}

- A01 : Shortened HVAC schedules - HVAC fans, pumps, chillers, and zone thermostat revert to nighttime setback mode either 2 hours or 4 hours (two sub-measures) earlier in the evening on weekdays, letting the building coast towards its unoccupied state while it is still partially occupied. The baseline building has HVAC schedules that are on from 6 a.m. to 10 p.m. on weekdays and from 6 a.m. to 6 p.m. on weekends.

- A02 : Static pressure reset - When a building's supply fan(s) system is operational, the supply fan's static pressure set point can be automatically adjusted to load conditions that will allow the supply fan to operate more efficiently. The variable frequency drive (VFD) of the supply fan is modulated to maintain a dynamically reset static pressure set point. This can be done by sorting all variable-air-volume (VAV) box dampers by position; if the average of the highest (most open) $10 \%$ of VAV boxes are open less that $70 \%$, the reset control will decrease the static pressure set point in 0.1 W.C. (inches of water column) increments until the set point achieves the low operation limit ( $30 \%$ of the original value). If the average of the highest $10 \%$ of VAV boxes is greater than $90 \%$ open, the reset control will increase the static pressure set point in 0.1 W.C. increments until the set point achieves the original set point.

- A03 : Supply-air temperature reset - The baseline building uses a constant supply-air (also referred to discharge-air) temperature set point of $55^{\circ} \mathrm{F}$. When a building's supply fan(s) system is operational, the supply-air temperature set point value should be automatically adjusting to internal/external conditions that will allow the supply fan to operate more efficiently.

- A04: Changing (but keeping constant) the supply-air set point - The baseline building uses a constant supply-air temperature of $55^{\circ} \mathrm{F}$ for all VAV systems. This measure changes the constant supply-air temperature set point to $53,54,56,57$, and $58^{\circ} \mathrm{F}$ (five sub-measures)

- A05: Reduce/lower VAV damper minimum air flow rate - The minimum air flow rate at each VAV terminal is lowered to $30 \%$ of the maximum flow. The pre- 1980 baseline uses $50 \%$ of the maximum flow for the minimum flow set point and the post- 1980 baseline uses $40 \%$ of the maximum flow for the minimum flow set point.

- A06: Wider thermostat temperature range - The heating season thermostat set point is $69^{\circ} \mathrm{F}$ during occupied hours, compared to the baseline of $71^{\circ} \mathrm{F}$. The cooling season thermostat set point is $75^{\circ} \mathrm{F}$, compared to the baseline of $73^{\circ} \mathrm{F}$. With these changes, the thermostat range increases from $2^{\circ} \mathrm{F}$ to $6^{\circ} \mathrm{F}$.

- A07: Minimum outdoor-air fraction set to " 0 " during unoccupied hours - the baseline assumes that the occupied minimum outdoor-air fraction is enforced at the time the HVAC system is started up in the morning (warm-up or cool-down period) at 6 a.m. This measure moves the minimum outdoor-air fraction schedule to 7 a.m., when the building is actually occupied. 
- W01: Chilled-water differential pressure (DP) reset - In the baseline, the set point of differential pressure between the supply and return water piping on the secondary loop is fixed at the design condition throughout the operation. Checking all the valves' position served by the loop to reset the differential pressure is recommended by ASHRAE Handbook - Application (ASHRAE, 2011). It is recommended that every 5 minutes the chilled-water valves' position should be checked or polled. If more than one valve has been saturated at $100 \%$, increase the differential pressure set point by a fixed value (e.g., $5 \%$ of the design value). Otherwise, if any of the valves is less than half-open, decrease the differential pressure set point by the same amount.

- W02: Chilled-water temperature reset - to maintain the chiller running at a more efficient part load ratio, increasing the chilled-water set point by $0.5^{\circ} \mathrm{F}$ when all the valves are less than $90 \%$ open, or decreasing the set point by $1 / 2$ degree when any valve is more than $90 \%$ open.

Compared to the constant set point temperature at $44^{\circ} \mathrm{F}$ for the baseline building, this measure changes the set point temperature at the chilled-water loop between $44^{\circ} \mathrm{F}$ and $50^{\circ} \mathrm{F}$.

- W03: Hot-water DP reset - similar to W01: chilled-water DP reset measure. The same energy saving strategy is recommended on the hot-water loop, and its energy saving potential is simulated by using the different pump curves.

- W04: Hot-water temperature reset - the baseline has a constant hot-water supply temperature of $180^{\circ} \mathrm{F}$; this measure simulates an outdoor-air temperature based set point reset strategy. When the outdoor-air temperature is below $20^{\circ} \mathrm{F}$, the hot-water loop targets a supply temperature at $180^{\circ} \mathrm{F}$; when the outdoor air is above $65^{\circ} \mathrm{F}$, supply temperature is reset to $150^{\circ} \mathrm{F}$. When the outdoor-air temperature is in between $20^{\circ} \mathrm{F}$ and $65^{\circ} \mathrm{F}$, the supply water temperature varies linearly between $180^{\circ} \mathrm{F}$ and $150^{\circ} \mathrm{F}$.

- W05: Condenser water temperature reset - reset the constant condensing loop supply temperature from constant $80^{\circ} \mathrm{F}$ to a dynamic range of $70^{\circ} \mathrm{F}$ to $80^{\circ} \mathrm{F}$ based on the outdoor-air wet-bulb temperature (WBT). When the outdoor-air wet-bulb temperature is below $60^{\circ} \mathrm{F}$, reset the condensing loop set point to $70^{\circ} \mathrm{F}$. When the outdoor-air wet-bulb temperature is above $70^{\circ} \mathrm{F}$, reset to $80^{\circ} \mathrm{F}$; when the outdoor-air wet-bulb temperature is in between, reset the condensing supply temperature to $10^{\circ} \mathrm{F}$ higher than the outdoor-air wet-bulb temperature.

- W06: Plant shut down when there is no load - the baseline assumes that for cooling, when outdoor-air temperature is below $40^{\circ} \mathrm{F}$, the central chiller plant (chilled-water pumps, chillers, and cooling towers) is OFF; when outdoor-air temperature is above $40^{\circ} \mathrm{F}$, the central chiller plant is on whenever air-handling unit (AHU) fan is ON. For heating, the central heating plant (hot-water pumps and boilers) is on whenever the AHU fan is ON. With this re-tuning measure, the central chiller plant is still OFF when outdoor-air temperature is below $40^{\circ} \mathrm{F}$; however, when outdoor-air temperature is above $40^{\circ} \mathrm{F}$, the central chiller plant is $\mathrm{ON}$ whenever there is cooling 
demand from the cooling coils in the AHUs. Similarly, the central heating plant is ON whenever there is heating demand from heating coils.

\section{Combination of Re-tuning Measures}

Combination 1 (A01, A02, A03, A05, A06, W01, W02, W03, W04, and W05) can be applied to the single duct VAV systems with VFDs installed on both chilled-water pumps and cooling tower fans. It includes most air-side and water-side measures except the chilled-water system scheduling (W06) and outdoorair damper closeout during warm-up.

Combination 2 (A01, A02, A03, W01, W03, W04, and W05) is the "lite" version of re-tuning measures for single duct VAV without the implementation of terminal box and zone level measures. Combination 2 also includes the condenser water temperature reset.

Combination 3 (A01, A02, A04, W01, W03, and W04) is another "lite" version of re-tuning measures without the condenser water temperature reset. Another difference between combination 2 and 3 is the method of supply-air temperature set point control (no reset schedule in combination 3).

Combination 4 (A01, A04, W01, W03, and W04) can be applied to the systems without direct digital control and no terminal box information feedback. Therefore, the supply-air temperature reset, duct static pressure reset, and terminal box minimum air flow reset are not included in combination 4.

Combination 5 (A01, A02, A03, A05, W01, W02, W03, and W04) can be applied to the old chiller without condenser water temperature reset.

Combination 6 ( $\mathrm{A01}, \mathrm{A02}, \mathrm{A03}, \mathrm{A05}, \mathrm{A06}, \mathrm{W} 01, \mathrm{~W} 02, \mathrm{~W} 03, \mathrm{~W} 04, \mathrm{~W} 05$, and W06) includes the comprehensive re-tuning measures for typical single duct $V A V$ and chilled-water systems.

\section{Calculation of Savings}

Energy savings from individual measures are presented in terms of percentage savings in annual HVAC system energy consumption, compared to each city's baseline. HVAC system energy consumption includes sub-components of site heating, cooling (including cooling tower fans), fans, and pumps. Total HVAC percentage savings is broken into these sub-components by dividing the total energy savings from each sub-component by the total HVAC energy consumption in the respective baseline.

A01a changes the availability schedule for the chiller and pumps, as well as minimum outdoor-air fraction and thermostat set points so that they each end 2 hours earlier on weekdays and remain off all day on Saturdays. A01b shuts down these same systems 4 hours earlier on weekdays, while keeping them off on Saturdays. This keeps the HVAC systems completely off unless the boilers or chillers turn on to maintain the zones at the setback temperatures. In total, this reduces the HVAC system "on" time by 22 hours each week for A01a and 32 hours per week for A01b, out of a total of 92 hours in the baseline ( $24 \%$ reduction and $35 \%$ reduction, respectively). Most locations show HVAC savings very close to $24 \%$ for A01a and 35\% for A01b. 
Static pressure reset works by changing the static pressure set point whenever possible; thereby reducing the air flow resistance on AHU fans (A02). The fan is then able to deliver the same amount of air flow with lower power. The primary energy savings result from reduction in fan energy consumption (fans sub-component). A secondary effect also occurs because of lower fan power consumption. Because the fans consume less power, they also reject less heat to the supply-air stream. This means that the cooling energy is also modestly reduced, and in the colder locations, more heating is needed to compensate for the reduced heat gains from the fan. The post-1980 baseline shows higher savings than the pre-1980 baseline because fan energy consumption is a higher fraction of overall HVAC consumption in the post-1980 baseline and range between $5 \%$ and $7 \%$.

Savings from the two methods of supply-air temperature reset (outdoor-air method, A03a, and alternative method, $\mathrm{A} 03 \mathrm{~b}$ ) save energy during the shoulder and the heating seasons by reducing reheating of supply air that is otherwise tempered lower than any zone really needs (constant $55^{\circ} \mathrm{F}$ in the baseline). The advantage of using the outdoor-air method of supply-air temperature reset is that it is relatively easy to program. It requires using only one sensor to determine what supply-air temperature set point should be applied for all VAV systems. The alternate method provides an interesting contrast to the supply-air temperature reset based on outdoor-air temperature alone. This alternate method is a "smarter" type of reset because it uses feedback directly from the VAV box cooling commands to determine whether to raise the supply-air temperature for individual AHUs. Aside from very hot climates, which typically require cool supply-air temperatures nearly year-round, there is consistent strong savings from this measure (predominately heating savings). The total savings range from a low of $2 \%$ (in Miami) to high of $19 \%$ (in Duluth) for measure A03a, and they range from a low of $2 \%$ (in Miami) to high of $35 \%$ (in Los Angeles).

A simple change in set point (A04) can be an easy alternative to supply-air temperature reset, but may begin to affect comfort if taken too far. For each degree rise in supply-air temperature set point, there is about $5 \%$ to $6 \%$ reduction in total HVAC energy consumption, depending on climate. Most of this savings comes from reduced heating energy consumption from a lower air temperature difference across the reheat coil. There is also some cooling energy savings as the supply-air temperature is increased because of reduced cooling coil load. Fan energy consumption, on the other hand, increases slightly as the supply-air temperature is raised.

Reducing the minimum VAV box air-flow set point from either $50 \%$ (pre-1980 baseline) or $40 \%$ (post1980 baseline) to $30 \%$ will save energy (A05). In all locations except the very coldest climates, the total HVAC savings range between $30 \%$ and $40 \%$ from lowering the VAV minimum air-flow set point from $50 \%$ to $30 \%$ (pre-1980 baseline). For the post-1980 building, the HVAC savings range between $15 \%$ and $25 \%$ from lowering the minimum air-flow set point from $40 \%$ to $30 \%$. Most of the savings are a result of reduced heating consumption (from enabling lower flow rates of $55^{\circ} \mathrm{F}$ supply air in the shoulder and heating season, which reduces reheat energy consumption significantly).

Measure A06 investigated increasing the thermostat's temperature range by 2 degrees on both heat and cooling set points. This reduces the driving temperature difference across the building envelope. The total HVAC energy savings appear to be fairly uniform, in the $12 \%$ to $20 \%$ range. 
The total HVAC savings available from closing the outside-air damper during unoccupied and start-up hours varies by climate (A07). Heating savings is only available in cold climates, where there are a significant number of hours in the year when the outside-air temperature is cold enough to drive the mixed-air temperature below the supply-air temperature set point (with the limited fraction of outdoor air coming from the minimum outside-air damper). In the coldest climates, the heating savings may be as much as $5 \%$ to $6 \%$. Cooling savings, likewise, are only available in climates where the early morning temperatures (during system warm-up) in the summer are still warm enough to require mechanical cooling.

The savings are small for chilled-water loop differential pressure reset (W01); with up to $1.4 \%$ of savings in very hot climates, $0.1 \%$ to $0.4 \%$ in moderate climates, and less than $0.1 \%$ savings in cold climates. The reason for the limited savings is that pump power accounts for only between $2 \%$ and $4 \%$ of baseline total HVAC energy consumption, and the chilled-water secondary loop pump is only one of several pumps serving the building. So even though the annual energy consumption of the chilled-water pump may be between 10 and $20 \%$ by reducing the differential pressure set point, the savings as a percent of HVAC energy is still quite small.

The chilled-water temperature reset saves chiller energy by raising the chilled-water temperature during times of low cooling demand, thereby reducing the pressure ratio in the chiller and raising the coefficient of performance. There is a slight increase in pump power consumption as a result of this measure because the chilled-water loop has to deliver a higher volume of chilled water to meet the same cooling coil loads. There is also a slight increase in fan energy consumption because a higher volume of air must be blown over a warmer cooling coil to deliver the same cooling energy. The results show some inconsistencies between the pre- and post-1980 baselines; however, typical savings range from $1 \%$ to $5 \%$ of HVAC energy consumption, based on climate.

The two hot-water loop measures, W03 (hot-water loop differential pressure reset) and W04 (hot-water temperature reset), yielded nearly zero savings for two reasons. First, operating at a lower hot-water loop temperature does not change the hot water coil heating load at any given time, meaning that the boiler's part load ratio does not change, and therefore, the heating efficiency does not change. Second, interior hot water pipes in this model are measured in a simplified form as adiabatic. Thus, there are no standby or transport losses in the pipes that are being modeled. Mitigation of these losses may produce savings in real buildings, especially when hot water pipes traverse unconditioned spaces.

Hot-water differential pressure reset produced very minimal savings. This is mainly because pump energy can be regarded as energy input to the hot-water loop. The reduction of pump electric energy has to be compensated by the increase of natural gas energy consumption in the boiler. Also, as mentioned in the results for W01, the chilled-water differential pressure reset measure produced very small savings because of the marginal energy consumption that the chilled-water pump was responsible for. Because the hot-water loop operates at an even lower flow rate, the hot-water loop secondary pump is a fraction of the size of the chilled-water secondary pump and produces even less savings. 
Measure W05 (condenser water temperature reset) saves cooling energy by decreasing the condenser loop supply temperature. The chiller COP (coefficient of performance) increases after the measure is applied. However, the condenser loop balances out the energy saving because the cooling tower fan works harder and longer to cool condensing water to a lower temperature. The resulting savings (primarily cooling) from this measure are roughly proportional to the amount of part-load cooling that is required in the baseline and range between $0.1 \%$ and $1.3 \%$.

Shutting down the central heating and cooling plants when they are not needed (W06) can save energy in a number of ways: at the pumps, at the primary cooling equipment (chiller compressors) as a result of false loading of the chillers, and at the cooling tower as a results of rejection of waste heat picked up from the distribution system (e.g., through the walls of the piping). The savings range between $0 \%$ (in Miami) to nearly 3\% (in Duluth).

Although six combinations of re-tuning measures were modeled, results for three combinations are discussed in the summary. Combination 1 can be applied to the single-duct VAV systems with VFDs installed on both chilled-water pumps and cooling tower fans. It includes most air-side and water-side measures except the chilled-water system scheduling (W06) and outdoor-air damper closeout during unoccupied and start-up periods. For the pre- 1980 baseline, HVAC energy savings range from $28 \%$ for hot climates to $59 \%$ for cool marine climates, to $29 \%$ for sub-arctic climates. For the post-1980 baseline, HVAC energy savings range from $28 \%$ for hot climates to $56 \%$ for cool marine climates, to $23 \%$ for subarctic climates. To generalize among the various climates, most of the energy savings is from heating (generally about $2 / 3$ ), with most of the rest of the savings coming from cooling.

Combination 2 is the "lite" version of re-tuning measures for single-duct VAV without the implementation of terminal box (A05) and zone level re-tuning measures (A06). Combination 2 also includes the condenser water temperature reset. This combination can be applied to the systems without direct digital control. Because there is no terminal box information feedback, the supplytemperature reset, duct static pressure reset, and terminal box minimum air flow reset are not included. Upgrading the terminal box from pneumatic control to direct digital controls can yield significant savings and is, therefore, recommended (which will require capital investment and is not considered a low-cost measure). Even with the restrictions imposed by the lack of direct digital controls, the use of "smarter" scheduling, combined with higher supply-air temperature set point, has the potential to save a significant fraction ( $30 \%$ ) of total HVAC energy consumption. Like the previous re-tuning combination packages, savings from heating energy are significantly greater than the other end uses.

Combination 6 includes all measures except A04 (which conflicts with A03); it is essentially the complete set of re-tuning measures. For the pre-1980 baseline, the HVAC energy savings range from $50 \%$ in hot climates to about $74 \%$ in marine climates and $42 \%$ in sub-arctic climates. For the post-1980 baseline, the savings ranges from $46 \%$ in hot climates to $70 \%$ in marine climates to $35 \%$ in sub-arctic climates. Like the previous five re-tuning combination packages, the heating energy savings constitute a significant portion of the total HVAC savings. 
Appendix B includes Table B-1 and B-2, which provide regression equation coefficients for the pre-1980 building HVAC energy savings and the post-1980 building, respectively. For some measures, such as $A 07, R^{2}$ (one of regression parameters that describe the "goodness of fit" values) is very high for the regression equations that use only HDD (heating degree day) and $\mathrm{HDD}^{2}$. In such cases, a simple equation is sufficient to generalize HVAC savings. For most measures, however, there is significant additional accuracy that is gained by using additional variables in the regression equations. As the results for individual measures demonstrated, for many measures, the savings was higher for the marine climates than would be expected based on cities with similar HDDs or CDDs (cooling degree days). For these measures, the addition of summer dew point as a regression variable helped the accuracy of the regression equations a great deal. The regression analysis was done using results from 12 of the 16 climate locations. The four remaining climate locations were used to test the prediction capabilities of the regression model.

In general, the comparison of predicted (regression model) compared to modeled (EnergyPlus simulation) showed that the regression equations do a good job of generalizing savings, and that new cities do not appear to have any more or less deviation than the points used to generate the regression equations, meaning that the regression equations can be reasonably used to predict savings for similar buildings in other climate locations.

\section{Conclusion}

The simulation of a wide variety of common re-tuning measures for large office buildings shows that there is the potential to save a substantial fraction of HVAC energy consumption through measures that require little to no capital investment. All of the re-tuning measures that were simulated can be implemented through simple controls programming changes in the building automation systems. The baseline buildings that were simulated assumed simple commonly used controls were in place. Common-practice inefficiencies in scheduling and other HVAC operations were modeled in this baseline building, and the individual measures show the effect of each improvement compared to that inefficient baseline.

The largest savings were by far from air-side measures, suggesting that demand-side inefficiencies can cause much higher energy consumption than supply-side HVAC inefficiencies. By ensuring that the HVAC system is supplying the "optimal" supply-air temperature at the minimum required flow, only when strictly needed, and in a coordinated fashion among the zones, there can be much lower energy demand on the fans, chillers, and boilers. The simulation results show typically, $10 \%$ to $40 \%$ HVAC savings is possible from using supply-air temperature reset; 5 to $7 \%$ savings is possible from static pressure reset; 20 to $40 \%$ savings are possible from lowering the minimum VAV damper flow set point; $15 \%$ savings from adopting a wider thermostat temperature range, and 20 to $30 \%$ is possible from aggressively shortening HVAC schedules. By contrast, only about $5 \%$ savings is available from the suite of water-side measures that were modeled.

When combined, the possible savings, compared to baseline that was modeled, are rather staggering. Combination 6 re-tuning measure includes all of the re-tuning measures implemented together. The 
model shows that through these simple re-tuning measures alone, between 40 and $75 \%$ of the HVAC energy of large office buildings (often accounting for about $60 \%$ of total site energy consumption) may be saved. This is a best-case scenario for savings. More efficient HVAC configurations and more energy conscious schedules and lockouts that exist in many large office buildings may preclude some of these savings. Also, limitations imposed by constant speed pumps and fans and old/analog control systems may limit the suite of re-tuning measures that can be implemented. Some of the combinations of measures that were modeled attempted to address this latter concern.

Another significant finding is that the measures are somewhat competitive when implemented in combination. A set of measures can be synergistic, meaning that one measure compliments or facilitates another measure, so that in tandem they produce a higher savings than the sum of their individual savings. Likewise, a set of measures can be competitive in the sense that one measure produces energy savings that reduces the energy available for another measure to save. Even by a looser measure of competition - the geometric sum of individual measure savings, the set of measures is still moderately competitive. The geometric sum applies the savings from measure $B$ to the fraction of energy consumption left over from measure $A$ and so on. So if measure $A$ saves $10 \%$ and measure $B$ saves $20 \%$, the geometric sum is $10 \%$ plus [ $20 \%$ times the remaining $90 \%$ ] or $28 \%$. The actual savings for Combination 6 in the pre-1980 baseline are typically 5\% to $10 \%$ below the geometric sum of individual savings. This may be because several of the measures produce savings partly by eliminating simultaneous heating and cooling. Thus, by partly acting on the same mechanism to provide savings, these measures are more competitive than the geometric sum might indicate. Still, because these measures should be very inexpensive and convenient to implement together as a package, the fact that they compete somewhat for savings should not be a big concern.

The regression analysis shows that the results can reliably be generalized by climate for a given baseline building. Given climate data for a new location, the regression equations provided in Equations 4-6, combined with the coefficients in Table B-1 and B-2 should allow an accurate prediction of savings for any of the measures or combinations of measures as they are modeled here. Buildings with different HVAC configurations and unique or idiosyncratic building characteristics are a source of additional variation in potential savings that is difficult to quantify. 


\section{Acknowledgement}

The authors would like to acknowledge the Buildings Technologies Program of the U.S. Department of Energy Office of Energy Efficiency and Renewable Energy for supporting the research and development effort. The authors would also like to thank Alan Schroeder, Technology Development Manager, for technical guidance, Ron Underhill for providing the technical review, Linda Sandahl (Program Manager at PNNL) for thoughtful comments and insights, Sue Arey for editorial support and Loren Ruiz for help in preparing this document. 


\section{Contents}

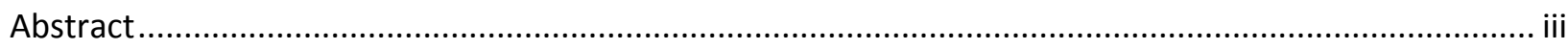

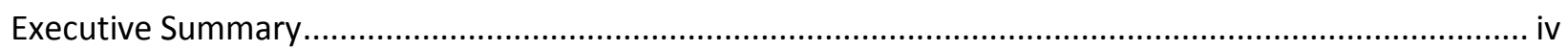

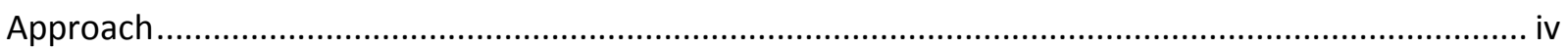

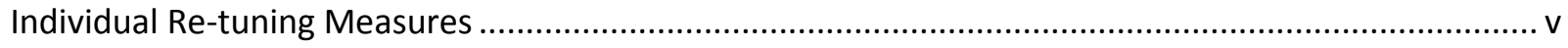

Combination of Re-tuning Measures ............................................................................................. vii

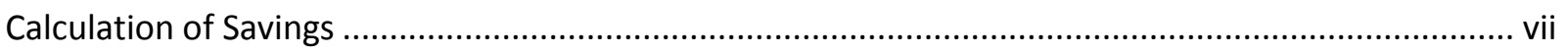

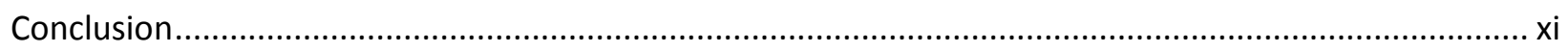

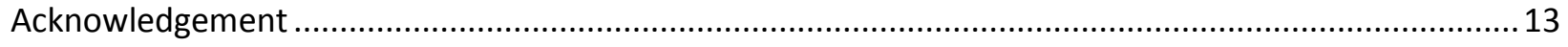

Introduction

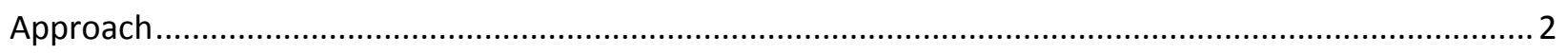

Scope

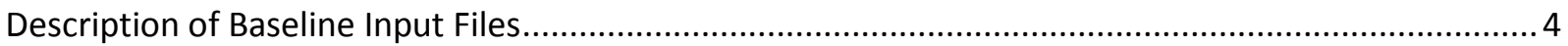

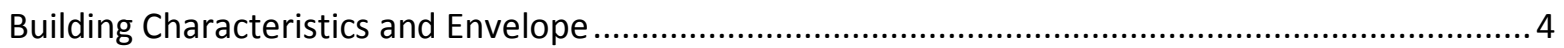

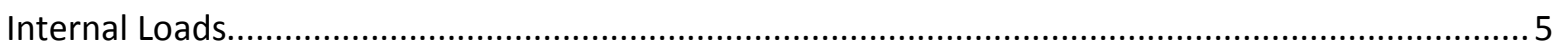

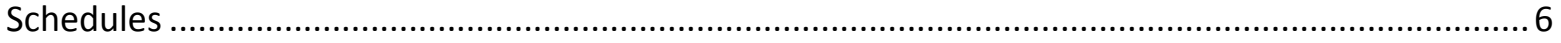

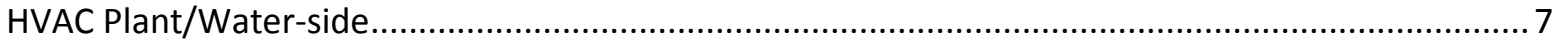

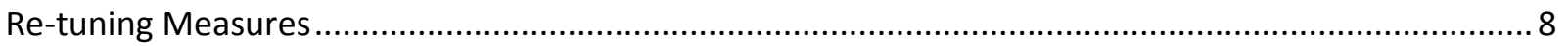

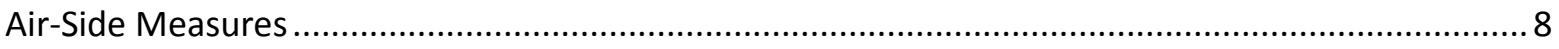

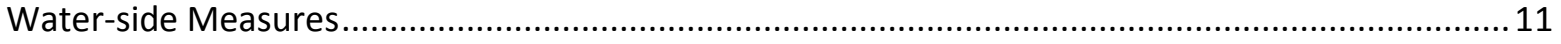

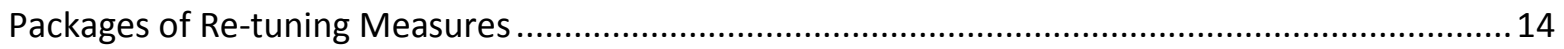

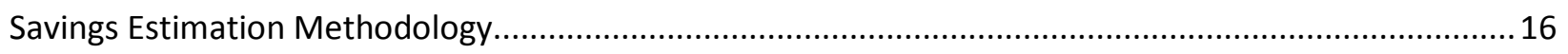

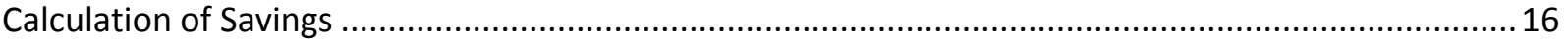

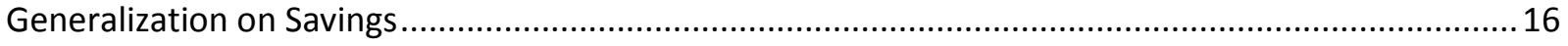

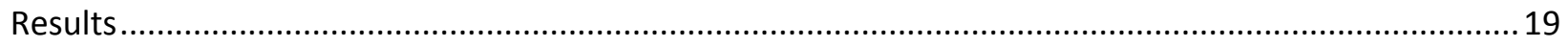

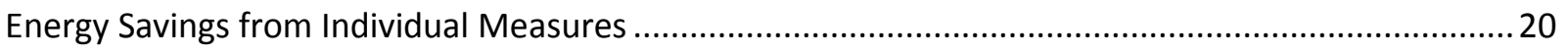

A01a - HVAC Schedules End 2 Hours Early and are Off on Saturdays..............................................20

A01b - HVAC Schedules End 4 Hours Early and are Off on Saturdays ............................................ 21

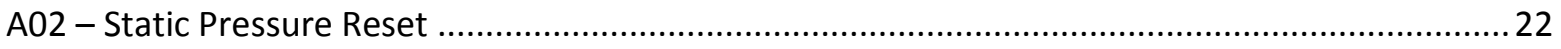

A03a - Supply-Air Temperature Reset based on Outdoor-Air Temperature …................................23

A03b - Supply-Air Temperature Reset - Alternate Method............................................................. 24 


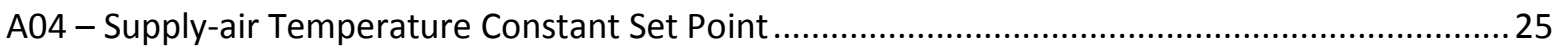

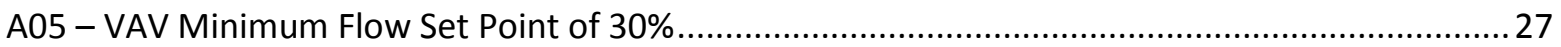

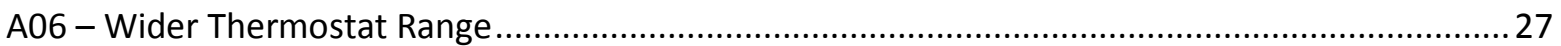

A07 - Zero Minimum Outside Air During Unoccupied Hours ........................................................ 28

W01 - Chilled-water Loop Differential Pressure Reset ....................................................................29

W02-Chilled-water Temperature Set point Reset......................................................................... 30

W05 - Condenser Water Temperature Reset …........................................................................... 31

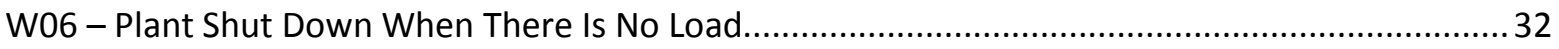

W03- Hot-water Differential Pressure Reset and W04 - Hot-water Temperature Reset .................. 33

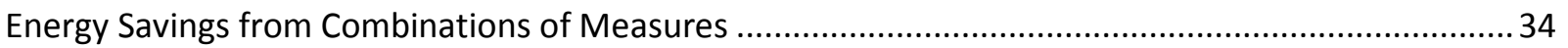

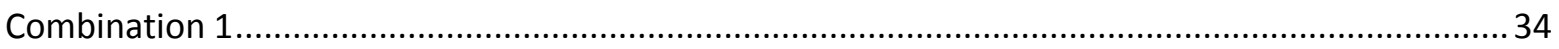

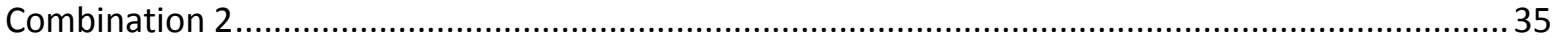

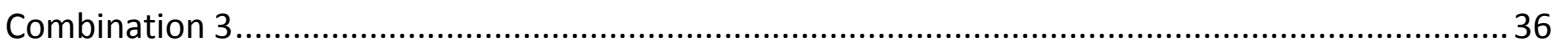

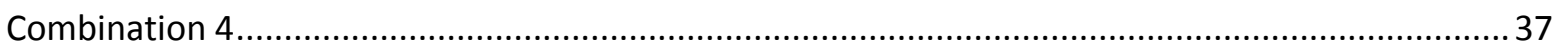

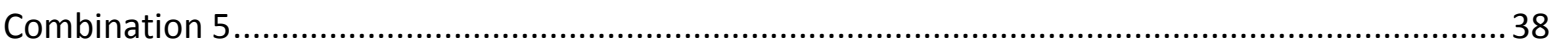

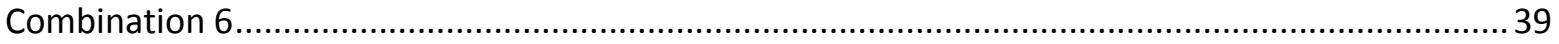

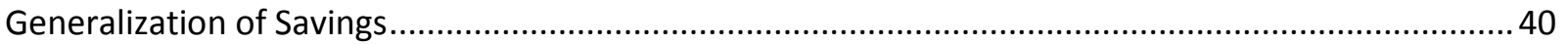

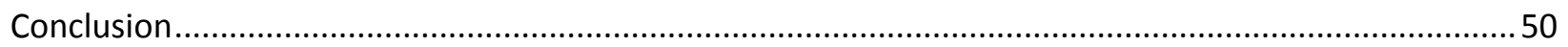

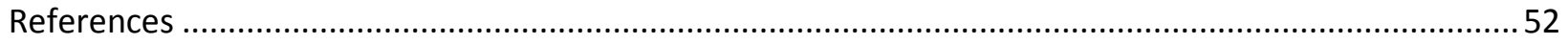

Appendix A:

Total Energy Savings from Each Re-tuning Measure ......................................................................... 54

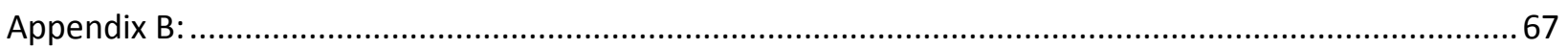

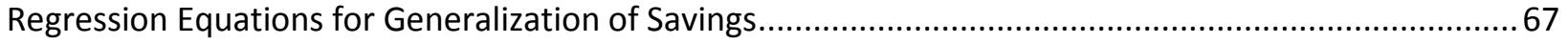




\section{Figures}

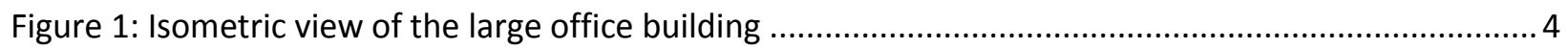

Figure 2: Weekday Schedules for Major Building Systems ............................................................ 6

Figure 3: Saturday Schedules for Major Building Systems.................................................................... 7

Figure 4: Fan Part Load Power Curve for Supply Fans with and Without Static Pressure Reset .................9

Figure 5: Pump Curves with and without DP Reset ........................................................................... 12

Figure 6: Hot-water Temperature Reset settings as a Function of Outdoor-Air Temperature ...................13

Figure 7: Condenser Water Temperature Reset Settings as a Function of WBT ....................................13

Figure 8: Modeled Energy Use Intensity (EUI) for HVAC systems in the Pre-1980 Baseline ..................... 19

Figure 9: Modeled Energy Use Intensity (EUI) for HVAC systems in the Post-1980 Baseline..................... 19

Figure 10: HVAC Energy Savings for A10a Re-tuning Measure (HVAC schedules end 2 hours early and are

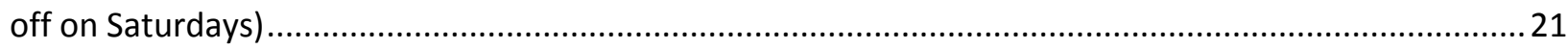

Figure 11: HVAC Energy Savings for A01b Re-tuning Measure (HVAC schedules end 4 hours early and are

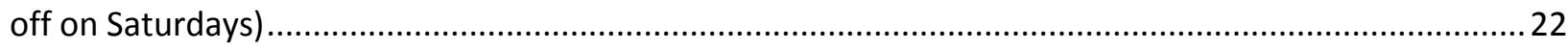

Figure 12: HVAC System Energy Savings for A02 Re-tuning Measure (Static Pressure Reset) ..................23

Figure 13: HVAC System Energy Savings for A03a Re-tuning Measure (Supply-Air Temperature Reset

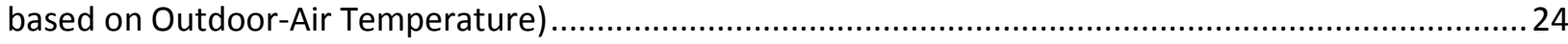

Figure 14: HVAC Energy Savings for A03b Re-tuning Measure (Supply-Air Temperature Reset base on the

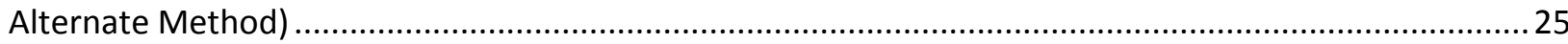

Figure 15: HVAC Energy Savings for A04a Re-tuning Measure (Constant Supply-Air Set Point of $53^{\circ} \mathrm{F}$ ) ... 26

Figure 16: HVAC Energy Savings for A04e Re-tuning Measure (Constant Supply-Air Set Point of $58^{\circ} \mathrm{F}$ ) ... 26

Figure 17: HVAC Energy Savings for Re-tuning Measure A05 (VAV Minimum Air Flow Set Point of 30\%) 27

Figure 18: HVAC Energy Savings - A06 (Wider Thermostat Range) .......................................................28

Figure 19: HVAC Savings for A07 Re-tuning Measure (Zero Minimum Outside Air During Unoccupied and

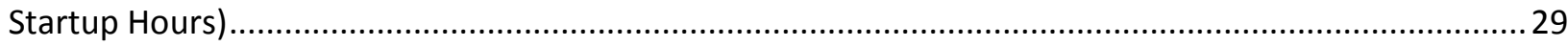

Figure 20: HVAC Energy Savings for W01 Re-tuning Measure (Chilled-Water Differential Pressure Reset)

Figure 21: HVAC Energy Savings for W01 Re-tuning Measure (Chilled-Water Temperature Set Point

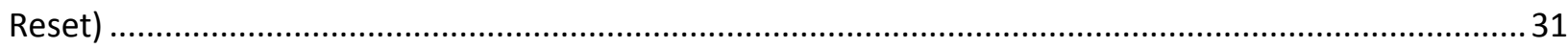

Figure 22: HVAC Energy Savings for W02 Re-tuning Measure (Condenser Water Reset)........................ 32

Figure 23: HVAC Energy Savings for W06 Re-tuning Measure (Plant Shut Down when there is No Load) 33

Figure 24: HVAC Energy Savings for Combination 1 Re-tuning Measures................................................35

Figure 25: HVAC Energy Savings for Combination 2 Re-tuning Measures............................................... 36

Figure 26: HVAC Energy Savings for Combination 3 Re-tuning Measures................................................. 37

Figure 27: HVAC Energy Savings for Combination 4 Re-tuning Measures............................................... 38

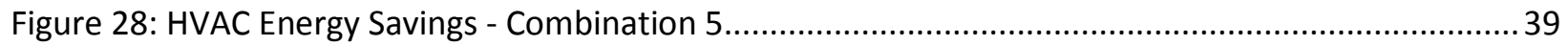

Figure 29: HVAC Energy Savings for Combination 6 Re-tuning Measures..............................................40

Figure 30: Comparison of Predicted and Simulated Energy Savings for A01b Re-tuning Measure (end

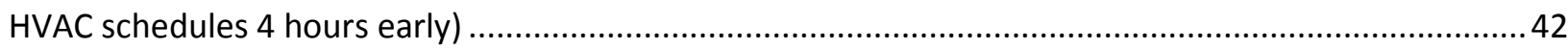


Figure 31: Comparison of Predicted and Simulated Energy Savings for A02 Re-tuning Measure (static pressure reset).

Figure 32: Comparison of Predicted and Simulated Energy Savings for A03a Re-tuning Measure (supplyair temperature reset based on outdoor-air temperature)

Figure 33: Comparison of Predicted and Simulated Energy Savings for A04 Re-tuning Measure (supply-air temperature set point of $58^{\circ} \mathrm{F}$ ).....

Figure 34: Comparison of Predicted and Simulated Energy Savings for A05 Re-tuning Measure (VAV damper minimum position of $30 \%)$. 44

Figure 35: Comparison of Predicted and Simulated Energy Savings for A06 Re-tuning Measure (wider thermostat range)

Figure 36: Comparison of Predicted and Simulated Energy Savings for A07 Re-tuning Measure (zero outside-air during unoccupied and start-up hours).....

Figure 37: Comparison of Predicted and Simulated Energy Savings for W02 Re-tuning Measure (chilledwater temperature set point reset)....

Figure 38: Comparison of Predicted and Simulated Energy Savings for W06 Re-tuning Measure (plant

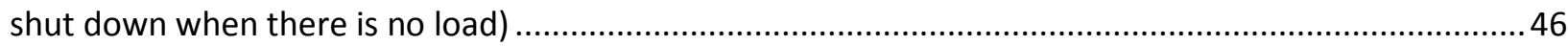

Figure 39: Comparison of Predicted and Simulated Energy Savings for Combination 1 .........................46

Figure 40: Comparison of Predicted and Simulated Energy Savings for Combination 2 ........................47

Figure 41: Comparison of Predicted and Simulated Energy Savings for Combination 3 .........................47

Figure 42: Comparison of Predicted and Simulated Energy Savings for Combination 4 .......................... 48

Figure 43: Comparison of Predicted and Simulated Energy Savings for Combination 5 ........................ 48

Figure 44: Comparison of Predicted and Simulated Energy Savings for Combination 6 ..........................49

Figure 45: Combining Measures: Competition or Synergy? .................................................................... 51

\section{Tables}

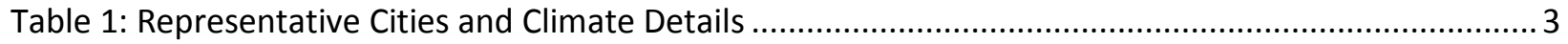

Table 2: Envelope Characteristics for the Two Baseline Models ....................................................... 5

Table 3: Part Load Curve Coefficients for Fan With and Without Static Pressure (SP) Reset..................... 9

Table 4: Supply-air Temperature Minimum and Maximum Set Points for the Alternate Method of Supply-

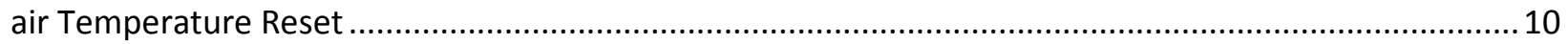

Table 5: Coefficients of Secondary Pump Curves in DP Reset ............................................................. 11

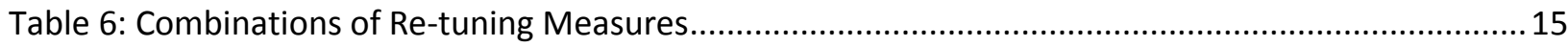

Table 7: EUI of Baseline Buildings in each City and in the CBECS 2003 Database .................................. 16

Table 8: Annual Energy Savings (kBtu/sf) by HVAC component and representative city for the Pre-1980 building

Table 9: Annual Energy Savings (kBtu/sf) by HVAC component and representative city for the Post-1980 building 


\section{Introduction}

Today, many large (>100,000 sf) commercial buildings use sophisticated building automation systems (BASs) to manage a wide range of building equipment. While the capabilities of BASs have increased over time, many buildings still do not fully use the BAS's capabilities and are not properly commissioned, operated or maintained, which leads to inefficient operation, increased energy use, and reduced lifetimes of the equipment. Periodically "tuning" building systems and controls, much like tuning automobiles, ensures maximum building energy efficiency and the comfort of building occupants. A poorly tuned system can and will maintain comfortable conditions but at a higher energy cost to overcome inefficiencies. Often, comfort complaints due to poorly tuned systems will result in operational changes that address the comfort problem, but result in "masked" inefficiencies.

Periodic re-tuning of building controls and heating, ventilation and air conditioning (HVAC) systems helps to reduce inefficient and faulty operations and improve building efficiency. Re-tuning, as it is practiced, is a systematic, semi-automated process of detecting, diagnosing and correcting operational problems with building systems and their controls. The focus of this process is to identify and correct building operational problems that lead to energy waste. The process is implemented primarily through BASs at little or no cost other than the labor required for making the necessary control changes. The focus of re-tuning is identifying and achieving significant energy savings at little cost; it might be thought of as a scaled-down retro-commissioning $(\mathrm{RCx})$ process. The process has been shown to identify operational problems that can be corrected with low- or no-cost - and the impact is immediate. Unlike the traditional RCx approach, which has a broader scope, re-tuning primarily targets HVAC systems and their controls (Katipamula and Brambley 2008; Brambley and Katipamula 2009; Brambley et al. 2009).

There is general agreement that RCx of existing buildings saves energy in the range from a few percent to over $60 \%$, with most reported savings in the range of $10 \%$ to $30 \%$ (U.S. DOE undated; Haasl and Sharp 1999; Claridge et al. 1996; 2000; Liu et al. 2002; 2003; Mills 2009). A number of studies (Katipamula and Brambley 2008; Mills 2009; Moore et al. 2008) have highlighted common operational problems that occur in buildings: 1) HVAC and lighting systems running longer than needed, 2) improper economizer operations, 3) outdoor-air intake not reset to zero (no ventilation) during morning warm-up or cooling, 4) optimal start/stop not working properly, 5) reset of chilled- and hot-water not properly implemented, 6) higher static pressure than necessary to meet the building needs, 7) exhaust fans running all day $(24 \times 7), 8)$ faulty sensors, 9) improper set points, and 10) improper control loop tuning. The re-tuning process is tailored to detect these problems by analyzing the information collected from the BAS.

Although many studies have documented measured savings from $\mathrm{RCx}$, much of the savings information is at the whole building level, which makes it difficult to associate savings by measure. The intent of this study is to estimate, through simulation, energy savings for common re-tuning/RCx measures.

In the next section the approach used in estimating the energy savings is discussed, followed by a section that describes the methodology used in estimating the energy savings for a large office building. 
The results section details energy savings estimates for individual measures and also energy savings for combination of measures. The report concludes with some discussion and references.

\section{Approach}

This report documents the energy savings from implementing a host of air-side and water-side HVAC retuning measures across the full spectrum of U.S. climates. The energy savings are estimated for individual measure as well as combination of measures using a detailed energy simulation tool.

This section describes the overall approach taken to develop individual re-tuning measures, as well as packages of re-tuning measures, and how the energy savings from individual measures and combinations of measures are estimated. The approach covers the scope of the report and the definition of the measures considered.

\section{Scope}

This report investigates a set of re-tuning measures that improves the operating efficiency of large office buildings. The re-tuning measures are associated with both air- and water-side HVAC systems. The retuning measures covered in this study are primarily associated with HVAC systems in large office and hospital type buildings ( $>100,000 \mathrm{sf}$ ). The results presented in this report are for large office buildings only. Each office building is unique in terms of the use of HVAC system and equipment, building geometry, internal load profiles, and envelope characteristics. The consequence of such diversity for this study is that for many large office buildings, only certain re-tuning measures may be applicable. Those that are applicable may yield a range of energy savings. The scope of this report is necessarily limited, and focuses on two typical 200,000 sf, large office buildings; one with a vintage prior to 1980 (referred to as pre-1980 building) and one with a vintage after 1980 (referred to as post-1980 building). The methodology section describes the details of the building characteristics for each of the two building prototypes.

Buildings with individual re-tuning measures and with packages of measures are modeled using DOE's EnergyPlus (U.S. Department of Energy, 2012) building energy modeling software and compared to a respective baseline building without these measures implemented. Each of the two prototype buildings are simulated in 16 U.S. cities, each representing a unique climate zone (as defined in ASHRAE 2010). The buildings' internal characteristics are identical from location to location; however the envelope characteristics vary according to DOE reference buildings (Deru et al. 2011). These variations are summarized in the Methodology section. For each building vintage, in each climate, systems are sized automatically using the baseline building, then the sizing information is hard-coded into the model for running each of the re-tuning measures in that climate location. This approach sizes the HVAC systems according to the original design of the building and does not allow size to change as a result of implementing any of the re-tuning measures.

The 16 cities modeled in this report and their climatological details [heating degree-days (HDD), cooling degree-days (CDD), and summer dew point, in $\left.{ }^{\circ} \mathrm{F}\right]$ are summarized in Table 1. 
Table 1: Representative Cities and Climate Details

\begin{tabular}{|c|c|c|c|c|c|c|c|}
\hline \multirow[t]{2}{*}{$\begin{array}{l}\text { Representative } \\
\text { City }\end{array}$} & \multicolumn{2}{|c|}{ DOE Climate Zone } & \multicolumn{2}{|c|}{$\begin{array}{l}\text { Heating Degree- } \\
\text { Days }\left({ }^{0} \mathrm{~F}\right)\end{array}$} & \multicolumn{2}{|c|}{$\begin{array}{l}\text { Cooling Degree- } \\
\text { Days }\left({ }^{\circ} \mathrm{F}\right)\end{array}$} & \multirow{2}{*}{$\begin{array}{c}\begin{array}{c}\text { Dew Point } \\
\left({ }^{\circ} \mathrm{F}\right)\end{array} \\
\begin{array}{c}\text { June- } \\
\text { September } \\
\text { Average }\end{array}\end{array}$} \\
\hline & Code & Description & HDD55 & HDD65 & CDD55 & CDD50 & \\
\hline Miami, FL & $1 \mathrm{~A}$ & Very Hot, Humid & 6 & 130 & 7,585 & 9,404 & 72 \\
\hline Houston, TX & $2 \mathrm{~A}$ & Hot, Humid & 626 & 1,557 & 5,403 & 6,942 & 70 \\
\hline Phoenix, AZ & $2 B$ & Hot, Dry & 307 & 1,200 & 6,712 & 8,324 & 52 \\
\hline Atlanta, GA & $3 \mathrm{~A}$ & Warm, Humid & 1,486 & 3,129 & 3,517 & 4,792 & 65 \\
\hline Los Angeles, CA & $3 B-C A$ & $\begin{array}{c}\text { Warm, Dry, } \\
\text { California }\end{array}$ & 82 & 1,442 & 2,636 & 4,380 & 58 \\
\hline Las Vegas, NV & $\begin{array}{l}\text { 3B - } \\
\text { other }\end{array}$ & Warm, Dry & 838 & 2,356 & 5,272 & 6,625 & 38 \\
\hline San Francisco, CA & $3 C$ & Warm, Marine & 743 & 3,497 & 947 & 2,208 & 51 \\
\hline Baltimore, MD & $4 \mathrm{~A}$ & Mixed, Humid & 2,818 & 4,862 & 2,710 & 3,719 & 62 \\
\hline $\begin{array}{c}\text { Albuquerque, } \\
\text { NM }\end{array}$ & $4 B$ & Mixed, Dry & 2,505 & 4,494 & 2,810 & 3,810 & 47 \\
\hline Seattle, WA & $4 C$ & Mixed, Marine & 2,208 & 5,003 & 959 & 1,824 & 50 \\
\hline Chicago, IL & $5 A$ & Cool, Humid & 4,099 & 6,405 & 2,111 & 2,978 & 58 \\
\hline Boulder, CO & $5 B$ & Cool, Dry & 3,733 & 6,141 & 1,833 & 2,687 & 44 \\
\hline Minneapolis, MN & $6 \mathrm{~A}$ & Cold, Humid & 5,503 & 7,898 & 1,907 & 2,717 & 57 \\
\hline Helena, MT & $6 B$ & Cold, Dry & 5,063 & 7,880 & 1,159 & 1,841 & 42 \\
\hline Duluth, MN & 7 & Very Cold & 7,094 & 10,107 & 796 & 1,351 & 51 \\
\hline Fairbanks, AK & 8 & Subarctic & 10,903 & 14,096 & 491 & 918 & 43 \\
\hline
\end{tabular}




\section{Description of Baseline Input Files}

This section describes the two EnergyPlus baseline models and how they were changed to simulate each of the various re-tuning measures. Justification is provided for key parameters. The building modeled for this study is the same as the building model used in the Advanced Energy Retrofit Guide (Deru et al. 2011), except that the chilled-water and hot water pumping configuration is changed from constant primary to constant primary and variable secondary. Further details may be found in that publication.

\section{Building Characteristics and Envelope}

The large office building modeled for both the pre- and post-1980 baselines is a 200,000 sf rectangular building with four floors, as shown in Figure 1; an aspect ratio of 1.5; and a window-to-wall ratio of 0.40. The building has a floor-to-floor height of $13 \mathrm{ft}$ and a floor-to-ceiling height of $9 \mathrm{ft}$. The foundation type is slab on grade. The infiltration rate is $0.84 \mathrm{cfm}$ per square foot of exterior envelope area when fans are off, and $25 \%$ of the peak infiltration rate when they are on. Table 2 shows the thermal characteristics of the envelope, which are taken from the DOE reference models (Deru et al. 2011).

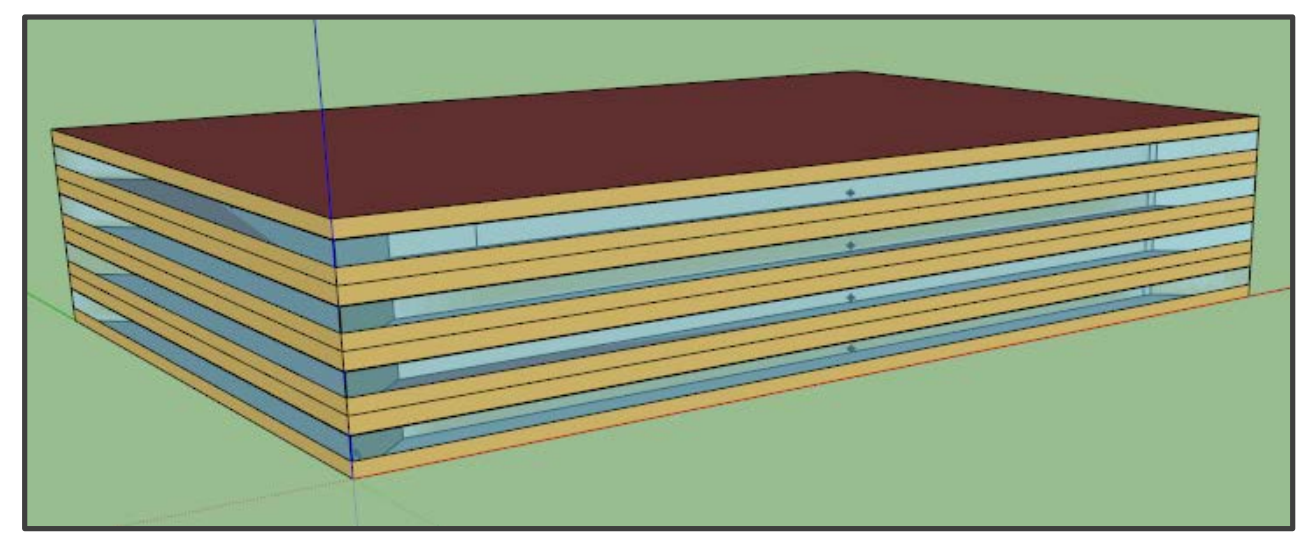

Figure 1: Isometric view of the large office building 
Table 2: Envelope Characteristics for the Two Baseline Models

\begin{tabular}{|c|c|c|c|c|c|c|c|c|}
\hline & \multicolumn{2}{|c|}{$\begin{array}{l}\text { Roof U-Values } \\
\text { (Btu/hr-sf-F) }\end{array}$} & \multicolumn{2}{|c|}{$\begin{array}{l}\text { Wall U-Values } \\
\text { (Btu/hr-sf-F) }\end{array}$} & \multicolumn{2}{|c|}{$\begin{array}{l}\text { Window U- } \\
\text { Values (Btu/hr- } \\
\text { sf-F) }\end{array}$} & \multicolumn{2}{|c|}{ Window SHGC } \\
\hline & $\begin{array}{l}\text { Pre- } \\
1980\end{array}$ & $\begin{array}{l}\text { Post- } \\
1980\end{array}$ & $\begin{array}{l}\text { Pre- } \\
1980\end{array}$ & $\begin{array}{l}\text { Post- } \\
1980\end{array}$ & $\begin{array}{l}\text { Pre- } \\
1980\end{array}$ & $\begin{array}{l}\text { Post- } \\
1980\end{array}$ & $\begin{array}{l}\text { Pre- } \\
1980\end{array}$ & $\begin{array}{l}\text { Post- } \\
1980\end{array}$ \\
\hline Miami, FL & 0.100 & 0.074 & 0.230 & 1.000 & 1.220 & 1.220 & 0.54 & 0.25 \\
\hline Houston, TX & 0.100 & 0.066 & 0.230 & 0.340 & 1.220 & 1.220 & 0.54 & 0.25 \\
\hline Phoenix, AZ & 0.100 & 0.046 & 0.230 & 0.410 & 1.220 & 1.220 & 0.54 & 0.25 \\
\hline Atlanta, GA & 0.100 & 0.072 & 0.225 & 0.290 & 1.220 & 0.720 & 0.54 & 0.25 \\
\hline Los Angeles, CA & 0.100 & 0.100 & 0.230 & 1.000 & 1.220 & 1.220 & 0.54 & 0.44 \\
\hline Las Vegas, NV & 0.100 & 0.048 & 0.230 & 0.290 & 1.220 & 1.220 & 0.54 & 0.25 \\
\hline San Francisco, CA & 0.100 & 0.088 & 0.224 & 0.490 & 1.220 & 0.720 & 0.54 & 0.39 \\
\hline Baltimore, MD & 0.086 & 0.058 & 0.178 & 0.120 & 1.220 & 0.590 & 0.54 & 0.36 \\
\hline Albuquerque, NM & 0.089 & 0.059 & 0.184 & 0.190 & 1.220 & 0.720 & 0.54 & 0.36 \\
\hline Seattle, WA & 0.085 & 0.064 & 0.175 & 0.100 & 1.220 & 0.720 & 0.54 & 0.39 \\
\hline Chicago, IL & 0.072 & 0.053 & 0.156 & 0.100 & 0.620 & 0.590 & 0.41 & 0.39 \\
\hline Denver, CO & 0.076 & 0.051 & 0.161 & 0.140 & 0.620 & 0.590 & 0.41 & 0.39 \\
\hline Minneapolis, MN & 0.060 & 0.045 & 0.145 & 0.071 & 0.620 & 0.520 & 0.41 & 0.39 \\
\hline Helena, MT & 0.060 & 0.049 & 0.145 & 0.079 & 0.620 & 0.520 & 0.41 & 0.39 \\
\hline Duluth, MN & 0.060 & 0.040 & 0.145 & 0.061 & 0.620 & 0.520 & 0.41 & 0.49 \\
\hline Fairbanks, AK & 0.060 & 0.031 & 0.136 & 0.047 & 0.620 & 0.520 & 0.41 & 0.49 \\
\hline
\end{tabular}

\section{$\underline{\text { Internal Loads }}$}

Both buildings have lighting power densities of $1.33 \mathrm{~W} / \mathrm{sf}$. Plug loads are $0.75 \mathrm{~W} / \mathrm{sf}$ for spaces other than computer server rooms, and $25 \mathrm{~W} / \mathrm{sf}$ for server rooms. Occupant density follows ASHRAE Standard 62.1-2004, using an average of 190 sf per occupant. Schedules for these end uses are described below. 
A gas-fired service water heater provides 1000 gal/day of $120^{\circ} \mathrm{F}$ water at $80 \%$ efficiency to the building. There are four elevators with 20 hp hydraulic motors.

\section{$\underline{\text { Schedules }}$}

Figure 2 visually depicts weekday schedules for the major building systems, including lighting, general plug loads, data center, HVAC operation, and minimum outdoor-air fraction. Figure 3 depicts the Saturday schedules for these systems. On Sundays and holidays, the schedules stay at their minimum values [15\% for lighting, 30\% for plug loads, $75 \%$ for data center, $0 \%$ for HVAC operation, and $0 \%$ for minimum outdoor-air (OA) fraction]. The 'HVAC Operation' schedule represents the times when the AHU fans and plant system are scheduled to be available to operate, however this availability is overridden during unoccupied hours any time one or more zone temperatures in any of the VAV networks fall above or below nighttime setback thermostat setpoints $\left(60^{\circ} \mathrm{F}\right.$ heating setpoint and $80^{\circ} \mathrm{F}$ cooling setpoint).

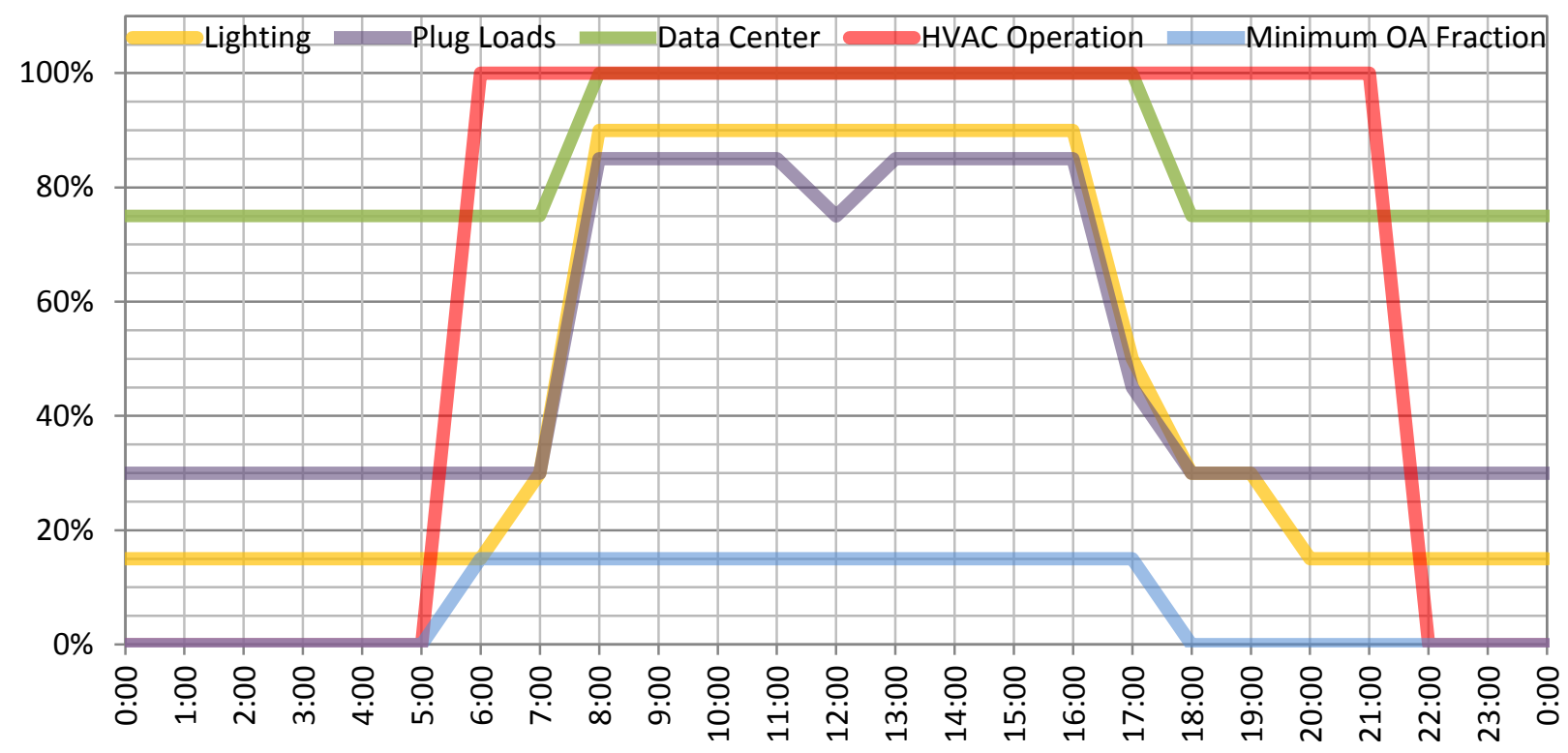

Figure 2: Weekday Schedules for Major Building Systems 


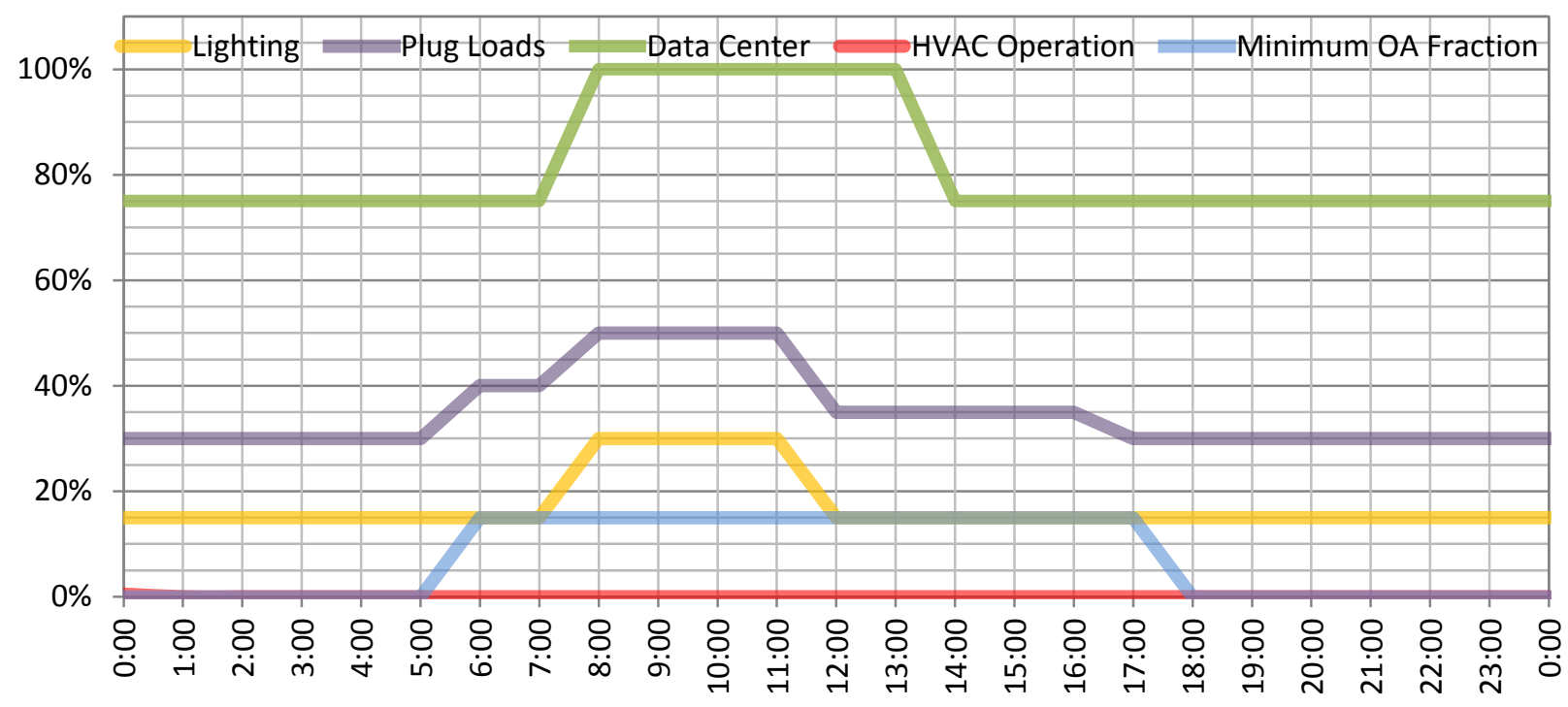

Figure 3: Saturday Schedules for Major Building Systems

\section{HVAC Plant/Water-side}

The building has a central plant that consists of two equal-sized gas-fired boilers ( $76 \%$ thermal efficiency) that heat a primary hot-water loop fed by a constant speed pump. A secondary loop served by a variable speed pump delivers the hot water to variable air volume (VAV) terminal box reheat coils. The hot-water primary loop is controlled to meet a constant supply set point of $180^{\circ} \mathrm{F}$.

Two equal-sized chillers (4.93 rated coefficient of performance) cool a primary chilled-water loop fed by a constant speed pump. A secondary loop served by a variable speed pump delivers chilled water to the cooling coils of the building's air-handling units. The chilled-water primary loop is controlled to meet a constant supply set point of $44^{\circ} \mathrm{F}$.

A constant speed pump delivers heated water from the chiller's condenser to two cooling towers, each with constant speed fans. The boilers, chillers, and cooling towers are staged to meet their respective loads.

\section{HVAC Air Side}

The building has three VAV air-handling units (AHU), one for the ground floor, one for the top floor, and the other for the two middle floors. Each of three building AHUs contain a water heating coil, a water cooling coil, and a variable speed supply fan. In Miami, no economizer controls are used. In Houston and Phoenix, fixed dry-bulb economizers are used. In all other locations, fixed enthalpy economizers are used. In the pre-1980 building, it is assumed that outside-air and return-air dampers do not have blade and jamb seals, and do not close completely when commanded to do so. Thus, the model assumes that a maximum of $70 \%$ OA is supplied during economizer operation. In the post-1980 baseline building, it is 
assumed that outside-air and return-air dampers have blade and jamb seals, and close completely when commanded to do so (maximum 95\% OA).

Flow from the air handlers is split to their respective terminal boxes, each with a reheat coil and terminal damper. The pre-1980 baseline building limits the terminal dampers to a minimum of $50 \%$ of the maximum air flow, while the post- 1980 baseline limits them to $40 \%$ of the maximum air flow. Terminal damper positions and heating coil valves are modulated to maintain zone thermostat set points $\left(73^{\circ} \mathrm{F}\right.$ for cooling and $71^{\circ} \mathrm{F}$ for heating).

\section{Re-tuning Measures}

This section lists the individual measures and describes conceptually how they are modeled in EnergyPlus. Then five sets of combinations of measures that are modeled in this report are described.

\section{Air-Side Measures}

- A01 : Shortened HVAC schedules - HVAC fans, pumps, chillers, and zone thermostat revert to nighttime setback mode either 2 hours or 4 hours (two sub-measures) earlier in the evening on weekdays, letting the building coast towards its unoccupied state while it is still partially occupied. The baseline building has HVAC schedules that are on from 6 a.m. to 10 p.m. on weekdays and from 6 a.m. to 6 p.m. on weekends

- A01a: HVAC schedules end 2 hours early- This measure shuts off the HVAC system (puts it in the setback mode) at 8 p.m. on weekdays. On weekends, the HVAC systems are kept entirely in setback mode.

0 A01b: HVAC schedules end 4 hours early - This measure shuts off the HVAC systems (puts it in the setback mode) at 6 p.m. on weekdays. On weekends, the HVAC systems are kept entirely in setback mode.

- A02 : Static pressure reset - When a building's supply fan(s) system is operational, the supply fan's static pressure set point can be automatically adjusted to load conditions that will allow the supply fan to operate more efficiently. The variable frequency drive (VFD) of the supply fan is modulated to maintain a dynamically reset static pressure set point. This can be done by sorting all VAV box dampers by position; if the average of the highest (most open) 10\% of VAV boxes are open less that $70 \%$, the reset control will decrease the static pressure set point in 0.1 W.C. (inches of water column) increments until the set point achieves the low operation limit ( $30 \%$ of the original value). If the average of the highest $10 \%$ of VAV boxes is greater than $90 \%$ open, the reset control will increase the static pressure set point in 0.1 W.C. increments until the set point achieves the original set point.

Because EnergyPlus does not control the supply fan and terminal dampers based on static pressure set points, an alternate strategy was used to simulate static pressure reset. The fan power curve was adjusted instead to account for the levels of flow resistance that would be 
present using a common static pressure reset strategy. Table 3 shows the coefficients of the part load factor equation (Equation 1) for the supply fans with and without static pressure reset (Energy Design Resources, 2009). In Equation 1, FF is the fan's air flow fraction (0-1). Figure 4 graphically depicts this relationship.

$$
P L F=C_{1}+C_{2} F F+C_{3} F F^{2}+C_{4} F F^{3}+C_{5} F F^{4}
$$

Table 3: Part Load Curve Coefficients for Fan With and Without Static Pressure (SP) Reset

\begin{tabular}{|l|r|r|}
\hline & SP Reset & No SP Reset \\
\hline C1 & 0.040759894 & 0.070428852 \\
\hline C2 & 0.08804497 & 0.385330201 \\
\hline C3 & -0.07292612 & -0.460864118 \\
\hline C4 & 0.943739823 & 1.00920344 \\
\hline C5 & 0 & 0 \\
\hline
\end{tabular}

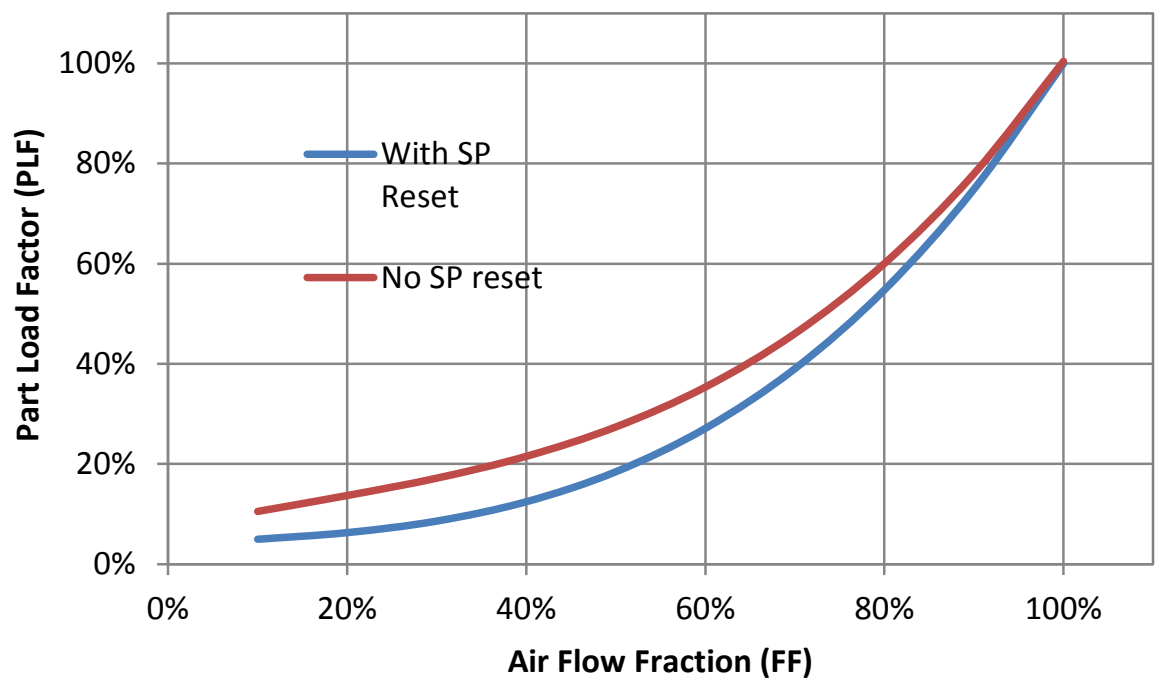

Figure 4: Fan Part Load Power Curve for Supply Fans with and Without Static Pressure Reset

- A03 : Supply-air temperature reset - The baseline building uses a constant supply-air (also referred to discharge-air) temperature set point of $55^{\circ} \mathrm{F}$. When a building's supply fan(s) system is operational, the supply-air temperature set point value should be automatically adjusting to internal/external conditions that will allow the supply fan to operate more efficiently:

- A03a: Outdoor-air temperature method - When outside-air temperature is greater than $75^{\circ} \mathrm{F}$, the supply-air temperature is set at $55^{\circ} \mathrm{F}$. When the outside-air temperature is less than $45^{\circ} \mathrm{F}$, the supply-air temperature is set at $60^{\circ} \mathrm{F}$. When the outside-air 
temperature is in between $45^{\circ} \mathrm{F}$ and $75^{\circ} \mathrm{F}$, the supply-air temperature varies linearly between $60^{\circ} \mathrm{F}$ and $55^{\circ} \mathrm{F}$.

o A03b Alternate method (Table 4) adapted from (Energy Design Resources, 2009)When the fan is on, the supply-air temperature set point is dynamically reset between T-min to T-max, according to the following logic: when the fan is on, the set point increases by $0.2^{\circ} \mathrm{F}$ (up to T-max), if there are no zone cooling requests (a cooling request is signaled when one of the zone set points cannot be maintained, even when modulating its VAV damper to $100 \%$ open). If there are more than two cooling requests, the supply-air temperature set point is reduced by $0.3^{\circ} \mathrm{F}$ (down to T-min)

Table 4: Supply-air Temperature Minimum and Maximum Set Points for the Alternate Method of Supply-air Temperature Reset

\begin{tabular}{|l|l|l|}
\hline Outside-Air Temperature & T-min & T-max \\
\hline$<65^{\circ} \mathrm{F}$ & 55 & 65 \\
\hline $65^{\circ} \mathrm{F}$ to $70^{\circ} \mathrm{F}$ & $55-0.4^{*}($ OAT-65) & $65-2.4^{*}($ OAT-65) \\
\hline$>70^{\circ} \mathrm{F}$ & 55 & 55 \\
\hline
\end{tabular}

- A04: Changing (but keeping constant) the supply-air set point - The baseline building uses a constant supply-air temperature of $55^{\circ} \mathrm{F}$ for all VAV systems. This measure changes the constant supply-air temperature set point to $53,54,56,57$, and $58^{\circ} \mathrm{F}$ (five sub-measures)

- A05: Reduce/lower VAV damper minimum air flow rate - The minimum air flow rate at each VAV terminal is lowered to $30 \%$ of the maximum flow. The pre- 1980 baseline uses $50 \%$ of the maximum flow for the minimum flow set point and the post- 1980 baseline uses $40 \%$ of the maximum flow for the minimum flow set point.

- A06: Wider thermostat temperature range - The heating season thermostat set point is $69^{\circ} \mathrm{F}$ during occupied hours, compared to the baseline of $71^{\circ} \mathrm{F}$. The cooling season thermostat set point is $75^{\circ} \mathrm{F}$, compared to the baseline of $73^{\circ} \mathrm{F}$. With these changes, the thermostat range increases from $2^{\circ} \mathrm{F}$ to $6^{\circ} \mathrm{F}$.

- A07: Minimum outdoor-air fraction set to " 0 " during unoccupied hours - the baseline assumes that the occupied minimum outdoor-air fraction is enforced at the time the HVAC system is started up in the morning (warm-up or cool-down period) at 6 a.m. This measure moves the minimum outdoor-air fraction schedule to 7 a.m., when the building is actually occupied. 


\section{Water-side Measures}

- W01: Chilled-water differential pressure (DP) reset - In the baseline, the set point of differential pressure between the supply and return water piping on the secondary loop is fixed at the design condition throughout the operation. Checking all the valves' position served by the loop to reset the differential pressure is recommended by ASHRAE Handbook - Application (ASHRAE, 2011). It is recommended that every 5 minutes the chilled-water valves' position should be checked or polled. If more than one valve has been saturated at $100 \%$, increase the differential pressure set point by a fixed value (e.g., $5 \%$ of the design value). Otherwise, if any of the valves is less than half-open, decrease the differential pressure set point by the same amount.

Because EnergyPlus only calculates the energy and loads based on the fluid's flow rate, the pump curve is adjusted to simulate the resistance change in the chilled water loop. Table 5 shows coefficients of the pump curves used for both baseline and chilled-water DP reset measure. These coefficients are used in the pump's power calculation equation

Fraction of Full Load Power $=\mathrm{C}_{1}+\mathrm{C}_{2} P L R+\mathrm{C}_{3} P L R^{2}+\mathrm{C}_{4} P L R^{3}$,

where PLR is the part load ratio of the pump. The minimum PLR allowed is 0.2 .

Table 5: Coefficients of Secondary Pump Curves in DP Reset

\begin{tabular}{|l|r|r|}
\hline & \multicolumn{1}{|c|}{ Chilled-water DP Reset } & \multicolumn{1}{|c|}{ No DP Reset } \\
\hline C1 & 0 & 0 \\
\hline C2 & 0.0205 & 0.5726 \\
\hline C3 & 0.4101 & -0.301 \\
\hline C4 & 0.5753 & 0.7347 \\
\hline
\end{tabular}




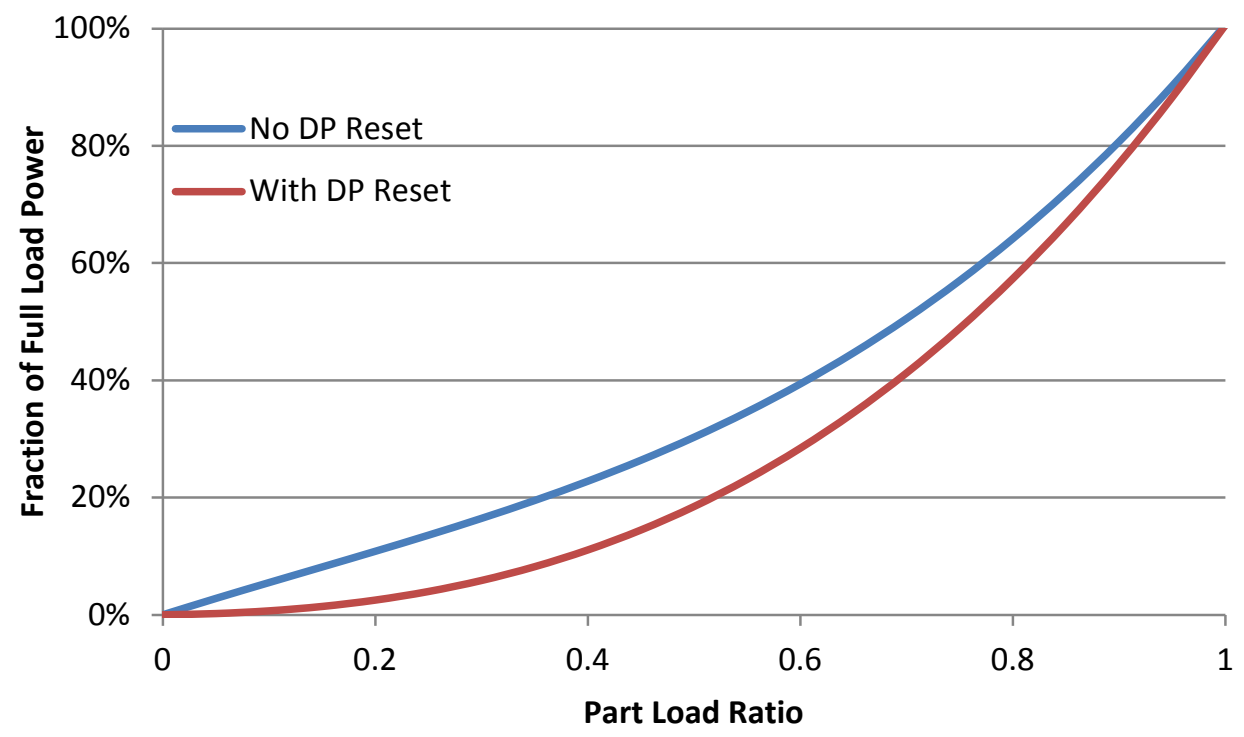

Figure 5: Pump Curves with and without DP Reset

- W02: Chilled-water temperature reset - to maintain the chiller running at a more efficient part load ratio, increasing the chilled-water set point by $0.5^{\circ} \mathrm{F}$ when all the valves are less than $90 \%$ open, or decreasing the set point by $1 / 2$ degree when any valve is more than $90 \%$ open. Compared to the constant set point temperature at $44^{\circ} \mathrm{F}$ for the baseline building, this measure changes the set point temperature at the chilled-water loop between $44^{\circ} \mathrm{F}$ and $50^{\circ} \mathrm{F}$.

- W03: Hot-water DP reset - similar to W01: chilled-water DP reset measure. The same energy saving strategy is recommended on the hot-water loop, and its energy saving potential is simulated by using the different pump curves shown in Table 5 and Figure 5.

- W04: Hot-water temperature reset - the baseline has a constant hot-water supply temperature of $180^{\circ} \mathrm{F}$; this measure simulates an outdoor-air temperature based set point reset strategy (Figure 6). When the outdoor-air temperature is below $20^{\circ} \mathrm{F}$, hot-water loop targets a supply temperature at $180^{\circ} \mathrm{F}$; when the outdoor air is above $65^{\circ} \mathrm{F}$, supply temperature is reset to $150^{\circ} \mathrm{F}$. When the outdoor-air temperature is in between $20^{\circ} \mathrm{F}$ and $65^{\circ} \mathrm{F}$, the supply water temperature varies linearly between $180^{\circ} \mathrm{F}$ and $150^{\circ} \mathrm{F}$ by:

Hot-water set point temperature $\left({ }^{\circ} \mathrm{F}\right)=180-(30 / 45) *(\mathrm{OAT}-20)$,

where OAT is the outdoor-air temperature. 


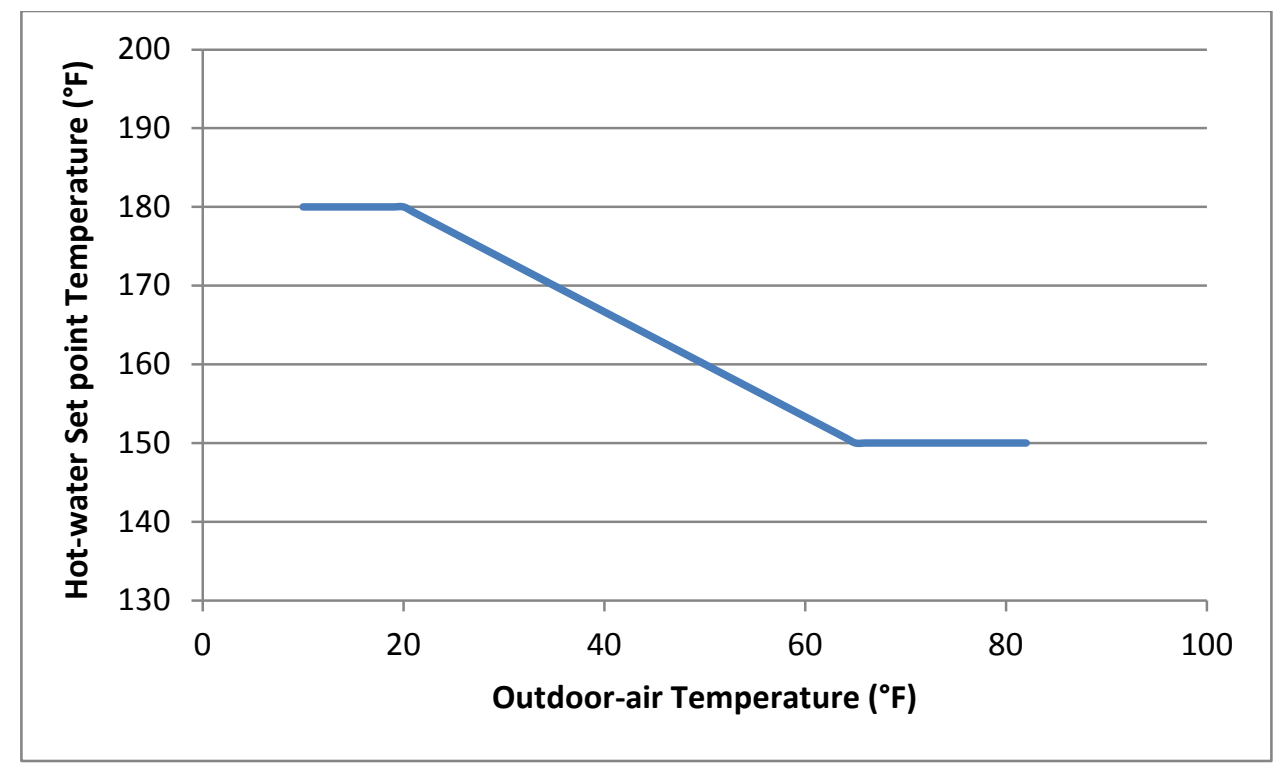

Figure 6: Hot-water Temperature Reset settings as a Function of Outdoor-Air Temperature

- W05: Condenser water temperature reset - reset the constant condensing loop supply temperature from constant $80^{\circ} \mathrm{F}$ to a dynamic range of $70^{\circ} \mathrm{F}$ to $80^{\circ} \mathrm{F}$ based on the outdoor-air wet-bulb temperature (WBT) (Figure 7). When the outdoor-air wet-bulb temperature is below $60^{\circ} \mathrm{F}$, reset the condensing loop set point to $70^{\circ} \mathrm{F}$. When the outdoor-air wet-bulb temperature is above $70^{\circ} \mathrm{F}$, reset to $80^{\circ} \mathrm{F}$; when the outdoor-air wet-bulb temperature is in between, reset the condensing supply temperature to $10^{\circ} \mathrm{F}$ higher than the outdoor-air wet-bulb temperature.

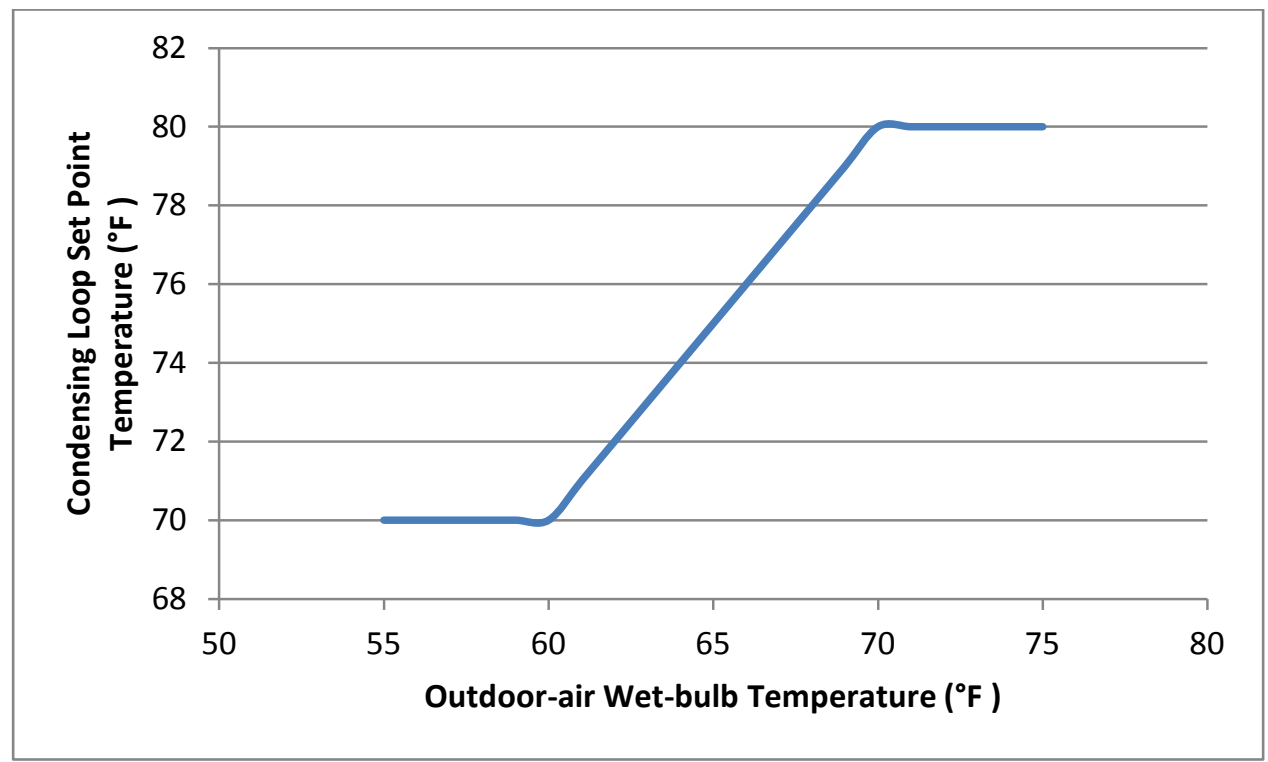

Figure 7: Condenser Water Temperature Reset Settings as a Function of WBT

W06: Plant shut down when there is no load - the baseline assumes that for cooling, when outdoor-air temperature is below $40^{\circ} \mathrm{F}$, the central chiller plant (chilled-water pumps, chillers, and cooling towers) is 
OFF; when outdoor-air temperature is above $40^{\circ} \mathrm{F}$, the central chiller plant is on whenever AHU fan is ON. For heating, the central heating plant (hot-water pumps and boilers) is on whenever the AHU fan is ON. With this re-tuning measure, the central chiller plant is still OFF when outdoor-air temperature is below $40^{\circ} \mathrm{F}$; however, when outdoor-air temperature is above $40^{\circ} \mathrm{F}$, the central chiller plant is $\mathrm{ON}$ whenever there is cooling demand from the cooling coils in the AHUs. Similarly, the central heating plant is $\mathrm{ON}$ whenever there is heating demand from heating coils.

\section{Packages of Re-tuning Measures}

Five packages of re-tuning measures have been formulated, representing combinations of measures that typically appear together, based on system type, existing operation and limitations. Table 6 shows

which measures are employed in each combination. Because some options have multiple sub-measures that are explored as individual options, the following sub-measures were chosen for the packages:

- A01 : The sub-measure A01a that shifts the setback mode to 2 hour early on weekday evenings and all day on Saturday

- A03 : Supply-air temperature reset using the Alternate Outdoor-Air Method (A03b)

- A04 : Constant supply-air temperature of $57^{\circ} \mathrm{F}(\mathrm{A} 04 \mathrm{~d})$

Combination 1 can be applied to the single duct VAV systems with VFDs installed on both chilled-water pumps and cooling tower fans. It includes most air side and water-side measures except the chilledwater system scheduling (W06) and outdoor-air damper closeout during warm-up.

Combination 2 is the "lite" version of re-tuning measures for single duct VAV without the implementation of terminal box and zone level measures. Combination 2 also includes the condenser water temperature reset.

Combination 3 is another "lite" version of re-tuning measures without the condenser water temperature reset. Another difference between combination 2 and 3 is the method of supply-air temperature set point control (no reset schedule in combination 3).

Combination 4 can be applied to the systems without direct digital control and no terminal box information feedback on air-side. Therefore, the supply-air temperature reset, duct static pressure reset, and terminal box minimum air flow reset are not included in combination 4 .

Combination 5 can be applied to the old chiller without condenser water temperature reset. Combination 6 includes the comprehensive re-tuning measures for typical single duct VAV and chilledwater systems. 
Table 6: Combinations of Re-tuning Measures

\begin{tabular}{|c|c|c|c|c|c|c|c|c|c|c|c|c|c|c|}
\hline \multicolumn{2}{|r|}{ Typical combinations } & \multirow[b]{2}{*}{ 定 } & \multirow[b]{2}{*}{ రั } & \multirow[b]{2}{*}{ m } & \multirow[b]{2}{*}{ ষ্ণ } & \multirow[b]{2}{*}{ 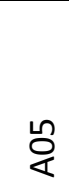 } & \multirow[b]{2}{*}{ ஜ } & \multirow[b]{2}{*}{ ồ } & \multirow[b]{2}{*}{ 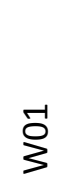 } & \multirow[b]{2}{*}{$\stackrel{N}{3}$} & \multirow[b]{2}{*}{$\stackrel{n}{\rho}$} & \multirow[b]{2}{*}{$\stackrel{১}{\lessgtr}$} & \multirow[b]{2}{*}{$\stackrel{\text { L }}{3}$} & \multirow[b]{2}{*}{$\stackrel{8}{3}$} \\
\hline & & & & & & & & & & & & & & \\
\hline 1 & $\begin{array}{l}\text { Single duct VAV, } \\
\text { VFD on chilled- } \\
\text { water pump and } \\
\text { cooling tower cell }\end{array}$ & $x$ & $x$ & $x$ & & $x$ & $x$ & & $x$ & $X$ & $X$ & $X$ & $x$ & \\
\hline 2 & $\begin{array}{l}\text { Single duct VAV, } \\
\text { VFD on chilled- } \\
\text { water pump and } \\
\text { cooling tower cell } \\
\text { (lite-1) }\end{array}$ & $\mathrm{x}$ & $x$ & $x$ & & & & & $x$ & & $\mathrm{X}$ & $x$ & $\mathrm{x}$ & \\
\hline 3 & $\begin{array}{l}\text { Single duct VAV, } \\
\text { VFD on chilled- } \\
\text { water pump and } \\
\text { cooling tower cell } \\
\text { (lite-2) }\end{array}$ & $x$ & $\mathrm{x}$ & & $\mathrm{x}$ & & & & $x$ & & $x$ & $x$ & & \\
\hline 4 & $\begin{array}{l}\text { No terminal box } \\
\text { feedback info on air } \\
\text { side (pneumatic for } \\
\text { example) }\end{array}$ & $x$ & & & $x$ & & & & $x$ & & $x$ & $x$ & & \\
\hline 5 & $\begin{array}{l}\text { Old chiller that } \\
\text { cannot handle low } \\
\text { condensing water }\end{array}$ & $\mathrm{x}$ & $x$ & $x$ & & $\mathrm{X}$ & & & $x$ & $\mathrm{X}$ & $\mathrm{X}$ & $x$ & & \\
\hline 6 & $\begin{array}{l}\text { Comprehensive set } \\
\text { of options for } \\
\text { single-duct VAV } \\
\text { and chilled-water } \\
\text { system }\end{array}$ & $x$ & $\mathrm{x}$ & $x$ & & $\mathrm{X}$ & $x$ & $x$ & $x$ & $\mathrm{x}$ & $\mathrm{x}$ & $x$ & $x$ & $x$ \\
\hline
\end{tabular}




\section{Savings Estimation Methodology}

In this section the methodology of how the energy savings were calculated and the process used to generalize energy savings for any location is described.

\section{Calculation of Savings}

Energy savings from individual measures are presented in terms of percentage savings in annual HVAC system energy consumption, compared to each city's baseline. HVAC system energy consumption includes sub-components of site heating, cooling (including cooling tower fans), fans, and pumps. Total HVAC percentage savings is broken into these sub-components by dividing the total energy savings from each sub-component by the total HVAC energy consumption in the respective baseline.

\section{Generalization on Savings}

One of the goals of this study is to produce energy savings numbers that can be generalized as much as possible so that they can be applicable to as many actual large office buildings as possible. Two strategies are used to facilitate this.

First, two different baseline buildings are used, representing the building characteristics found in pre1980 vintage and post-1980 vintage buildings, respectively. Some variation in building characteristics is facilitated through use of multiple baselines; however, the reader of the report must use caution before applying these savings numbers to any specific building. Buildings that have similar levels of inefficiency in the HVAC systems and schedules will likely have similar savings, while buildings that begin from more of a well-tuned starting point may see only a fraction of the savings presented here. Table 7 compares the modeled energy use intensity (EUI) of each of the baseline prototype buildings with the EUI of buildings in the CBECS 2003 (Energy Information Administration, 2003) public use database. 
Table 7: EUI of Baseline Buildings in each City and in the CBECS 2003 Database

\begin{tabular}{|c|c|c|}
\hline City & $\begin{array}{c}\text { Pre-1980 } \\
\text { Baseline EUI } \\
\text { (kBtu/sf) }\end{array}$ & $\begin{array}{c}\text { Post-1980 } \\
\text { Baseline EUI } \\
\text { (kBtu/sf) }\end{array}$ \\
\hline Seattle & 93.2 & 77.4 \\
\hline San Francisco & 85.4 & 73.2 \\
\hline Phoenix & 94.9 & 81.9 \\
\hline Minneapolis & 87.0 & 73.8 \\
\hline Miami & 87.7 & 81.4 \\
\hline Los Angeles & 86.4 & 76.4 \\
\hline Las Vegas & 99.4 & 88.1 \\
\hline Houston & 93.7 & 83.4 \\
\hline Helena & 83.0 & 70.9 \\
\hline Fairbanks & 102.3 & 86.1 \\
\hline Duluth & 88.5 & 72.7 \\
\hline Chicago & 87.7 & 75.7 \\
\hline Boulder & 81.8 & 71.8 \\
\hline Baltimore & 96.3 & 81.4 \\
\hline Atlanta & 94.8 & 82.3 \\
\hline Albuquerque & 92.3 & 80.3 \\
\hline $\begin{array}{l}\text { CBECS } 2003 \\
\text { (All Office } \\
\text { Buildings over } \\
\text { 100,000 sf) }\end{array}$ & 113.7 & 99.5 \\
\hline
\end{tabular}

The second strategy used to generalize the results is to develop equations for each measure that allows savings to be estimated based on climate data. This way, savings can be estimated for buildings in cities not studied in this report. Multiple linear regression analysis is used to generate such equations.

Multiple linear regression equation used is of the form

Savings $=a+b B+b C+d D+e E+f F+g G$

where the lower case letters are coefficients and the upper case letters are climate-specific variables.

The following climate-specific variables are used in regression equation:

- B: HDD55 - Heating-degree-days in ${ }^{\circ} \mathrm{F}$, with a base of $55^{\circ} \mathrm{F}$

- C: $\mathrm{CDD} 55$ - Cooling-degree-days in ${ }^{\circ} \mathrm{F}$, with a base of $55^{\circ} \mathrm{F}$

- D: Summer dew point - The average dew point temperature in ${ }^{\circ} \mathrm{F}$ over the months JuneSeptember

- $\quad \mathbf{E}: \mathrm{HDD} 55^{2}-$ The square of heating-degree-days with base $55^{\circ} \mathrm{F}$

- F: CDD55 $5^{2}$ - The square of cooling-degree-days with base $55^{\circ} \mathrm{F}$

- G: Summer dew point squared 
- Savings: Total HVAC system energy savings (fraction).

These variables were selected through a trial and error process that used heating and cooling degree days with different bases to determine which base was the best predictor of savings. Summer dew point and its square term were added because for several measures, the marine climates, with their cool, moist summers and hot and humid climates were major outliers when only CDD and HDD terms were used in the regression. For the cities used in this report, climate-specific data for variables $B, C$, and $D$ can be found in Table 1 , and variables $E, F$, and $G$ can be found by squaring $B, C$, and $D$, respectively.

For each measure, the regression equation is developed based on only 12 of the 16 cities. The remaining 4 cities (Albuquerque, Houston, San Francisco, and Helena) are then used as verification to test the ability of the regression equations to predict the savings from the EnergyPlus results for new cities. For each measure, three regression equations are developed:

$$
\begin{aligned}
& \text { Savings }=a+b B+e E \\
& \text { Savings }=a+b B+c C+e E+f F \\
& \text { Savings }=a+b B+c C+d D+e E+f F+g G
\end{aligned}
$$

The rationale for developing three separate equations for each measure is that for some measures, Equation 4 or Equation 5 can be used with almost as much accuracy as Equation 6. 


\section{Results}

Figure 8 shows the modeled energy use intensity (in kBtu/sf) for each of the HVAC end uses in each climate in the pre-1980 baseline. Figure 9 shows the same data for the post-1980 baseline. Each of the sub-components of HVAC consumption has their EUls labeled. The total HVAC system EUI for each climate is labeled at the top of each bar in black.

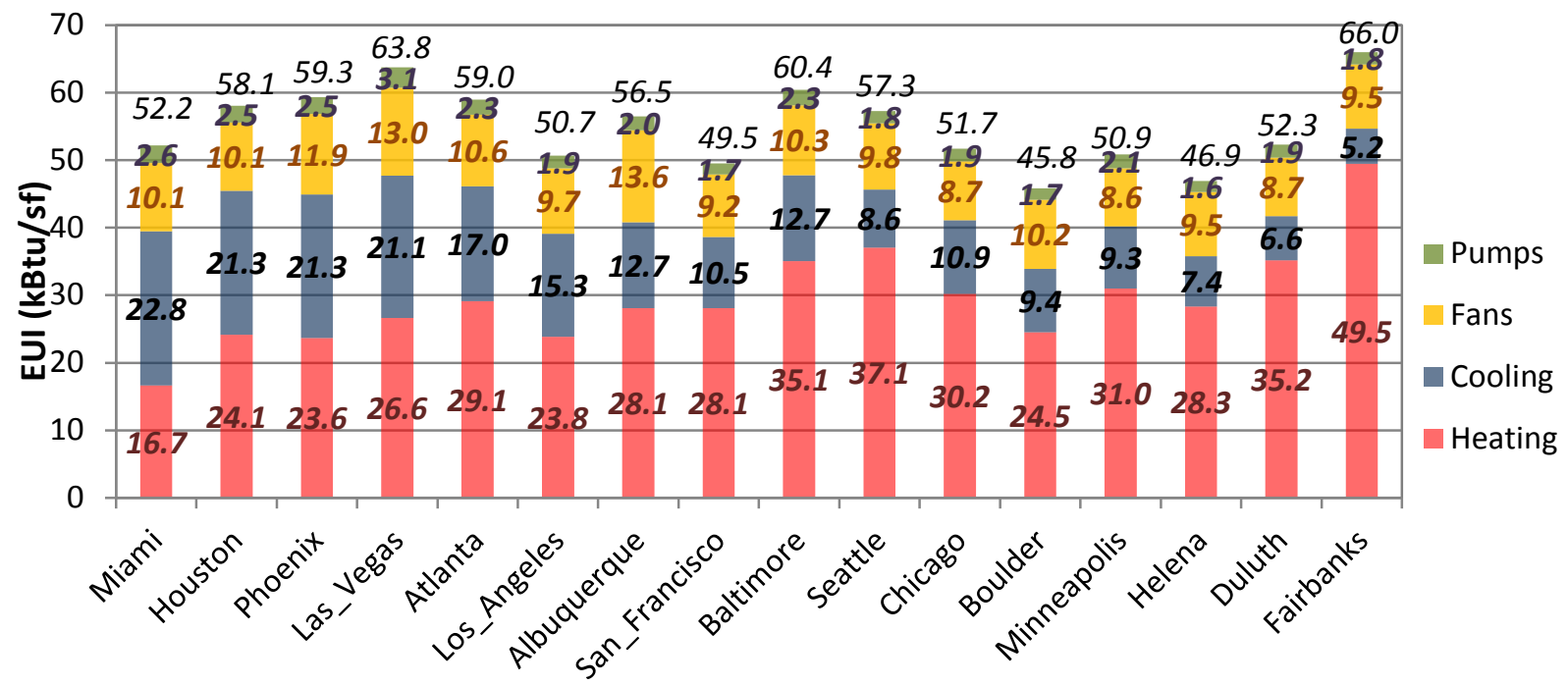

Figure 8: Modeled Energy Use Intensity (EUI) for HVAC systems in the Pre-1980 Baseline

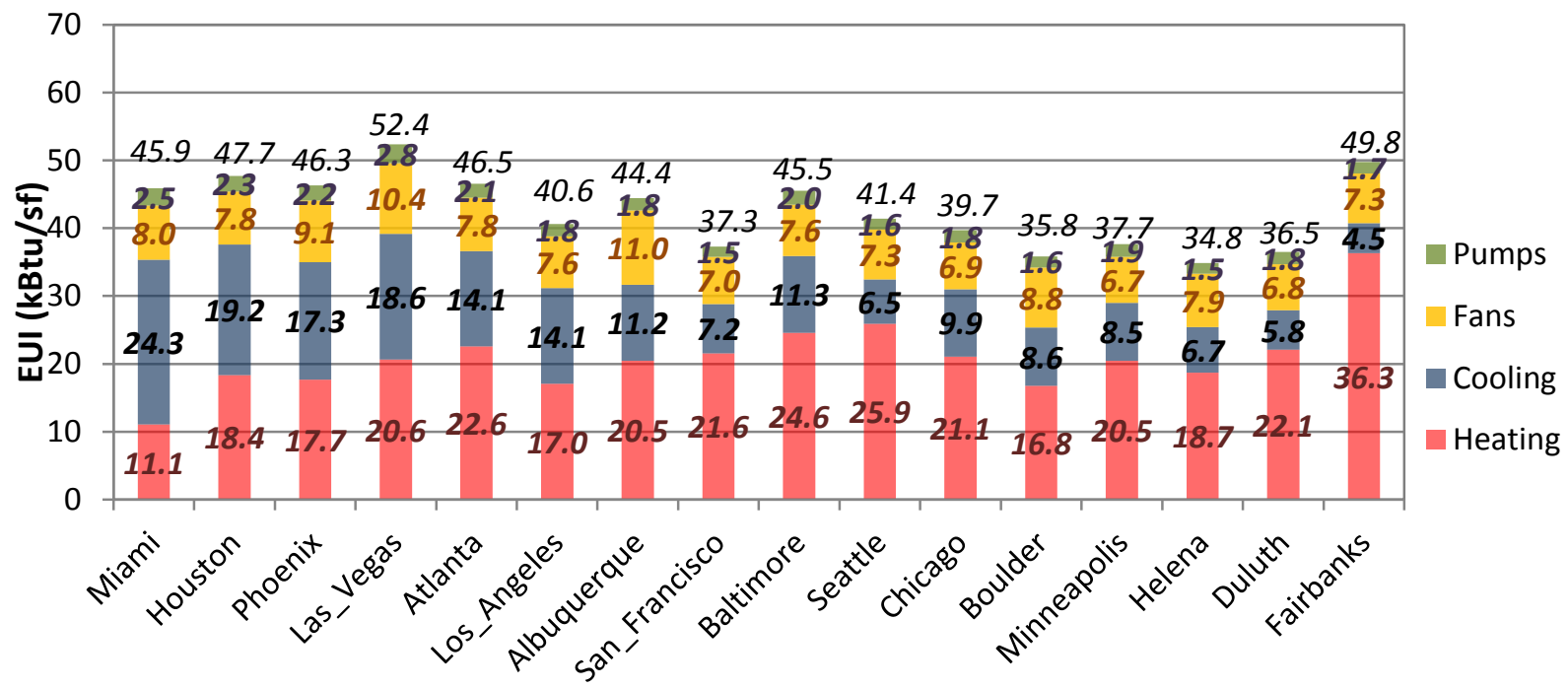

Figure 9: Modeled Energy Use Intensity (EUI) for HVAC systems in the Post-1980 Baseline

In this section the energy savings calculated from EnergyPlus for each of the individual and combinations of measures, for each of the 16 cities, and each of the 2 baselines (pre-1980 and post-1980) are 
presented. At the end of the section, results of the multiple regression analysis are presented, generalizing the savings based on climate characteristics.

\section{Energy Savings from Individual Measures}

Presented below are the energy savings from each individual measure in terms of percentage savings compared to the relevant baseline model. Absolute savings are presented in Appendix A

\section{A01a - HVAC Schedules End 2 Hours Early and are Off on Saturdays}

Measure A01a is the first of two sub measures that are geared towards shutting down the HVAC system when it is running unnecessarily. A01a changes the availability schedule for the chiller and pumps, as well as minimum outdoor-air fraction and thermostat set points so that they each end 2 hours earlier on weekdays and remain off all day on Saturdays. This keeps the HVAC systems completely off unless the boilers or chillers turn on to maintain the zones at the setback temperatures. In total, this reduces the HVAC system "on" time by 22 hours each week, out of a total of 92 hours in the baseline (24\% reduction in hours). Most locations also show HVAC savings very close to $24 \%$, as shown in Figure 10 . The figure shows the savings for each individual sub-component (pumps, fans, cooling and heating) and the total savings as shown on top of each bar. In some locations, the HVAC savings are less than $24 \%$ because the additional downtime (caused by reduced occupied period) forces more night cycle operation to maintain set points and/or because the hours of avoided operation are less energy intensive than average. In some locations, the HVAC savings exceed $24 \%$ because the hours of avoided operation may be more HVAC energy-intensive than average, with minimal night time increase. 


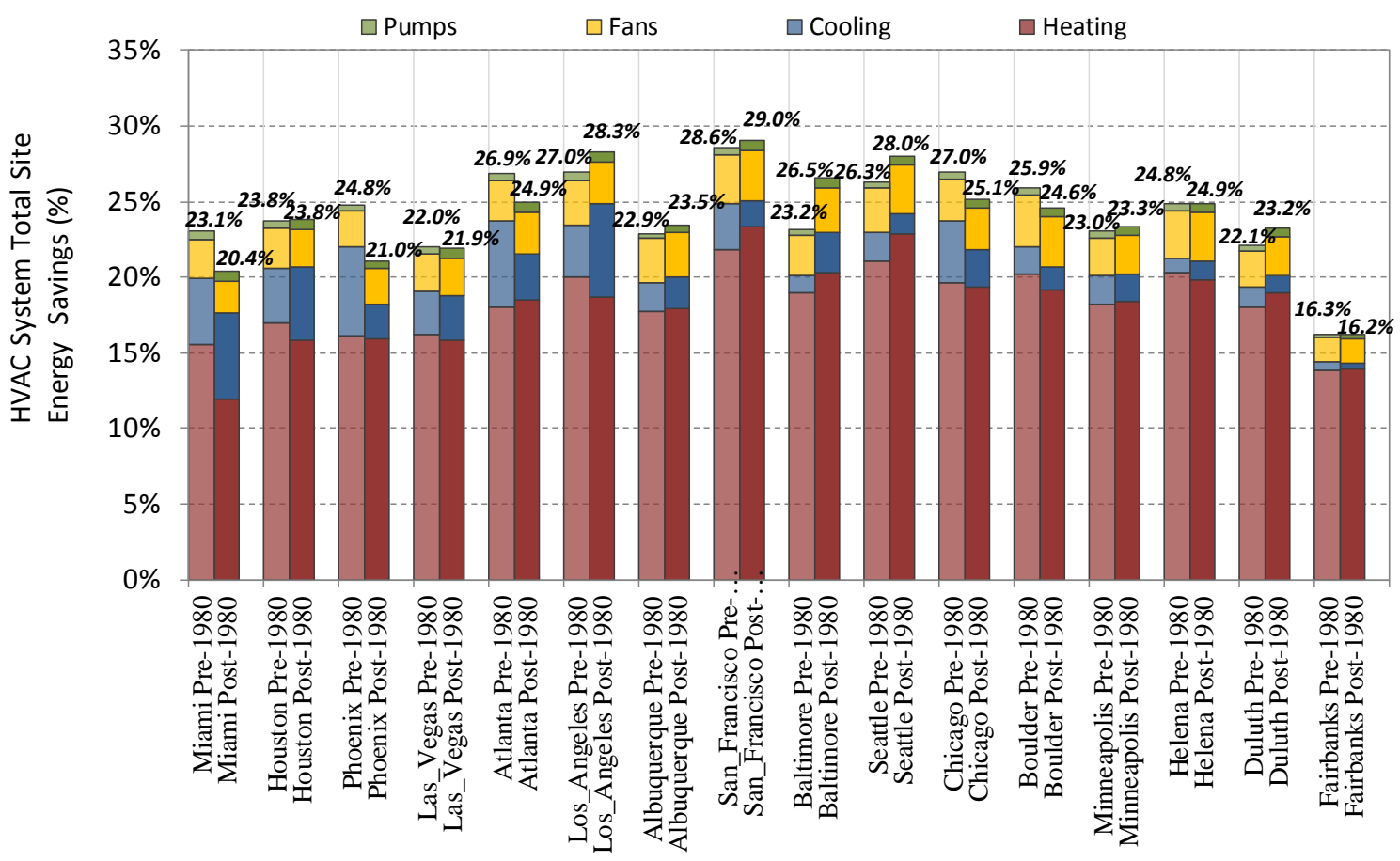

Figure 10: HVAC Energy Savings for A10a Re-tuning Measure (HVAC schedules end 2 hours early and are off on Saturdays)

\section{A01b - HVAC Schedules End 4 Hours Early and are Off on Saturdays}

Measure $\mathrm{A} 01 \mathrm{~b}$ is the second of the two sub-measures reducing HVAC system operation. Beyond the reductions in A01a, this measure shuts down the HVAC system an additional 2 hours early on weekdays, for a total of 4 hours earlier than the baseline. This adds 10 additional hours, or 32 total hours out of the original $92(35 \%)$ that the HVAC system is OFF and in setback mode. The HVAC savings in most locations is close to $35 \%$, as shown in Figure 11. 


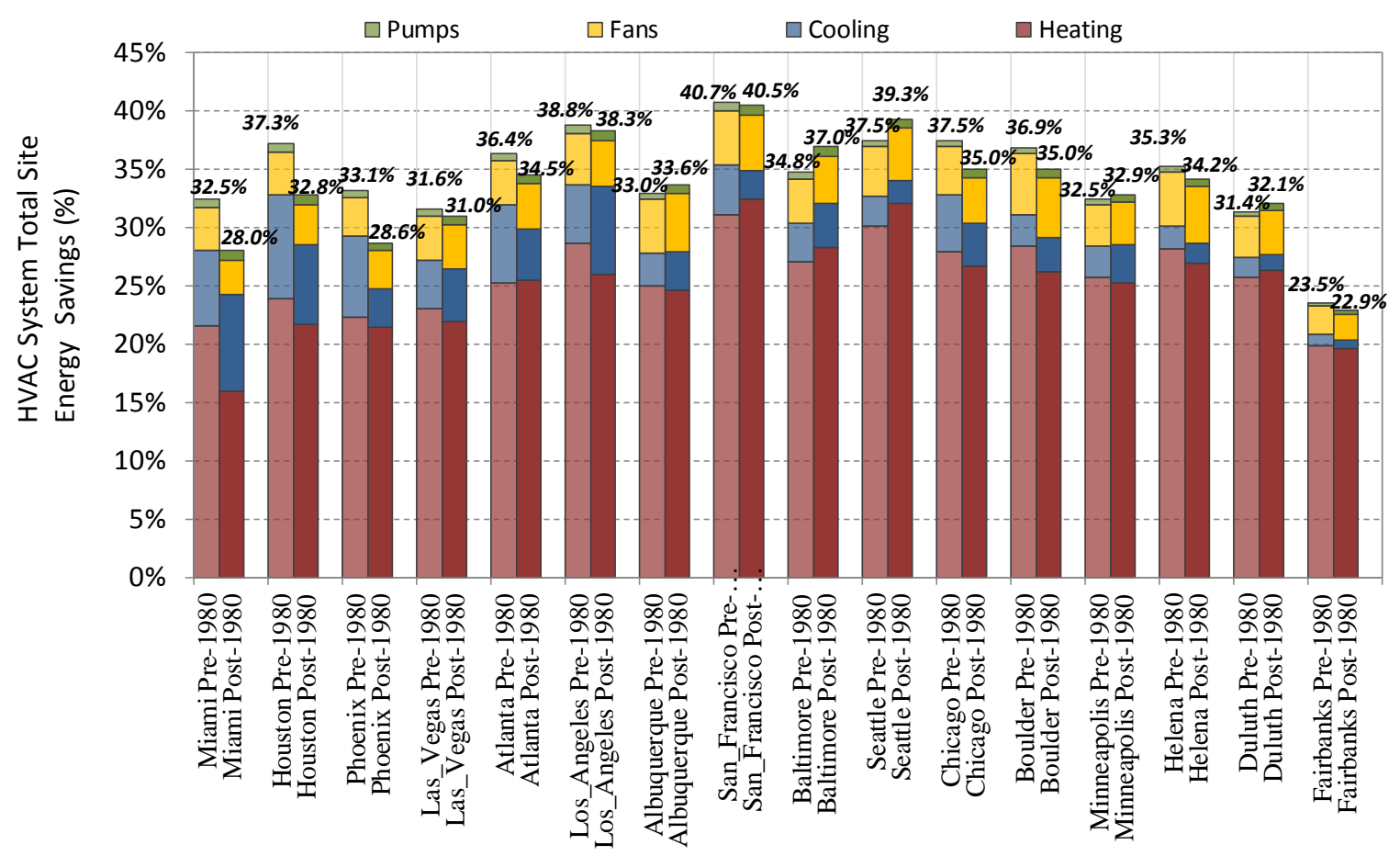

Figure 11: HVAC Energy Savings for A01b Re-tuning Measure (HVAC schedules end 4 hours early and are off on Saturdays)

\section{$\underline{\text { A02 - Static Pressure Reset }}$}

Static pressure reset works by changing the static pressure set point whenever possible; thereby reducing the air flow resistance that the AHU supply fans must overcome. The fan is then able to deliver the same amount of air flow with lower power consumption. The primary energy savings result from reduction in fan energy consumption (fans sub-component), as Figure 12 shows. A secondary effect also occurs because of lower fan power consumption. Because the fans consume less power, they also reject less heat to the supply-air stream. This means that in all locations, the cooling energy is also modestly reduced, and in the colder locations, more heating is needed to compensate for the reduced heat gains from the fan. The post-1980 baseline shows higher savings than the pre-1980 baseline because fan energy consumption is a higher fraction of overall HVAC consumption in the post-1980 baseline. 


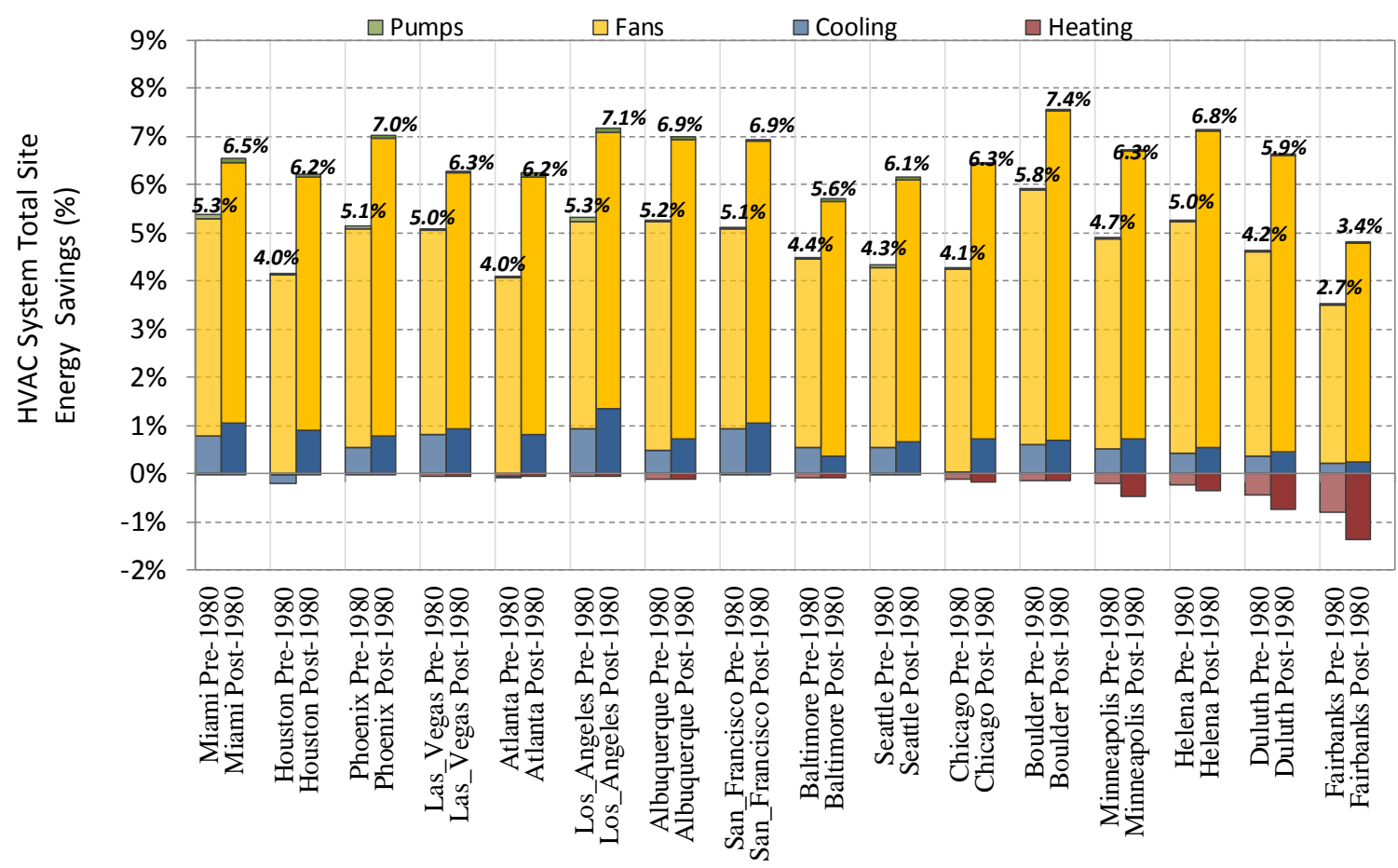

Figure 12: HVAC System Energy Savings for A02 Re-tuning Measure (Static Pressure Reset)

\section{A03a - Supply-Air Temperature Reset based on Outdoor-Air Temperature}

Supply-air temperature reset based on outdoor-air temperature (A03a) is the first of two 'supply-air temperature reset' sub-measures. This measure uses outside-air temperature to determine when and by how much the supply-air temperature should be changed (raised or lowered). This generally saves energy during the shoulder and the heating seasons by reducing reheating of supply air that is otherwise tempered lower than any zone really needs (constant $55^{\circ} \mathrm{F}$ in the baseline). The advantage of using the outdoor air method of supply-air temperature reset is that it is relatively easy to program. It requires using only one sensor to determine what supply-air temperature set point should be applied for all VAV systems. The HVAC savings range between $2 \%$ and $20 \%$ across various climate locations, as shown Figure 13. The reheat energy in hot climates is typically low because of reduced heating demand; therefore, they generally tend to use less reheat energy and thus show lower heating and cooling savings from this measure. On the other hand, milder climates typical have an extended shoulder season when both heating and cooling demand is low; increasing the supply-air temperature set point during those conditions reduces reheating energy signification. Therefore, the savings in those locations are significantly higher than either hot or cold locations.

Most of the saving from modeled supply-air temperature reset is from partial mitigation of simultaneous heating and cooling that occurs as a result of high minimum air flow set points at the VAV boxes (50\% for pre-1980 and 40\% for post-1980). Supply-air temperature reset on the pre-1980 baseline has higher savings than on the post-1980 baseline because the pre-1980 baseline has a higher minimum air flow set point ( $50 \%$, compared to $40 \%)$, and consequently more simultaneous heating and cooling taking place. 
Increasing the supply-air set point often reduces or eliminates reheating when it is not strictly necessary (during shoulder and heating seasons) and also enables the supply-air set point to be met more frequently using economizers alone. Note that in almost all locations the fan energy consumption increases slightly.

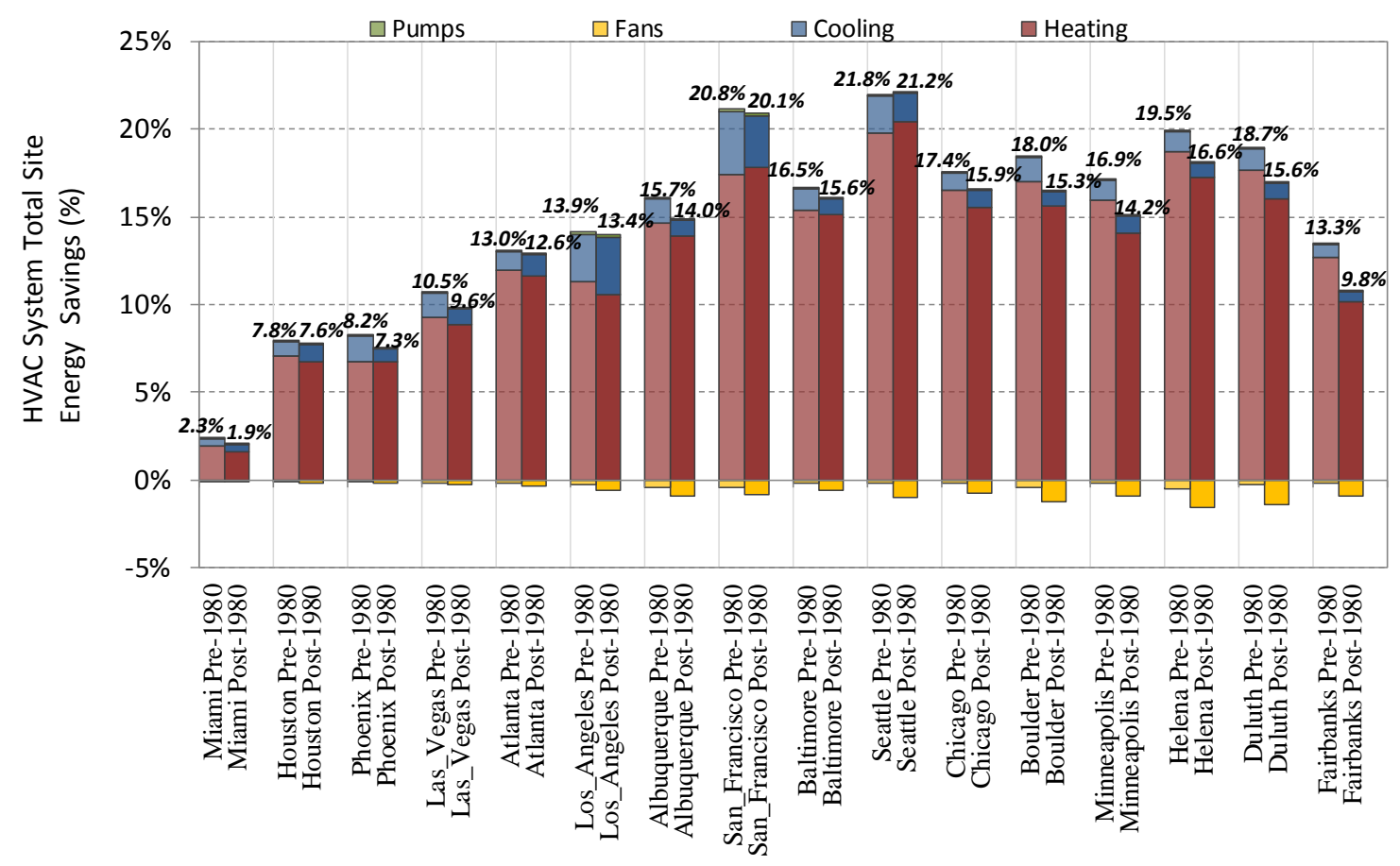

Figure 13: HVAC System Energy Savings for A03a Re-tuning Measure (Supply-Air Temperature Reset based on Outdoor-Air Temperature)

\section{A03b - Supply-Air Temperature Reset - Alternate Method}

The supply-air temperature reset based on outdoor-air temperature is easy to implement, but it may not be ideal because it does not rely on feedback from the zones. The alternate method provides an interesting contrast to the supply-air temperature reset based on outdoor-air temperature alone. This alternate method is a "smarter" type of reset because it uses feedback directly from the VAV box cooling commands to determine whether to raise the supply-air temperature. The results from the alternate method reveal a very similar pattern in savings to the outdoor air method (low savings in cooling-dominated climates and higher savings in mild/marine climates). The magnitude of the savings, however, is almost twice as high, indicating that the outdoor-air method still misses a lot of opportunities to raise the supply-air temperature. The range of savings in mixed and cold climates is between $20 \%$ and $30 \%$, and for mild and marine climates, it is between $30 \%$ and $45 \%$, as shown in Figure 14. In some climate locations (mild and marine), there is significant increase in fan energy consumption because lowering the supply-air temperature increase the supply-air flow leading to increased fan energy. 


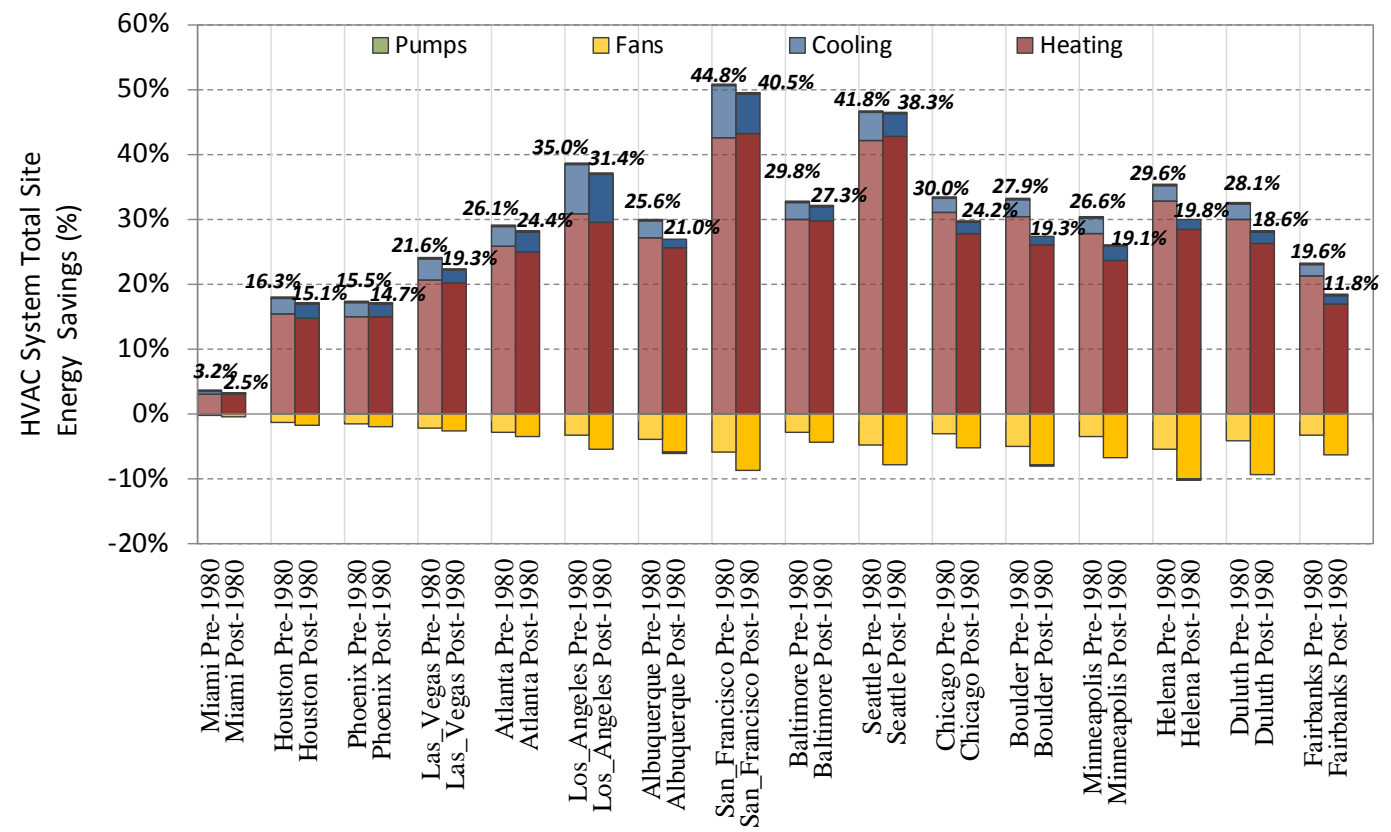

Figure 14: HVAC Energy Savings for A03b Re-tuning Measure (Supply-Air Temperature Reset base on the Alternate Method)

\section{A04 - Supply-air Temperature Constant Set Point}

Figure 15 shows HVAC energy savings for the re-tuning measure A04a, the lowest constant supply-air temperature set point $\left(53^{\circ} \mathrm{F}\right)$ in this series of sub-measures, while Figure 16 shows HVAC energy savings for $\mathrm{A} 04 \mathrm{e}$, the highest constant set point $\left(58^{\circ} \mathrm{F}\right)$ in the series. For brevity, the intermediate set point results are omitted; however, the results are included in Appendix A. A clear pattern emerges from this set. For each degree rise in supply-air temperature set point, there is about $5 \%$ to $6 \%$ reduction in total HVAC energy consumption, depending on climate. Most of this savings comes from reduced heating energy consumption from a lower air temperature difference across the reheat coil. There is also some cooling energy savings as the supply-air temperature is increased because of reduced cooling coil load. Fan energy consumption, on the other hand, increases slightly as the supply-air temperature is raised. The higher supply-air temperature means that more air flow is required to meet the same cooling loads. At least for this kind of VAV setup, however, the model shows that even in the hottest climates, the heating and cooling savings far outweigh the fan power increase, for supply-air temperatures up to $58^{\circ} \mathrm{F}$. For the warmer climates, however, some zones may start to have problems meeting their thermostat set points during hot summer days as supply-air temperature set points are raised. In hot-humid climates, the supply-air temperature should be lowered to at least $55^{\circ} \mathrm{F}$ during summer time to avoid comfort problems. 


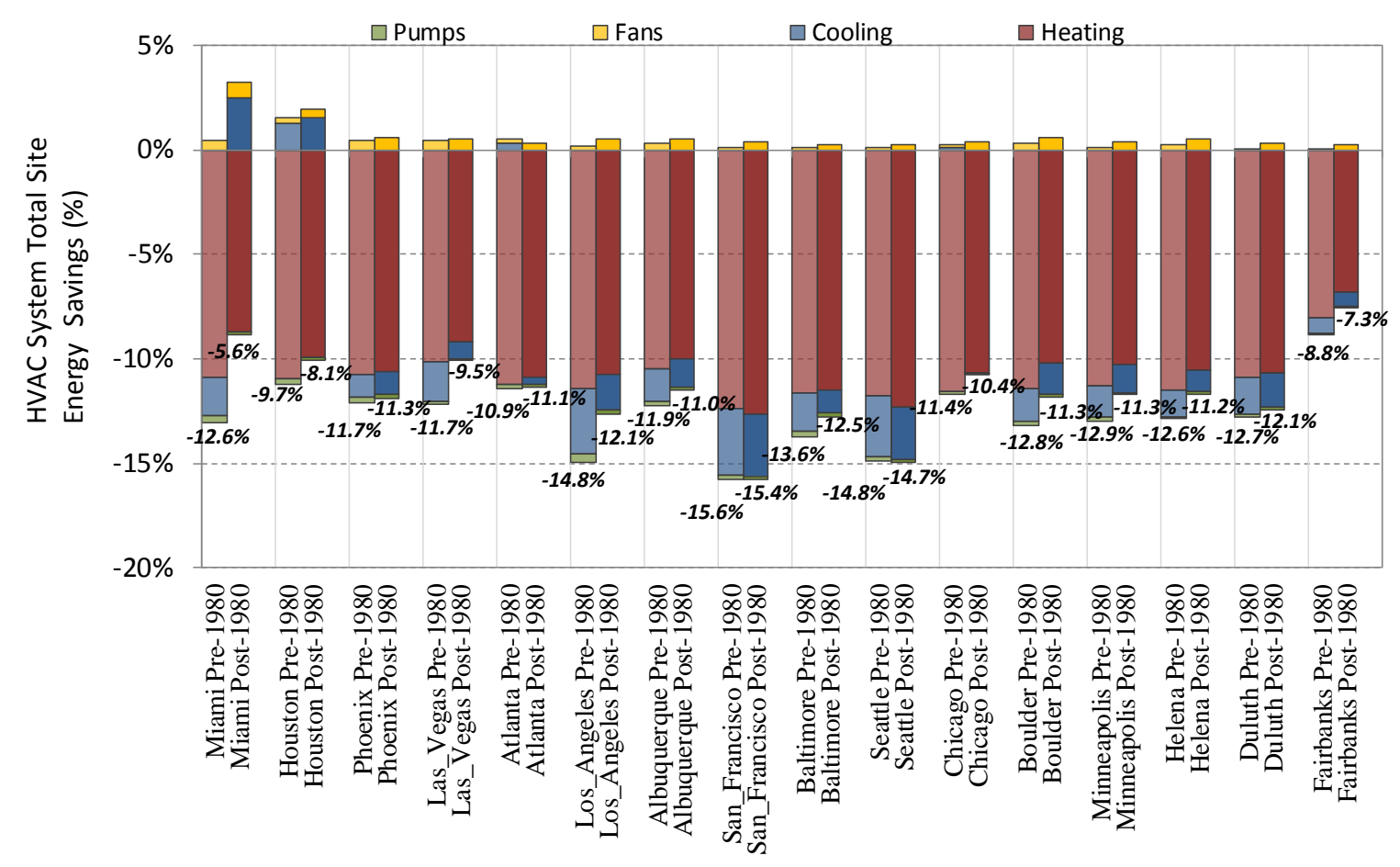

Figure 15: HVAC Energy Savings for A04a Re-tuning Measure (Constant Supply-Air Set Point of $53^{\circ} \mathrm{F}$ )

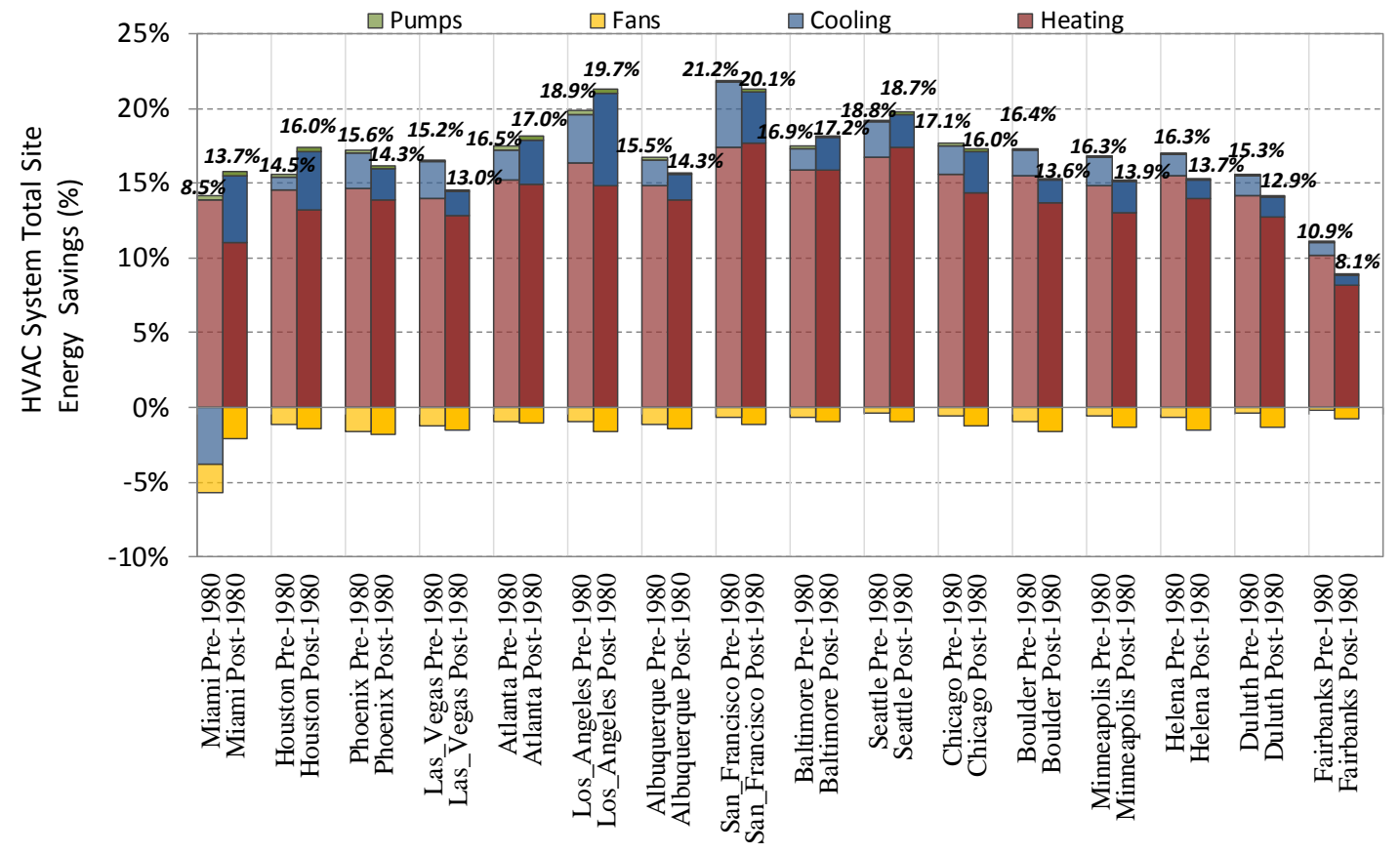

Figure 16: HVAC Energy Savings for A04e Re-tuning Measure (Constant Supply-Air Set Point of $58^{\circ} \mathrm{F}$ ) 


\section{A05 - VAV Minimum Flow Set Point of $30 \%$}

Measure A05 reveals just how much energy savings is possible in large office buildings that use VAV boxes with high minimum flow set points. In all locations with exception to Fairbanks, the total HVAC savings range between $30 \%$ and $40 \%$ from lowering the VAV minimum air-flow set point from $50 \%$ to $30 \%$ (pre-1980 baseline). For the post-1980 building, the HVAC savings range between $15 \%$ and $25 \%$ from lowering the minimum flow set point from $40 \%$ to $30 \%$. Most of the savings are a result of reduced heating consumption (from enabling lower flow rates of $55^{\circ} \mathrm{F}$ supply air in the shoulder and heating season, which reduces reheat energy consumption significantly).

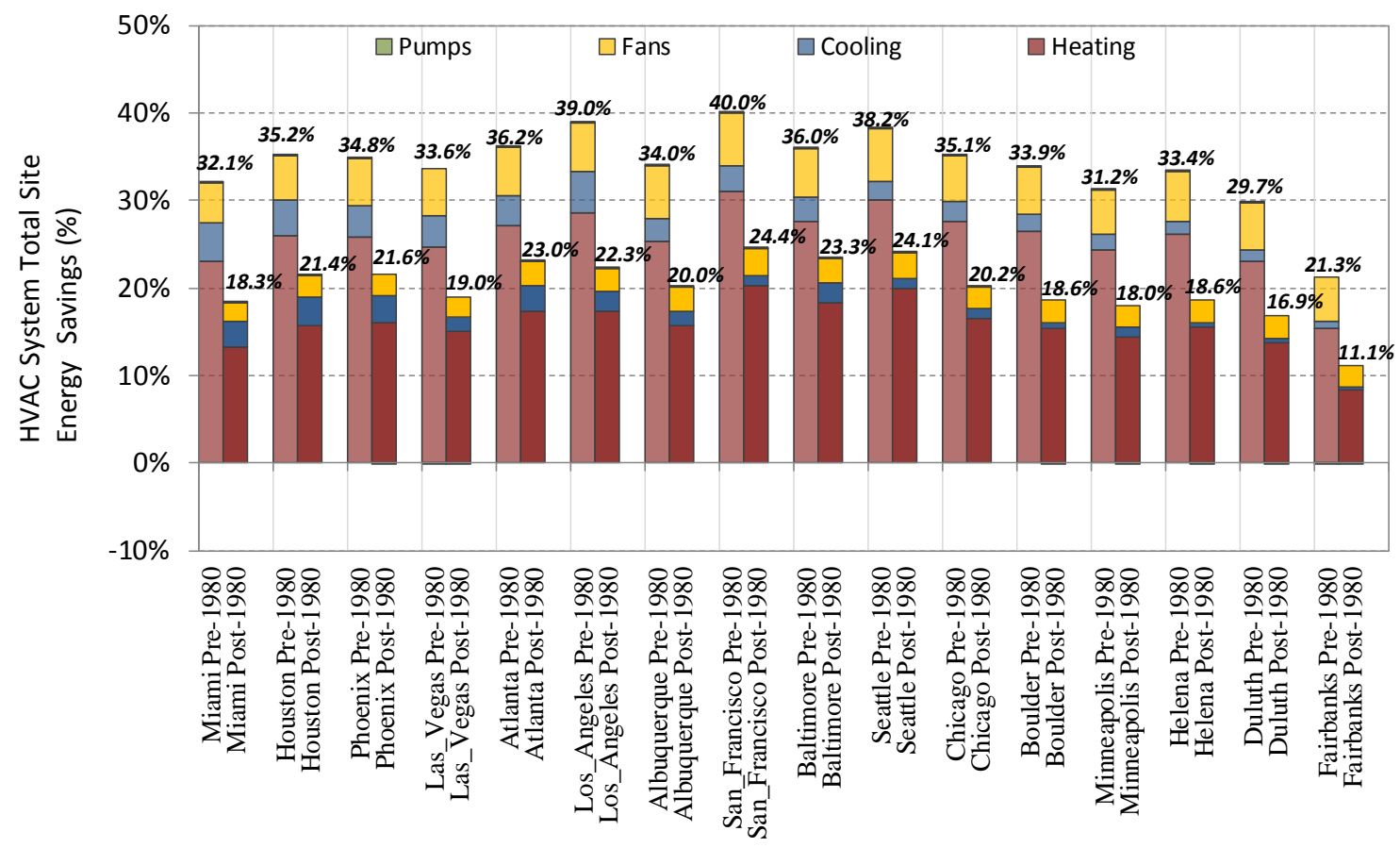

Figure 17: HVAC Energy Savings for Re-tuning Measure A05 (VAV Minimum Air Flow Set Point of 30\%)

\section{A06 - Wider Thermostat Range}

Measure A06 investigated increasing the thermostat's temperature range by 2 degrees on both heat and cooling set points. The most important mechanism for savings here is that in the winter, interior zones are allowed to drift higher in temperature (caused by internal heat gains) than the surrounding perimeter zones. The difference in temperature (which is not allowed to establish itself under tight thermostat control) allows the interior zones (through interior wall conduction and air exchange) to heat the colder perimeter spaces and vice versa. There is also significant savings from not having to mechanically heat the spaces at a higher temperature or cool them at a lower temperature. This reduces the driving temperature difference across the building envelope. According to the graph in Figure 18 , savings appear to be fairly uniform, in the $12 \%$ to $20 \%$ range, except for the coldest climates (Fairbanks is around 9\%). 


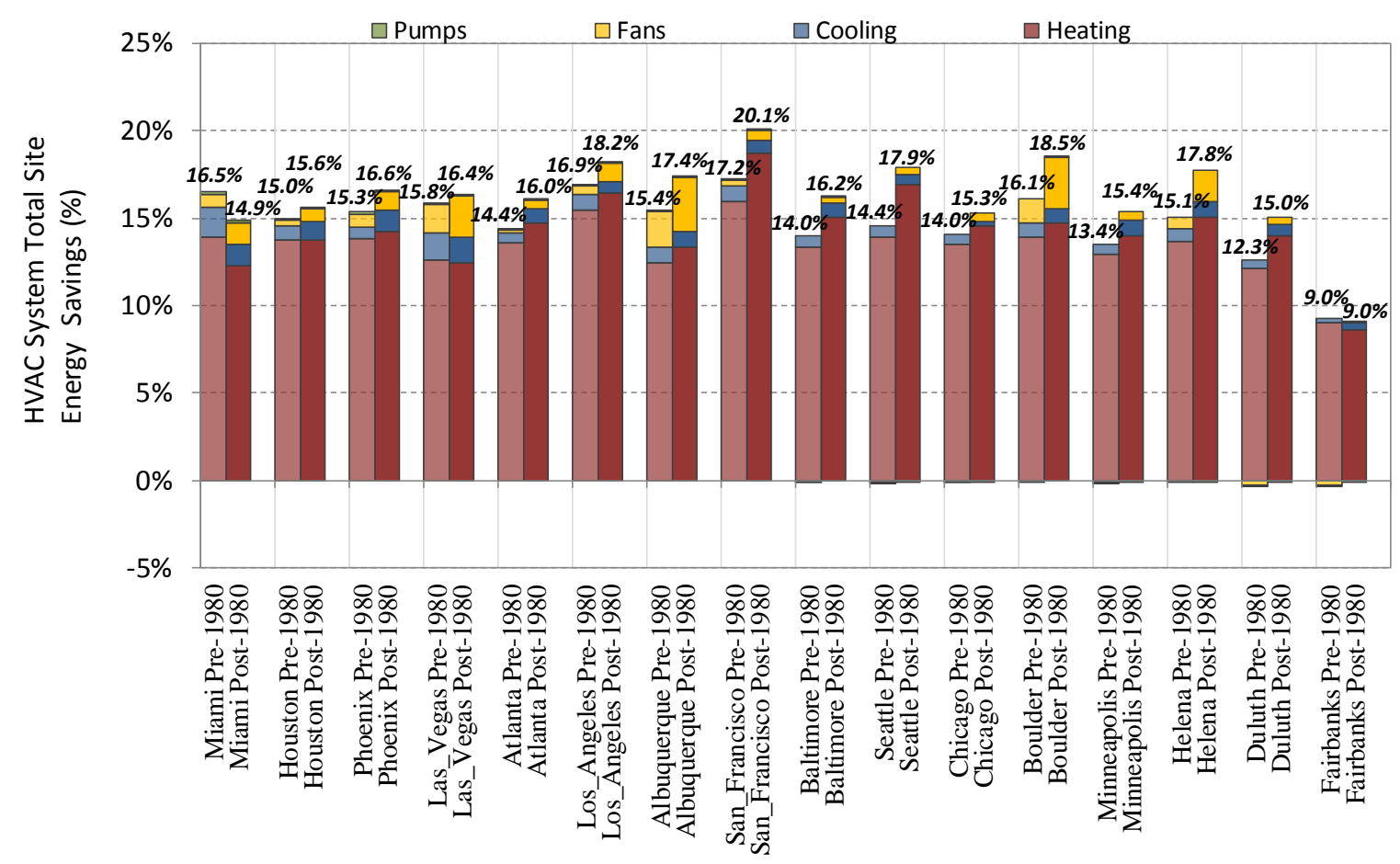

Figure 18: HVAC Energy Savings - A06 (Wider Thermostat Range)

\section{A07 - Zero Minimum Outside Air During Unoccupied Hours}

The HVAC savings available from closing the outside-air damper during unoccupied and start-up hours varies by climate (Figure 19). Heating savings is only available in cold climates, where there are a significant number of hours in the year when the outside-air temperature is cold enough to drive the mixed-air temperature below the supply-air temperature set point (with the limited fraction of outdoor air coming from the minimum outside-air damper). In the coldest climates, the heating savings may be as much as $5 \%$ to $6 \%$. Cooling savings, likewise, are only available in climates where the early morning temperatures (during system warm-up) in the summer are still warm enough to require mechanical cooling. In places like San Francisco and Seattle, this is never the case. In these mild climates, there is no potential savings from this measure. This measure appears to be more suitable for colder climates. 


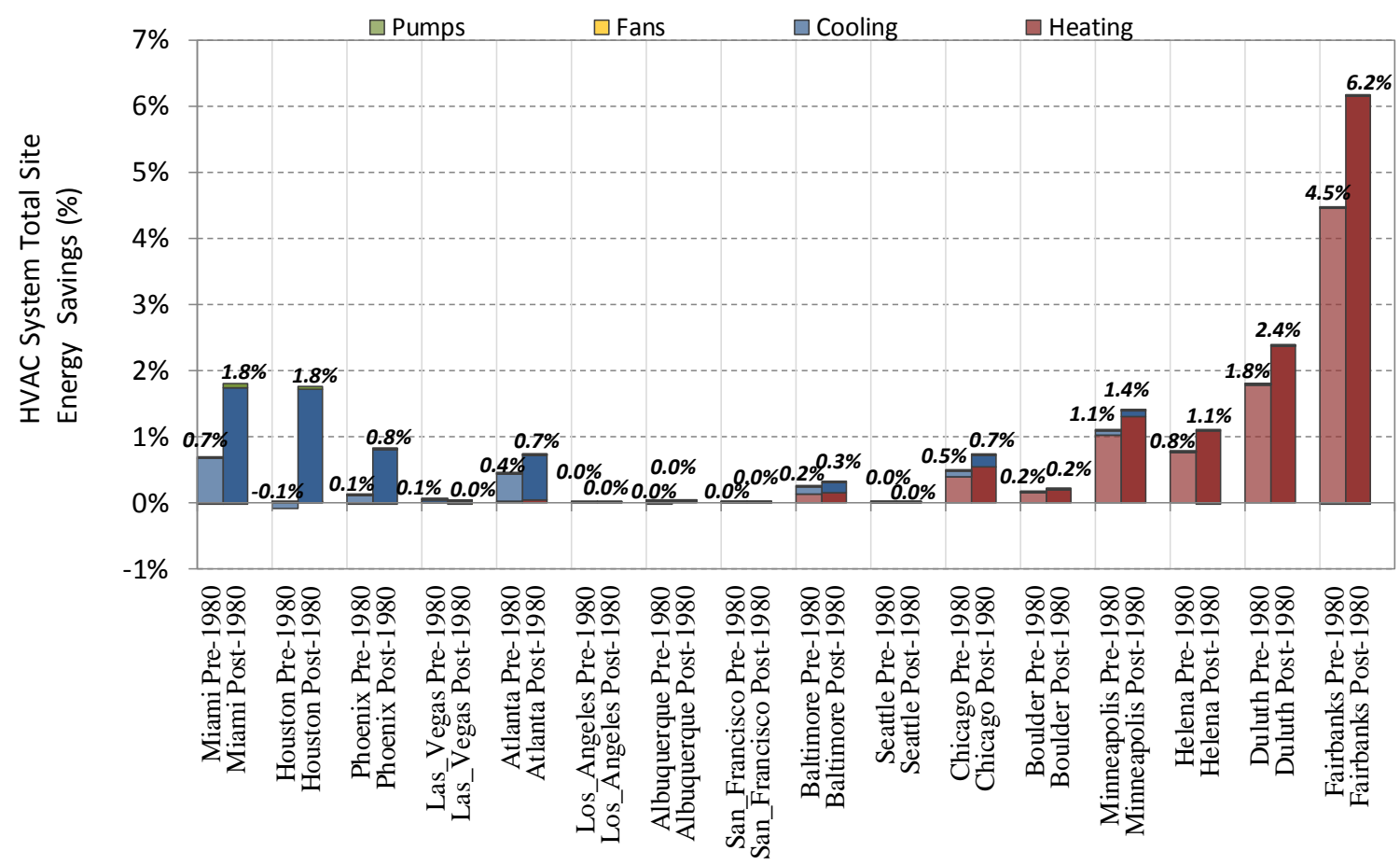

Figure 19: HVAC Savings for A07 Re-tuning Measure (Zero Minimum Outside Air During Unoccupied and Startup Hours)

\section{W01 - Chilled-water Loop Differential Pressure Reset}

Figure 20 shows energy savings for chilled-water loop differential pressure reset. The savings are small, with up to $1.4 \%$ of savings in very hot climates, $0.1-0.4 \%$ in moderate climates, and less than $0.1 \%$ savings in cold climates. The reason for the limited savings is that pump power accounts for only between $2 \%$ and $4 \%$ of baseline HVAC energy consumption, and the chilled-water secondary loop pump is only one of several pumps serving the building. So even though the annual energy consumption of the chilled-water pump may be reduced by between 10 and $20 \%$ by reducing the differential pressure set point, the savings as a percent of HVAC energy is still quite small. 


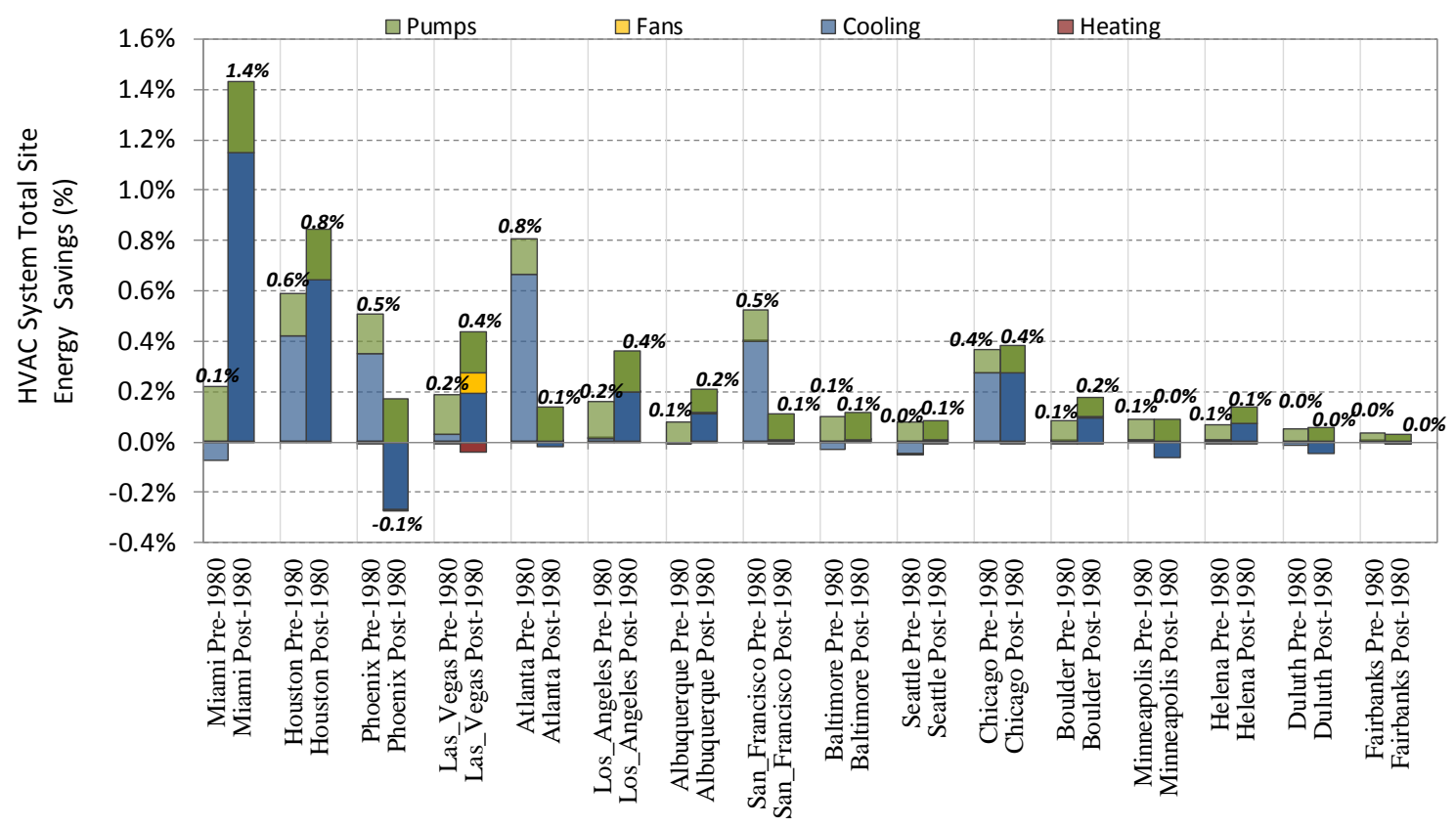

Figure 20: HVAC Energy Savings for W01 Re-tuning Measure (Chilled-Water Differential Pressure Reset)

\section{W02-Chilled-water Temperature Set point Reset}

Figure 21 shows the savings from chilled-water temperature reset. This measure saves chiller energy by raising the chilled-water temperature during times of low chilled-water demand, thereby reducing the pressure ratio in the chiller and raising the coefficient of performance. There is a slight increase in pump power consumption as a result of this measure because the chilled-water loop has to deliver a higher volume of chilled-water to meet the same cooling coil loads. There is also a slight increase in fan energy consumption because a higher volume of air must be blown over a warmer cooling coil to deliver the same cooling energy. Savings from this measure are roughly proportional to the number of coolingdegree-days in each climate. The results show some inconsistencies between the pre- and post-1980 baselines, however, typical savings range from $1 \%$ to $5 \%$ of HVAC energy consumption, based on climate. 


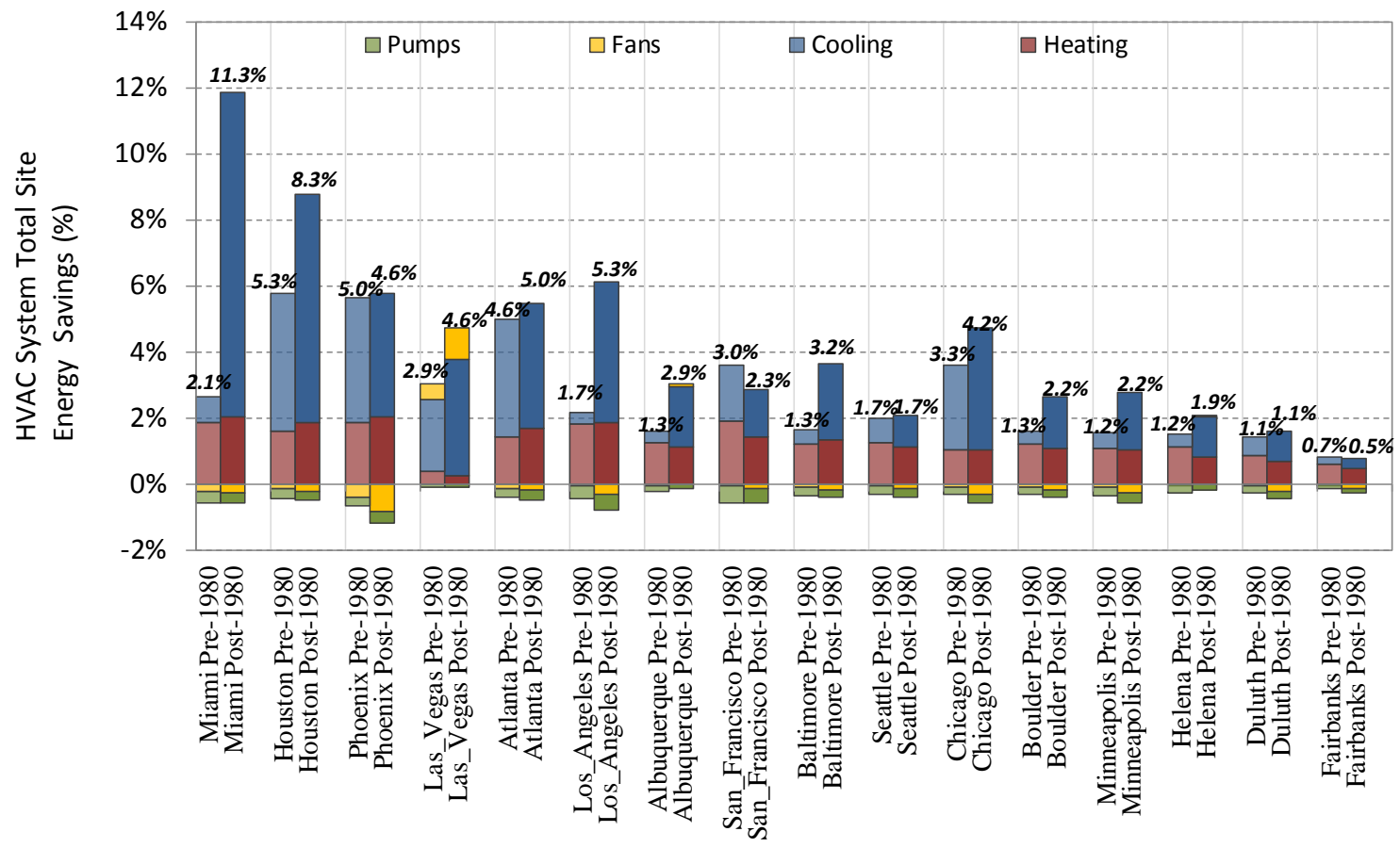

Figure 21: HVAC Energy Savings for W01 Re-tuning Measure (Chilled-Water Temperature Set Point Reset)

\section{W05 - Condenser Water Temperature Reset}

Measure W05 saves cooling energy by decreasing the condenser loop supply temperature. The chiller COP (coefficient of performance) increases after the measure is applied. However, the condenser loop balances out the energy saving because the cooling tower fan works harder and longer to cool condensing water to a lower temperature. The resulting savings (primarily cooling) from this measure are shown in Figure 22. 


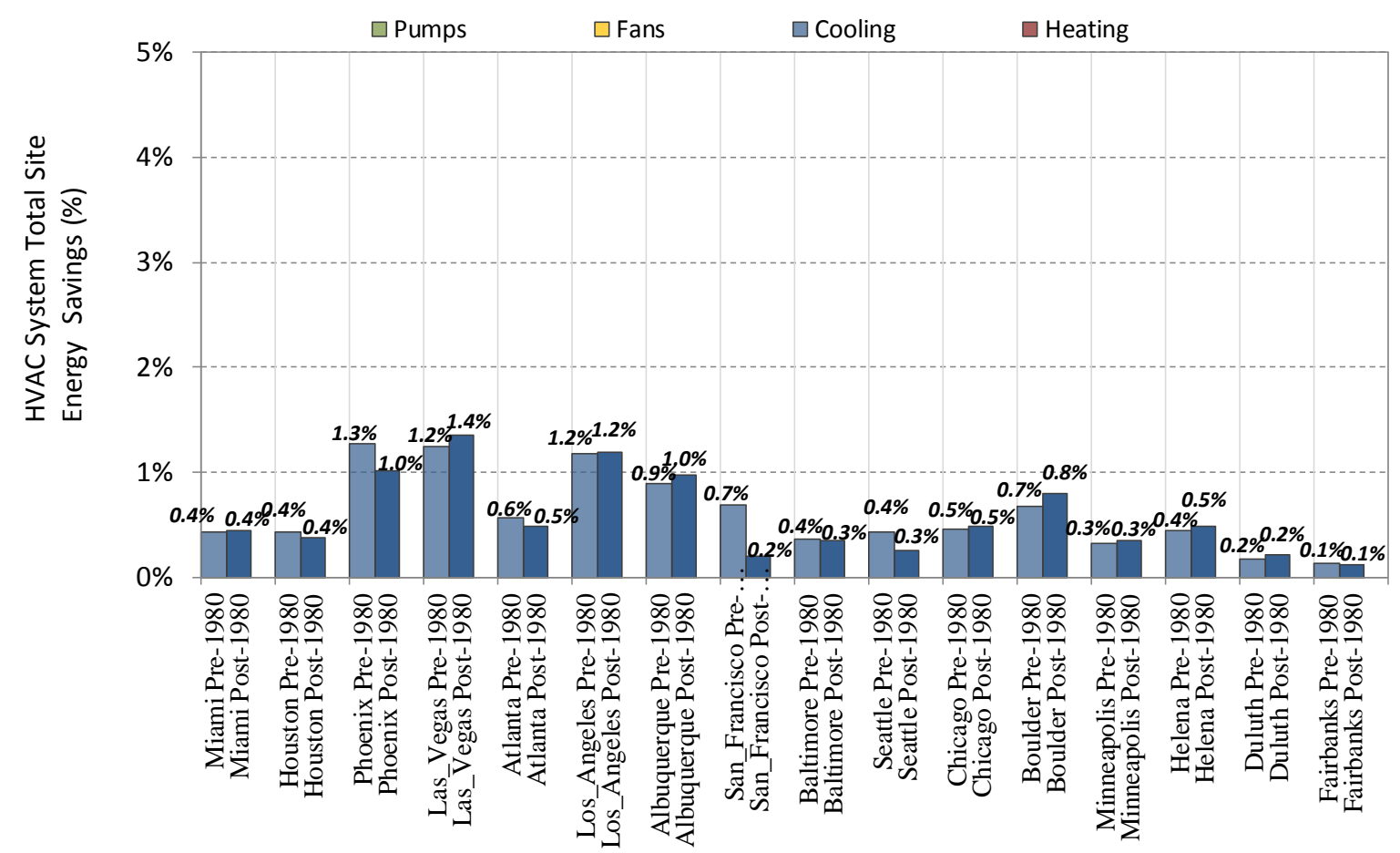

Figure 22: HVAC Energy Savings for W02 Re-tuning Measure (Condenser Water Reset)

\section{W06 - Plant Shut Down When There Is No Load}

Shutting down the central heating and cooling plants when they are not needed can save energy in a number of ways: at the pumps, at the primary cooling equipment (chiller compressors) as a result of false loading of the chillers, at the cooling tower as a results of rejection of waste heat picked up from the distribution system (e.g., through the walls of the piping). 


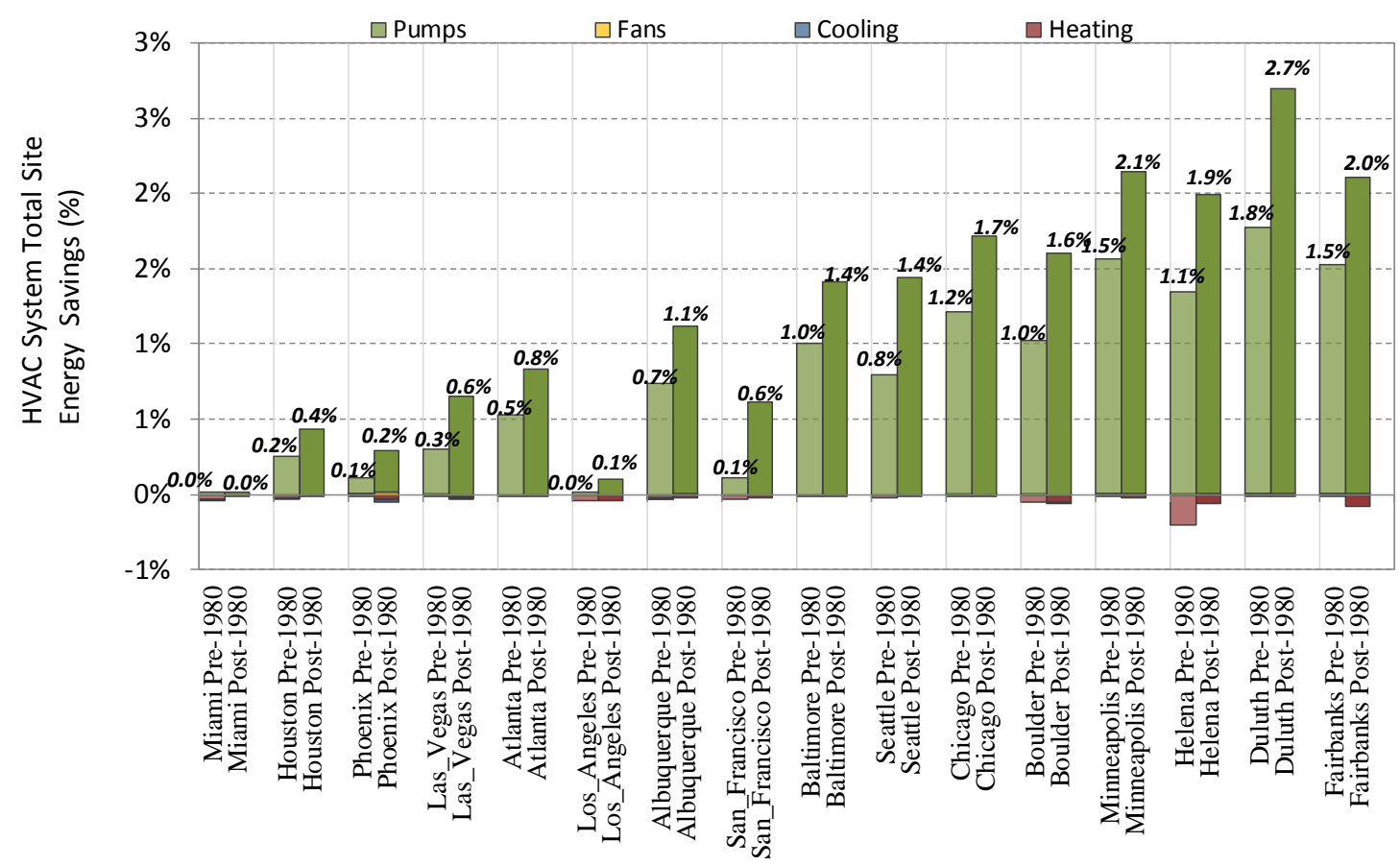

Figure 23: HVAC Energy Savings for W06 Re-tuning Measure (Plant Shut Down when there is No Load)

\section{W03- Hot-water Differential Pressure Reset and W04 - Hot-water Temperature Reset}

The two hot-water loop measures, W03 (hot-water loop differential pressure reset) and W04 (hot-water temperature reset), are discussed here without providing graphical HVAC energy savings because both measures yielded nearly zero savings as modeled. Hot-water temperature reset did not produce any savings as modeled for two reasons. First, operating at a lower hot-water loop temperature does not change the hot water coil heating load at any given time, meaning that the boiler's part load ratio does not change and therefore the heating efficiency does not change. Second, interior hot water pipes in this model are measured in a simplified form as adiabatic. Thus, there are no standby or transport losses in the pipes that are being modeled. Mitigation of these losses may produce savings in real buildings, especially when hot water pipes traverse unconditioned spaces.

Hot-water differential pressure reset produced very minimal savings. This is mainly because pump energy can be regarded as energy input to the hot-water loop. The reduction of pump electric energy has to be compensated by the increase of gas energy consumption in the boiler. Also, as mentioned in the results for W01, the chilled-water differential pressure reset measure produced very small savings because of the marginal energy consumption that the chilled-water pump was responsible for. Because the hot-water loop operates at an even lower flow rate, the hot-water loop secondary pump is a fraction of the size of the chilled-water secondary pump and produces even less savings. 


\section{Energy Savings from Combinations of Measures}

In the previous section the energy savings for individual re-tuning measure for the two building vintages at various climate locations where presented. In this section the energy savings estimates for combination of re-tuning measures are presented for the same two building vintages and climate locations. Six different combinations of re-tuning packages considered.

\section{Combination 1}

Combination 1 can be applied to the single-duct VAV systems with VFDs installed on both chilled-water pumps and cooling tower fans. It includes most air-side and water-side measures except the chilledwater system scheduling (W06) and outdoor-air damper closeout during unoccupied and start-up periods.

Combination 1 includes the following measures:

- A01a - HVAC schedules end 2 hours early on weekdays and are off Saturdays

- A02 - static pressure reset

- $\mathrm{A} 03 \mathrm{~b}$ - supply-air temperature reset (alternate method)

- A05 - VAV minimum air flow set point of $30 \%$

- A06 - wider thermostat range

- W01 - chilled-water differential pressure reset

- W02 - chilled-water temperature reset

- W03 - hot-water differential pressure reset

- W04 - hot-water temperature reset

- W05 - condenser water temperature reset

Figure 24 shows the annual energy savings in each climate for Combination 1. A typical pattern observed in many of the individual measures is apparent for this combination of measures. Energy savings relative to the baseline building increase as the climate becomes more mild. This is intuitive in the sense that in more extreme climates, a larger fraction of the HVAC energy in the baseline is going towards necessary or structural conditioning requirements (i.e., meeting envelope and outdoor-air-driven loads). For the pre-1980 baseline, HVAC energy savings range from $49 \%$ for hot climates to $73 \%$ for cool marine climates, to $33 \%$ for sub-arctic climates. For the post-1980 baseline, HVAC energy savings range from $46 \%$ for hot climates to $70 \%$ for cool marine climates, to $24 \%$ for sub-arctic climates. To generalize among the various climates, most of the energy savings (about two-thirds) is from heating, with roughly an equal measure of fan and cooling savings accounting for most of the remaining third. 


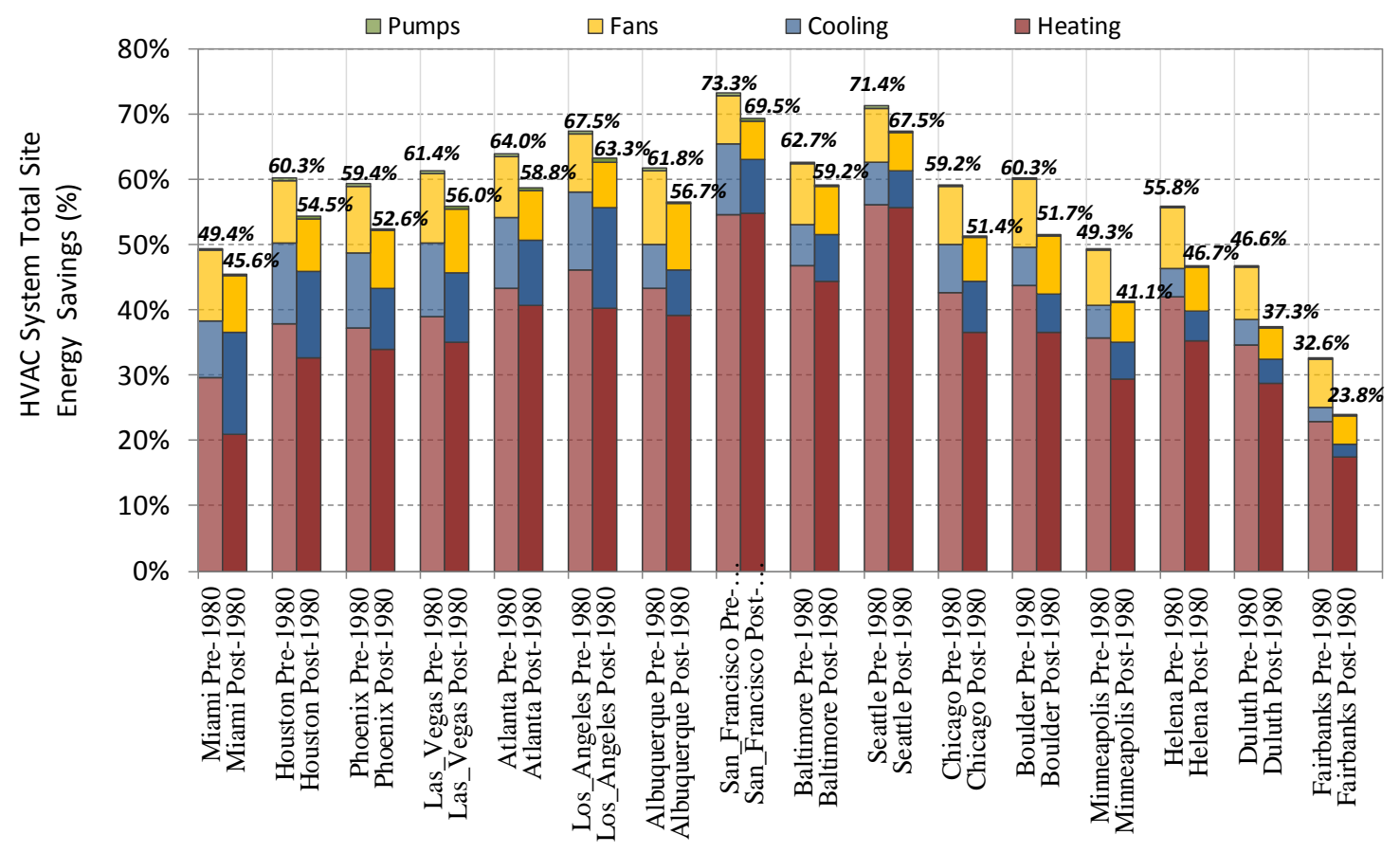

Figure 24: HVAC Energy Savings for Combination 1 Re-tuning Measures

\section{Combination 2}

Combination 2 is the "lite" version of re-tuning measures for single-duct VAV without the implementation of terminal box (A05) and zone level re-tuning measures (A06). Combination 2 also includes the condenser water temperature reset.

Combination 2 includes the following measures:

- A01a - HVAC schedules end 2 hours early on weekdays and are off Saturdays

- A02 - static pressure reset

- $\mathrm{A} 03 \mathrm{~b}$ - supply-air temperature reset (alternate method)

- W01 - chilled-water differential pressure reset

- W03 - hot-water differential pressure reset

- W04 - hot-water temperature reset

- W05 - condenser water temperature reset

Figure 25 shows the HVAC energy savings from Combination 2. The pattern of savings is very similar to Combination 1, except at a lower level because of the smaller set of measures. Because measure A05 (damper minimum flow rate of $30 \%$ ) is not included, there is also a smaller difference between the results for the two baselines. Like the previous combination, the heating savings account for two-thirds of the savings in all most all climate location. 


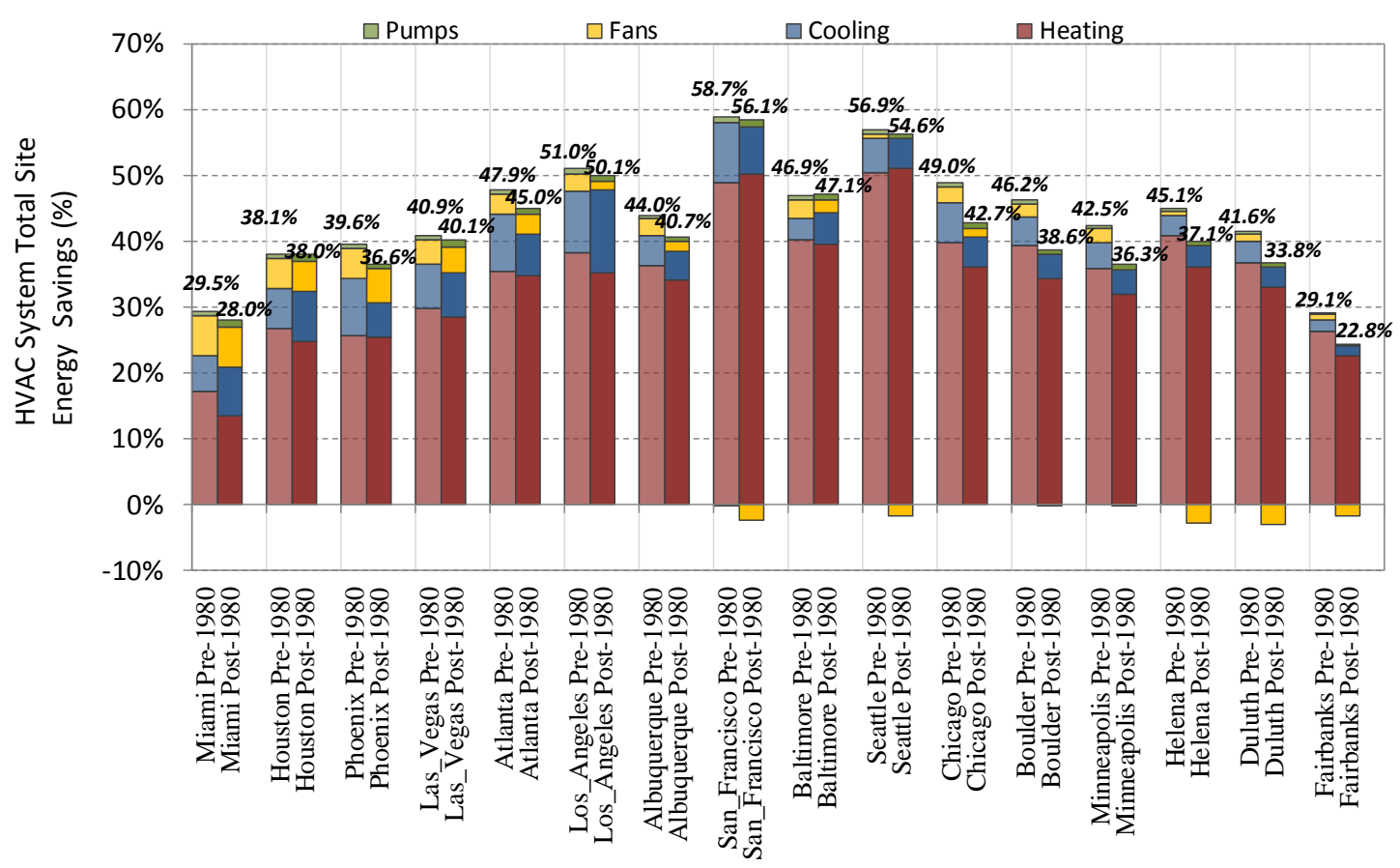

Figure 25: HVAC Energy Savings for Combination 2 Re-tuning Measures

\section{Combination 3}

The condenser water temperature reset (W05) is not included in Combination 3 compared to Combination 2. Another difference between Combination 2 and Combination 3 is the method of supplyair temperature set point control. Combination 3 uses constant supply-air temperature set point at $57^{\circ} \mathrm{F}$ instead of the dynamic reset schedule.

Combination 3 includes the following measures:

- A01a - HVAC schedules end 2 hours early on weekdays and are off Saturdays

- A02 - static pressure reset

- A04d - constant supply-air temperature (SAT) set point of $57^{\circ} \mathrm{F}$

- W01 - chilled-water differential pressure reset

- W03 - hot-water differential pressure reset

- W04 - hot-water temperature reset.

The savings from Combination 3, shown in Figure 26, has a flatter profile across the various climates compared to Combinations 1 and 2 . This is because of the switch from dynamic supply-air temperature reset to a higher, but constant supply-air temperature. Referring to the individual measure savings, Figure 14 shows the highly variable savings by climate from supply-air temperature reset, while Figure 16 shows the flatter savings from a higher constant supply-air temperature set point. Like the previous two re-tuning combination packages, heating energy savings are greater than other end-uses. 


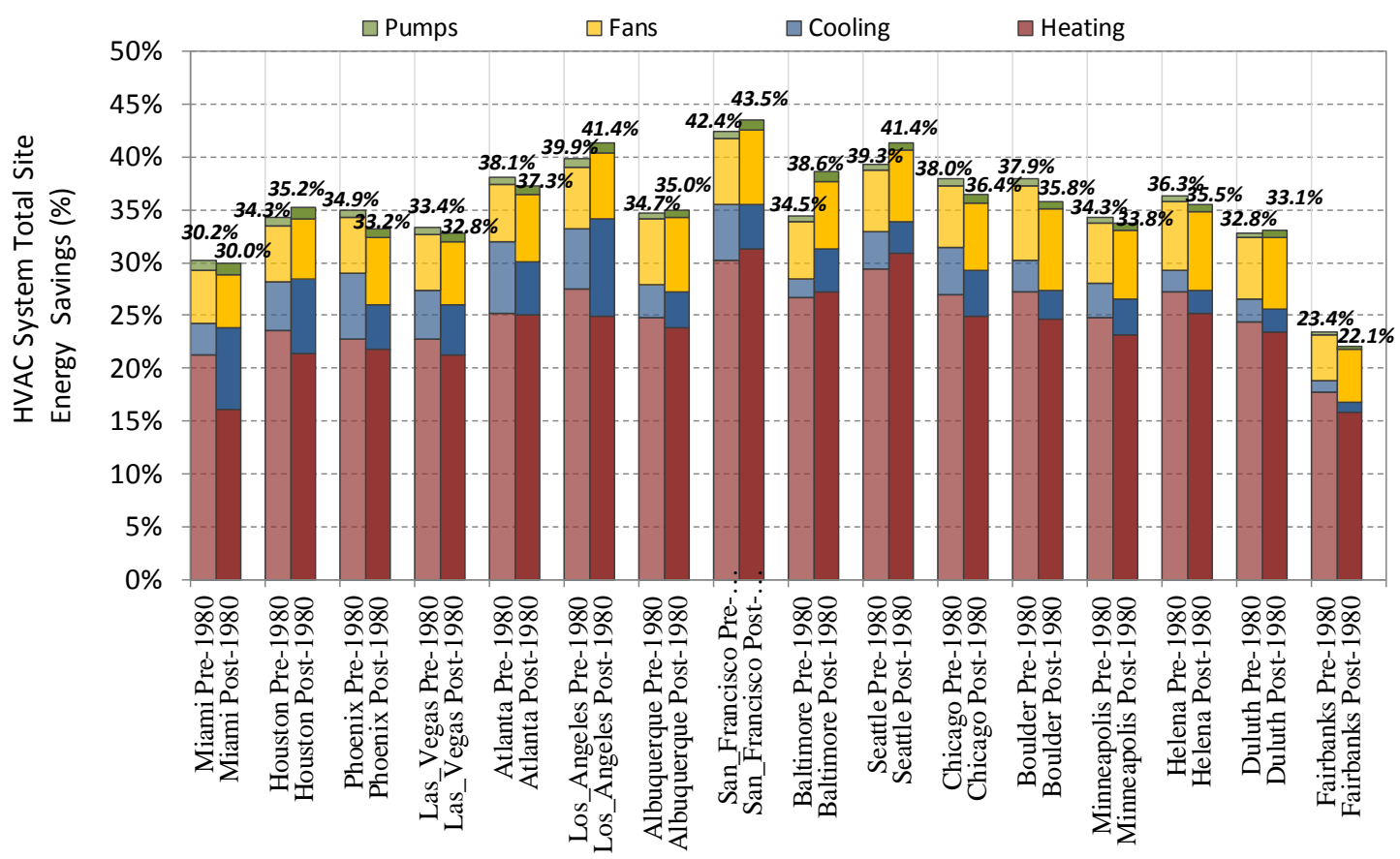

Figure 26: HVAC Energy Savings for Combination 3 Re-tuning Measures

\section{Combination 4}

Combination 4 can be applied to the systems without direct digital control. Because there is no terminal box information feedback, the supply-temperature reset, duct static pressure reset, and terminal box minimum air flow reset are not included in Combination 4. Upgrading the terminal box from pneumatic control to direct digital controls can yield significant savings and is, therefore, recommended.

Combination 4 includes the following measures:

- A01a - HVAC schedules end 2 hours early on weekdays and are off Saturdays

- A04d-constant supply-air temperature set point of $57^{\circ} \mathrm{F}$

- W01 - chilled-water differential pressure reset

- W03 - hot-water differential reset

- W04-hot-water temperature reset.

Combination 4 has the most limited set of measures. However, even with the restrictions imposed by the lack of direct digital controls, the use of "smarter" scheduling, combined with higher supply-air temperature set point, has the potential to save a significant fraction ( $30 \%$, see Figure 27 ) of HVAC energy consumption. Like the previous re-tuning combination packages, savings from heating energy are significantly greater than the other end uses. 


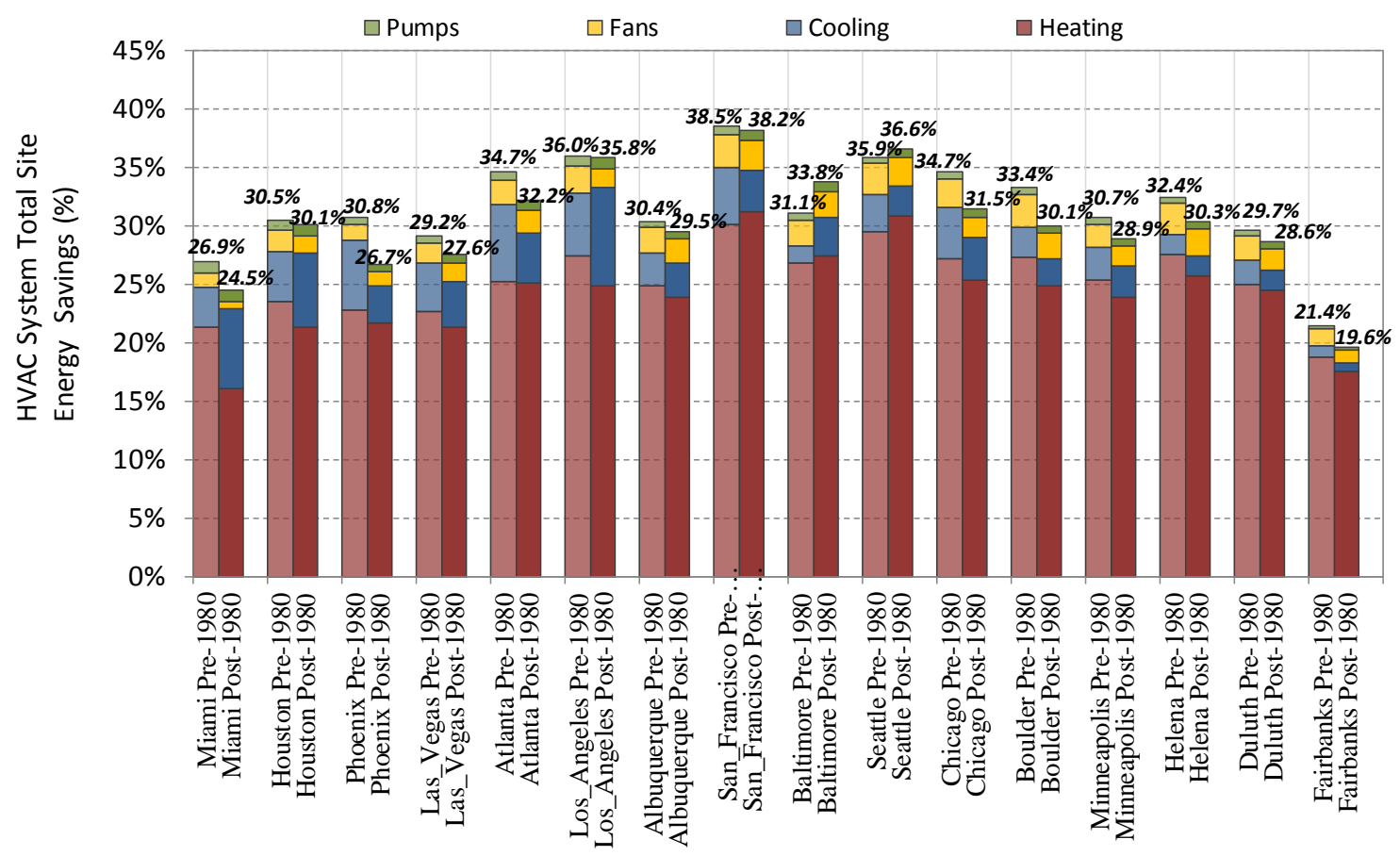

Figure 27: HVAC Energy Savings for Combination 4 Re-tuning Measures

\section{Combination 5}

Combination 5 can be applied to the chilled-water systems without condenser water temperature reset, and it includes the following measures:

- A01a - HVAC schedules end 2 hours early on weekdays and are off Saturdays

- A02 - static pressure reset

- $\mathrm{A03b}$ - supply-air temperature reset (alternate method)

- A05 - VAV minimum air flow set point of $30 \%$

- W01 - chilled-water differential pressure reset

- W02 - chilled-water temperature reset

- W03 - hot-water differential pressure reset

- W04 - hot-water temperature reset

Savings for Combination 5 can be seen in Figure 28. Combination 5 includes most of the re-tuning measures except condenser water temperature reset. For the pre-1980 baseline, the HVAC energy savings range from $55 \%$ in hot climates to about $67 \%$ in marine climates and $40 \%$ in sub-arctic climates. For the post- 1980 baseline, the savings ranges from $45 \%$ in hot climates to $55 \%$ in marine climates to $35 \%$ in sub-arctic climates. Like the previous re-tuning combination packages, heating energy savings are a significant portion of the total HVAC savings. 


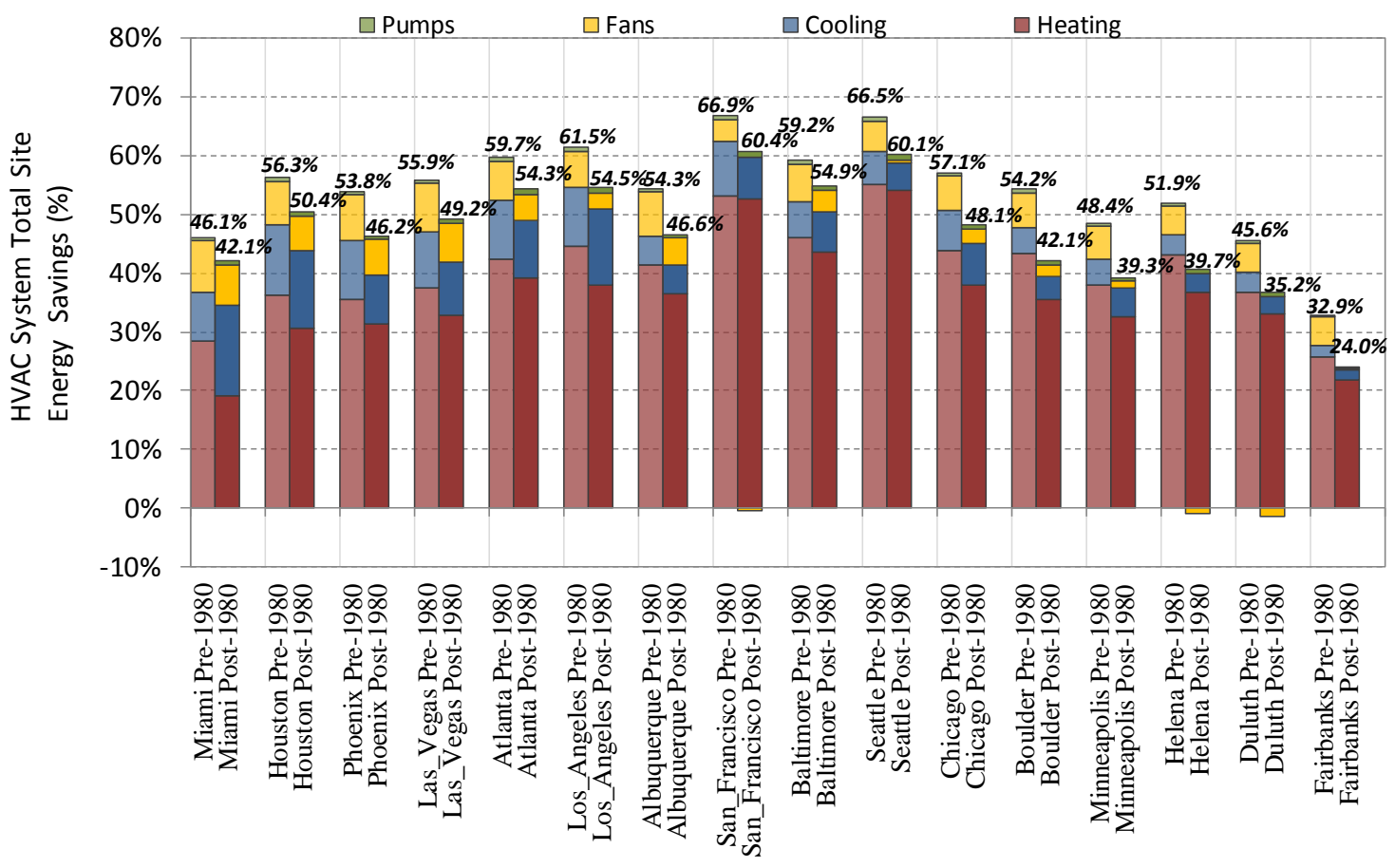

Figure 28: HVAC Energy Savings - Combination 5

\section{Combination 6}

Combination 6 includes all measures except A04 (which conflicts with A03). It is essentially the complete set of re-tuning measures. For the pre-1980 baseline, the HVAC energy savings range from $50 \%$ in hot climates to about $74 \%$ in marine climates and $42 \%$ in sub-arctic climates. For the post-1980 baseline, the savings ranges from $46 \%$ in hot climates to $70 \%$ in marine climates to $35 \%$ in sub-arctic climates (Figure 29). Like the previous five re-tuning combination packages, the heating energy savings constitute a significant portion of the total HVAC savings. 


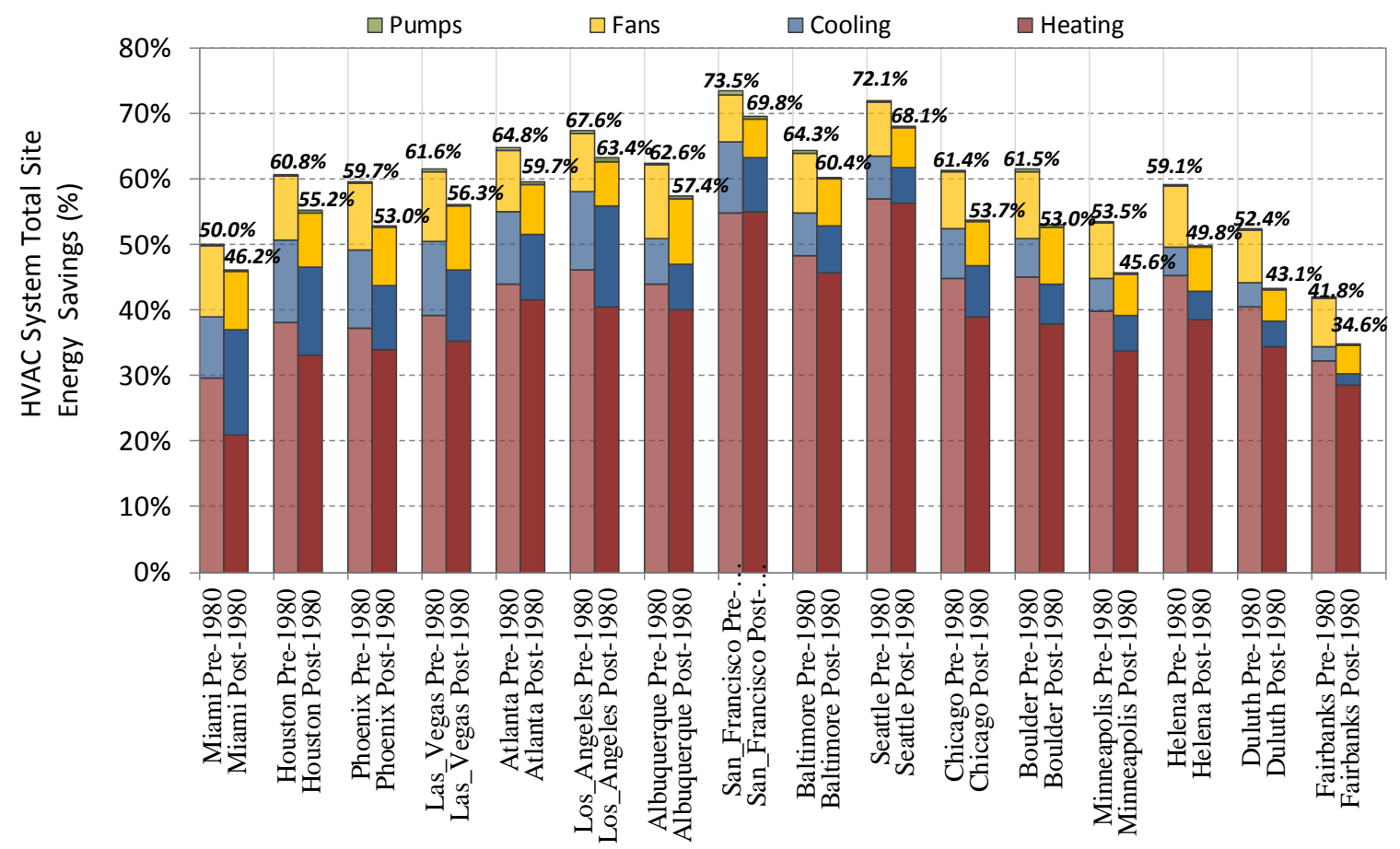

Figure 29: HVAC Energy Savings for Combination 6 Re-tuning Measures

\section{Generalization of Savings}

Table B-1 provides regression equation coefficients for the pre-1980 building HVAC energy savings results and Table B-2 provides regression equations for the post-1980 results. Both of these tables are located in Appendix B. For some measures, such as $A 07, R^{2}$ (one of regression parameters that describe the "goodness of fit" values) is very high for the regression equations that use only HDD and HDD". In such cases, a simple equation is sufficient to generalize HVAC savings. For most measures, however, there is significant additional accuracy that is gained by using additional variables in the regression equations. As the results for individual measures demonstrated, for many measures, the savings was higher for the marine climates than would be expected based on cities with similar HDDs or CDDs. For these measures, the addition of summer dew point as a regression variable helped the accuracy of the regression equations a great deal. The regression analysis was done using results from 12 of the 16 climate locations. The four remaining climate locations were used to test the prediction capabilities of the regression model. 
Figure 30 through Figure 44 show predicted energy savings using the regression model as a function of calculated savings from the simulations for each of the measures and combinations of measures. From these plots the difference between the predicted and simulated HVAC energy savings can be seen. The central "gray" line represents a "perfect" prediction, i.e., there is no difference between the predicted and simulated savings. A data point (on the graph) that deviates from the central gray line indicates difference in the regression equation to predict the result for a given city. As indicated earlier, the regression equations were all developed using 12 of the 16 cities. The remaining four cities (Albuquerque, Houston, San Francisco, and Helena) were used to test the regression equations predictive capability for new cities. In the graphs below, the four cities appear as darker shaded circles, compared to the lighter red for the 12 cities used to develop the pre-1980 baseline regression equations and the lighter blue for the 12 cities used to develop the post-1980 baseline. Each data series uses the most detailed of the three regression equations developed for each measure. The plots convey two pieces of information: first, the deviation of points from the center line conveys how well the equation fits the data in general, and second, the deviation of the darker points from the center line compared the deviation of the lighter points conveys the apparent ability of the regression equations to predict HVAC savings for new cities. The red-dashed error lines are also included in each plot to indicate approximate bounds to the observed deviation. This error bound is presented in terms of absolute error (for example, if the modeled savings for a certain city is $18 \%$ and the regression equation predicts $15 \%$ savings based on the climate, then the absolute error is $3 \%$ ). For any given measure, the magnitude of the dashed error lines in each plot corresponds to the $R^{2}$ value of the regression equation for that measure. Tight error lines correspond to $R^{2}$ values approaching 1 , while wider error bars correspond to lower $\mathrm{R}^{2}$ values.

In general, the plots tend to show that the regression equations do a good job of generalizing savings, and that new cities do not appear to have any more or less deviation than the points used to generate the regression equations, meaning that the regression equations can be reasonably used to predict savings for similar buildings in other climate locations.

For HVAC schedules ending fours hours early, predicted energy savings from the regression analysis deviate from modeled energy savings by less than $2.5 \%$. Average savings for this measure are $33.4 \%$, so the $2.5 \%$ maximum nominal deviation represents about $7.5 \%$ of the average savings. Cities not included in the regression have prediction accuracy at least as good as the cities that were included in the regression for post-1980 cities and slightly worse than cities that were included in the regression for pre1980 cities. 


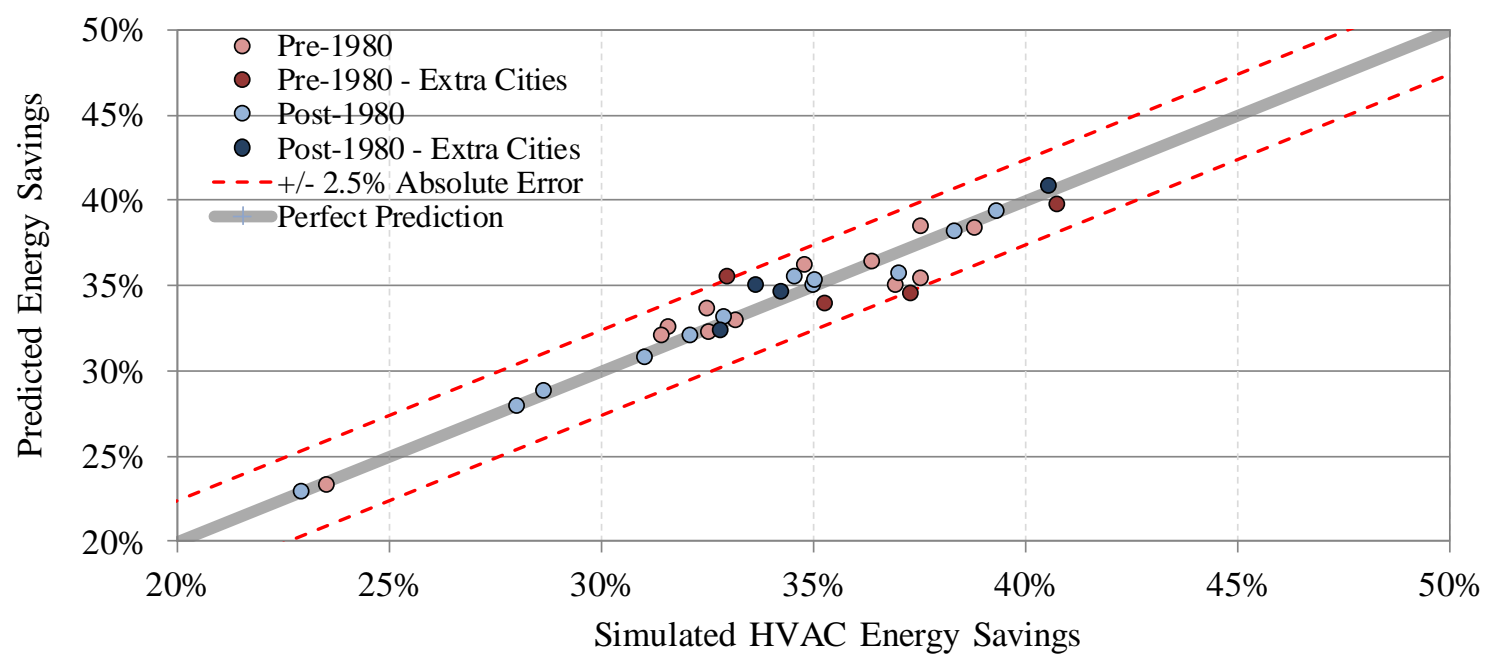

Figure 30: Comparison of Predicted and Simulated Energy Savings for A01b Re-tuning Measure (end HVAC schedules 4 hours early)

For static pressure reset, predicted energy savings from the regression analysis deviate from modeled energy savings by less than $1 \%$. Average savings for this measure are $5.4 \%$, so the $1 \%$ maximum nominal deviation represents about $18.6 \%$ of the average savings. Cities not included in the regression have prediction accuracy at least as good as the cities that were included in the regression.

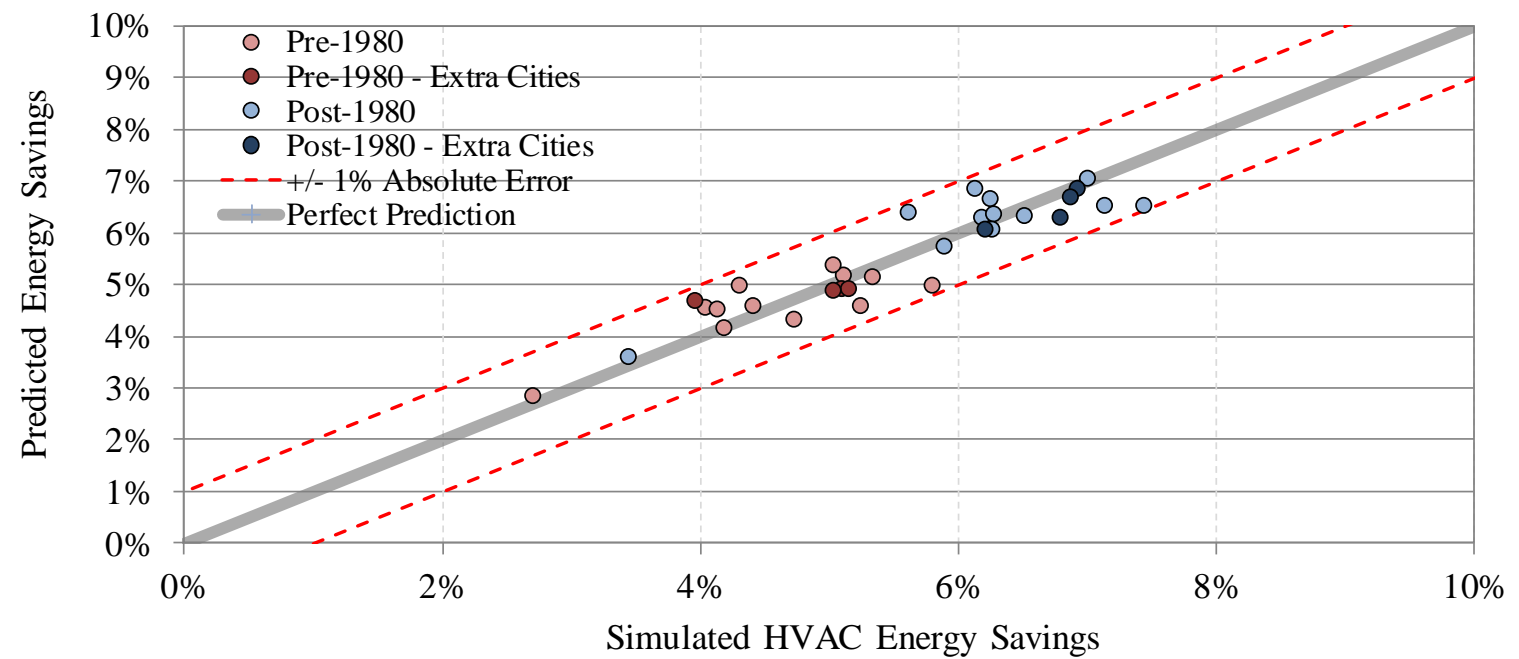

Figure 31: Comparison of Predicted and Simulated Energy Savings for A02 Re-tuning Measure (static pressure reset)

For supply-air temperature reset based on outdoor-air temperature, predicted energy savings from the regression analysis deviate from modeled energy savings by less than $1.5 \%$. Average savings for this measure are $13.5 \%$, so the $1.5 \%$ maximum nominal deviation represents about $11 \%$ of the average savings. Cities not included in the regression generally have prediction accuracy at least as good as the 
cities that were included in the regression with the exception of one pre-1980 city that has the highest deviation in the entire set.

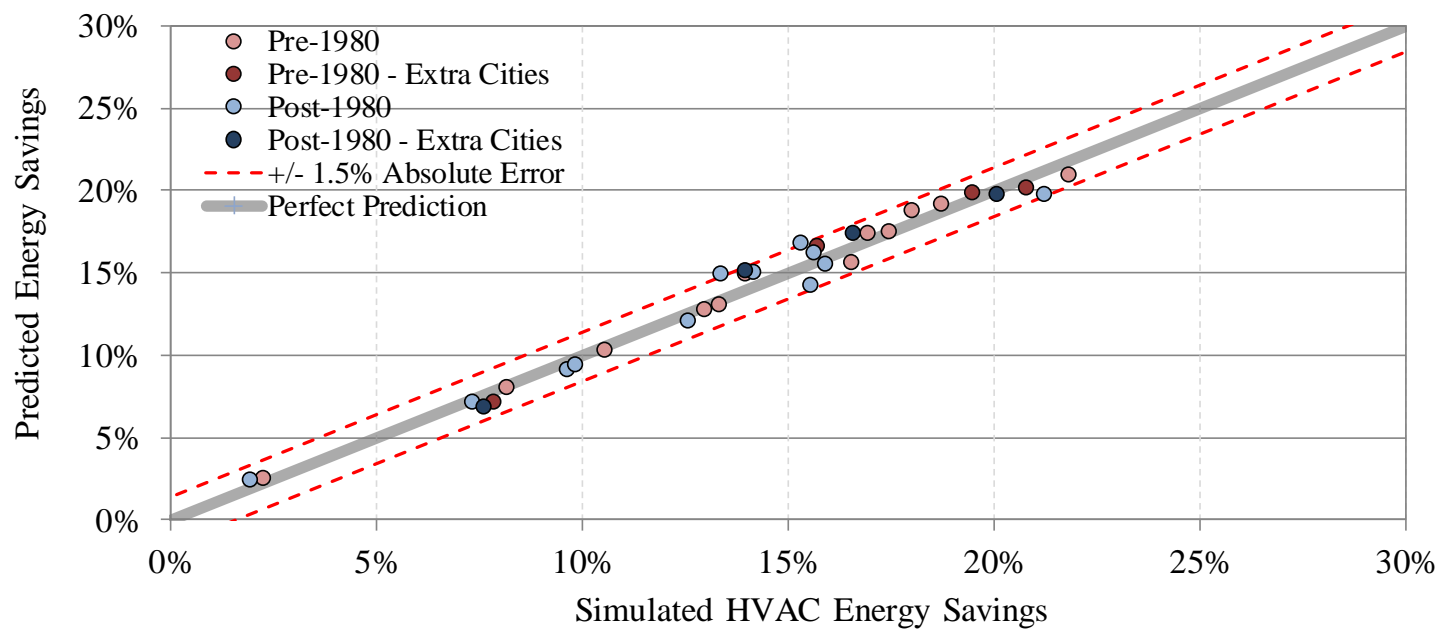

Figure 32: Comparison of Predicted and Simulated Energy Savings for A03a Re-tuning Measure (supply-air temperature reset based on outdoor-air temperature)

For supply-air temperature set point changed to $58^{\circ} \mathrm{F}$, predicted energy savings from the regression analysis deviate from modeled energy savings by up to around $2 \%$. Average savings for this measure are $15.2 \%$, so the $2 \%$ maximum nominal deviation represents $13.2 \%$ of the average savings. Cities not included in the regression have prediction accuracy at least as good as the cities that were included in the regression.

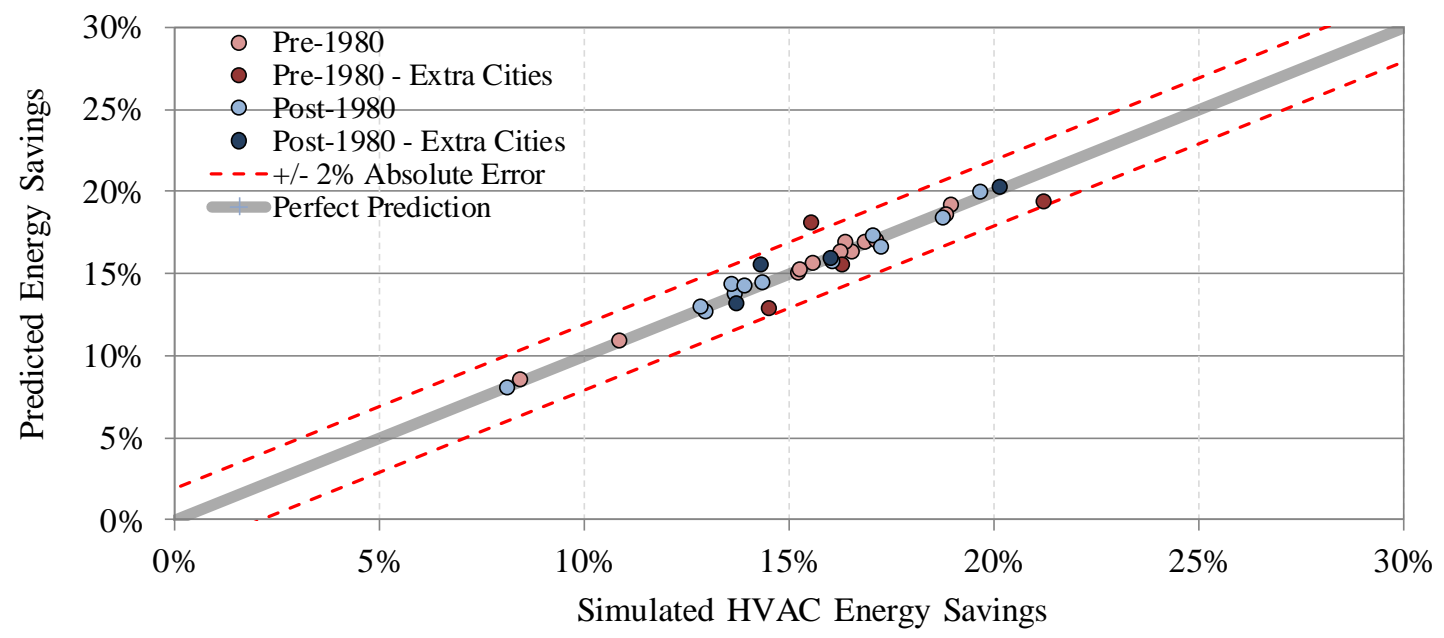

Figure 33: Comparison of Predicted and Simulated Energy Savings for A04 Re-tuning Measure (supply-air temperature set point of $58^{\circ} \mathrm{F}$ ) 
For VAV minimum air flow damper set points reduced to $30 \%$, predicted energy savings from the regression analysis deviate from modeled energy savings by up to $1.5 \%$. Average savings for this measure are $27 \%$, so the $1.5 \%$ maximum nominal deviation represents about $5.5 \%$ of the average savings. Cities not included in the regression have prediction accuracy at least as good as the cities that were included in the regression.

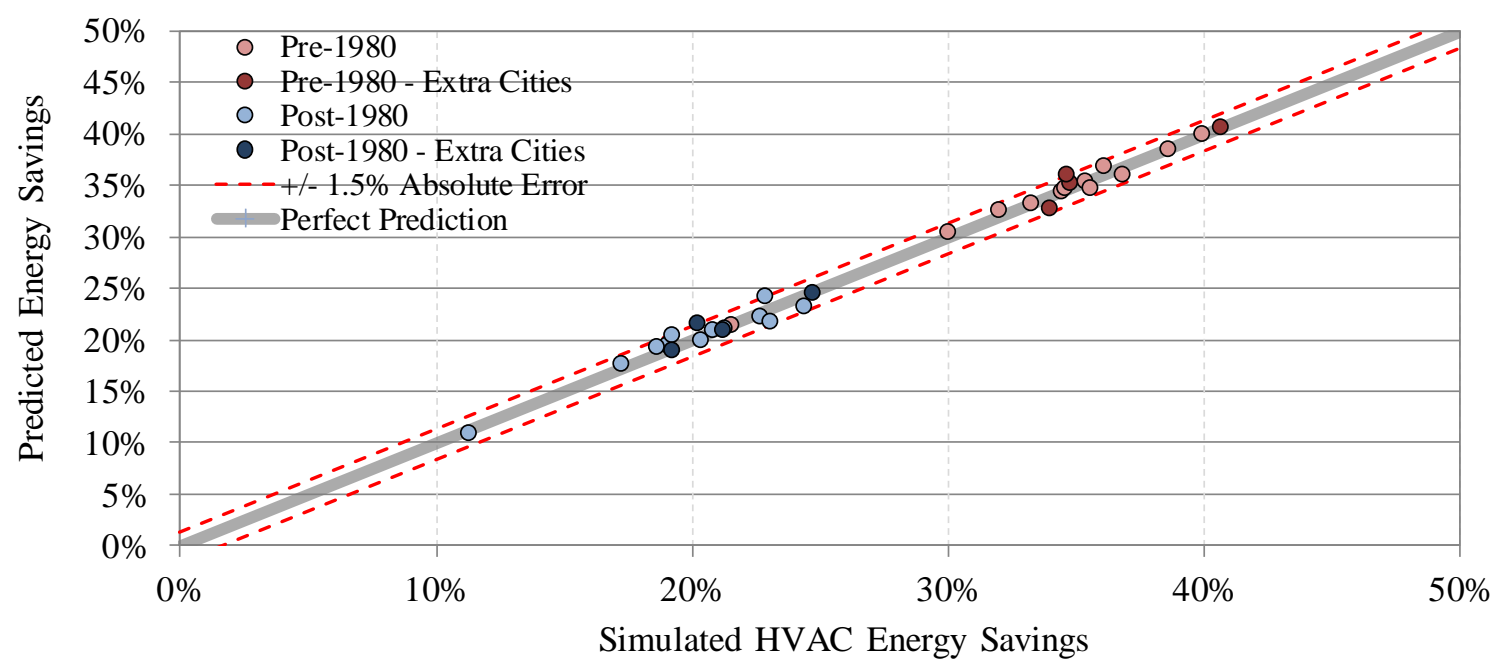

Figure 34: Comparison of Predicted and Simulated Energy Savings for A05 Re-tuning Measure (VAV damper minimum position of $30 \%$ )

For wider thermostat ranges, predicted energy savings from the regression analysis deviate from modeled energy savings by up to $1 \%$. Average savings for this measure are $15.1 \%$, so the $1 \%$ maximum nominal deviation represents $6.6 \%$ of the average savings. Cities not included in the regression have prediction accuracy at least as good as those cities included in the regression.

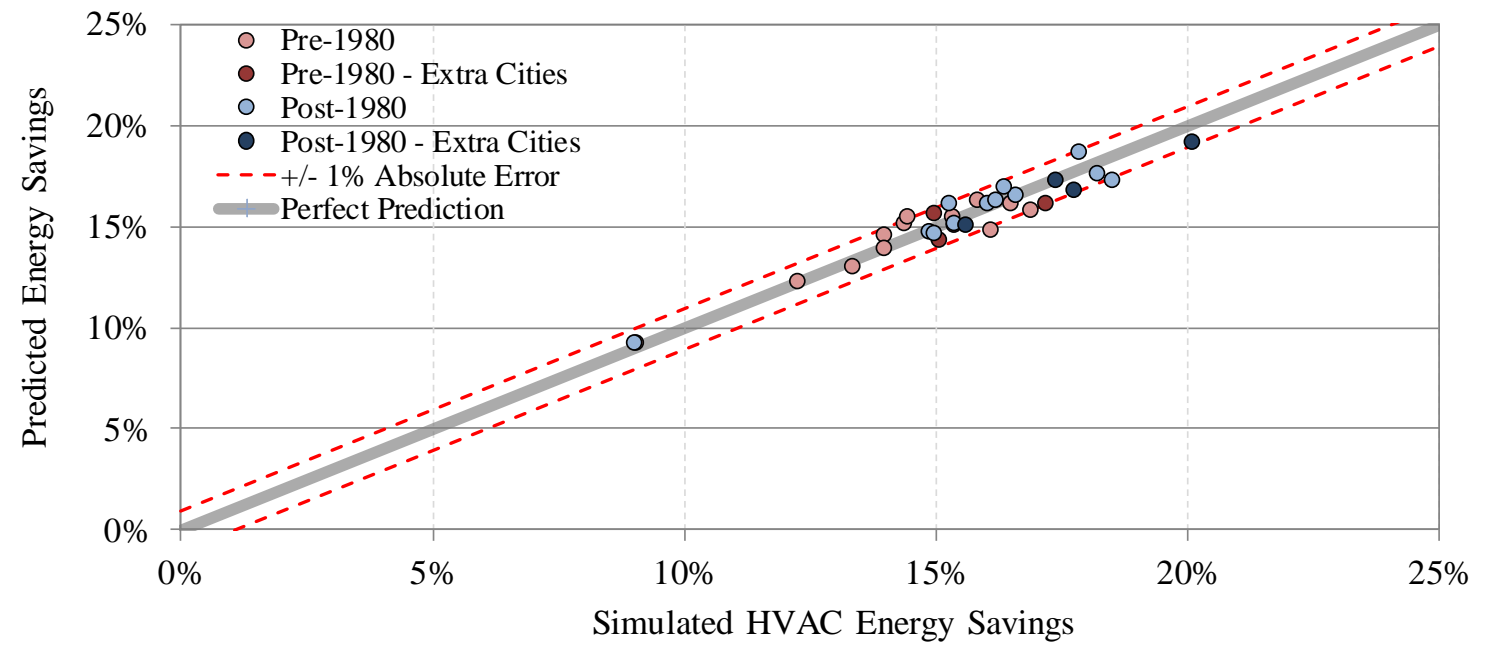

Figure 35: Comparison of Predicted and Simulated Energy Savings for A06 Re-tuning Measure (wider thermostat range) 
For zero outside air during unoccupied hours and during start-up hours, predicted energy savings from the regression analysis align very well with modeled energy savings for cites included in the regression however, savings from one post-1980 city that was not included in the regression was not predicted accurately.

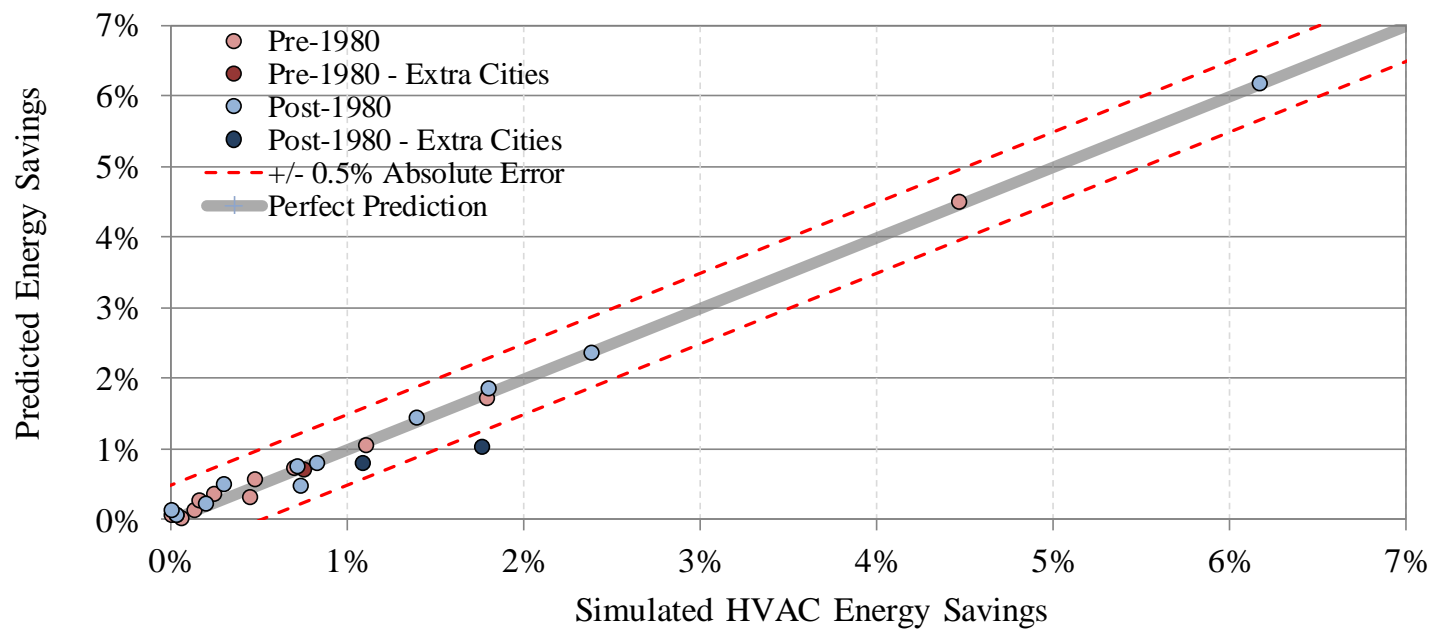

Figure 36: Comparison of Predicted and Simulated Energy Savings for A07 Re-tuning Measure (zero outside-air during unoccupied and start-up hours)

For chilled-water temperature reset, predicted energy savings from the regression analysis deviates from modeled energy savings by up to around $2 \%$. Average savings for this measure are about $4 \%$, so the $2 \%$ maximum nominal deviation represents about $50 \%$ of the average savings. This is a poor prediction accuracy. Cities not included in the regression have prediction accuracy slightly worse than cities that were included in the regression.

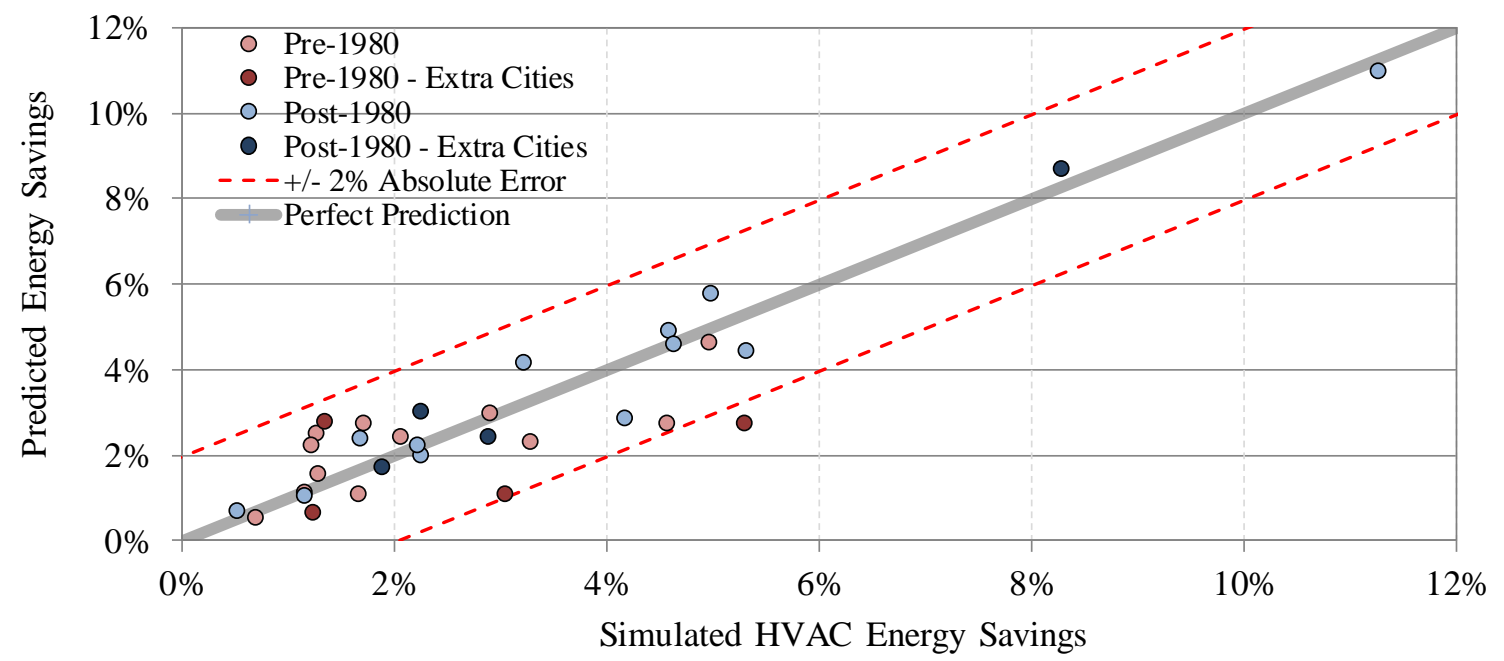

Figure 37: Comparison of Predicted and Simulated Energy Savings for W02 Re-tuning Measure (chilled-water temperature set point reset) 
For the measure that shuts down the pumps during times of no load, predicted energy savings from the regression analysis deviates from modeled energy savings by up to $0.3 \%$. Average savings for this measure are about $1 \%$, so the $0.3 \%$ maximum nominal deviation represents about $29 \%$ of the average savings. Cities not included in the regression have prediction accuracy slightly worse than cities that were included in the regression.

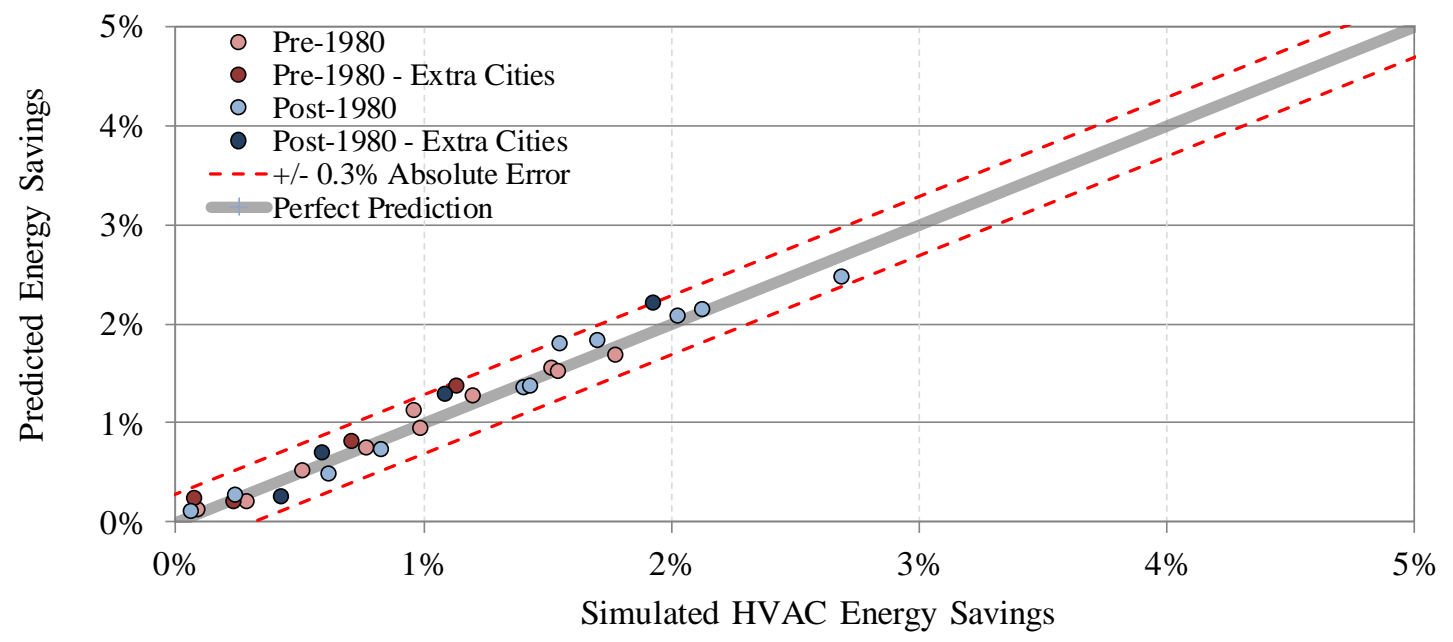

Figure 38: Comparison of Predicted and Simulated Energy Savings for W06 Re-tuning Measure (plant shut down when there is no load)

For Combination 1, predicted energy savings from the regression analysis deviates from modeled energy savings by up to $5 \%$. Average savings for this combination are about $53.8 \%$, so the $5 \%$ maximum nominal deviation represents about $9.3 \%$ of the average savings. Cities not included in the regression have prediction accuracy at least as good as cities that were included in the regression.

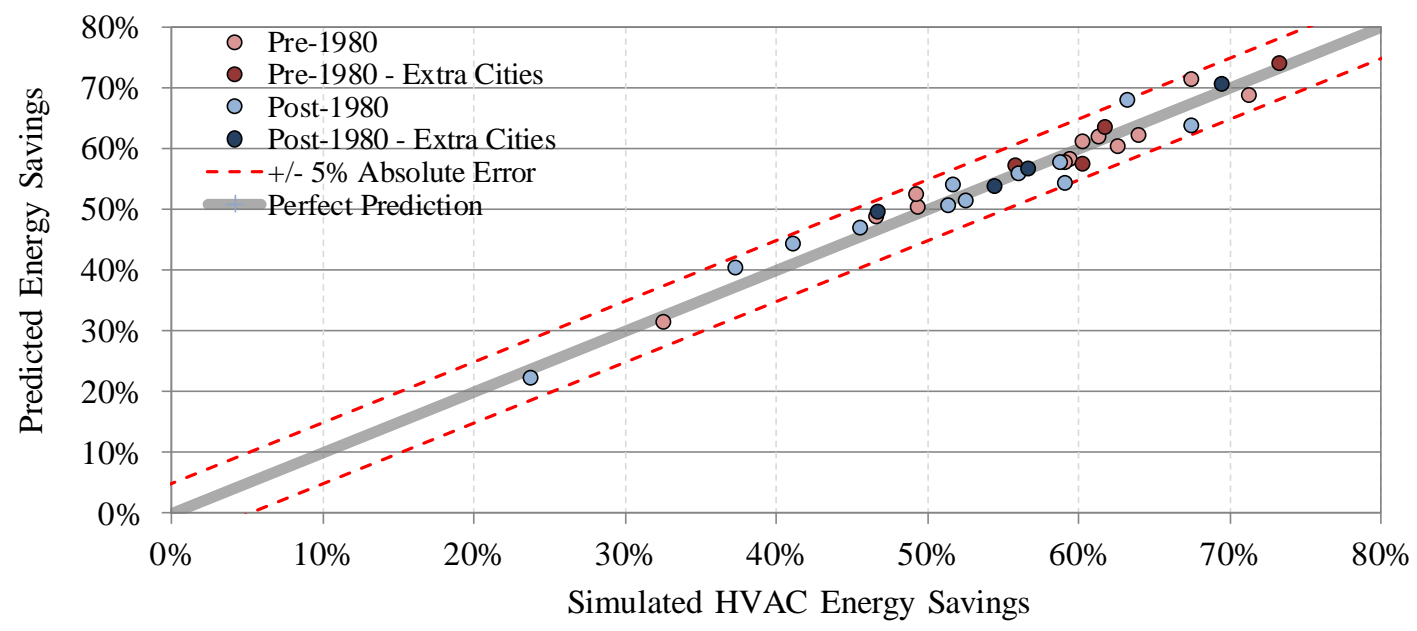

Figure 39: Comparison of Predicted and Simulated Energy Savings for Combination 1 
For Combination 2, predicted energy savings from the regression analysis deviates from modeled energy savings by up to $5 \%$. Average savings for this combination are $41.5 \%$, so the $5 \%$ maximum nominal deviation represents about $12 \%$ of the average savings. Cities not included in the regression have prediction accuracy at least as good as cities that were included in the regression.

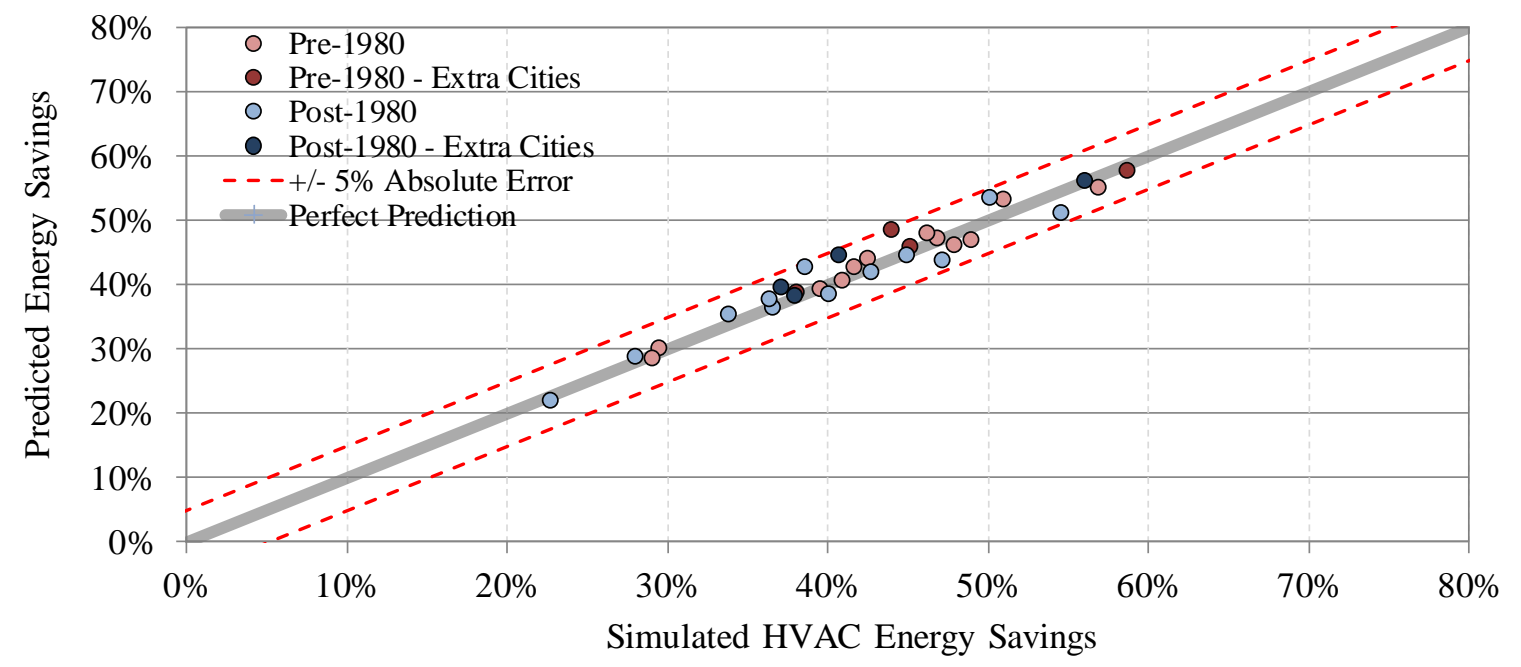

Figure 40: Comparison of Predicted and Simulated Energy Savings for Combination 2

For Combination 3, predicted energy savings from the regression analysis deviates from modeled energy savings by up to $3 \%$. Average savings for this combination are $34.7 \%$, so the $3 \%$ maximum nominal deviation represents about $8.6 \%$ of the average savings. Cities not included in the regression have prediction accuracy somewhat worse than cities that were included in the regression.

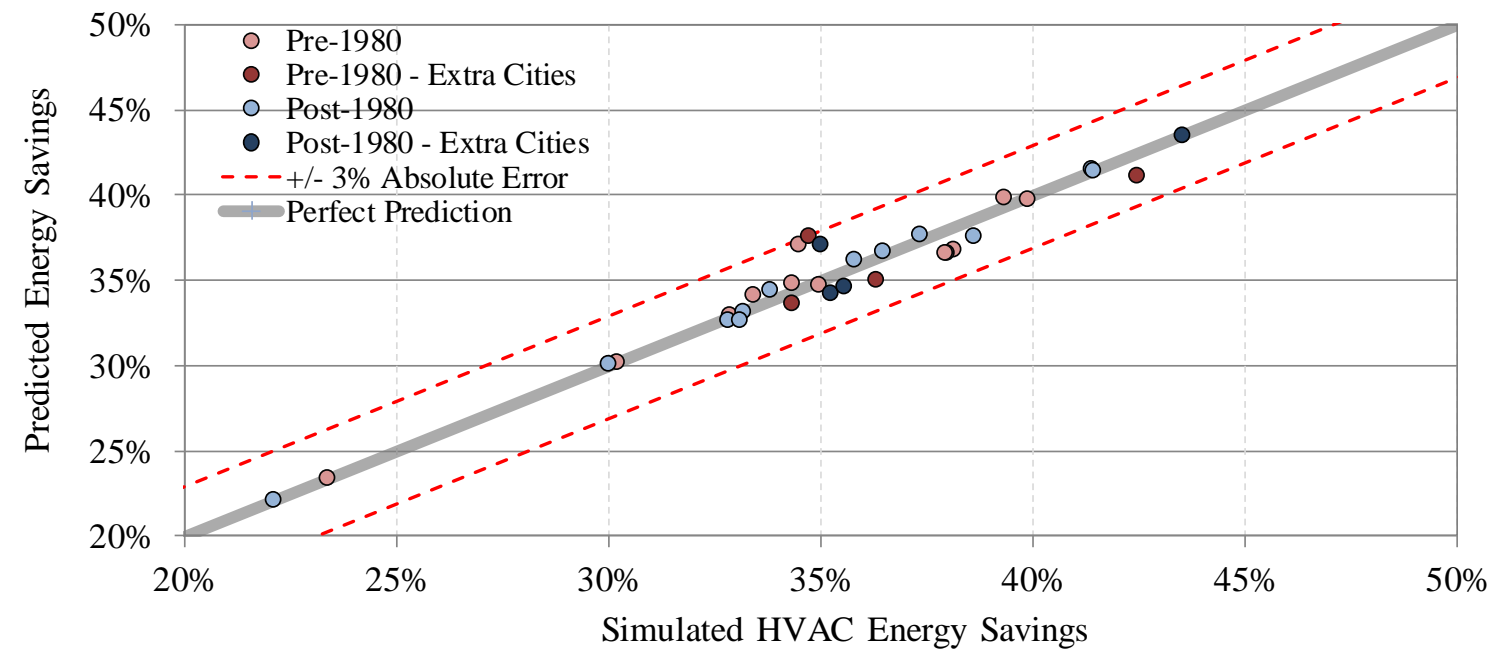

Figure 41: Comparison of Predicted and Simulated Energy Savings for Combination 3 
For Combination 4, predicted energy savings from the regression analysis deviates from modeled energy savings by up to $3 \%$. Average savings for this combination are about $30 \%$, so the $3 \%$ maximum nominal deviation represents $9.9 \%$ of the average savings. Cities not included in the regression have prediction accuracy somewhat worse cities that were included in the regression.

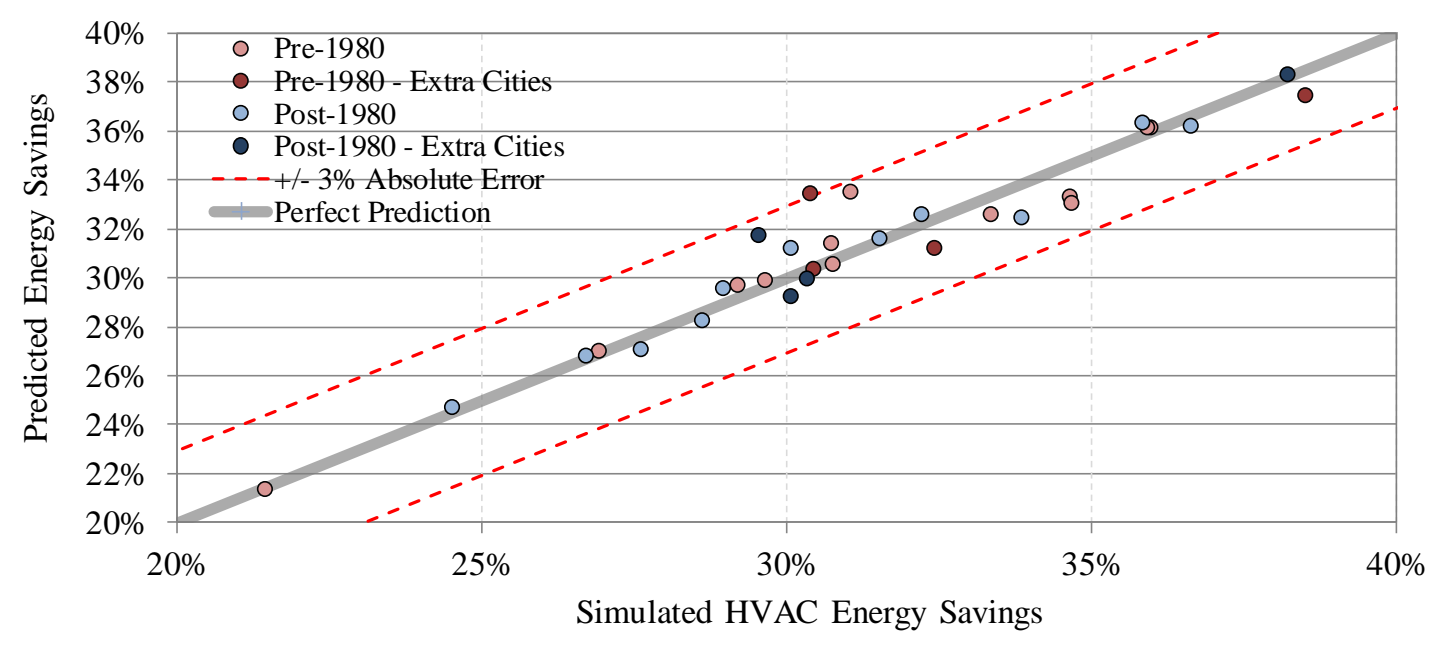

Figure 42: Comparison of Predicted and Simulated Energy Savings for Combination 4

For Combination 5, predicted energy savings from the regression analysis deviates from modeled energy savings by up to $4.5 \%$. Average savings for this measure are $49.6 \%$, so the $4.5 \%$ maximum nominal deviation represents $9.1 \%$ of the average savings. Cities not included in the regression have prediction accuracy at least as good as cities that were included in the regression.

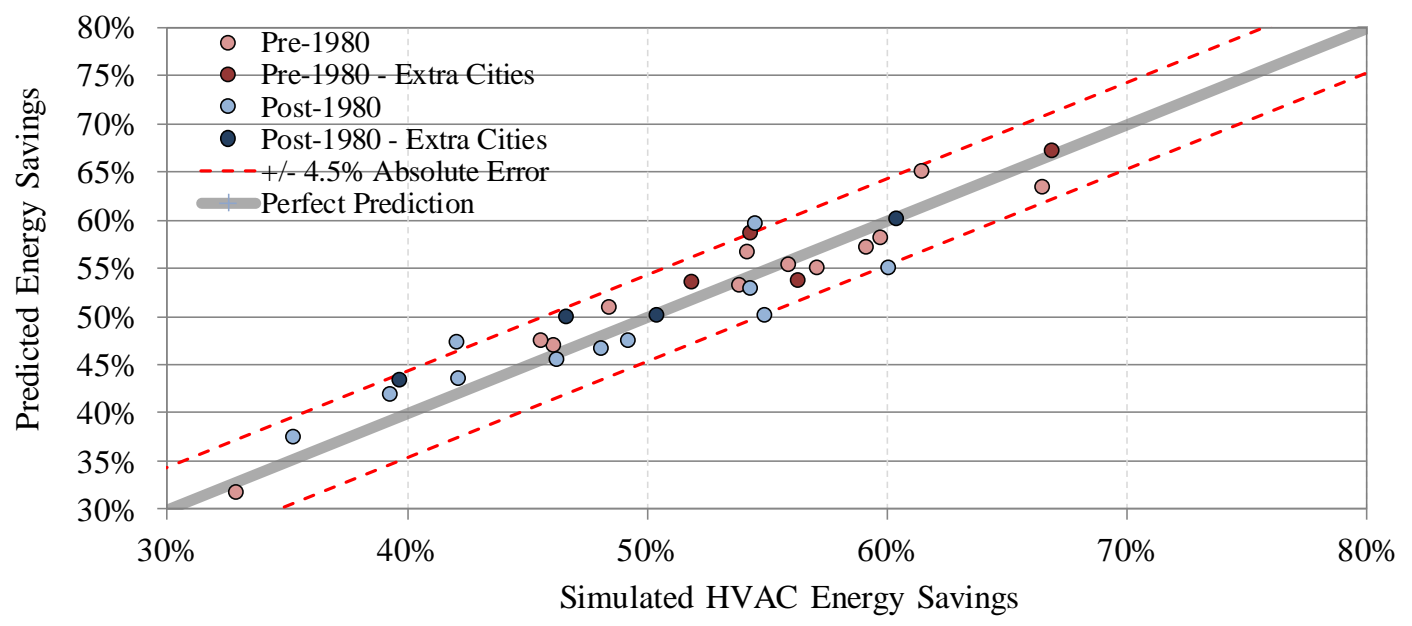

Figure 43: Comparison of Predicted and Simulated Energy Savings for Combination 5

Finally, for Combination 6, predicted energy savings from the regression analysis deviate from modeled energy savings by up to $4.5 \%$. Average savings for this measure are about $56.2 \%$, so the $4.5 \%$ maximum 
nominal deviation represents about $8 \%$ of the average savings. Cities not included in the regression have prediction accuracy at least as good as cities that were included in the regression.

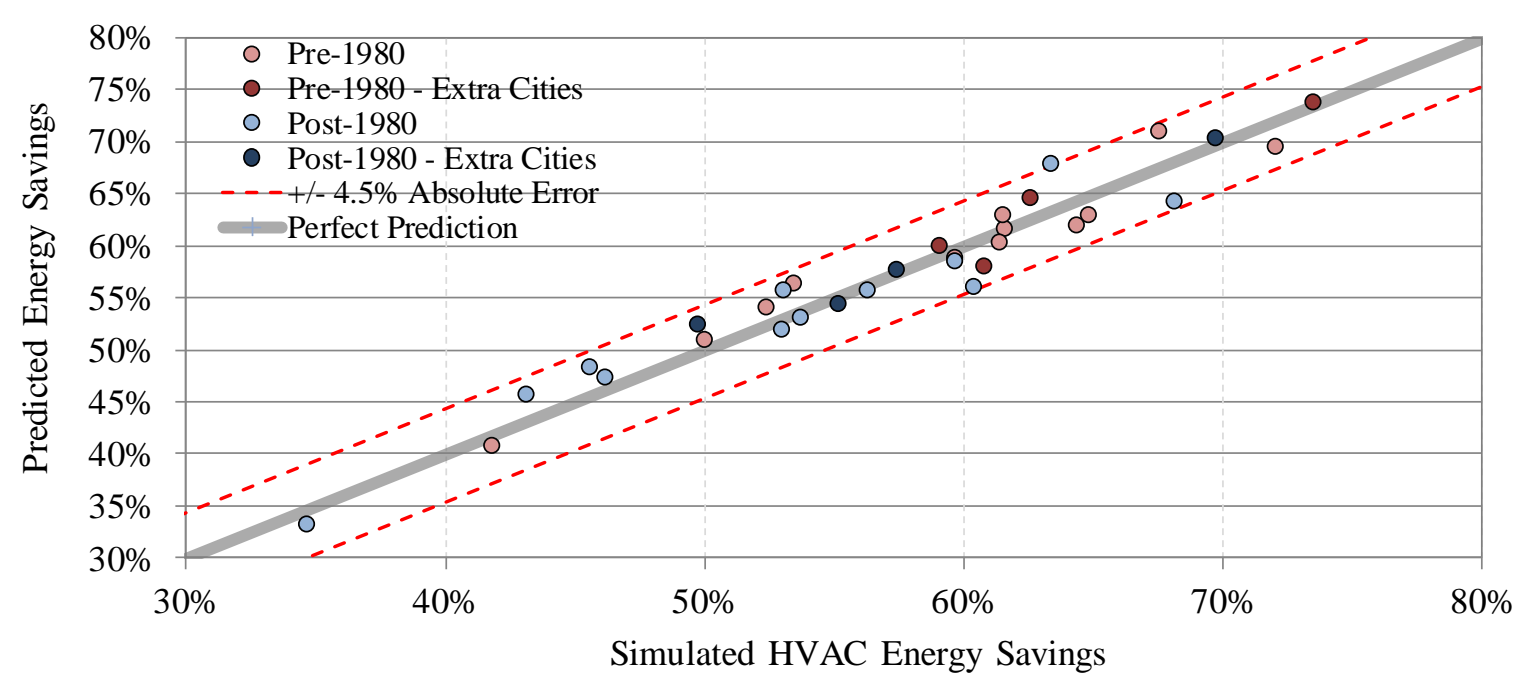

Figure 44: Comparison of Predicted and Simulated Energy Savings for Combination 6 


\section{Conclusion}

The simulation of a wide variety of common re-tuning measures for large office buildings shows that there is the potential to save a substantial fraction of HVAC energy consumption through measures that require little to no capital investment. All of the re-tuning measures that were simulated can be implemented through simple controls programming changes in the building automation systems. The baseline buildings that were simulated assumed simple commonly used controls were in place. Common-practice inefficiencies in scheduling and other HVAC operations were modeled in this baseline building, and the individual measures show the effect of each improvement compared to that inefficient baseline.

The largest savings were by far from air-side measures, suggesting that demand-side inefficiencies can cause much higher energy consumption than supply-side HVAC inefficiencies. By ensuring that the HVAC system is supplying the "optimal" supply-air temperature at the minimum required flow, only when strictly needed, and in a coordinated fashion among the zones, there can be much lower energy demand on the fans, chillers, and boilers. The simulation results show typically, $10 \%$ to $40 \% \mathrm{HVAC}$ savings is possible from using supply-air temperature reset; 5 to $7 \%$ savings is possible from static pressure reset; 20 to $40 \%$ savings are possible from lowering the minimum VAV damper flow set point; $15 \%$ savings from adopting a wider thermostat temperature range, and 20 to $30 \%$ possible from aggressively shortening HVAC schedules. By contrast, only about $5 \%$ savings is available from the suite of water-side measures that were modeled.

When combined, the possible savings, compared to baseline that was modeled, are rather staggering. Combination 6 re-tuning measure includes all of the re-tuning measures implemented together. The model shows that through these simple re-tuning measures alone, between 40 and $75 \%$ of the HVAC energy of large office buildings (often accounting for about $60 \%$ of total site energy consumption) may be saved. This is a best-case scenario for savings. More efficient HVAC configurations and more energy conscious schedules and lockouts that exist in many large office buildings may preclude some of these savings. Also, limitations imposed by constant speed pumps and fans and old/analog control systems may limit the suite of re-tuning measures that can be implemented. Some of the combinations of measures that were modeled attempted to address this latter concern.

Another significant finding is that the measures are somewhat competitive when implemented in combination. A set of measures can be synergistic, meaning that one measure compliments or facilitates another measure, so that in tandem they produce a higher savings than the sum of their individual savings. Likewise, a set of measures can be competitive in the sense that one measure produces energy savings that reduces the energy available for another measure to save. Figure 45 shows that when summed together; the savings from each of the individual measures is often over $100 \%$, meaning the measures must be competitive. Even by a looser measure of competition - the geometric sum of individual measure savings, the set of measures is still moderately competitive. The geometric sum applies the savings from measure $B$ to the fraction of energy consumption left over from measure $A$ and so on. So if measure A saves $10 \%$ and measure B saves $20 \%$, the geometric sum is $10 \%$ plus [ $20 \%$ times the remaining $90 \%$ ] or $28 \%$. The actual savings for Combination 6 in the pre-1980 
baseline are typically $5 \%$ to $10 \%$ below the geometric sum of individual savings. This may be because several of the measures produce savings partly by eliminating simultaneous heating and cooling. Thus, by partly acting on the same mechanism to provide savings, these measures are more competitive than the geometric sum might indicate. Still, because these measures should be very inexpensive and convenient to implement together as a package, the fact that they compete somewhat for savings should not be a big concern.

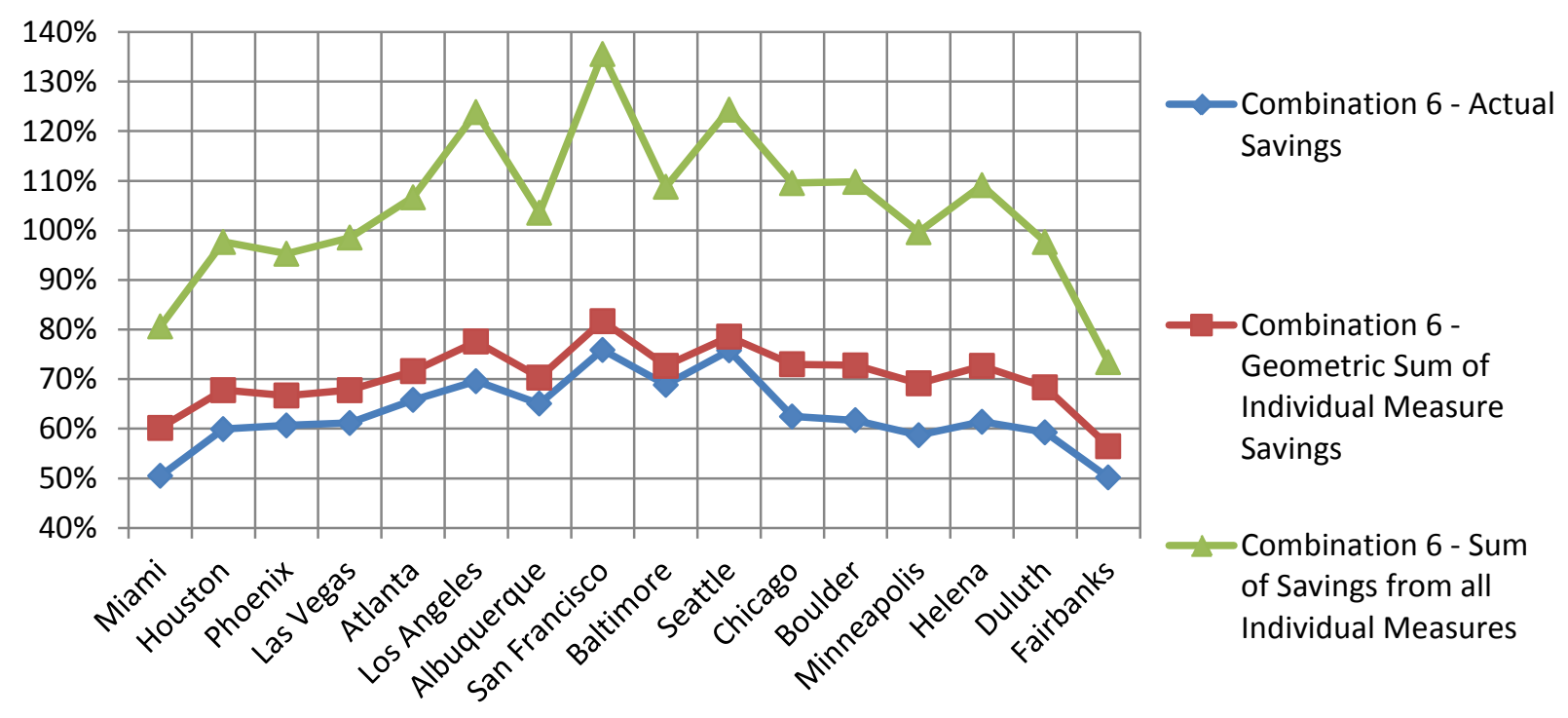

Figure 45: Combining Measures: Competition or Synergy?

The regression analysis shows that the results can reliably be generalized by climate for a given baseline building. Given climate data for a new location, the regression equations provided in Equations 4-6, combined with the coefficients in Table B-1 and B-2 should allow an accurate prediction of savings for any of the measures or combinations of measures as they are modeled here. Buildings with different HVAC configurations and unique or idiosyncratic building characteristics are a source of additional variation in potential savings that is difficult to quantify. 


\section{References}

ASHRAE. 2010. ANSI/ASHRAE/IESNA 90.1-2010, Energy Standard for Buildings Except Low-Rise Residential Buildings. American Society of Heating, Refrigerating and Air-Conditioning Engineers, Atlanta, Georgia.

ASHRAE. 2011. ASHRAE Handbook: Applications. American Society of Heating, Refrigeration and AirConditioning Engineers, Atlanta, GA.

Brambley, M.R., and S. Katipamula. 2009. "Commercial Building Re-Tuning: A Low-Cost Approach to Improved Performance and Energy Efficiency." ASHRAE Journal, 51(10):12-23.

Brambley, M.R., S. Katipamula, and P. O'Neill. 2009. "Diagnostics for Monitoring-Based Commissioning." In Proceedings of the 2009 National Conference on Building Commissioning, Seattle, WA.

Claridge, D.E., M. Liu, Y. Zhu, M. Abbas, A. Athar, and J.S. Haberl. 1996. "Implementation of Continuous Commissioning in the Texas LoanSTAR Program: Can You Achieve 150\% Estimated Retrofit Savings Revisited." In Proceedings of the 1996 ACEEE Summer Study. ACEEE: American Council for an Energy Efficient Economy, Washington, D.C.

Claridge, D.E, C.H. Culp, M. Liu, S. Deng, W.D. Turner, and J.S. Haberl. 2000. "Campus-Wide Continuous Commissioning ${ }^{\text {SM }}$ of University Buildings." In Proceedings of the 2000 ACEEE Summer Study. American Council for an Energy Efficient Economy, Washington, D.C.

Deru, M., K. Field, D. Studer, K. Benne, B. Griffith, P. Torcellini, B. Liu, M. Halverson, D. Winiarski, M. Yazdazian, J. Huang, D. Crawley. 2011. U.S. Department of Energy Commercial Reference Building Models of the National Building Stock. NREL/TP-5500-46861, National Renewable Energy Laboratory, Golden, Colorado.

Energy Design Resources. 2009. Advanced Variable Air Volume VAV System Design Guide. Accessed June 5, 2012, from http://www.energydesignresources.com/media/2651/EDR_DesignGuidelines_VAV.pdf

Energy Information Administration. 2003. File 17: Consumption of Major Fuels by End Use. Accessed June 4, 2012, from CBECS Public Use Microdata Files:

http://www.eia.gov/emeu/cbecs/cbecs2003/public_use_2003/cbecs_pudata2003.html

Katipamula, S. and M.R. Brambley. 2008. "Transforming the Practices of Building Operation and Maintenance Professionals: A Washington State Pilot Program." 2008 ACEEE Summer Study on Energy Efficiency in Buildings: American Council for an Energy-Efficient Economy, Washington, D.C.

Liu, M., D.E. Claridge, and W.D. Turner. 2002. "Continuous Commissioning ${ }^{\text {SM }}$ Guidebook." Washington, D.C.: Federal Energy Management Program, U.S. Department of Energy, Washington, D.C. Accessed June 22, 2012, from http://www.eere.energy.gov/femp/pdfs/ccg01_covers.pdf.

Liu, M, D.E. Claridge, and W.D. Turner. 2003. "Continuous CommissioningSM of Building Energy Systems." ASME Journal of Solar Energy Engineering, Transactions of the ASME, Special Issue on Emerging Trends in Building Design, Diagnosis and Operation 125(3):275-281. 
Mills, E. 2009. "A Golden Opportunity for Reducing Energy Costs and Greenhouse Gas

Emissions." http://cx.Ibl.gov/2009-assessment.htm. Accessed on November 15th, 2009.

Moore, E., E. Crowe, A. Robbins, and B. Walker. 2008. "Making the Leap: Data and Lessons Learned from Scaling Up Retrocommissioning Programs." 2008 ACEEE Summer Study on Energy Efficiency in Buildings: American Council for an Energy-Efficient Economy, Washington, D.C.

U.S. Department of Energy. 2012. Retrieved June 5, 2012, EnergyPlus Energy Simulation Software: http://apps1.eere.energy.gov/buildings/energyplus/ 


\section{Appendix A:}

Total Energy Savings from Each Re-tuning Measure 
Table 8: Annual Energy Savings (kBtu/sf) by HVAC component and representative city for the Pre-1980 building

\begin{tabular}{|c|c|c|c|c|c|c|c|c|c|c|c|c|c|c|c|c|c|}
\hline 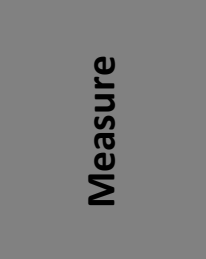 & 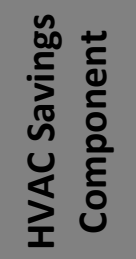 & $\frac{E}{2}$ & $\begin{array}{l}\text { 오 } \\
\text { th } \\
\text { o } \\
\text { 오 }\end{array}$ & $\begin{array}{l}\frac{x}{\mathrm{C}} \\
\frac{\mathrm{d}}{\alpha}\end{array}$ & 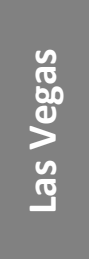 & 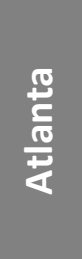 & $\begin{array}{l}\frac{y}{0} \\
\frac{0}{2} \\
\frac{a}{4} \\
0\end{array}$ & $\begin{array}{l}\frac{0}{2} \\
\frac{0}{0} \\
\frac{0}{2} \\
\frac{0}{0} \\
\frac{0}{4}\end{array}$ & 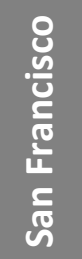 & 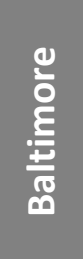 & 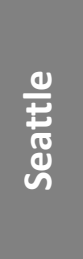 & 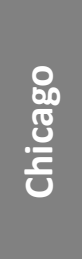 & $\frac{\text { ฮั }}{\frac{1}{3}}$ & $\begin{array}{l}\frac{u}{\circ} \\
\frac{\circ}{80} \\
\frac{d}{E} \\
\frac{E}{\Sigma}\end{array}$ & $\frac{\text { d }}{\frac{1}{0}}$ & $\frac{}{\frac{5}{2}}$ & 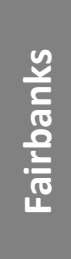 \\
\hline \multirow{5}{*}{$\begin{array}{l}\text { A01a: HVAC } \\
\text { Schedules } \\
\text { Start } 2 \text { Hours } \\
\text { Late }\end{array}$} & Heating & 8.09 & 9.86 & 9.56 & 10.35 & 10.65 & 10.12 & 10.00 & 10.82 & 11.46 & 12.08 & 10.17 & 9.26 & 9.27 & 9.51 & 9.44 & 9.15 \\
\hline & Cooling & 2.33 & 2.12 & 3.51 & 1.78 & 3.33 & 1.73 & 1.07 & 1.50 & 0.72 & 1.06 & 2.09 & 0.82 & 0.99 & 0.47 & 0.67 & 0.38 \\
\hline & Fans & 1.31 & 1.52 & 1.41 & 1.59 & 1.58 & 1.53 & 1.66 & 1.59 & 1.57 & 1.68 & 1.44 & 1.58 & 1.24 & 1.47 & 1.26 & 1.06 \\
\hline & Pumps & 0.31 & 0.30 & 0.24 & 0.29 & 0.31 & 0.27 & 0.19 & 0.26 & 0.26 & 0.24 & 0.25 & 0.22 & 0.22 & 0.21 & 0.21 & 0.14 \\
\hline & Total & 12.04 & 13.80 & 14.72 & 14.01 & 15.87 & 13.65 & 12.92 & 14.17 & 14.01 & 15.06 & 13.95 & 11.88 & 11.72 & 11.66 & 11.58 & 10.73 \\
\hline \multirow{5}{*}{$\begin{array}{l}\text { A01b: HVAC } \\
\text { Schedules } \\
\text { Start } 4 \text { Hours } \\
\text { Late }\end{array}$} & Heating & 11.28 & 13.87 & 13.20 & 14.72 & 14.86 & 14.50 & 14.12 & 15.40 & 16.35 & 17.27 & 14.44 & 13.04 & 13.09 & 13.22 & 13.43 & 13.11 \\
\hline & Cooling & 3.38 & 5.17 & 4.15 & 2.64 & 3.97 & 2.53 & 1.57 & 2.14 & 2.03 & 1.48 & 2.56 & 1.20 & 1.37 & 0.92 & 0.91 & 0.65 \\
\hline & Fans & 1.88 & 2.17 & 1.99 & 2.37 & 2.24 & 2.26 & 2.64 & 2.31 & 2.29 & 2.45 & 2.10 & 2.39 & 1.80 & 2.17 & 1.84 & 1.58 \\
\hline & Pumps & 0.43 & 0.43 & 0.32 & 0.42 & 0.38 & 0.37 & 0.28 & 0.33 & 0.35 & 0.29 & 0.31 & 0.28 & 0.26 & 0.24 & 0.24 & 0.18 \\
\hline & Total & 16.97 & 21.64 & 19.66 & 20.15 & 21.45 & 19.66 & 18.61 & 20.18 & 21.02 & 21.49 & 19.41 & 16.91 & 16.52 & 16.55 & 16.42 & 15.52 \\
\hline \multirow{5}{*}{$\begin{array}{l}\text { A02: Static } \\
\text { Pressure } \\
\text { Reset }\end{array}$} & Heating & -0.02 & -0.02 & -0.02 & -0.04 & -0.02 & -0.03 & -0.07 & -0.01 & -0.04 & -0.01 & -0.07 & -0.06 & -0.10 & -0.11 & -0.23 & -0.53 \\
\hline & Cooling & 0.41 & -0.10 & 0.32 & 0.51 & 0.00 & 0.47 & 0.27 & 0.46 & 0.32 & 0.31 & 0.01 & 0.27 & 0.25 & 0.20 & 0.19 & 0.14 \\
\hline & Fans & 2.35 & 2.39 & 2.69 & 2.71 & 2.39 & 2.18 & 2.68 & 2.06 & 2.36 & 2.15 & 2.18 & 2.42 & 2.23 & 2.26 & 2.22 & 2.17 \\
\hline & Pumps & 0.04 & 0.03 & 0.04 & 0.03 & 0.02 & 0.04 & 0.03 & 0.02 & 0.03 & 0.02 & 0.01 & 0.02 & 0.02 & 0.01 & 0.01 & 0.01 \\
\hline & Total & 2.78 & 2.30 & 3.03 & 3.21 & 2.39 & 2.66 & 2.91 & 2.53 & 2.67 & 2.47 & 2.13 & 2.65 & 2.40 & 2.36 & 2.19 & 1.79 \\
\hline \multirow{5}{*}{$\begin{array}{l}\text { A03a: SAT } \\
\text { Reset Based } \\
\text { on OAT }\end{array}$} & Heating & 0.99 & 4.10 & 3.99 & 5.90 & 7.03 & 5.74 & 8.25 & 8.61 & 9.29 & 11.34 & 8.54 & 7.78 & 8.13 & 8.78 & 9.24 & 8.39 \\
\hline & Cooling & 0.21 & 0.47 & 0.89 & 0.88 & 0.66 & 1.36 & 0.80 & 1.80 & 0.74 & 1.19 & 0.51 & 0.64 & 0.56 & 0.55 & 0.64 & 0.50 \\
\hline & Fans & -0.04 & -0.06 & -0.07 & -0.10 & -0.09 & -0.11 & -0.25 & -0.21 & -0.09 & -0.12 & -0.07 & -0.21 & -0.10 & -0.23 & -0.12 & -0.14 \\
\hline & Pumps & 0.01 & 0.04 & 0.04 & 0.05 & 0.05 & 0.08 & 0.06 & 0.08 & 0.06 & 0.08 & 0.04 & 0.04 & 0.04 & 0.03 & 0.04 & 0.03 \\
\hline & Total & 1.17 & 4.55 & 4.85 & 6.73 & 7.65 & 7.07 & 8.86 & 10.28 & 10.00 & 12.49 & 9.02 & 8.25 & 8.63 & 9.13 & 9.80 & 8.78 \\
\hline
\end{tabular}




\begin{tabular}{|c|c|c|c|c|c|c|c|c|c|c|c|c|c|c|c|c|c|}
\hline 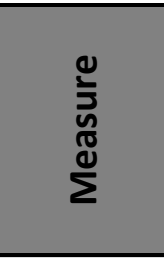 & 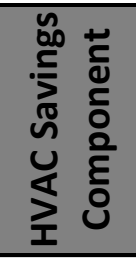 & 를 & 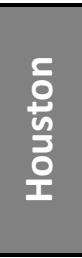 & $\begin{array}{l}\frac{x}{c} \\
\frac{d}{2} \\
\frac{o}{\alpha}\end{array}$ & 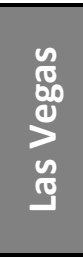 & 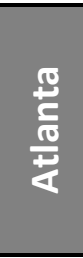 & $\begin{array}{l}\frac{y}{0} \\
\frac{0}{2} \\
\frac{c}{4} \\
0\end{array}$ & $\frac{0}{\frac{0}{3}}$ & 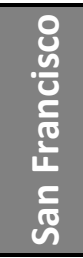 & $\frac{\text { d }}{\frac{2}{2}}$ & 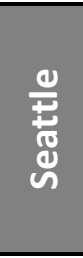 & 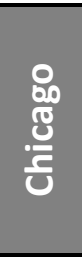 & $\frac{\text { ฮั }}{\frac{1}{3}}$ & 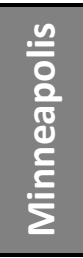 & 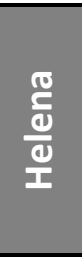 & $\frac{\frac{5}{2}}{\frac{2}{3}}$ & $\begin{array}{l}\frac{y}{5} \\
\frac{0}{0} \\
\frac{0}{\frac{2}{0}} \\
\frac{1}{4}\end{array}$ \\
\hline \multirow{5}{*}{$\begin{array}{l}\text { A03b: SAT } \\
\text { Reset - } \\
\text { Alternate } \\
\text { Method }\end{array}$} & Heating & 1.55 & 8.57 & 8.53 & 12.95 & 14.81 & 15.66 & 15.47 & 21.11 & 18.33 & 24.35 & 15.89 & 14.09 & 14.30 & 15.61 & 15.90 & 14.19 \\
\hline & Cooling & 0.24 & 1.66 & 1.36 & 1.90 & 2.04 & 3.53 & 1.27 & 4.07 & 1.47 & 2.45 & 1.19 & 1.04 & 1.14 & 0.99 & 1.21 & 0.99 \\
\hline & Fans & -0.17 & -0.84 & -0.95 & -1.38 & -1.62 & -1.74 & -2.31 & -2.97 & -1.73 & -2.78 & -1.65 & -2.32 & -1.81 & -2.68 & -2.28 & -2.24 \\
\hline & Pumps & 0.00 & 0.07 & 0.05 & 0.10 & 0.11 & 0.15 & 0.06 & 0.18 & 0.09 & 0.15 & 0.08 & 0.05 & 0.06 & 0.05 & 0.06 & 0.04 \\
\hline & Total & 1.62 & 9.46 & 8.99 & 13.57 & 15.34 & 17.60 & 14.49 & 22.39 & 18.16 & 24.17 & 15.51 & 12.86 & 13.69 & 13.97 & 14.89 & 12.98 \\
\hline \multirow{5}{*}{$\begin{array}{c}\text { A04a: SAT } \\
\text { Setpoint = } \\
53\end{array}$} & Heating & -5.67 & -6.36 & -6.40 & -6.47 & -6.61 & -5.78 & -5.92 & -6.14 & -7.03 & -6.76 & -5.97 & -5.25 & -5.76 & -5.40 & -5.68 & -5.28 \\
\hline & Cooling & -0.97 & 0.74 & -0.64 & -1.21 & 0.20 & -1.60 & -0.89 & -1.58 & -1.13 & -1.65 & 0.07 & -0.71 & -0.77 & -0.59 & -0.95 & -0.51 \\
\hline & Fans & 0.24 & 0.14 & 0.25 & 0.27 & 0.12 & 0.09 & 0.18 & 0.07 & 0.08 & 0.05 & 0.05 & 0.16 & 0.05 & 0.12 & 0.02 & 0.02 \\
\hline & Pumps & -0.18 & -0.17 & -0.15 & -0.08 & -0.14 & -0.19 & -0.12 & -0.10 & -0.14 & -0.12 & -0.07 & -0.08 & -0.08 & -0.06 & -0.06 & -0.04 \\
\hline & Total & -6.58 & -5.65 & -6.94 & -7.49 & -6.43 & -7.48 & -6.75 & -7.75 & -8.22 & -8.48 & -5.92 & -5.88 & -6.56 & -5.93 & -6.67 & -5.81 \\
\hline \multirow{5}{*}{$\begin{array}{c}\text { A04b: SAT } \\
\text { Setpoint = } \\
54\end{array}$} & Heating & -2.79 & -3.13 & -3.17 & -3.22 & -3.27 & -2.94 & -2.97 & -3.03 & -3.47 & -3.39 & -2.91 & -2.60 & -2.82 & -2.66 & -2.73 & -2.57 \\
\hline & Cooling & -0.46 & 0.56 & -0.23 & -0.63 & 0.40 & -0.79 & -0.45 & -0.77 & -0.54 & -0.77 & 0.09 & -0.35 & -0.37 & -0.28 & -0.74 & -0.25 \\
\hline & Fans & 0.13 & 0.08 & 0.15 & 0.16 & 0.07 & 0.06 & 0.12 & 0.04 & 0.05 & 0.02 & 0.04 & 0.09 & 0.03 & 0.07 & 0.02 & 0.02 \\
\hline & Pumps & -0.07 & -0.06 & -0.06 & -0.03 & -0.04 & -0.08 & -0.05 & -0.04 & -0.06 & -0.05 & -0.02 & -0.03 & -0.03 & -0.02 & -0.02 & -0.02 \\
\hline & Total & -3.19 & -2.55 & -3.31 & -3.72 & -2.84 & -3.75 & -3.35 & -3.80 & -4.02 & -4.19 & -2.80 & -2.89 & -3.19 & -2.89 & -3.47 & -2.82 \\
\hline \multirow{5}{*}{$\begin{array}{c}\text { A04c: SAT } \\
\text { Setpoint }= \\
56\end{array}$} & Heating & 2.60 & 2.97 & 3.06 & 3.12 & 3.13 & 2.91 & 2.91 & 2.98 & 3.36 & 3.31 & 2.85 & 2.47 & 2.71 & 2.56 & 2.66 & 2.44 \\
\hline & Cooling & 0.39 & -0.06 & 0.61 & 0.64 & 0.00 & 0.77 & 0.32 & 0.79 & 0.49 & 0.52 & 0.12 & 0.30 & 0.35 & 0.25 & 0.26 & 0.22 \\
\hline & Fans & -0.20 & -0.13 & -0.22 & -0.19 & -0.11 & -0.08 & -0.18 & -0.06 & -0.07 & -0.04 & -0.04 & -0.10 & -0.05 & -0.07 & -0.02 & -0.02 \\
\hline & Pumps & 0.05 & 0.04 & 0.05 & 0.03 & 0.03 & 0.06 & 0.04 & 0.03 & 0.04 & 0.04 & 0.02 & 0.02 & 0.03 & 0.02 & 0.02 & 0.01 \\
\hline & Total & 2.84 & 2.82 & 3.50 & 3.60 & 3.05 & 3.66 & 3.09 & 3.74 & 3.82 & 3.83 & 2.95 & 2.69 & 3.04 & 2.76 & 2.92 & 2.65 \\
\hline \multirow{5}{*}{$\begin{array}{c}\text { A04d: SAT } \\
\text { Setpoint }= \\
57\end{array}$} & Heating & 5.01 & 5.78 & 5.95 & 6.09 & 6.12 & 5.68 & 5.71 & 5.87 & 6.55 & 6.52 & 5.52 & 4.84 & 5.16 & 4.99 & 5.13 & 4.68 \\
\hline & Cooling & -0.70 & 0.76 & 0.87 & 1.20 & 0.50 & 1.35 & 0.70 & 1.50 & 0.90 & 0.95 & 0.56 & 0.55 & 0.68 & 0.47 & 0.51 & 0.40 \\
\hline & Fans & -0.52 & -0.35 & -0.51 & -0.46 & -0.28 & -0.23 & -0.39 & -0.16 & -0.19 & -0.11 & -0.14 & -0.23 & -0.15 & -0.17 & -0.08 & -0.07 \\
\hline & Pumps & 0.09 & 0.09 & 0.09 & 0.05 & 0.07 & 0.11 & 0.07 & 0.06 & 0.08 & 0.07 & 0.05 & 0.04 & 0.04 & 0.03 & 0.03 & 0.02 \\
\hline & Total & 3.88 & 6.28 & 6.40 & 6.88 & 6.41 & 6.91 & 6.09 & 7.27 & 7.34 & 7.43 & 5.99 & 5.20 & 5.73 & 5.32 & 5.59 & 5.03 \\
\hline
\end{tabular}




\begin{tabular}{|c|c|c|c|c|c|c|c|c|c|c|c|c|c|c|c|c|c|}
\hline 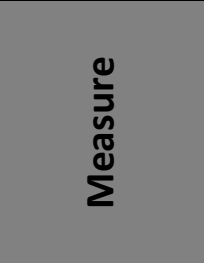 & 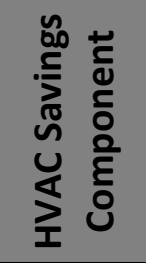 & "ह & $\begin{array}{l}\text { 음 } \\
\text { 홀 } \\
\text { 오 }\end{array}$ & $\begin{array}{l}\frac{x}{c} \\
\frac{0}{0} \\
\frac{g}{2}\end{array}$ & 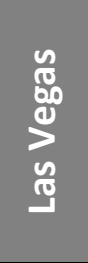 & 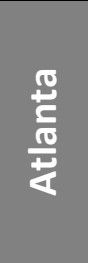 & 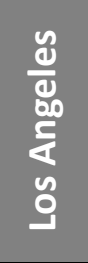 & $\frac{\sqrt{2}}{\frac{0}{2}}$ & 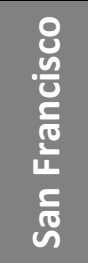 & 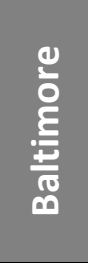 & 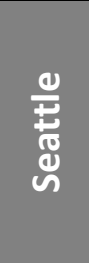 & $\begin{array}{l}\stackrel{8}{0} \\
80 \\
\frac{8}{2} \\
0\end{array}$ & $\begin{array}{c}\frac{1}{0} \\
\frac{0}{3} \\
\text { ○े }\end{array}$ & 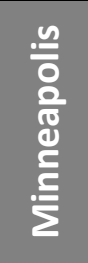 & $\begin{array}{l}\frac{0}{\frac{0}{0}} \\
\frac{10}{10} \\
\frac{1}{1}\end{array}$ & 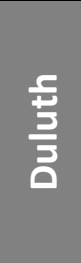 & $\begin{array}{l}\frac{y}{2} \\
\frac{0}{0} \\
\frac{0}{2} \\
\frac{0}{5}\end{array}$ \\
\hline \multirow{5}{*}{$\begin{array}{l}\text { A04e: SAT } \\
\text { Setpoint = } \\
58\end{array}$} & & 7.25 & 8.44 & 67 & 3.90 & 97 & 8.29 & 3.36 & 8.61 & 9.60 & .61 & 3.07 & 7.09 & 7.54 & .28 & 39 & 5.73 \\
\hline & Cooling & -2.00 & 0.52 & 1.40 & 1.56 & 1.21 & 1.64 & 0.98 & 2.15 & 0.87 & 1.32 & 0.98 & 0.78 & 0.97 & 0.65 & .74 & 0.56 \\
\hline & Fans & -0.96 & -0.66 & -0.94 & -0.82 & -0.54 & -0.48 & -0.66 & 0.34 & 0.38 & 0.24 & 0.28 & -0.43 & -0.29 & 0.33 & 0.19 & -0.15 \\
\hline & Pumps & 0.11 & 0.12 & 0.11 & 0.07 & 0.12 & 0.14 & 0.09 & 0.08 & 0.11 & 0.09 & 0.09 & 0.06 & 0.06 & 0.04 & 0.04 & 0.03 \\
\hline & Total & 4.40 & 8.42 & 9.24 & 9.71 & 9.76 & 9.59 & 8.77 & 10.50 & 10.20 & 10.78 & 8.86 & 7.50 & 8.28 & 7.64 & & 7.17 \\
\hline \multirow{5}{*}{$\begin{array}{c}\text { A05: } \\
\text { Damper } \\
\text { Minimum } \\
\text { Airflow 30\% }\end{array}$} & Heating & 11.97 & 14.58 & 14.82 & 15.45 & 15.65 & 14.61 & 14.44 & 15.42 & 16.84 & 17.33 & 14.13 & 12.25 & 12.57 & 12.49 & 12.26 & 10.30 \\
\hline & Cooling & 2.81 & 2.61 & 2.97 & 3.09 & 2.24 & 2.61 & 1.61 & 1.70 & 1.86 & 1.24 & 1.47 & 1.01 & 1.05 & 0.71 & 0.60 & 0.47 \\
\hline & Fans & 2.41 & 2.86 & 3.07 & 3.34 & 3.27 & 2.87 & 3.43 & 2.97 & 3.43 & 3.48 & 2.72 & 2.53 & 2.62 & 2.71 & 2.84 & 3.46 \\
\hline & Pumps & 0.16 & 0.15 & 0.13 & 0.07 & 0.13 & 0.14 & 0.09 & 0.06 & 0.11 & 0.06 & 0.06 & 0.04 & 0.03 & 0.02 & 0.01 & -0.01 \\
\hline & Total & 17.35 & 20.20 & 20.99 & 21.95 & 21.29 & 20.23 & 19.57 & 20.15 & 22.24 & 22.11 & 18.38 & 15.83 & 16.27 & 15.93 & 15.71 & 14.22 \\
\hline \multirow{5}{*}{$\begin{array}{l}\text { A06: Wider } \\
\text { Deadband }\end{array}$} & & 7.28 & 98 & 8.2 & 8.06 & 8.03 & 7.83 & 7.02 & 7.92 & 8.05 & 7.99 & 6.98 & 6.37 & 6.57 & 6.42 & 5.34 & 5.94 \\
\hline & Cooling & 0.89 & 0.47 & 0.38 & 0.96 & 0.30 & 0.45 & 0.51 & 0.41 & 0.41 & נינ. & 0.25 & 0.40 & 0.32 & 0.32 & 0.25 & 0.21 \\
\hline & Fans & 0.38 & 0.21 & 0.46 & 1.04 & 0.17 & 0.23 & 1.14 & 0.17 & -0.01 & -0.06 & -0.03 & 0.61 & -0.06 & 0.34 & -0.14 & -0.15 \\
\hline & Pumps & 0.06 & 0.03 & 0.05 & 0.04 & 0.01 & 0.03 & 0.01 & 0.02 & -0.01 & -0.02 & 0.01 & 0.00 & -0.03 & -0.01 & 0.03 & -0.02 \\
\hline & Total & 8.61 & 8.69 & 9.10 & 10.10 & 8.48 & 8.54 & 8.68 & 8.52 & 8.44 & 0.20 & 7.23 & 7.38 & 6.80 & 7.07 & .42 & 5.98 \\
\hline \multirow{5}{*}{$\begin{array}{c}\text { A07: } \\
\text { Minimum } \\
\text { Occupied OA } \\
\text { Schedule } \\
\text { starts 7AM }\end{array}$} & Heating & 0.99 & 4.10 & ק. & 5.90 & 703 & 5.74 & 8.25 & 8.61 & 9.29 & 11.34 & 0.07 & 7.78 & 8.13 & & & 8.39 \\
\hline & Cooling & 0.21 & (4) & & 0.88 & & & 0.80 & 1.80 & & & & 0.64 & & & & 0.50 \\
\hline & Fans & -0.04 & -0.06 & -0.07 & -0.10 & -0.09 & -0.11 & -0.25 & -0.21 & -0.09 & -0.12 & -0.07 & -0.21 & -0.10 & -0.23 & -0.12 & -0.14 \\
\hline & Pumps & 0.01 & 0.04 & 0.04 & 0.05 & 0.05 & 0.08 & 0.06 & 0.08 & 0.06 & 0.08 & 0.04 & 0.04 & 0.04 & 0.03 & 0.04 & 0.03 \\
\hline & Total & 1.17 & 4.55 & 4.85 & 6.73 & 7.65 & 7.07 & 8.86 & $\begin{array}{l}10.28 \\
\end{array}$ & 10.00 & 12.49 & 9.02 & 8.25 & 8.63 & 9.13 & .80 & 8.78 \\
\hline \multirow{5}{*}{$\begin{array}{c}\text { W01: Chilled } \\
\text { Water DP } \\
\text { Reset }\end{array}$} & Heating & 0.00 & 0.00 & 0.00 & 0.00 & 0.00 & 0.00 & 0.00 & 0.00 & 0.00 & 0.00 & 0.00 & 0.00 & 0.00 & 0.00 & & 0.00 \\
\hline & Cooling & -0.04 & 0.24 & 0.21 & 0.02 & 0.39 & 0.01 & 0.00 & 0.20 & -0.02 & -0.03 & 0.14 & 0.00 & 0.00 & 0.00 & -0.01 & 0.00 \\
\hline & Fans & 0.00 & 0.00 & 0.00 & 0.00 & 0.00 & 0.00 & 0.00 & 0.00 & 0.00 & 0.00 & 0.00 & 0.00 & 0.00 & 0.00 & 0.00 & 0.00 \\
\hline & Pumps & 0.11 & 0.10 & 0.09 & 0.10 & 0.08 & 0.07 & 0.05 & 0.06 & 0.06 & 0.04 & 0.05 & 0.03 & 0.04 & 0.03 & 0.03 & 0.02 \\
\hline & Total & 0.07 & 0.34 & 0.30 & 0.12 & 0.47 & 0.08 & 0.05 & 0.26 & 0.04 & 0.01 & 0.19 & 0.03 & 0.04 & 0.03 & 0.02 & 0.02 \\
\hline
\end{tabular}




\begin{tabular}{|c|c|c|c|c|c|c|c|c|c|c|c|c|c|c|c|c|c|}
\hline 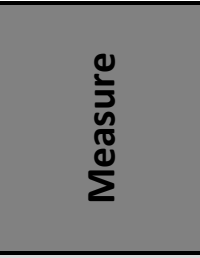 & 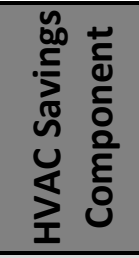 & "를 & $\begin{array}{l}\text { 음 } \\
\text { th } \\
\text { 울 } \\
\text { 오 }\end{array}$ & $\begin{array}{l}\frac{x}{\mathrm{E}} \\
\frac{\mathrm{d}}{\alpha} \\
\frac{\mathrm{g}}{2}\end{array}$ & 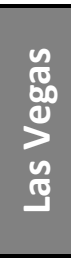 & 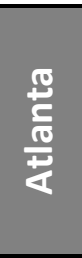 & 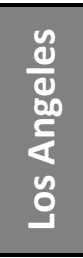 & $\frac{0}{\frac{1}{3}}$ & 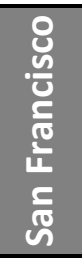 & $\frac{\text { o }}{\frac{2}{2}}$ & 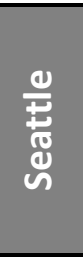 & 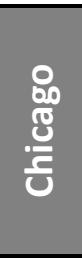 & $\frac{\text { đั] }}{\frac{0}{3}}$ & $\begin{array}{l}\frac{n}{8} \\
\frac{0}{d 0} \\
\frac{d}{5} \\
\frac{5}{\Sigma}\end{array}$ & 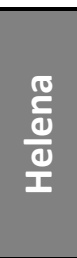 & $\frac{\frac{5}{2}}{\frac{2}{3}}$ & 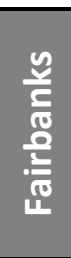 \\
\hline \multirow{5}{*}{$\begin{array}{c}\text { W02: Chilled } \\
\text { Water } \\
\text { Temperature } \\
\text { Reset }\end{array}$} & Heating & 0.97 & 0.92 & 1.09 & 0.25 & 0.84 & 0.92 & 0.71 & 0.94 & 0.73 & 0.71 & 0.54 & 0.55 & 0.55 & 0.53 & 0.45 & 0.40 \\
\hline & Cooling & 0.40 & 2.42 & 2.26 & 1.36 & 2.09 & 0.18 & 0.19 & 0.84 & 0.25 & 0.43 & 1.31 & 0.18 & 0.25 & 0.18 & 0.29 & 0.14 \\
\hline & Fans & -0.12 & -0.08 & -0.25 & 0.31 & -0.08 & -0.04 & -0.04 & -0.04 & -0.06 & -0.03 & -0.04 & -0.05 & -0.04 & -0.01 & -0.03 & -0.02 \\
\hline & Pumps & -0.19 & -0.19 & -0.16 & -0.08 & -0.15 & -0.20 & -0.10 & -0.24 & -0.16 & -0.16 & -0.11 & -0.10 & -0.13 & -0.11 & -0.11 & -0.07 \\
\hline & Total & 1.06 & 3.07 & 2.94 & 1.84 & 2.70 & 0.86 & 0.76 & 1.50 & 0.76 & 0.95 & 1.70 & 0.58 & 0.63 & 0.59 & 0.60 & 0.45 \\
\hline \multirow{5}{*}{$\begin{array}{c}\text { W03: Hot } \\
\text { Water } \\
\text { Temperature } \\
\text { Reset }\end{array}$} & Heating & -0.01 & -0.01 & -0.05 & -0.05 & -0.03 & -0.03 & -0.03 & -0.06 & -0.01 & -0.02 & 0.01 & 0.00 & 0.00 & -0.01 & 0.00 & 0.00 \\
\hline & Cooling & 0.00 & 0.00 & 0.00 & 0.01 & 0.00 & 0.00 & 0.00 & 0.00 & 0.00 & 0.00 & 0.00 & 0.00 & 0.00 & 0.00 & 0.00 & 0.00 \\
\hline & Fans & 0.00 & 0.00 & 0.00 & 0.00 & 0.00 & 0.00 & 0.00 & 0.00 & 0.00 & 0.00 & 0.00 & 0.00 & 0.00 & 0.00 & 0.00 & 0.00 \\
\hline & Pumps & 0.00 & 0.00 & 0.00 & 0.00 & 0.00 & 0.00 & 0.00 & -0.01 & 0.00 & -0.01 & 0.00 & 0.00 & 0.00 & 0.00 & 0.00 & 0.00 \\
\hline & Total & -0.01 & -0.01 & -0.05 & -0.04 & -0.03 & -0.03 & -0.03 & -0.07 & -0.01 & -0.03 & 0.01 & 0.00 & 0.00 & -0.01 & 0.00 & 0.00 \\
\hline \multirow{5}{*}{$\begin{array}{l}\text { W04: Hot } \\
\text { Water DP } \\
\text { Reset }\end{array}$} & Heating & -0.01 & -0.01 & -0.01 & -0.01 & -0.01 & -0.01 & -0.01 & -0.01 & -0.01 & -0.01 & -0.01 & -0.01 & -0.01 & -0.01 & -0.02 & -0.03 \\
\hline & Cooling & 0.00 & 0.00 & 0.00 & 0.00 & 0.00 & 0.00 & 0.00 & 0.00 & 0.00 & 0.00 & 0.00 & 0.00 & 0.00 & 0.00 & -0.01 & -0.02 \\
\hline & Fans & 0.00 & 0.00 & 0.00 & 0.00 & 0.00 & 0.00 & 0.00 & 0.00 & 0.00 & 0.00 & 0.00 & 0.00 & 0.00 & 0.00 & 0.00 & 0.00 \\
\hline & Pumps & 0.01 & 0.01 & 0.01 & 0.01 & 0.01 & 0.01 & 0.01 & 0.01 & 0.01 & 0.01 & 0.01 & 0.01 & 0.01 & 0.01 & 0.00 & -0.01 \\
\hline & Total & 0.00 & 0.00 & 0.00 & 0.00 & 0.00 & 0.00 & 0.00 & 0.00 & 0.00 & 0.00 & 0.00 & 0.00 & 0.00 & 0.00 & -0.03 & -0.06 \\
\hline \multirow{5}{*}{$\begin{array}{c}\text { W05: } \\
\text { Condenser } \\
\text { Water } \\
\text { Temperature } \\
\text { Reset }\end{array}$} & Heating & 0.00 & 0.00 & 0.00 & 0.00 & 0.00 & 0.00 & 0.00 & 0.00 & 0.00 & 0.00 & 0.00 & 0.00 & 0.00 & 0.00 & 0.00 & 0.00 \\
\hline & Cooling & 0.23 & 0.25 & 0.75 & 0.79 & 0.33 & 0.59 & 0.51 & 0.34 & 0.22 & 0.24 & 0.24 & 0.31 & 0.16 & 0.21 & 0.09 & 0.09 \\
\hline & Fans & 0.00 & 0.00 & 0.00 & 0.00 & 0.00 & 0.00 & 0.00 & 0.00 & 0.00 & 0.00 & 0.00 & 0.00 & 0.00 & 0.00 & 0.00 & 0.00 \\
\hline & Pumps & 0.00 & 0.00 & 0.00 & 0.00 & 0.00 & 0.00 & 0.00 & 0.00 & 0.00 & 0.00 & 0.00 & 0.00 & 0.00 & 0.00 & 0.00 & 0.00 \\
\hline & Total & 0.23 & 0.25 & 0.75 & 0.79 & 0.33 & 0.59 & 0.51 & 0.34 & 0.22 & 0.24 & 0.24 & 0.31 & 0.16 & 0.21 & 0.09 & 0.09 \\
\hline \multirow{5}{*}{$\begin{array}{l}\text { W06: Plant } \\
\text { Shut Down } \\
\text { When There } \\
\text { is no Load }\end{array}$} & Heating & -0.02 & -0.01 & -0.01 & -0.01 & -0.01 & -0.02 & -0.01 & -0.02 & -0.01 & -0.01 & 0.00 & -0.02 & -0.01 & -0.10 & 0.00 & -0.01 \\
\hline & Cooling & 0.00 & 0.00 & 0.00 & 0.00 & 0.00 & 0.00 & 0.00 & 0.00 & 0.00 & 0.00 & 0.00 & 0.00 & 0.00 & 0.00 & 0.00 & 0.00 \\
\hline & Fans & 0.00 & 0.00 & 0.00 & 0.00 & 0.00 & 0.00 & 0.00 & 0.00 & 0.00 & 0.00 & 0.00 & 0.00 & 0.00 & 0.00 & 0.00 & 0.00 \\
\hline & Pumps & 0.01 & 0.15 & 0.06 & 0.19 & 0.31 & 0.01 & 0.41 & 0.06 & 0.61 & 0.45 & 0.63 & 0.47 & 0.79 & 0.63 & 0.93 & 1.01 \\
\hline & Total & -0.01 & 0.14 & 0.05 & 0.18 & 0.30 & -0.01 & 0.40 & 0.04 & 0.60 & 0.44 & 0.63 & 0.45 & 0.78 & 0.53 & 0.93 & 1.00 \\
\hline
\end{tabular}




\begin{tabular}{|c|c|c|c|c|c|c|c|c|c|c|c|c|c|c|c|c|c|}
\hline 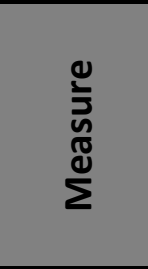 & 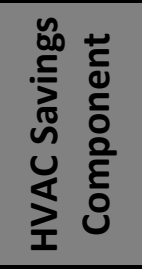 & $\begin{array}{l}\text { 를 } \\
\text { 를 }\end{array}$ & 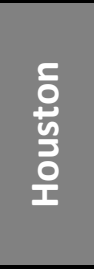 & $\begin{array}{l}\frac{x}{2} \\
\frac{0}{2} \\
\frac{o}{\alpha}\end{array}$ & 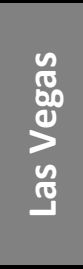 & 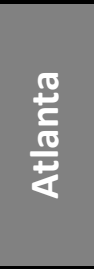 & $\begin{array}{l}\frac{y}{0} \\
\frac{0}{0} \\
\frac{0}{4} \\
y \\
0\end{array}$ & $\begin{array}{l}\frac{y}{2} \\
\frac{0}{0} \\
\frac{d}{2} \\
\frac{0}{\partial} \\
\frac{0}{4}\end{array}$ & 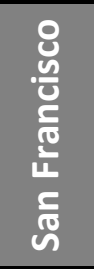 & 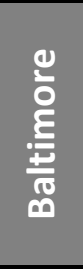 & 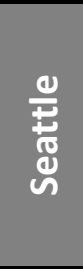 & 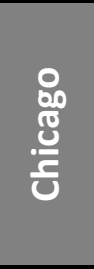 & 훙 & $\begin{array}{l}\frac{\underline{u}}{8} \\
\frac{0}{d 0} \\
\frac{d}{5} \\
\frac{5}{\Sigma}\end{array}$ & $\begin{array}{c}\text { d] } \\
\frac{0}{\mathbf{d}} \\
\end{array}$ & $\frac{\frac{5}{2}}{\frac{2}{3}}$ & $\begin{array}{l}\frac{y}{2} \\
\frac{0}{0} \\
\frac{0}{2} \\
\frac{1}{10}\end{array}$ \\
\hline \multirow{5}{*}{ Combo 1} & Heating & 15.50 & 22.03 & 22.12 & 24.85 & 25.60 & 23.37 & 24.46 & 27.12 & 28.27 & 32.24 & 22.10 & 20.06 & 18.20 & 19.70 & 18.12 & 15.10 \\
\hline & Cooling & 4.54 & 7.14 & 6.87 & 7.18 & 6.45 & 6.11 & 3.86 & 5.34 & 3.89 & 3.70 & 3.86 & 2.71 & 2.52 & 2.12 & 2.01 & 1.52 \\
\hline & Fans & 5.62 & 5.61 & 6.05 & 6.87 & 5.48 & 4.44 & 6.35 & 3.61 & 5.55 & 4.74 & 4.56 & 4.72 & 4.29 & 4.30 & 4.21 & 4.84 \\
\hline & Pumps & 0.12 & 0.20 & 0.20 & 0.25 & 0.24 & 0.28 & 0.23 & 0.26 & 0.17 & 0.19 & 0.09 & 0.13 & 0.06 & 0.08 & 0.05 & 0.02 \\
\hline & Total & 25.78 & 34.98 & 35.24 & 39.15 & 37.77 & 34.20 & 34.90 & 36.33 & 37.88 & 40.87 & 30.61 & 27.62 & 25.07 & 26.20 & 24.39 & 21.48 \\
\hline \multirow{5}{*}{ Combo 2} & Heating & 8.98 & 15.51 & 15.26 & 18.98 & 20.91 & 19.43 & 20.50 & 24.27 & 24.27 & 28.89 & 20.61 & 18.06 & 18.27 & 19.19 & 19.26 & 17.38 \\
\hline & Cooling & 2.84 & 3.61 & 5.15 & 4.29 & 5.12 & 4.68 & 2.62 & 4.51 & 2.04 & 3.04 & 3.10 & 1.92 & 1.99 & 1.47 & 1.66 & 1.19 \\
\hline & Fans & 3.11 & 2.57 & 2.69 & 2.34 & 1.75 & 1.30 & 1.42 & -0.13 & 1.62 & 0.27 & 1.30 & 0.91 & 1.07 & 0.25 & 0.58 & 0.47 \\
\hline & Pumps & 0.44 & 0.45 & 0.38 & 0.47 & 0.46 & 0.42 & 0.30 & 0.41 & 0.39 & 0.37 & 0.34 & 0.28 & 0.31 & 0.27 & 0.27 & 0.17 \\
\hline & Total & 15.37 & 22.14 & 23.48 & 26.08 & 28.24 & 25.83 & 24.84 & 29.06 & 28.32 & 32.57 & 25.35 & 21.17 & 21.64 & 21.18 & 21.77 & 19.21 \\
\hline \multirow{5}{*}{ Combo 3} & Heating & 11.10 & 13.67 & 13.48 & 14.47 & 14.86 & 13.90 & 13.98 & 14.95 & 16.13 & 16.88 & 13.91 & 12.45 & 12.63 & 12.77 & 12.72 & 11.66 \\
\hline & Cooling & 1.56 & 2.74 & 3.72 & 3.02 & 3.98 & 2.89 & 1.82 & 2.67 & 1.05 & 2.00 & 2.37 & 1.39 & 1.64 & 0.95 & 1.20 & 0.76 \\
\hline & Fans & 2.61 & 3.06 & 3.14 & 3.38 & 3.21 & 2.99 & 3.49 & 3.04 & 3.28 & 3.30 & 3.03 & 3.24 & 2.90 & 3.07 & 3.01 & 2.86 \\
\hline & Pumps & 0.49 & 0.47 & 0.39 & 0.42 & 0.45 & 0.43 & 0.31 & 0.35 & 0.38 & 0.33 & 0.33 & 0.29 & 0.29 & 0.25 & 0.24 & 0.14 \\
\hline & Total & 15.76 & 19.94 & 20.73 & 21.29 & 22.50 & 20.21 & 19.60 & 21.01 & 20.84 & 22.51 & 19.64 & 17.37 & 17.46 & 17.04 & 17.17 & 15.42 \\
\hline \multirow{5}{*}{ Combo 4} & Heating & 11.11 & 13.69 & 13.50 & 14.50 & 14.91 & 13.91 & 14.05 & 14.95 & 16.22 & 16.91 & 14.05 & 12.54 & 12.88 & 12.94 & 13.09 & 12.39 \\
\hline & Cooling & 1.80 & 2.46 & 3.56 & 2.63 & 3.88 & 2.69 & 1.57 & 2.41 & 0.87 & 1.80 & 2.32 & 1.18 & 1.43 & 0.80 & 1.04 & 0.66 \\
\hline & Fans & 0.66 & 1.09 & 0.82 & 1.09 & 1.23 & 1.21 & 1.25 & 1.38 & 1.32 & 1.54 & 1.25 & 1.29 & 1.04 & 1.25 & 1.14 & 0.95 \\
\hline & Pumps & 0.47 & 0.45 & 0.37 & 0.40 & 0.43 & 0.41 & 0.29 & 0.34 & 0.36 & 0.32 & 0.32 & 0.27 & 0.28 & 0.24 & 0.24 & 0.14 \\
\hline & Total & 14.04 & 17.69 & 18.25 & 18.62 & 20.45 & 18.22 & 17.16 & 19.08 & 18.77 & 20.57 & 17.94 & 15.28 & 15.63 & 15.23 & 15.51 & 14.14 \\
\hline \multirow{5}{*}{ Combo 5} & Heating & 14.81 & 21.08 & 21.08 & 23.88 & 24.93 & 22.51 & 23.30 & 26.24 & 27.84 & 31.52 & 22.69 & 19.80 & 19.30 & 20.22 & 19.23 & 16.90 \\
\hline & Cooling & 4.36 & 6.95 & 6.00 & 6.12 & 6.00 & 5.16 & 2.86 & 4.65 & 3.60 & 3.29 & 3.52 & 2.09 & 2.26 & 1.66 & 1.78 & 1.33 \\
\hline & Fans & 4.56 & 4.25 & 4.54 & 5.21 & 3.88 & 3.04 & 4.17 & 1.84 & 3.94 & 2.90 & 3.04 & 2.67 & 2.81 & 2.22 & 2.58 & 3.31 \\
\hline & Pumps & 0.30 & 0.40 & 0.31 & 0.44 & 0.42 & 0.43 & 0.33 & 0.41 & 0.38 & 0.37 & 0.29 & 0.28 & 0.26 & 0.26 & 0.24 & 0.16 \\
\hline & Total & 24.03 & 32.68 & 31.93 & 35.65 & 35.23 & 31.14 & 30.66 & 33.14 & 35.76 & 38.08 & 29.54 & 24.84 & 24.63 & 24.36 & 23.83 & 21.70 \\
\hline
\end{tabular}




\begin{tabular}{|c|c|c|c|c|c|c|c|c|c|c|c|c|c|c|c|c|c|}
\hline 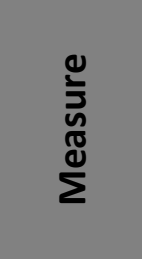 & 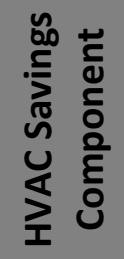 & $\begin{array}{l}\frac{\mathrm{E}}{\mathrm{E}} \\
\frac{\mathrm{J}}{\Sigma}\end{array}$ & 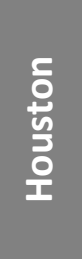 & $\begin{array}{l}\frac{x}{0} \\
\frac{0}{0} \\
\frac{0}{2}\end{array}$ & 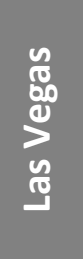 & $\frac{\text { d }}{\frac{d}{0}}$ & $\begin{array}{l}\frac{y}{0} \\
\frac{0}{0} \\
\frac{0}{4} \\
y \\
0\end{array}$ & $\begin{array}{l}\frac{0}{2} \\
\frac{0}{d} \\
\frac{d}{0} \\
\frac{0}{3} \\
\frac{0}{4}\end{array}$ & 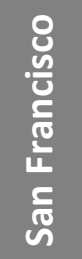 & 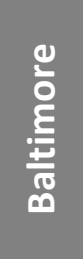 & 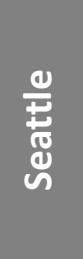 & $\begin{array}{l}\stackrel{\circ}{\circ} \\
\frac{8}{8} \\
\frac{8}{3} \\
0\end{array}$ & $\begin{array}{l}\frac{1}{0} \\
\frac{0}{3} \\
0 \\
0\end{array}$ & $\begin{array}{l}\frac{u}{\circ} \\
\frac{8}{d 0} \\
\frac{d}{d} \\
\frac{5}{\Sigma}\end{array}$ & 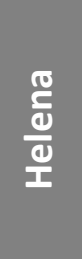 & $\frac{5}{\frac{5}{3}}$ & 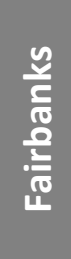 \\
\hline \multirow{5}{*}{ Combo 6} & Heating & 15.50 & 22.15 & 22.17 & 24.98 & 25.99 & 23.39 & 24.90 & 27.21 & 29.23 & 32.66 & 23.24 & 20.64 & 20.32 & 21.23 & 21.16 & 21.23 \\
\hline & Cooling & 4.85 & 7.35 & 7.00 & 7.19 & 6.54 & 6.11 & 3.86 & 5.34 & 3.95 & 3.70 & 3.87 & 2.71 & 2.54 & 2.11 & 2.00 & 1.49 \\
\hline & Fans & 5.62 & 5.61 & 6.05 & 6.88 & 5.47 & 4.44 & 6.34 & 3.60 & 5.53 & 4.73 & 4.55 & 4.71 & 4.29 & 4.31 & 4.20 & 4.83 \\
\hline & Pumps & 0.13 & 0.21 & 0.21 & 0.25 & 0.25 & 0.28 & 0.23 & 0.26 & 0.18 & 0.20 & 0.10 & 0.13 & 0.07 & 0.09 & 0.05 & 0.02 \\
\hline & Total & 26.10 & 35.32 & 35.43 & 39.30 & 38.25 & 34.22 & 35.33 & 36.41 & 38.89 & 41.29 & 31.76 & 28.19 & 27.22 & 27.74 & 27.41 & 27.57 \\
\hline
\end{tabular}

Table 9: Annual Energy Savings (kBtu/sf) by HVAC component and representative city for the Post-1980 building

\begin{tabular}{|c|c|c|c|c|c|c|c|c|c|c|c|c|c|c|c|c|c|}
\hline 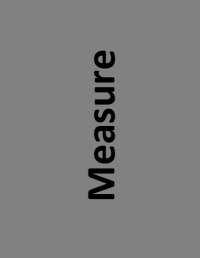 & 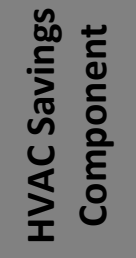 & $\begin{array}{l}\text { 를 } \\
\text { 를 }\end{array}$ & $\begin{array}{l}\text { 응 } \\
\frac{3}{3} \\
\text { 오 }\end{array}$ & $\begin{array}{l}\frac{x}{e} \\
\frac{0}{0} \\
\frac{o}{\alpha}\end{array}$ & 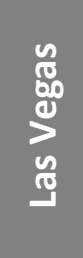 & $\frac{\frac{d}{d}}{\frac{0}{0}}$ & 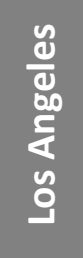 & $\begin{array}{l}\frac{0}{2} \\
\frac{0}{0} \\
\frac{0}{2} \\
\frac{0}{3} \\
\frac{0}{4}\end{array}$ & 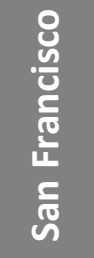 & $\frac{\text { 을 }}{\frac{2}{2}}$ & 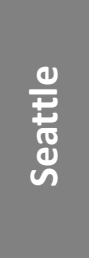 & $\begin{array}{l}\stackrel{0}{0} \\
\frac{8}{8} \\
\frac{8}{0}\end{array}$ & $\frac{0}{0}$ & 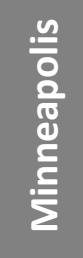 & $\frac{\text { d }}{\frac{d}{d}}$ & $\frac{}{\frac{5}{3}}$ & $\frac{\frac{y}{5}}{\frac{8}{\frac{2}{5}}}$ \\
\hline \multirow{5}{*}{$\begin{array}{c}\text { A01a: HVAC } \\
\text { Schedules } \\
\text { Start } 2 \text { Hours } \\
\text { Late }\end{array}$} & Heating & 5.49 & 7.54 & 7.36 & 8.29 & 8.62 & 7.60 & 7.96 & 8.69 & 9.22 & 9.48 & 7.69 & 6.85 & 6.92 & 6.92 & 6.93 & 6.91 \\
\hline & Cooling & 2.60 & 2.35 & 1.07 & 1.56 & 1.40 & 2.51 & 0.92 & 0.64 & 1.23 & 0.56 & 0.97 & 0.58 & 0.70 & 0.42 & 0.40 & 0.23 \\
\hline & Fans & 0.95 & 1.14 & 1.10 & 1.29 & 1.27 & 1.09 & 1.33 & 1.24 & 1.32 & 1.31 & 1.08 & 1.18 & 0.96 & 1.13 & 0.96 & 0.78 \\
\hline & Pumps & 0.30 & 0.33 & 0.21 & 0.32 & 0.30 & 0.28 & 0.21 & 0.26 & 0.31 & 0.25 & 0.23 & 0.20 & 0.21 & 0.20 & 0.19 & 0.13 \\
\hline & Total & 9.34 & 11.36 & 9.74 & 11.46 & 11.59 & 11.48 & 10.42 & 10.83 & 12.08 & 11.60 & 9.97 & 8.81 & 8.79 & 8.67 & 8.48 & 8.05 \\
\hline \multirow{5}{*}{$\begin{array}{c}\text { A01b: HVAC } \\
\text { Schedules } \\
\text { Start } 4 \text { Hours } \\
\text { Late }\end{array}$} & Heating & 7.33 & 10.36 & 9.94 & 11.51 & 11.85 & 10.54 & 10.97 & 12.11 & 12.88 & 13.30 & 10.62 & 9.39 & 9.52 & 9.39 & 9.60 & 9.79 \\
\hline & Cooling & 3.79 & 3.28 & 1.53 & 2.34 & 2.06 & 3.08 & 1.44 & 0.92 & 1.71 & 0.81 & 1.45 & 1.07 & 1.26 & 0.61 & 0.51 & 0.32 \\
\hline & Fans & 1.34 & 1.62 & 1.53 & 1.98 & 1.81 & 1.59 & 2.24 & 1.78 & 1.88 & 1.88 & 1.54 & 1.84 & 1.36 & 1.70 & 1.38 & 1.14 \\
\hline & Pumps & 0.39 & 0.41 & 0.26 & 0.41 & 0.36 & 0.35 & 0.28 & 0.31 & 0.37 & 0.29 & 0.28 & 0.26 & 0.25 & 0.22 & 0.23 & 0.16 \\
\hline & Total & 12.85 & 15.67 & 13.26 & 16.24 & 16.08 & 15.56 & 14.93 & 15.12 & 16.84 & 16.28 & 13.89 & 12.56 & 12.39 & 11.92 & 11.72 & 11.41 \\
\hline
\end{tabular}




\begin{tabular}{|c|c|c|c|c|c|c|c|c|c|c|c|c|c|c|c|c|c|}
\hline 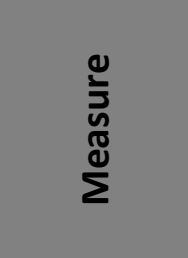 & 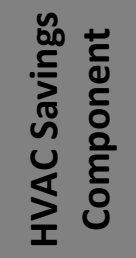 & 들 & $\begin{array}{l}\text { 을 } \\
\text { th } \\
\text { 오 } \\
\text { 오 }\end{array}$ & $\begin{array}{l}\frac{x}{e} \\
\frac{0}{2} \\
\frac{0}{2}\end{array}$ & 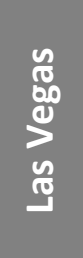 & 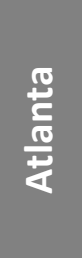 & $\begin{array}{l}\frac{y}{1} \\
\vdots 0 \\
\frac{1}{4} \\
y \\
0\end{array}$ & $\begin{array}{l}\frac{1}{2} \\
\frac{0}{\frac{0}{2}} \\
\frac{d}{\partial} \\
\frac{0}{2} \\
\frac{0}{4}\end{array}$ & 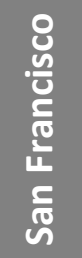 & $\frac{\text { 을 }}{\frac{2}{2}}$ & 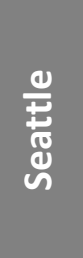 & 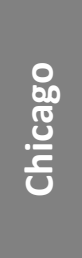 & $\frac{\frac{2}{0}}{\frac{1}{3}}$ & $\begin{array}{l}\frac{. n}{0} \\
\frac{0}{d 0} \\
\frac{d}{g} \\
\frac{5}{\Sigma}\end{array}$ & $\frac{\text { d }}{\frac{d}{d}}$ & $\frac{5}{\frac{5}{2}}$ & $\begin{array}{l}\frac{y}{\frac{y}{70}} \\
\frac{0}{\frac{2}{70}} \\
\frac{1}{4}\end{array}$ \\
\hline \multirow{5}{*}{$\begin{array}{l}\text { A02: Static } \\
\text { Pressure } \\
\text { Reset }\end{array}$} & Heating & -0.01 & -0.01 & -0.01 & -0.02 & -0.02 & -0.02 & -0.05 & 0.00 & -0.04 & -0.01 & -0.07 & -0.05 & -0.18 & -0.12 & -0.27 & -0.68 \\
\hline & Cooling & 0.49 & 0.43 & 0.36 & 0.48 & 0.37 & 0.54 & 0.32 & 0.40 & 0.16 & 0.27 & 0.28 & 0.25 & 0.27 & 0.19 & 0.17 & 0.12 \\
\hline & Fans & 2.47 & 2.51 & 2.87 & 2.79 & 2.50 & 2.34 & 2.76 & 2.18 & 2.41 & 2.26 & 2.26 & 2.45 & 2.25 & 2.29 & 2.24 & 2.27 \\
\hline & Pumps & 0.04 & 0.04 & 0.03 & 0.03 & 0.03 & 0.04 & 0.03 & 0.02 & 0.02 & 0.02 & 0.02 & 0.02 & 0.01 & 0.01 & 0.01 & 0.01 \\
\hline & Total & 2.99 & 2.97 & 3.25 & 3.28 & 2.88 & 2.90 & 3.06 & 2.60 & 2.55 & 2.54 & 2.49 & 2.67 & 2.35 & 2.37 & 2.15 & 1.72 \\
\hline \multirow{5}{*}{$\begin{array}{c}\text { A03a: SAT } \\
\text { Reset Based } \\
\text { on OAT }\end{array}$} & Heating & 0.74 & 3.21 & 3.11 & 4.65 & 5.41 & 4.28 & 6.17 & 6.65 & 6.90 & 8.46 & 6.17 & 5.59 & 5.31 & 6.00 & 5.84 & 5.05 \\
\hline & Cooling & 0.18 & 0.48 & 0.37 & 0.48 & 0.58 & 1.33 & 0.41 & 1.08 & 0.41 & 0.68 & 0.41 & 0.32 & 0.35 & 0.29 & 0.34 & 0.27 \\
\hline & Fans & -0.04 & -0.10 & -0.10 & -0.13 & -0.17 & -0.25 & -0.40 & -0.31 & -0.26 & -0.40 & -0.28 & -0.44 & -0.35 & -0.54 & -0.51 & -0.45 \\
\hline & Pumps & 0.01 & 0.03 & 0.02 & 0.04 & 0.04 & 0.06 & 0.03 & 0.06 & 0.03 & 0.04 & 0.03 & 0.02 & 0.03 & 0.02 & 0.03 & 0.02 \\
\hline & Total & 0.89 & 3.62 & 3.40 & 5.04 & 5.86 & 5.42 & 6.21 & 7.48 & 7.08 & 8.78 & 6.33 & 5.49 & 5.34 & 5.77 & 5.70 & 4.89 \\
\hline \multirow{5}{*}{$\begin{array}{l}\text { A03b: SAT } \\
\text { Reset - } \\
\text { Alternate } \\
\text { Method }\end{array}$} & Heating & 1.24 & 6.71 & 6.76 & 10.30 & 11.41 & 11.65 & 11.35 & 16.28 & 13.48 & 17.92 & 10.88 & 9.37 & 9.01 & 9.97 & 9.69 & 8.57 \\
\hline & Cooling & 0.07 & 0.95 & 0.79 & 1.14 & 1.45 & 3.59 & 0.59 & 2.36 & 1.00 & 1.45 & 0.82 & 0.46 & 0.79 & 0.55 & 0.72 & 0.58 \\
\hline & Fans & -0.20 & -0.85 & -0.97 & -1.43 & -1.66 & -2.22 & -2.63 & -3.33 & -2.06 & -3.36 & -2.12 & -2.86 & -2.56 & -3.54 & -3.50 & -3.24 \\
\hline & Pumps & 0.00 & 0.05 & 0.04 & 0.08 & 0.08 & 0.14 & 0.02 & 0.14 & 0.06 & 0.09 & 0.05 & 0.01 & 0.05 & 0.02 & 0.04 & 0.02 \\
\hline & Total & 1.11 & 6.86 & 6.62 & 10.09 & 11.28 & 13.16 & 9.33 & 15.45 & 12.48 & 16.10 & 9.63 & 6.98 & 7.29 & 7.00 & 6.95 & 5.93 \\
\hline \multirow{5}{*}{$\begin{array}{c}\text { A04a: SAT } \\
\text { Setpoint }= \\
53\end{array}$} & Heating & -4.01 & -4.74 & -4.93 & -4.83 & -5.07 & -4.37 & -4.45 & -4.73 & -5.24 & -5.09 & -4.23 & -3.67 & -3.87 & -3.68 & -3.89 & -3.41 \\
\hline & Cooling & 1.14 & 0.73 & -0.50 & -0.40 & -0.15 & -0.67 & -0.61 & -1.10 & -0.49 & -1.04 & -0.01 & -0.53 & -0.51 & -0.36 & -0.61 & -0.32 \\
\hline & Fans & 0.35 & 0.22 & 0.26 & 0.27 & 0.15 & 0.21 & 0.24 & 0.14 & 0.12 & 0.11 & 0.15 & 0.20 & 0.16 & 0.17 & 0.12 & 0.12 \\
\hline & Pumps & -0.05 & -0.08 & -0.09 & -0.04 & -0.08 & -0.09 & -0.06 & -0.06 & -0.08 & -0.06 & -0.04 & -0.04 & -0.04 & -0.03 & -0.04 & -0.02 \\
\hline & Total & -2.57 & -3.87 & -5.26 & -5.00 & -5.15 & -4.92 & -4.88 & -5.75 & -5.69 & -6.08 & -4.13 & -4.04 & -4.26 & -3.90 & -4.42 & -3.63 \\
\hline \multirow{5}{*}{$\begin{array}{c}\text { A04b: SAT } \\
\text { Setpoint }= \\
54\end{array}$} & Heating & -1.96 & -2.33 & -2.41 & -2.39 & -2.50 & -2.15 & -2.20 & -2.33 & -2.59 & -2.52 & -2.07 & -1.79 & -1.88 & -1.80 & -2.00 & -1.65 \\
\hline & Cooling & -0.18 & 0.49 & -0.18 & -0.36 & -0.03 & -0.46 & -0.35 & -0.50 & -0.18 & -0.37 & -0.06 & -0.26 & -0.17 & -0.18 & -0.24 & -0.15 \\
\hline & Fans & 0.19 & 0.12 & 0.15 & 0.14 & 0.09 & 0.13 & 0.14 & 0.08 & 0.07 & 0.07 & 0.09 & 0.11 & 0.09 & 0.10 & 0.06 & 0.07 \\
\hline & Pumps & -0.04 & -0.02 & -0.03 & -0.02 & -0.03 & -0.04 & -0.03 & -0.03 & -0.04 & -0.02 & -0.02 & -0.02 & -0.02 & -0.01 & -0.02 & -0.01 \\
\hline & Total & -1.99 & -1.74 & -2.47 & -2.63 & -2.47 & -2.52 & -2.44 & -2.78 & -2.74 & -2.84 & -2.06 & -1.96 & -1.98 & -1.89 & -2.20 & -1.74 \\
\hline
\end{tabular}




\begin{tabular}{|c|c|c|c|c|c|c|c|c|c|c|c|c|c|c|c|c|c|}
\hline 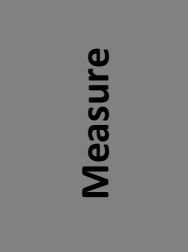 & 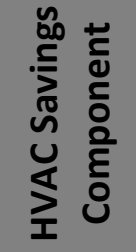 & 틀 & $\begin{array}{l}\text { 을 } \\
\text { th } \\
\text { 오 } \\
\text { 오 }\end{array}$ & $\begin{array}{l}\frac{x}{e} \\
\frac{0}{2} \\
\frac{0}{2}\end{array}$ & 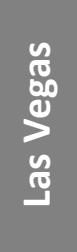 & 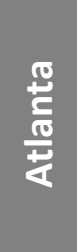 & $\begin{array}{l}\frac{y}{d} \\
\frac{0}{0} \\
\frac{c}{4} \\
0\end{array}$ & $\begin{array}{l}\frac{1}{2} \\
\frac{0}{\frac{0}{2}} \\
\frac{d}{\partial} \\
\frac{0}{2} \\
\frac{0}{4}\end{array}$ & 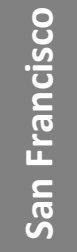 & $\frac{\text { d }}{\frac{2}{2}}$ & 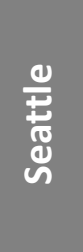 & 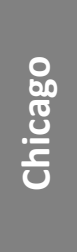 & $\frac{\frac{2}{0}}{\frac{1}{3}}$ & 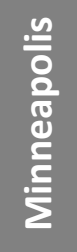 & $\frac{\text { d }}{\frac{d}{d}}$ & $\frac{5}{\frac{5}{2}}$ & $\begin{array}{l}\frac{y}{c} \\
\frac{0}{0} \\
\frac{0}{10} \\
\end{array}$ \\
\hline \multirow{5}{*}{$\begin{array}{l}\text { A04c: SAT } \\
\text { Setpoint }= \\
56\end{array}$} & Heating & 1.84 & 2.22 & 2.30 & 2.39 & 2.41 & 2.09 & 2.14 & 2.27 & 2.51 & 2.46 & 2.00 & 1.72 & 1.78 & 1.72 & 1.68 & 1.50 \\
\hline & Cooling & 0.47 & 0.47 & 0.25 & 0.35 & 0.39 & 0.71 & 0.26 & 0.47 & 0.17 & 0.33 & 0.32 & 0.20 & 0.25 & 0.16 & 0.16 & 0.13 \\
\hline & Fans & -0.25 & -0.17 & -0.20 & -0.22 & -0.12 & -0.17 & -0.17 & -0.11 & -0.10 & -0.10 & -0.12 & -0.15 & -0.12 & -0.13 & -0.12 & -0.09 \\
\hline & Pumps & 0.05 & 0.04 & 0.03 & 0.02 & 0.04 & 0.04 & 0.02 & 0.02 & 0.03 & 0.02 & 0.02 & 0.01 & 0.01 & 0.01 & 0.01 & 0.00 \\
\hline & Total & 2.11 & 2.56 & 2.38 & 2.54 & 2.72 & 2.67 & 2.25 & 2.65 & 2.61 & 2.71 & 2.22 & 1.78 & 1.92 & 1.76 & 1.73 & 1.54 \\
\hline \multirow{5}{*}{$\begin{array}{c}\text { A04d: SAT } \\
\text { Setpoint }= \\
57\end{array}$} & Heating & 3.53 & 4.33 & 4.45 & 4.62 & 4.73 & 4.09 & 4.19 & 4.47 & 4.93 & 4.87 & 3.83 & 3.36 & 3.42 & 3.35 & 3.23 & 2.86 \\
\hline & Cooling & 1.14 & 1.12 & 0.54 & 0.62 & 0.91 & 1.62 & 0.54 & 0.90 & 0.52 & 0.64 & 0.68 & 0.38 & 0.51 & 0.30 & 0.32 & 0.25 \\
\hline & Fans & -0.56 & -0.38 & -0.48 & -0.49 & -0.29 & -0.39 & -0.37 & -0.25 & -0.25 & -0.24 & -0.30 & -0.36 & -0.28 & -0.31 & -0.28 & -0.22 \\
\hline & Pumps & 0.11 & 0.10 & 0.05 & 0.03 & 0.07 & 0.09 & 0.05 & 0.05 & 0.05 & 0.04 & 0.04 & 0.02 & 0.03 & 0.02 & 0.02 & 0.01 \\
\hline & Total & 4.22 & 5.17 & 4.56 & 4.78 & 5.42 & 5.41 & 4.41 & 5.17 & 5.25 & 5.31 & 4.25 & 3.40 & 3.68 & 3.36 & 3.29 & 2.90 \\
\hline \multirow{5}{*}{$\begin{array}{l}\text { A04e: SAT } \\
\text { Setpoint }= \\
58\end{array}$} & Heating & 5.06 & 6.30 & 6.45 & 6.73 & 6.94 & 6.00 & 6.15 & 6.61 & 7.23 & 7.20 & 5.70 & 4.90 & 4.91 & 4.88 & 4.66 & 4.06 \\
\hline & Cooling & 2.04 & 1.87 & 0.97 & 0.86 & 1.40 & 2.53 & 0.78 & 1.27 & 0.97 & 0.92 & 1.10 & 0.53 & 0.78 & 0.43 & 0.49 & 0.34 \\
\hline & Fans & -0.97 & -0.67 & -0.84 & -0.82 & -0.51 & -0.67 & -0.62 & -0.43 & -0.44 & -0.41 & -0.50 & -0.59 & -0.50 & -0.55 & -0.49 & -0.39 \\
\hline & Pumps & 0.15 & 0.14 & 0.07 & 0.03 & 0.11 & 0.12 & 0.06 & 0.06 & 0.08 & 0.05 & 0.07 & 0.03 & 0.04 & 0.02 & 0.03 & 0.02 \\
\hline & Total & 6.28 & 7.64 & 6.65 & 6.80 & 7.94 & 7.98 & 6.37 & 7.51 & 7.84 & 7.76 & 6.37 & 4.87 & 5.23 & 4.78 & 4.69 & 4.03 \\
\hline \multirow{5}{*}{$\begin{array}{c}\text { A05: } \\
\text { Damper } \\
\text { Minimum } \\
\text { Airflow 30\% }\end{array}$} & Heating & 5.54 & 7.12 & 7.25 & 7.65 & 7.94 & 6.86 & 6.97 & 7.63 & 8.36 & 8.39 & 6.45 & 5.51 & 5.49 & 5.47 & 5.11 & 4.22 \\
\hline & Cooling & 2.19 & 1.83 & 1.44 & 1.81 & 1.29 & 1.33 & 0.78 & 0.45 & 0.85 & 0.42 & 0.78 & 0.47 & 0.60 & 0.31 & 0.21 & 0.13 \\
\hline & Fans & 0.89 & 1.08 & 1.14 & 1.19 & 1.25 & 1.05 & 1.21 & 1.13 & 1.26 & 1.27 & 0.99 & 0.89 & 0.93 & 0.94 & 0.97 & 1.26 \\
\hline & Pumps & 0.09 & 0.09 & 0.04 & 0.03 & 0.07 & 0.06 & 0.04 & 0.01 & 0.05 & 0.02 & 0.03 & 0.01 & 0.01 & 0.00 & -0.01 & 0.00 \\
\hline & Total & 8.71 & 10.12 & 9.87 & 10.68 & 10.55 & 9.30 & 9.00 & 9.22 & 10.52 & 10.10 & 8.25 & 6.88 & 7.03 & 6.72 & 6.28 & 5.61 \\
\hline \multirow{5}{*}{$\begin{array}{l}\text { A06: Wider } \\
\text { Deadband }\end{array}$} & Heating & 5.63 & 6.58 & 6.61 & 6.51 & 6.84 & 6.68 & 5.92 & 6.97 & 6.87 & 7.02 & 5.79 & 5.28 & 5.28 & 5.25 & 5.11 & 4.30 \\
\hline & Cooling & 0.55 & 0.49 & 0.53 & 0.80 & 0.40 & 0.26 & 0.42 & 0.28 & 0.36 & 0.22 & 0.10 & 0.30 & 0.35 & 0.30 & 0.22 & 0.19 \\
\hline & Fans & 0.59 & 0.34 & 0.50 & 1.23 & 0.20 & 0.42 & 1.37 & 0.22 & 0.14 & 0.16 & 0.19 & 1.03 & 0.18 & 0.64 & 0.16 & 0.03 \\
\hline & Pumps & 0.05 & 0.04 & 0.05 & 0.04 & 0.02 & 0.03 & 0.02 & 0.01 & 0.00 & 0.00 & -0.01 & 0.01 & -0.02 & 0.00 & -0.03 & -0.02 \\
\hline & Total & 6.82 & 7.45 & 7.69 & 8.58 & 7.46 & 7.39 & 7.73 & 7.48 & 7.37 & 7.40 & 6.07 & 6.62 & 5.79 & 6.19 & 5.46 & 4.50 \\
\hline
\end{tabular}




\begin{tabular}{|c|c|c|c|c|c|c|c|c|c|c|c|c|c|c|c|c|c|}
\hline 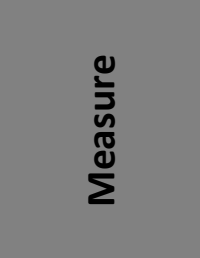 & 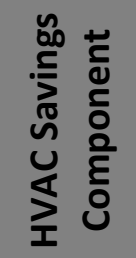 & 틀 & $\begin{array}{l}\text { 을 } \\
\frac{5}{4} \\
\text { 울 }\end{array}$ & $\begin{array}{l}\frac{x}{c} \\
\frac{0}{2} \\
\frac{0}{2}\end{array}$ & 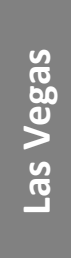 & 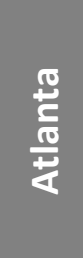 & $\begin{array}{l}\frac{y}{0} \\
\frac{1}{0} \\
\frac{5}{4} \\
y \\
0\end{array}$ & $\begin{array}{l}\frac{1}{2} \\
\frac{0}{0} \\
\frac{0}{\partial} \\
\frac{0}{0} \\
\frac{0}{4}\end{array}$ & $\begin{array}{l}\frac{8}{8} \\
\frac{n}{8} \\
\frac{2}{0} \\
\frac{2}{2} \\
\frac{5}{7}\end{array}$ & $\frac{\text { 을 }}{\frac{2}{\mathrm{n}}}$ & 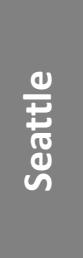 & $\begin{array}{l}\text { 영 } \\
\text { 을 } \\
\frac{}{3}\end{array}$ & $\frac{\frac{1}{0}}{\frac{1}{3}}$ & 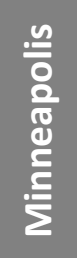 & $\frac{\text { d }}{\frac{d}{d}}$ & $\frac{\frac{5}{3}}{3}$ & 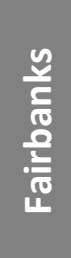 \\
\hline \multirow{5}{*}{$\begin{array}{c}\text { A07: } \\
\text { Minimum } \\
\text { Occupied OA } \\
\text { Schedule } \\
\text { starts 7AM }\end{array}$} & Heating & 0.74 & 3.21 & 3.11 & 4.65 & 5.41 & 4.28 & 6.17 & 6.65 & 6.90 & 8.46 & 6.17 & 5.59 & 5.31 & 6.00 & 5.84 & 5.05 \\
\hline & Cooling & 0.18 & 0.48 & 0.37 & 0.48 & 0.58 & 1.33 & 0.41 & 1.08 & 0.41 & 0.68 & 0.41 & 0.32 & 0.35 & 0.29 & 0.34 & 0.27 \\
\hline & Fans & -0.04 & -0.10 & -0.10 & -0.13 & -0.17 & -0.25 & -0.40 & -0.31 & -0.26 & -0.40 & -0.28 & -0.44 & -0.35 & -0.54 & -0.51 & -0.45 \\
\hline & Pumps & 0.01 & 0.03 & 0.02 & 0.04 & 0.04 & 0.06 & 0.03 & 0.06 & 0.03 & 0.04 & 0.03 & 0.02 & 0.03 & 0.02 & 0.03 & 0.02 \\
\hline & Total & 0.89 & 3.62 & 3.40 & 5.04 & 5.86 & 5.42 & 6.21 & 7.48 & 7.08 & 8.78 & 6.33 & 5.49 & 5.34 & 5.77 & 5.70 & 4.89 \\
\hline \multirow{5}{*}{$\begin{array}{c}\text { W01: Chilled } \\
\text { Water DP } \\
\text { Reset }\end{array}$} & Heating & 0.00 & 0.00 & 0.00 & -0.02 & 0.00 & 0.00 & 0.00 & 0.00 & 0.00 & 0.00 & 0.00 & 0.00 & 0.00 & 0.00 & 0.00 & 0.00 \\
\hline & Cooling & 0.53 & 0.31 & -0.12 & 0.10 & -0.01 & 0.08 & 0.05 & 0.00 & 0.00 & 0.00 & 0.11 & 0.03 & -0.02 & 0.03 & -0.02 & 0.00 \\
\hline & Fans & 0.00 & 0.00 & 0.00 & 0.04 & 0.00 & 0.00 & 0.00 & 0.00 & 0.00 & 0.00 & 0.00 & 0.00 & 0.00 & 0.00 & 0.00 & 0.00 \\
\hline & Pumps & 0.13 & 0.10 & 0.08 & 0.08 & 0.06 & 0.07 & 0.04 & 0.04 & 0.05 & 0.03 & 0.04 & 0.03 & 0.03 & 0.02 & 0.02 & 0.01 \\
\hline & Total & 0.66 & 0.41 & -0.04 & 0.20 & 0.05 & 0.15 & 0.09 & 0.04 & 0.05 & 0.03 & 0.15 & 0.06 & 0.01 & 0.05 & 0.00 & 0.01 \\
\hline \multirow{5}{*}{$\begin{array}{c}\text { W02: Chilled } \\
\text { Water } \\
\text { Temperature } \\
\text { Reset }\end{array}$} & Heating & 0.94 & 0.88 & 0.94 & 0.12 & 0.77 & 0.75 & 0.49 & 0.52 & 0.61 & 0.46 & 0.41 & 0.39 & 0.39 & 0.29 & 0.25 & 0.22 \\
\hline & Cooling & 4.50 & 3.31 & 1.73 & 1.86 & 1.77 & 1.73 & 0.81 & 0.53 & 1.05 & 0.40 & 1.46 & 0.56 & 0.66 & 0.43 & 0.33 & 0.16 \\
\hline & Fans & -0.13 & -0.11 & -0.39 & 0.50 & -0.10 & -0.12 & 0.04 & -0.06 & -0.09 & -0.07 & -0.13 & -0.07 & -0.11 & 0.01 & -0.09 & -0.08 \\
\hline & Pumps & -0.13 & -0.12 & -0.15 & -0.05 & -0.13 & -0.20 & -0.06 & -0.15 & -0.10 & -0.10 & -0.09 & -0.08 & -0.11 & -0.07 & -0.07 & -0.05 \\
\hline & Total & 5.18 & 3.96 & 2.13 & 2.43 & 2.31 & 2.16 & 1.28 & 0.84 & 1.47 & 0.69 & 1.65 & 0.80 & 0.83 & 0.66 & 0.42 & 0.25 \\
\hline \multirow{5}{*}{$\begin{array}{c}\text { W03: Hot } \\
\text { Water } \\
\text { Temperature } \\
\text { Reset }\end{array}$} & Heating & 0.00 & -0.01 & -0.03 & -0.04 & -0.02 & -0.02 & -0.03 & -0.04 & -0.02 & -0.02 & 0.00 & -0.01 & 0.00 & -0.01 & 0.00 & 0.00 \\
\hline & Cooling & 0.00 & 0.00 & -0.01 & 0.00 & 0.00 & 0.00 & 0.00 & 0.00 & 0.00 & 0.00 & 0.00 & 0.00 & 0.00 & 0.00 & 0.00 & 0.00 \\
\hline & Fans & 0.00 & 0.00 & 0.01 & 0.00 & 0.00 & 0.00 & 0.00 & 0.00 & 0.00 & 0.00 & 0.00 & 0.00 & 0.00 & 0.00 & 0.00 & 0.00 \\
\hline & Pumps & 0.00 & 0.00 & 0.00 & 0.00 & 0.00 & 0.00 & 0.00 & 0.00 & 0.00 & 0.00 & 0.00 & 0.00 & 0.00 & 0.00 & 0.00 & 0.00 \\
\hline & Total & 0.00 & -0.01 & -0.03 & -0.04 & -0.02 & -0.02 & -0.03 & -0.04 & -0.02 & -0.02 & 0.00 & -0.01 & 0.00 & -0.01 & 0.00 & 0.00 \\
\hline \multirow{5}{*}{$\begin{array}{l}\text { W04: Hot } \\
\text { Water DP } \\
\text { Reset }\end{array}$} & Heating & -0.01 & -0.01 & -0.01 & -0.01 & -0.01 & -0.01 & -0.01 & -0.01 & -0.01 & -0.01 & -0.01 & -0.01 & -0.01 & -0.01 & -0.01 & -0.02 \\
\hline & Cooling & 0.00 & 0.00 & -0.01 & 0.00 & 0.00 & 0.00 & 0.00 & 0.00 & 0.00 & 0.00 & 0.00 & 0.00 & 0.00 & 0.00 & -0.01 & -0.02 \\
\hline & Fans & 0.00 & 0.00 & 0.01 & 0.00 & 0.00 & 0.00 & 0.00 & 0.00 & 0.00 & 0.00 & 0.00 & 0.00 & 0.00 & 0.00 & 0.00 & 0.00 \\
\hline & Pumps & 0.01 & 0.01 & 0.01 & 0.01 & 0.01 & 0.01 & 0.01 & 0.01 & 0.01 & 0.01 & 0.01 & 0.01 & 0.00 & 0.00 & 0.00 & -0.02 \\
\hline & Total & 0.00 & 0.00 & 0.00 & 0.00 & 0.00 & 0.00 & 0.00 & 0.00 & 0.00 & 0.00 & 0.00 & 0.00 & -0.01 & -0.01 & -0.02 & -0.06 \\
\hline
\end{tabular}




\begin{tabular}{|c|c|c|c|c|c|c|c|c|c|c|c|c|c|c|c|c|c|}
\hline 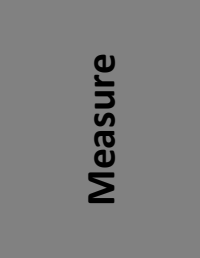 & 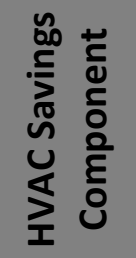 & 틀 & $\begin{array}{l}\text { 응 } \\
\text { th } \\
\text { 울 } \\
\text { 오 }\end{array}$ & $\begin{array}{l}\frac{x}{e} \\
\frac{0}{0} \\
\frac{o}{2}\end{array}$ & 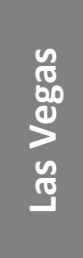 & $\frac{\frac{\pi}{3}}{\frac{0}{0}}$ & $\begin{array}{l}\frac{y}{1} \\
\vdots 0 \\
\frac{1}{4} \\
y \\
0\end{array}$ & $\begin{array}{l}\frac{1}{2} \\
\frac{0}{\frac{0}{2}} \\
\frac{d}{\partial} \\
\frac{0}{2} \\
\frac{0}{4}\end{array}$ & 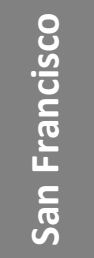 & $\frac{\frac{d}{2}}{\frac{2}{2}}$ & 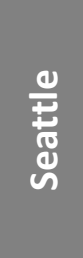 & 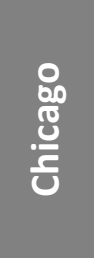 & $\frac{\frac{2}{0}}{\frac{1}{3}}$ & 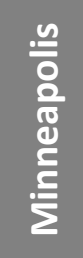 & $\frac{\text { d }}{\frac{d}{d}}$ & $\frac{5}{\frac{5}{2}}$ & $\begin{array}{l}\frac{y}{\frac{y}{70}} \\
\frac{0}{\frac{2}{70}} \\
\frac{1}{4}\end{array}$ \\
\hline \multirow{5}{*}{$\begin{array}{c}\text { W05: } \\
\text { Condenser } \\
\text { Water } \\
\text { Temperature } \\
\text { Reset }\end{array}$} & Heating & 0.00 & 0.00 & 0.00 & 0.00 & 0.00 & 0.00 & 0.00 & 0.00 & 0.00 & 0.00 & 0.00 & 0.00 & 0.00 & 0.00 & 0.00 & 0.00 \\
\hline & Cooling & 0.20 & 0.18 & 0.47 & 0.71 & 0.23 & 0.48 & 0.43 & 0.07 & 0.16 & 0.11 & 0.19 & 0.29 & 0.13 & 0.17 & 0.08 & 0.06 \\
\hline & Fans & 0.00 & 0.00 & 0.00 & 0.00 & 0.00 & 0.00 & 0.00 & 0.00 & 0.00 & 0.00 & 0.00 & 0.00 & 0.00 & 0.00 & 0.00 & 0.00 \\
\hline & Pumps & 0.00 & 0.00 & 0.00 & 0.00 & 0.00 & 0.00 & 0.00 & 0.00 & 0.00 & 0.00 & 0.00 & 0.00 & 0.00 & 0.00 & 0.00 & 0.00 \\
\hline & Total & 0.20 & 0.18 & 0.47 & 0.71 & 0.23 & 0.48 & 0.43 & 0.07 & 0.16 & 0.11 & 0.19 & 0.29 & 0.13 & 0.17 & 0.08 & 0.06 \\
\hline \multirow{5}{*}{$\begin{array}{l}\text { W06: Plant } \\
\text { Shut Down } \\
\text { When There } \\
\text { is no Load }\end{array}$} & Heating & -0.01 & -0.01 & -0.01 & -0.01 & 0.00 & -0.02 & -0.01 & -0.01 & 0.00 & -0.01 & 0.00 & -0.02 & -0.01 & -0.02 & 0.00 & -0.04 \\
\hline & Cooling & 0.00 & 0.00 & -0.01 & 0.00 & 0.00 & 0.00 & 0.00 & 0.00 & 0.00 & 0.00 & 0.00 & 0.00 & 0.00 & 0.00 & 0.00 & 0.00 \\
\hline & Fans & 0.00 & 0.00 & 0.01 & 0.00 & 0.00 & 0.00 & 0.00 & 0.00 & 0.00 & 0.00 & 0.00 & 0.00 & 0.00 & 0.00 & 0.00 & 0.00 \\
\hline & Pumps & 0.01 & 0.21 & 0.13 & 0.34 & 0.39 & 0.04 & 0.49 & 0.23 & 0.64 & 0.60 & 0.68 & 0.57 & 0.81 & 0.70 & 0.98 & 1.05 \\
\hline & Total & 0.00 & 0.20 & 0.12 & 0.33 & 0.39 & 0.02 & 0.48 & 0.22 & 0.64 & 0.59 & 0.68 & 0.55 & 0.80 & 0.68 & 0.98 & 1.01 \\
\hline \multirow{5}{*}{ Combo 1} & Heating & 9.64 & 15.66 & 15.71 & 18.40 & 19.00 & 16.41 & 17.46 & 20.48 & 20.26 & 23.12 & 14.54 & 13.13 & 11.11 & 12.34 & 10.50 & 8.75 \\
\hline & Cooling & 7.12 & 6.31 & 4.40 & 5.62 & 4.65 & 6.25 & 3.09 & 3.07 & 3.27 & 2.26 & 3.08 & 2.11 & 2.09 & 1.57 & 1.38 & 0.93 \\
\hline & Fans & 4.02 & 3.86 & 4.12 & 5.12 & 3.57 & 2.78 & 4.48 & 2.18 & 3.28 & 2.46 & 2.72 & 3.19 & 2.30 & 2.31 & 1.74 & 2.15 \\
\hline & Pumps & 0.13 & 0.20 & 0.10 & 0.21 & 0.17 & 0.26 & 0.16 & 0.19 & 0.12 & 0.13 & 0.05 & 0.09 & 0.01 & 0.05 & 0.01 & 0.01 \\
\hline & Total & 20.91 & 26.03 & 24.33 & 29.35 & 27.39 & 25.70 & 25.19 & 25.92 & 26.93 & 27.97 & 20.39 & 18.52 & 15.51 & 16.27 & 13.63 & 11.84 \\
\hline \multirow{5}{*}{ Combo 2} & Heating & 6.21 & 11.89 & 11.77 & 14.97 & 16.19 & 14.27 & 15.20 & 18.75 & 17.99 & 21.16 & 14.34 & 12.30 & 12.01 & 12.59 & 12.10 & 11.21 \\
\hline & Cooling & 3.36 & 3.53 & 2.39 & 3.54 & 2.92 & 5.12 & 1.93 & 2.65 & 2.18 & 1.85 & 1.81 & 1.32 & 1.46 & 1.10 & 1.09 & 0.76 \\
\hline & Fans & 2.81 & 2.24 & 2.43 & 2.05 & 1.40 & 0.52 & 0.67 & -0.86 & 0.88 & -0.75 & 0.51 & -0.01 & -0.05 & -1.00 & -1.09 & -0.80 \\
\hline & Pumps & 0.44 & 0.47 & 0.34 & 0.46 & 0.43 & 0.42 & 0.27 & 0.38 & 0.40 & 0.34 & 0.30 & 0.24 & 0.28 & 0.23 & 0.23 & 0.15 \\
\hline & Total & 12.82 & 18.13 & 16.93 & 21.02 & 20.94 & 20.33 & 18.07 & 20.92 & 21.45 & 22.60 & 16.96 & 13.85 & 13.70 & 12.92 & 12.33 & 11.32 \\
\hline \multirow{5}{*}{ Combo 3} & Heating & 7.39 & 10.19 & 10.07 & 11.15 & 11.64 & 10.10 & 10.59 & 11.66 & 12.40 & 12.78 & 9.91 & 8.83 & 8.75 & 8.80 & 8.55 & 7.90 \\
\hline & Cooling & 3.53 & 3.41 & 1.97 & 2.45 & 2.37 & 3.78 & 1.52 & 1.57 & 1.83 & 1.24 & 1.72 & 0.99 & 1.25 & 0.75 & 0.80 & 0.47 \\
\hline & Fans & 2.33 & 2.72 & 2.99 & 3.19 & 2.94 & 2.53 & 3.15 & 2.67 & 2.93 & 2.81 & 2.54 & 2.76 & 2.48 & 2.60 & 2.49 & 2.51 \\
\hline & Pumps & 0.48 & 0.49 & 0.33 & 0.41 & 0.42 & 0.40 & 0.29 & 0.32 & 0.40 & 0.31 & 0.30 & 0.25 & 0.26 & 0.23 & 0.22 & 0.12 \\
\hline & Total & 13.73 & 16.81 & 15.36 & 17.20 & 17.37 & 16.81 & 15.55 & 16.22 & 17.56 & 17.14 & 14.47 & 12.83 & 12.74 & 12.38 & 12.06 & 11.00 \\
\hline
\end{tabular}




\begin{tabular}{|c|c|c|c|c|c|c|c|c|c|c|c|c|c|c|c|c|c|}
\hline 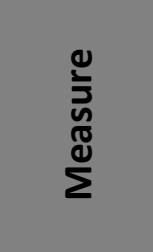 & 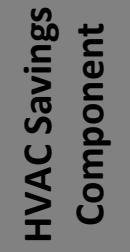 & $\begin{array}{l}\frac{E}{0} \\
\frac{0}{2}\end{array}$ & $\begin{array}{l}\text { 응 } \\
\text { 놀 } \\
\text { 오 }\end{array}$ & $\begin{array}{l}\frac{x}{2} \\
\frac{0}{2} \\
\frac{0}{2}\end{array}$ & 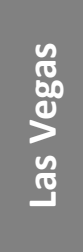 & $\frac{\mathbb{8}}{\frac{0}{0}}$ & $\begin{array}{l}\frac{y}{0} \\
\frac{0}{0} \\
\frac{5}{4} \\
y \\
0\end{array}$ & $\begin{array}{l}\frac{0}{2} \\
\frac{0}{0} \\
\frac{0}{2} \\
\frac{0}{\partial} \\
\frac{0}{4}\end{array}$ & $\begin{array}{l}\frac{8}{8} \\
\frac{n}{8} \\
\frac{2}{0} \\
\frac{2}{2} \\
\frac{5}{7}\end{array}$ & $\frac{\text { 을 }}{\frac{2}{2}}$ & 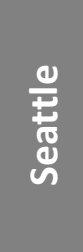 & $\begin{array}{l}\text { 잉 } \\
\text { 엉 } \\
\text { 을 }\end{array}$ & $\begin{array}{l}\frac{1}{0} \\
\frac{0}{3} \\
0\end{array}$ & 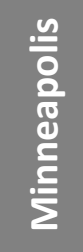 & $\frac{\text { 인 }}{\frac{0}{\text { d }}}$ & $\frac{5}{\frac{5}{3}}$ & $\begin{array}{l}\frac{y}{\frac{y}{0}} \\
\frac{0}{\frac{0}{0}} \\
\frac{10}{10}\end{array}$ \\
\hline \multirow{5}{*}{ Combo 4} & Heating & 7.40 & 10.21 & 10.07 & 11.16 & 11.69 & 10.10 & 10.65 & 11.67 & 12.47 & 12.80 & 10.05 & 8.91 & 9.02 & 8.97 & 8.92 & 8.72 \\
\hline & Cooling & 3.10 & 3.00 & 1.44 & 2.06 & 1.99 & 3.42 & 1.28 & 1.32 & 1.54 & 1.04 & 1.46 & 0.82 & 1.00 & 0.61 & 0.65 & 0.39 \\
\hline & Fans & 0.29 & 0.69 & 0.55 & 0.86 & 0.92 & 0.64 & 0.93 & 0.95 & 1.02 & 1.02 & 0.72 & 0.80 & 0.63 & 0.77 & 0.64 & 0.54 \\
\hline & Pumps & 0.45 & 0.46 & 0.31 & 0.39 & 0.40 & 0.38 & 0.28 & 0.32 & 0.38 & 0.30 & 0.29 & 0.24 & 0.25 & 0.22 & 0.22 & 0.12 \\
\hline & Total & 11.24 & 14.36 & 12.37 & 14.47 & 15.00 & 14.54 & 13.14 & 14.26 & 15.41 & 15.16 & 12.52 & 10.77 & 10.90 & 10.57 & 10.43 & 9.77 \\
\hline \multirow{5}{*}{ Combo 5} & Heating & 8.83 & 14.57 & 14.56 & 17.20 & 18.23 & 15.45 & 16.24 & 19.60 & 19.80 & 22.34 & 15.10 & 12.76 & 12.30 & 12.83 & 12.06 & 10.90 \\
\hline & Cooling & 7.06 & 6.31 & 3.83 & 4.71 & 4.52 & 5.23 & 2.20 & 2.68 & 3.17 & 2.00 & 2.75 & 1.36 & 1.85 & 1.09 & 1.09 & 0.76 \\
\hline & Fans & 3.12 & 2.78 & 2.78 & 3.44 & 2.12 & 1.04 & 1.99 & -0.13 & 1.65 & 0.20 & 0.98 & 0.71 & 0.42 & -0.31 & -0.50 & 0.17 \\
\hline & Pumps & 0.33 & 0.41 & 0.25 & 0.44 & 0.40 & 0.40 & 0.29 & 0.37 & 0.38 & 0.33 & 0.27 & 0.23 & 0.23 & 0.22 & 0.21 & 0.14 \\
\hline & Total & 19.34 & 24.07 & 21.42 & 25.79 & 25.27 & 22.12 & 20.72 & 22.52 & 25.00 & 24.87 & 19.10 & 15.06 & 14.80 & 13.83 & 12.86 & 11.97 \\
\hline \multirow{5}{*}{ Combo 6} & Heating & 9.64 & 15.80 & 15.75 & 18.52 & 19.34 & 16.43 & 17.79 & 20.58 & 20.78 & 23.37 & 15.45 & 13.63 & 12.71 & 13.42 & 12.61 & 14.19 \\
\hline & Cooling & 7.39 & 6.49 & 4.54 & 5.64 & 4.71 & 6.25 & 3.09 & 3.07 & 3.31 & 2.26 & 3.10 & 2.11 & 2.11 & 1.57 & 1.37 & 0.90 \\
\hline & Fans & 4.02 & 3.85 & 4.13 & 5.12 & 3.56 & 2.78 & 4.47 & 2.17 & 3.28 & 2.45 & 2.71 & 3.18 & 2.31 & 2.30 & 1.72 & 2.14 \\
\hline & Pumps & 0.14 & 0.21 & 0.11 & 0.21 & 0.18 & 0.26 & 0.16 & 0.19 & 0.13 & 0.13 & 0.06 & 0.09 & 0.04 & 0.05 & 0.03 & 0.01 \\
\hline & Total & 21.19 & 26.35 & 24.53 & 29.49 & 27.79 & 25.72 & 25.51 & 26.01 & 27.50 & 28.21 & 21.32 & 19.01 & 17.17 & 17.34 & 15.73 & 17.24 \\
\hline
\end{tabular}


Appendix B:

Regression Equations for Generalization of Savings 
Table B-1: Regression Equation Coefficients for Pre-1980 Building HVAC Energy Savings (All Measures)

\begin{tabular}{|c|c|c|c|c|c|c|c|c|c|}
\hline \multirow{3}{*}{$\#$} & \multirow{3}{*}{ 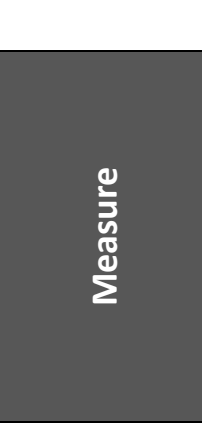 } & \multirow{3}{*}{$\tilde{c}$} & \multicolumn{7}{|c|}{ Coefficients of Regression Equation } \\
\hline & & & $\begin{array}{l}\frac{2}{0} \\
\frac{5}{0} \\
\frac{5}{0}\end{array}$ & 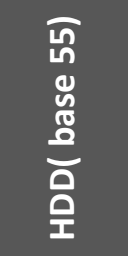 & $\begin{array}{l}\text { n } \\
\text { บ } \\
\frac{0}{0} \\
\frac{0}{0}\end{array}$ & 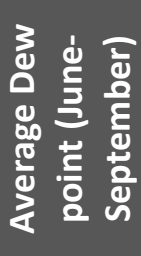 & 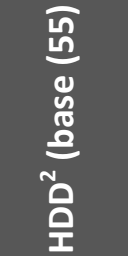 & 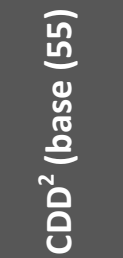 & 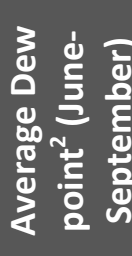 \\
\hline & & & a & b & C & d & e & f & $g$ \\
\hline \multirow{3}{*}{ A01a } & \multirow{3}{*}{$\begin{array}{c}\text { HVAC } \\
\text { Schedules Start } \\
2 \text { Hours Late }\end{array}$} & 0.85 & 0.0832 & $-2.45 \mathrm{E}-06$ & $-6.91 E-06$ & 7.05E-03 & $-7.00 \mathrm{E}-10$ & $1.53 \mathrm{E}-10$ & $-6.09 \mathrm{E}-05$ \\
\hline & & 0.81 & 0.2880 & $-1.86 \mathrm{E}-06$ & $-9.43 E-06$ & & $-8.50 \mathrm{E}-10$ & $2.64 \mathrm{E}-10$ & \\
\hline & & 0.70 & 0.2449 & $6.73 E-06$ & & & $-1.33 \mathrm{E}-09$ & & \\
\hline \multirow{3}{*}{$A 01 b$} & \multirow{3}{*}{$\begin{array}{c}\text { HVAC } \\
\text { Schedules Start } \\
4 \text { Hours Late }\end{array}$} & 0.92 & 0.2829 & $-4.94 \mathrm{E}-06$ & $-1.36 \mathrm{E}-05$ & $4.31 \mathrm{E}-03$ & $-9.41 \mathrm{E}-10$ & $1.71 \mathrm{E}-10$ & $-3.41 \mathrm{E}-05$ \\
\hline & & 0.90 & 0.4180 & $-4.38 \mathrm{E}-06$ & $-1.57 \mathrm{E}-05$ & & $-1.08 \mathrm{E}-09$ & $3.58 \mathrm{E}-10$ & \\
\hline & & 0.72 & 0.3434 & $1.08 \mathrm{E}-05$ & & & $-1.94 \mathrm{E}-09$ & & \\
\hline \multirow{3}{*}{ A02 } & \multirow{3}{*}{ SP Reset } & 0.67 & 0.0772 & $1.03 \mathrm{E}-06$ & $-2.05 E-06$ & $-8.05 E-04$ & $-2.90 \mathrm{E}-10$ & $3.39 \mathrm{E}-10$ & $5.41 \mathrm{E}-06$ \\
\hline & & 0.61 & 0.0489 & $8.64 \mathrm{E}-07$ & $-1.49 E-06$ & & $-2.49 \mathrm{E}-10$ & $2.68 \mathrm{E}-10$ & \\
\hline & & 0.57 & 0.0498 & $-1.86 \mathrm{E}-07$ & & & $-1.62 \mathrm{E}-10$ & & \\
\hline \multirow{3}{*}{$\mathrm{A03a}$} & \multirow{3}{*}{$\begin{array}{c}\text { SAT Reset } \\
\text { Based on OAT }\end{array}$} & 0.99 & 0.0677 & $9.76 \mathrm{E}-06$ & $-2.73 E-05$ & $6.41 \mathrm{E}-03$ & $-1.54 \mathrm{E}-09$ & $8.95 \mathrm{E}-10$ & $-6.70 \mathrm{E}-05$ \\
\hline & & 0.96 & 0.2176 & $9.58 \mathrm{E}-06$ & $-2.76 \mathrm{E}-05$ & & $-1.49 \mathrm{E}-09$ & $5.61 \mathrm{E}-10$ & \\
\hline & & 0.61 & 0.0844 & $3.69 \mathrm{E}-05$ & & & $-3.04 \mathrm{E}-09$ & & \\
\hline \multirow{3}{*}{$\mathrm{A} 03 \mathrm{~b}$} & \multirow{3}{*}{$\begin{array}{l}\text { SAT Reset : } \\
\text { Alternate } \\
\text { Method }\end{array}$} & 0.98 & 0.0796 & $-2.31 \mathrm{E}-05$ & $-4.31 \mathrm{E}-05$ & $1.64 \mathrm{E}-02$ & $-1.62 \mathrm{E}-10$ & $-9.64 \mathrm{E}-10$ & $-1.62 \mathrm{E}-04$ \\
\hline & & 0.95 & 0.4927 & $-2.29 \mathrm{E}-05$ & $-4.55 E-05$ & & $-2.01 \mathrm{E}-10$ & $-1.46 \mathrm{E}-09$ & \\
\hline & & 0.28 & 0.1914 & $4.76 \mathrm{E}-05$ & & & $-4.48 \mathrm{E}-09$ & & \\
\hline \multirow{3}{*}{$\mathrm{A} 04 \mathrm{a}$} & \multirow{3}{*}{$\begin{array}{c}\text { SAT Set point }= \\
53\end{array}$} & 0.77 & -0.1465 & $3.30 \mathrm{E}-06$ & $2.04 \mathrm{E}-05$ & $-1.19 \mathrm{E}-03$ & $3.56 \mathrm{E}-10$ & $-1.74 \mathrm{E}-09$ & $1.04 \mathrm{E}-05$ \\
\hline & & 0.76 & -0.1807 & $3.21 \mathrm{E}-06$ & $2.08 \mathrm{E}-05$ & & $3.79 \mathrm{E}-10$ & $-1.76 \mathrm{E}-09$ & \\
\hline & & 0.43 & -0.1255 & $-3.24 \mathrm{E}-06$ & & & $5.87 \mathrm{E}-10$ & & \\
\hline \multirow{3}{*}{$A 04 b$} & \multirow{3}{*}{$\begin{array}{c}\text { SAT Set point }= \\
54\end{array}$} & 0.66 & -0.0809 & $1.81 \mathrm{E}-06$ & $1.27 \mathrm{E}-05$ & $-5.26 E-04$ & $1.91 \mathrm{E}-10$ & $-1.13 E-09$ & $5.43 \mathrm{E}-06$ \\
\hline & & 0.66 & -0.0934 & $1.82 \mathrm{E}-06$ & $1.27 \mathrm{E}-05$ & & $1.89 \mathrm{E}-10$ & $-1.10 \mathrm{E}-09$ & \\
\hline & & 0.29 & -0.0607 & $-1.79 \mathrm{E}-06$ & & & $2.94 \mathrm{E}-10$ & & \\
\hline
\end{tabular}




\begin{tabular}{|c|c|c|c|c|c|c|c|c|c|}
\hline \multirow[t]{2}{*}{ \# } & \multirow[t]{2}{*}{ 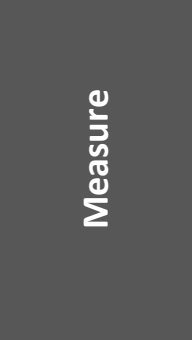 } & \multirow[t]{2}{*}{$\widetilde{N}$} & $\begin{array}{l}\text { है } \\
\text { है } \\
\frac{\text { th }}{0}\end{array}$ & 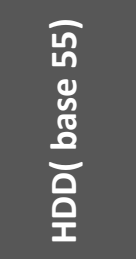 & 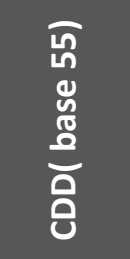 & 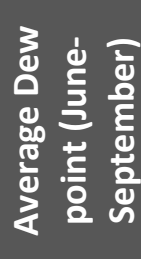 & 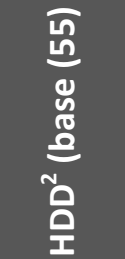 & 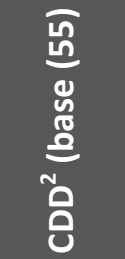 & 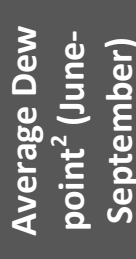 \\
\hline & & & a & b & C & d & e & $f$ & g \\
\hline \multirow{3}{*}{ A04c } & \multirow{3}{*}{$\begin{array}{c}\text { SAT Set point }= \\
56\end{array}$} & 0.82 & 0.0088 & $-2.42 \mathrm{E}-06$ & $-5.01 E-06$ & $2.65 \mathrm{E}-03$ & $-6.15 E-11$ & $3.53 \mathrm{E}-10$ & $-2.47 \mathrm{E}-05$ \\
\hline & & 0.76 & 0.0799 & $-2.31 \mathrm{E}-06$ & $-5.63 E-06$ & & $-8.93 E-11$ & $3.25 \mathrm{E}-10$ & \\
\hline & & 0.51 & 0.0598 & $1.04 \mathrm{E}-06$ & & & $-2.54 \mathrm{E}-10$ & & \\
\hline \multirow{3}{*}{ A04d } & \multirow{3}{*}{$\begin{array}{c}\text { SAT Set point }= \\
57\end{array}$} & 0.98 & -0.0503 & $-4.19 \mathrm{E}-06$ & $3.12 \mathrm{E}-07$ & 7.33E-03 & $-1.06 \mathrm{E}-10$ & $-7.12 \mathrm{E}-10$ & $-7.03 E-05$ \\
\hline & & 0.86 & 0.1410 & $-4.00 \mathrm{E}-06$ & $-1.10 \mathrm{E}-06$ & & $-1.55 \mathrm{E}-10$ & $-8.55 \mathrm{E}-10$ & \\
\hline & & 0.41 & 0.1058 & $6.45 \mathrm{E}-06$ & & & $-8.51 E-10$ & & \\
\hline \multirow{3}{*}{ A04e } & \multirow{3}{*}{$\begin{array}{c}\text { SAT Set point }= \\
58\end{array}$} & 0.99 & -0.1633 & $-4.77 \mathrm{E}-06$ & $6.94 \mathrm{E}-06$ & 1.37E-02 & $-2.07 \mathrm{E}-10$ & $-1.80 \mathrm{E}-09$ & $-1.32 \mathrm{E}-04$ \\
\hline & & 0.85 & 0.1920 & $-4.46 \mathrm{E}-06$ & $4.41 \mathrm{E}-06$ & & $-2.90 \mathrm{E}-10$ & $-2.09 \mathrm{E}-09$ & \\
\hline & & 0.38 & 0.1450 & $1.25 \mathrm{E}-05$ & & & $-1.49 \mathrm{E}-09$ & & \\
\hline \multirow{3}{*}{ A05 } & \multirow{3}{*}{$\begin{array}{c}\text { Damper } \\
\text { Minimum Air } \\
\text { flow } 30 \%\end{array}$} & 0.99 & 0.2223 & $-1.18 \mathrm{E}-05$ & $-8.65 E-06$ & $7.24 \mathrm{E}-03$ & $-5.72 \mathrm{E}-10$ & $-1.78 \mathrm{E}-10$ & $-6.46 \mathrm{E}-05$ \\
\hline & & 0.98 & 0.4263 & $-1.13 E-05$ & $-1.09 E-05$ & & $-6.95 E-10$ & $-1.39 \mathrm{E}-10$ & \\
\hline & & 0.85 & 0.3613 & $3.35 \mathrm{E}-06$ & & & $-1.57 \mathrm{E}-09$ & & \\
\hline \multirow{3}{*}{ A06 } & \multirow{3}{*}{$\begin{array}{c}\text { Wider } \\
\text { Deadband }\end{array}$} & 0.89 & 0.2664 & $-3.64 \mathrm{E}-06$ & $-3.99 E-06$ & $-3.44 \mathrm{E}-03$ & $-3.29 E-10$ & $3.40 \mathrm{E}-10$ & $2.95 \mathrm{E}-05$ \\
\hline & & 0.87 & 0.1658 & $-3.95 E-06$ & $-2.72 \mathrm{E}-06$ & & $-2.53 \mathrm{E}-10$ & $2.77 \mathrm{E}-10$ & \\
\hline & & 0.87 & 0.1602 & $-3.60 \mathrm{E}-06$ & & & $-2.46 \mathrm{E}-10$ & & \\
\hline \multirow{3}{*}{ A07 } & \multirow{3}{*}{$\begin{array}{c}\text { Minimum } \\
\text { Occupied OA } \\
\text { Schedule starts } \\
\text { 7AM }\end{array}$} & 1.00 & 0.0095 & $-5.36 \mathrm{E}-07$ & $4.53 \mathrm{E}-07$ & $-5.62 E-04$ & $4.45 \mathrm{E}-10$ & $2.90 \mathrm{E}-12$ & $6.64 \mathrm{E}-06$ \\
\hline & & 0.98 & -0.0012 & $-4.72 \mathrm{E}-07$ & $3.42 \mathrm{E}-07$ & & $4.30 \mathrm{E}-10$ & $6.10 \mathrm{E}-11$ & \\
\hline & & 0.97 & 0.0028 & $-1.54 \mathrm{E}-06$ & & & $4.98 \mathrm{E}-10$ & & \\
\hline \multirow{3}{*}{ W01 } & \multirow{3}{*}{$\begin{array}{l}\text { Chilled-water } \\
\text { DP Reset }\end{array}$} & 0.48 & -0.0267 & $-1.18 \mathrm{E}-07$ & $3.08 \mathrm{E}-06$ & $8.22 \mathrm{E}-04$ & $3.54 \mathrm{E}-11$ & $-2.99 \mathrm{E}-10$ & $-7.03 E-06$ \\
\hline & & 0.36 & -0.0025 & $-4.49 \mathrm{E}-08$ & 2.77E-06 & & 1.67E-11 & $-2.84 \mathrm{E}-10$ & \\
\hline & & 0.16 & 0.0031 & $-3.78 \mathrm{E}-07$ & & & $8.91 \mathrm{E}-12$ & & \\
\hline \multirow{3}{*}{ W02 } & \multirow{3}{*}{$\begin{array}{c}\text { Chilled-water } \\
\text { Temperature } \\
\text { Reset }\end{array}$} & 0.60 & -0.1741 & $-1.67 \mathrm{E}-07$ & $1.41 \mathrm{E}-05$ & $6.45 \mathrm{E}-03$ & $6.80 \mathrm{E}-11$ & $-1.05 E-09$ & $-6.02 E-05$ \\
\hline & & 0.47 & -0.0006 & $9.75 \mathrm{E}-08$ & $1.26 \mathrm{E}-05$ & & $-8.10 \mathrm{E}-13$ & $-1.11 E-09$ & \\
\hline & & 0.32 & 0.0311 & $-3.27 \mathrm{E}-06$ & & & $8.95 \mathrm{E}-11$ & & \\
\hline
\end{tabular}




\begin{tabular}{|c|c|c|c|c|c|c|c|c|c|}
\hline \multirow[t]{2}{*}{ \# } & \multirow[t]{2}{*}{ 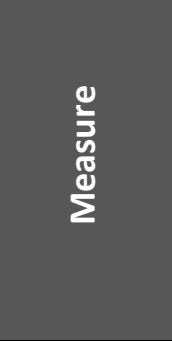 } & \multirow[t]{2}{*}{ } & $\begin{array}{l}\text { tै } \\
\text { है } \\
\frac{\text { पे }}{0} \\
\text { 8 }\end{array}$ & 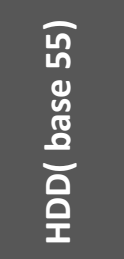 & 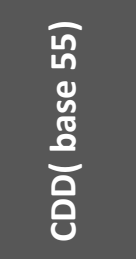 & 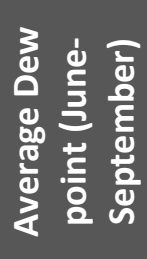 & 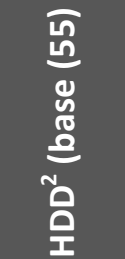 & 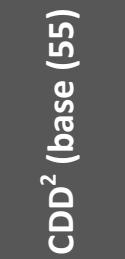 & 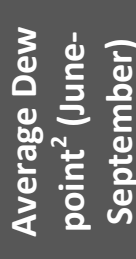 \\
\hline & & & a & b & C & d & e & f & g \\
\hline \multirow{3}{*}{ W03 } & \multirow{3}{*}{$\begin{array}{c}\text { Hot-water } \\
\text { Temperature } \\
\text { Reset }\end{array}$} & 0.60 & 0.0022 & $2.41 \mathrm{E}-07$ & $-1.41 \mathrm{E}-07$ & $-1.22 \mathrm{E}-04$ & $-1.59 \mathrm{E}-11$ & $1.59 \mathrm{E}-11$ & $1.26 \mathrm{E}-06$ \\
\hline & & 0.47 & -0.0007 & $2.43 \mathrm{E}-07$ & $-1.34 \mathrm{E}-07$ & & $-1.65 E-11$ & $2.18 \mathrm{E}-11$ & \\
\hline & & 0.32 & -0.0007 & $1.73 \mathrm{E}-07$ & & & $-1.03 \mathrm{E}-11$ & & \\
\hline \multirow{3}{*}{ W04 } & \multirow{3}{*}{$\begin{array}{c}\text { Hot-water DP } \\
\text { Reset }\end{array}$} & 0.99 & 0.0000 & $1.25 \mathrm{E}-08$ & $2.97 \mathrm{E}-10$ & $1.01 \mathrm{E}-06$ & $-8.67 E-12$ & $-1.31 \mathrm{E}-13$ & $-1.47 \mathrm{E}-08$ \\
\hline & & 0.99 & 0.0000 & $1.22 \mathrm{E}-08$ & $9.80 \mathrm{E}-10$ & & $-8.60 \mathrm{E}-12$ & $-3.39 \mathrm{E}-13$ & \\
\hline & & 0.99 & 0.0000 & $1.46 \mathrm{E}-08$ & & & $-8.77 \mathrm{E}-12$ & & \\
\hline \multirow{4}{*}{ W05 } & \multirow{4}{*}{$\begin{array}{l}\text { Condenser } \\
\text { Water } \\
\text { Temperature } \\
\text { Reset }\end{array}$} & 0.96 & -0.0180 & $-1.89 \mathrm{E}-06$ & $2.99 \mathrm{E}-06$ & $1.10 \mathrm{E}-03$ & $1.18 \mathrm{E}-10$ & $-2.84 \mathrm{E}-10$ & $-1.22 \mathrm{E}-05$ \\
\hline & & 0.67 & 0.0055 & $-1.96 \mathrm{E}-06$ & $3.07 \mathrm{E}-06$ & & $1.37 \mathrm{E}-10$ & $-3.69 \mathrm{E}-10$ & \\
\hline & & 0.57 & 00099 & $-175 \mathrm{~F}_{-06}$ & & & 800511 & & \\
\hline & & 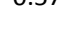 & כתטס. & 1.7 L & & & 0.00 & & \\
\hline \multirow{3}{*}{ W06 } & \multirow{3}{*}{$\begin{array}{l}\text { Plant Shut } \\
\text { Down When } \\
\text { There Is No } \\
\text { Load }\end{array}$} & 0.99 & -0.0089 & $4.24 \mathrm{E}-06$ & $-9.90 \mathrm{E}-08$ & $2.79 \mathrm{E}-04$ & $-2.49 \mathrm{E}-10$ & $2.70 \mathrm{E}-11$ & $-2.33 \mathrm{E}-06$ \\
\hline & & 0.99 & -0.0005 & 4.27E-06 & $-2.14 \mathrm{E}-07$ & & $-2.57 \mathrm{E}-10$ & $3.46 \mathrm{E}-11$ & \\
\hline & & 0.99 & -0.0005 & 4.16E-06 & & & $-2.47 \mathrm{E}-10$ & & \\
\hline \multirow{3}{*}{$\mathrm{CO1}$} & \multirow{3}{*}{ Combo 1} & 0.96 & 0.6354 & $-3.38 \mathrm{E}-05$ & $-1.76 \mathrm{E}-05$ & $6.74 \mathrm{E}-03$ & $-8.05 E-10$ & $-1.57 \mathrm{E}-09$ & $-7.54 \mathrm{E}-05$ \\
\hline & & 0.94 & 0.7773 & $-3.43 E-05$ & $-1.70 \mathrm{E}-05$ & & $-6.84 \mathrm{E}-10$ & $-2.11 E-09$ & \\
\hline & & 0.72 & 0.6111 & $8.83 \mathrm{E}-06$ & & & $-3.42 E-09$ & & \\
\hline \multirow{3}{*}{$\mathrm{CO} 2$} & \multirow{3}{*}{ Combo 2} & 0.97 & 0.1835 & $-1.48 \mathrm{E}-05$ & $-2.64 \mathrm{E}-05$ & $1.64 \mathrm{E}-02$ & $-1.19 \mathrm{E}-09$ & $-9.10 E-10$ & $-1.56 \mathrm{E}-04$ \\
\hline & & 0.94 & 0.6156 & $-1.43 E-05$ & $-2.98 \mathrm{E}-05$ & & $-1.32 \mathrm{E}-09$ & $-1.18 \mathrm{E}-09$ & \\
\hline & & 0.47 & 0.4105 & $3.43 \mathrm{E}-05$ & & & $-4.29 \mathrm{E}-09$ & & \\
\hline \multirow{3}{*}{$\mathrm{CO3}$} & \multirow{3}{*}{ Combo 3} & 0.94 & 0.1480 & $-4.83 E-06$ & $-7.40 \mathrm{E}-06$ & $1.03 \mathrm{E}-02$ & $-1.03 E-09$ & $-5.52 E-10$ & $-9.56 \mathrm{E}-05$ \\
\hline & & 0.91 & 0.4243 & $-4.40 \mathrm{E}-06$ & $-9.85 E-06$ & & $-1.15 E-09$ & $-6.50 \mathrm{E}-10$ & \\
\hline & & 0.69 & 0.3477 & $1.44 \mathrm{E}-05$ & & & $-2.31 E-09$ & & \\
\hline \multirow{3}{*}{$\mathrm{CO4}$} & \multirow{3}{*}{ Combo 4} & 0.94 & 0.1147 & $-5.93 E-06$ & $-9.63 E-06$ & $9.94 \mathrm{E}-03$ & $-7.91 \mathrm{E}-10$ & $-3.83 E-10$ & $-8.96 \mathrm{E}-05$ \\
\hline & & 0.90 & 0.3921 & $-5.32 E-06$ & $-1.26 \mathrm{E}-05$ & & $-9.47 E-10$ & $-3.63 \mathrm{E}-10$ & \\
\hline & & 0.63 & 0.3103 & $1.37 \mathrm{E}-05$ & & & $-2.10 \mathrm{E}-09$ & & \\
\hline
\end{tabular}




\begin{tabular}{|c|c|c|c|c|c|c|c|c|c|}
\hline \multirow[t]{2}{*}{ \# } & \multirow[t]{2}{*}{ 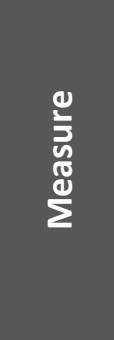 } & \multirow[t]{2}{*}{ N } & 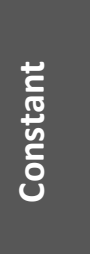 & 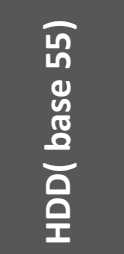 & 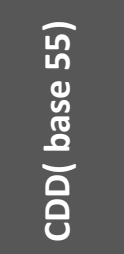 & 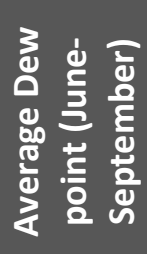 & 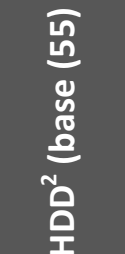 & 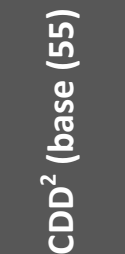 & 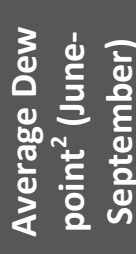 \\
\hline & & & a & b & C & d & e & $f$ & g \\
\hline \multirow{3}{*}{ C05 } & \multirow{3}{*}{ Combo 5} & 0.94 & 0.4979 & $-2.37 E-05$ & $-1.46 \mathrm{E}-05$ & $8.15 \mathrm{E}-03$ & $-9.90 E-10$ & $-1.53 E-09$ & $-7.99 \mathrm{E}-05$ \\
\hline & & 0.93 & 0.7050 & $-2.36 \mathrm{E}-05$ & $-1.58 \mathrm{E}-05$ & & $-1.02 \mathrm{E}-09$ & $-1.76 \mathrm{E}-09$ & \\
\hline & & 0.69 & 0.5574 & $1.43 \mathrm{E}-05$ & & & $-3.41 E-09$ & & \\
\hline \multirow{3}{*}{ C06 } & \multirow{3}{*}{ Combo 6} & 0.94 & 0.5783 & $-2.80 \mathrm{E}-05$ & $-1.66 \mathrm{E}-05$ & $8.34 \mathrm{E}-03$ & $-4.53 E-10$ & $-1.51 \mathrm{E}-09$ & $-8.78 \mathrm{E}-05$ \\
\hline & & 0.92 & 0.7716 & $-2.83 \mathrm{E}-05$ & $-1.68 \mathrm{E}-05$ & & $-3.89 \mathrm{E}-10$ & $-1.96 \mathrm{E}-09$ & \\
\hline & & 0.60 & 0.6117 & $1.29 \mathrm{E}-05$ & & & $-3.00 \mathrm{E}-09$ & & \\
\hline
\end{tabular}


Table B-2: Regression Equation Coefficients for Post-1980 Building HVAC Energy Savings (All Measures)

\begin{tabular}{|c|c|c|c|c|c|c|c|c|c|}
\hline \multirow{3}{*}{$\#$} & \multirow{3}{*}{ 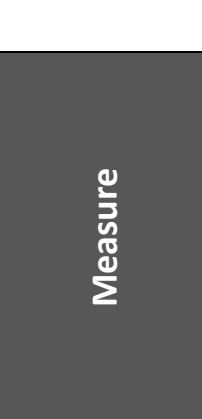 } & \multirow{3}{*}{$\widetilde{N}$} & \multicolumn{7}{|c|}{ Coefficients of Regression Equation } \\
\hline & & & $\frac{t}{\frac{t}{8}}$ & 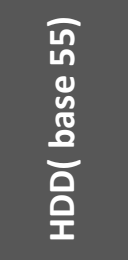 & 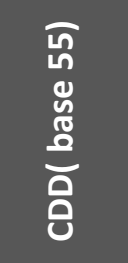 & 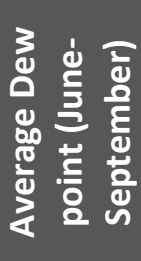 & 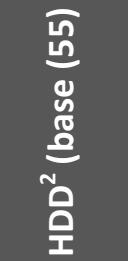 & 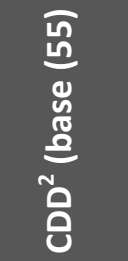 & 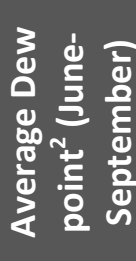 \\
\hline & & & a & $b$ & C & d & e & $f$ & $g$ \\
\hline \multirow{3}{*}{ A01a } & \multirow{3}{*}{$\begin{array}{c}\text { HVAC } \\
\text { Schedules Start } \\
2 \text { Hours Late }\end{array}$} & 0.98 & 0.2092 & $-6.83 \mathrm{E}-06$ & $-1.41 \mathrm{E}-05$ & $3.41 \mathrm{E}-03$ & $-5.33 \mathrm{E}-10$ & $-1.40 \mathrm{E}-10$ & $-2.63 \mathrm{E}-05$ \\
\hline & & 0.96 & 0.3182 & $-6.34 \mathrm{E}-06$ & $-1.59 \mathrm{E}-05$ & & $-6.55 E-10$ & $3.36 \mathrm{E}-11$ & \\
\hline & & 0.56 & 0.2314 & $1.25 \mathrm{E}-05$ & & & $-1.76 \mathrm{E}-09$ & & \\
\hline \multirow{3}{*}{$A 01 b$} & \multirow{3}{*}{$\begin{array}{c}\text { HVAC } \\
\text { Schedules Start } \\
4 \text { Hours Late }\end{array}$} & 0.99 & 0.3957 & $-6.27 \mathrm{E}-06$ & $-1.98 \mathrm{E}-05$ & 8.77E-04 & $-1.02 \mathrm{E}-09$ & $-2.25 \mathrm{E}-10$ & $-3.17 \mathrm{E}-06$ \\
\hline & & 0.98 & 0.4351 & $-5.93 E-06$ & $-2.09 E-05$ & & $-1.10 \mathrm{E}-09$ & $-4.50 \mathrm{E}-11$ & \\
\hline & & 0.59 & 0.3181 & $1.98 \mathrm{E}-05$ & & & $-2.62 \mathrm{E}-09$ & & \\
\hline \multirow{3}{*}{$\mathrm{A} 02$} & \multirow{3}{*}{ SP Reset } & 0.77 & 0.0299 & $1.08 \mathrm{E}-06$ & $-2.10 \mathrm{E}-06$ & $1.62 \mathrm{E}-03$ & $-3.70 \mathrm{E}-10$ & $3.25 \mathrm{E}-10$ & $-1.66 \mathrm{E}-05$ \\
\hline & & 0.73 & 0.0691 & $1.06 \mathrm{E}-06$ & $-2.23 \mathrm{E}-06$ & & $-3.65 \mathrm{E}-10$ & $2.55 \mathrm{E}-10$ & \\
\hline & & 0.72 & 0.0654 & $1.04 \mathrm{E}-06$ & & & $-3.40 \mathrm{E}-10$ & & \\
\hline \multirow{3}{*}{$\mathrm{A03a}$} & \multirow{3}{*}{$\begin{array}{c}\text { SAT Reset } \\
\text { Based on OAT }\end{array}$} & 0.96 & 0.0715 & $3.91 \mathrm{E}-06$ & $-2.80 \mathrm{E}-05$ & $6.08 \mathrm{E}-03$ & $-1.30 \mathrm{E}-09$ & $8.20 \mathrm{E}-10$ & $-6.15 E-05$ \\
\hline & & 0.94 & 0.2198 & $3.86 \mathrm{E}-06$ & $-2.86 \mathrm{E}-05$ & & $-1.29 \mathrm{E}-09$ & $5.78 \mathrm{E}-10$ & \\
\hline & & 0.51 & 0.0813 & $3.23 \mathrm{E}-05$ & & & $-2.90 \mathrm{E}-09$ & & \\
\hline \multirow{3}{*}{$\mathrm{A} 03 \mathrm{~b}$} & \multirow{3}{*}{$\begin{array}{l}\text { SAT Reset : } \\
\text { Alternate } \\
\text { Method }\end{array}$} & 0.92 & -0.0150 & $-4.05 E-05$ & $-3.39 E-05$ & $1.84 \mathrm{E}-02$ & $9.77 \mathrm{E}-10$ & $-1.89 \mathrm{E}-09$ & $-1.76 \mathrm{E}-04$ \\
\hline & & 0.90 & 0.4699 & $-4.00 \mathrm{E}-05$ & $-3.76 \mathrm{E}-05$ & & $8.35 \mathrm{E}-10$ & $-2.21 \mathrm{E}-09$ & \\
\hline & & 0.20 & 0.1865 & $2.91 \mathrm{E}-05$ & & & $-3.43 E-09$ & & \\
\hline \multirow{3}{*}{$\mathrm{A} 04 \mathrm{a}$} & \multirow{3}{*}{$\begin{array}{c}\text { SAT Set point }= \\
53\end{array}$} & 0.91 & 0.1698 & $1.50 \mathrm{E}-06$ & $9.58 \mathrm{E}-06$ & $-1.25 \mathrm{E}-02$ & $4.40 \mathrm{E}-10$ & $-4.54 \mathrm{E}-10$ & $1.20 \mathrm{E}-04$ \\
\hline & & 0.71 & -0.1558 & $1.20 \mathrm{E}-06$ & $1.20 \mathrm{E}-05$ & & $5.22 \mathrm{E}-10$ & $-2.03 E-10$ & \\
\hline & & 0.36 & -0.0966 & $-1.11 E-05$ & & & $1.22 \mathrm{E}-09$ & & \\
\hline \multirow{3}{*}{$A 04 b$} & \multirow{3}{*}{$\begin{array}{c}\text { SAT Set point }= \\
54\end{array}$} & 0.90 & -0.0002 & $1.18 \mathrm{E}-06$ & 7.51E-06 & $-2.99 \mathrm{E}-03$ & $2.02 \mathrm{E}-10$ & $-5.64 \mathrm{E}-10$ & $2.84 \mathrm{E}-05$ \\
\hline & & 0.83 & -0.0794 & 1.09E-06 & $8.15 E-06$ & & $2.28 \mathrm{E}-10$ & $-5.18 \mathrm{E}-10$ & \\
\hline & & 0.46 & -0.0520 & $-3.25 \mathrm{E}-06$ & & & $4.32 \mathrm{E}-10$ & & \\
\hline
\end{tabular}




\begin{tabular}{|c|c|c|c|c|c|c|c|c|c|}
\hline \multirow[t]{2}{*}{ \# } & \multirow[t]{2}{*}{ 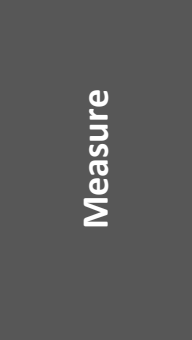 } & \multirow[t]{2}{*}{$\widetilde{N}$} & $\begin{array}{l}\text { है } \\
\text { है } \\
\frac{\text { th }}{0}\end{array}$ & 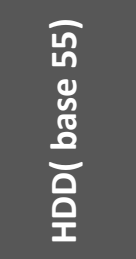 & 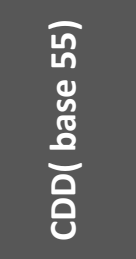 & 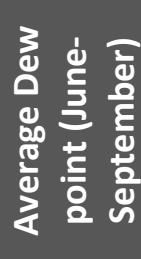 & 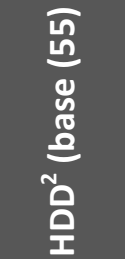 & 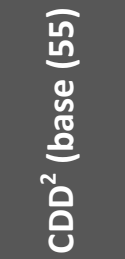 & 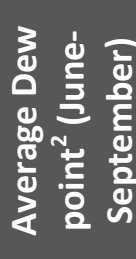 \\
\hline & & & a & b & C & d & e & $f$ & g \\
\hline \multirow{3}{*}{ A04c } & \multirow{3}{*}{$\begin{array}{c}\text { SAT Set point }= \\
56\end{array}$} & 0.98 & 0.0006 & $-3.22 \mathrm{E}-06$ & $-3.20 \mathrm{E}-06$ & $2.57 \mathrm{E}-03$ & $-2.59 \mathrm{E}-11$ & $-6.09 \mathrm{E}-12$ & $-2.21 \mathrm{E}-05$ \\
\hline & & 0.92 & 0.0758 & $-2.99 \mathrm{E}-06$ & $-4.15 E-06$ & & $-8.29 \mathrm{E}-11$ & $4.02 \mathrm{E}-11$ & \\
\hline & & 0.60 & 0.0543 & $1.60 \mathrm{E}-06$ & & & $-3.48 \mathrm{E}-10$ & & \\
\hline \multirow{3}{*}{ A04d } & \multirow{3}{*}{$\begin{array}{c}\text { SAT Set point }= \\
57\end{array}$} & 0.99 & 0.0067 & $-8.29 \mathrm{E}-06$ & $-6.68 \mathrm{E}-06$ & 4.84E-03 & $8.22 \mathrm{E}-11$ & $-1.07 \mathrm{E}-10$ & $-3.97 \mathrm{E}-05$ \\
\hline & & 0.90 & 0.1543 & $-7.75 E-06$ & $-8.79 E-06$ & & $-5.42 \mathrm{E}-11$ & $5.02 \mathrm{E}-11$ & \\
\hline & & 0.57 & 0.1075 & $2.34 \mathrm{E}-06$ & & & $-6.41 \mathrm{E}-10$ & & \\
\hline \multirow{3}{*}{ A04e } & \multirow{3}{*}{$\begin{array}{c}\text { SAT Set point }= \\
58\end{array}$} & 0.98 & -0.0042 & $-1.28 \mathrm{E}-05$ & $-1.01 \mathrm{E}-05$ & 7.49E-03 & $1.39 \mathrm{E}-10$ & $-1.59 \mathrm{E}-10$ & $-6.00 \mathrm{E}-05$ \\
\hline & & 0.88 & 0.2284 & $-1.18 \mathrm{E}-05$ & $-1.36 \mathrm{E}-05$ & & $-9.40 \mathrm{E}-11$ & $1.38 \mathrm{E}-10$ & \\
\hline & & 0.57 & 0.1579 & $3.15 \mathrm{E}-06$ & & & $-9.59 \mathrm{E}-10$ & & \\
\hline \multirow{3}{*}{ A05 } & \multirow{3}{*}{$\begin{array}{c}\text { Damper } \\
\text { Minimum Air } \\
\text { flow } 30 \%\end{array}$} & 0.94 & 0.0765 & $-7.10 \mathrm{E}-06$ & $-4.59 \mathrm{E}-06$ & $6.32 \mathrm{E}-03$ & $-4.79 \mathrm{E}-10$ & $-2.52 \mathrm{E}-10$ & $-5.55 \mathrm{E}-05$ \\
\hline & & 0.92 & 0.2576 & $-6.63 E-06$ & $-6.70 \mathrm{E}-06$ & & $-6.01 E-10$ & $-1.84 \mathrm{E}-10$ & \\
\hline & & 0.81 & 0.2143 & $3.44 \mathrm{E}-06$ & & & $-1.21 \mathrm{E}-09$ & & \\
\hline \multirow{3}{*}{ A06 } & \multirow{3}{*}{$\begin{array}{c}\text { Wider } \\
\text { Deadband }\end{array}$} & 0.94 & 0.1728 & $-1.05 E-06$ & $-1.01 \mathrm{E}-05$ & $1.58 \mathrm{E}-03$ & $-8.07 \mathrm{E}-10$ & $7.05 \mathrm{E}-10$ & $-1.98 \mathrm{E}-05$ \\
\hline & & 0.90 & 0.1993 & $-1.30 \mathrm{E}-06$ & $-9.56 \mathrm{E}-06$ & & $-7.45 \mathrm{E}-10$ & $4.98 \mathrm{E}-10$ & \\
\hline & & 0.80 & 0.1634 & $4.96 \mathrm{E}-06$ & & & $-1.06 \mathrm{E}-09$ & & \\
\hline \multirow{3}{*}{ A07 } & \multirow{3}{*}{$\begin{array}{c}\text { Minimum } \\
\text { Occupied OA } \\
\text { Schedule starts } \\
\text { 7AM }\end{array}$} & 1.00 & -0.0038 & $-1.00 \mathrm{E}-06$ & $-8.20 \mathrm{E}-07$ & $-1.48 \mathrm{E}-04$ & $6.36 \mathrm{E}-10$ & $3.15 \mathrm{E}-10$ & $4.01 \mathrm{E}-06$ \\
\hline & & 0.97 & 0.0006 & $-8.47 \mathrm{E}-07$ & $-1.25 \mathrm{E}-06$ & & $5.97 \mathrm{E}-10$ & $4.15 \mathrm{E}-10$ & \\
\hline & & 0.93 & 0.0078 & $-3.76 \mathrm{E}-06$ & & & $8.08 \mathrm{E}-10$ & & \\
\hline \multirow{3}{*}{ W01 } & \multirow{3}{*}{$\begin{array}{l}\text { Chilled-water } \\
\text { DP Reset }\end{array}$} & 0.84 & 0.0785 & $-2.72 \mathrm{E}-07$ & $-2.66 \mathrm{E}-06$ & $-2.85 \mathrm{E}-03$ & $-1.87 \mathrm{E}-11$ & $2.81 \mathrm{E}-10$ & $2.78 \mathrm{E}-05$ \\
\hline & & 0.44 & 0.0053 & $-3.18 \mathrm{E}-07$ & $-2.18 \mathrm{E}-06$ & & $-5.94 \mathrm{E}-12$ & $3.53 \mathrm{E}-10$ & \\
\hline & & 0.24 & 0.0053 & $-1.44 \mathrm{E}-06$ & & & $9.38 \mathrm{E}-11$ & & \\
\hline \multirow{3}{*}{ W02 } & \multirow{3}{*}{$\begin{array}{c}\text { Chilled-water } \\
\text { Temperature } \\
\text { Reset }\end{array}$} & 0.95 & 0.2337 & $-4.42 \mathrm{E}-06$ & $-5.25 E-07$ & $-8.50 \mathrm{E}-03$ & $1.80 \mathrm{E}-10$ & $4.48 \mathrm{E}-10$ & $8.95 \mathrm{E}-05$ \\
\hline & & 0.75 & 0.0373 & $-4.13 \mathrm{E}-06$ & $-2.91 \mathrm{E}-07$ & & $1.13 \mathrm{E}-10$ & $9.17 \mathrm{E}-10$ & \\
\hline & & 0.59 & 0.0670 & $-1.35 \mathrm{E}-05$ & & & $7.53 \mathrm{E}-10$ & & \\
\hline
\end{tabular}




\begin{tabular}{|c|c|c|c|c|c|c|c|c|c|}
\hline \multirow[t]{2}{*}{ \# } & \multirow[t]{2}{*}{ 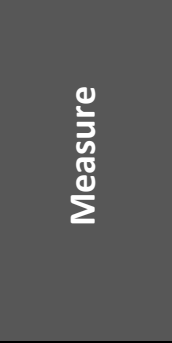 } & \multirow[t]{2}{*}{ ce } & $\begin{array}{l}\text { है } \\
\text { है } \\
\text { है } \\
\text { ᄋ }\end{array}$ & 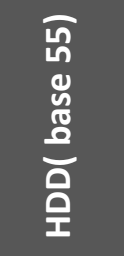 & 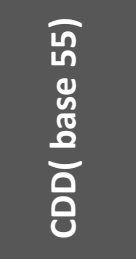 & 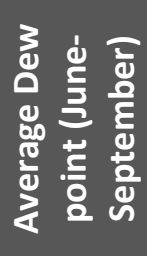 & 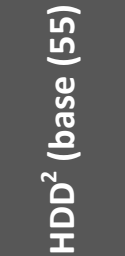 & 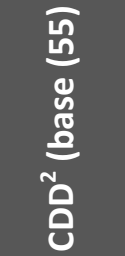 & 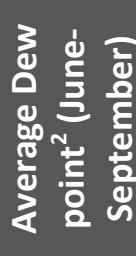 \\
\hline & & & a & b & $\mathrm{C}$ & d & e & f & g \\
\hline \multirow{3}{*}{ W03 } & \multirow{3}{*}{$\begin{array}{c}\text { Hot-water } \\
\text { Temperature } \\
\text { Reset }\end{array}$} & 0.95 & 0.0021 & $1.61 \mathrm{E}-07$ & $-1.30 \mathrm{E}-07$ & $-1.18 \mathrm{E}-04$ & $-9.15 E-12$ & 1.37E-11 & $1.23 \mathrm{E}-06$ \\
\hline & & 0.75 & -0.0006 & $1.64 \mathrm{E}-07$ & $-1.25 \mathrm{E}-07$ & & $-9.90 \mathrm{E}-12$ & $1.98 \mathrm{E}-11$ & \\
\hline & & 0.59 & -0.0006 & $1.04 \mathrm{E}-07$ & & & $-4.49 \mathrm{E}-12$ & & \\
\hline \multirow{3}{*}{ W04 } & \multirow{3}{*}{$\begin{array}{c}\text { Hot-water DP } \\
\text { Reset }\end{array}$} & 0.99 & 0.0010 & $2.29 \mathrm{E}-08$ & $-2.50 \mathrm{E}-08$ & $-3.73 \mathrm{E}-05$ & $-1.38 \mathrm{E}-11$ & $-2.43 E-13$ & $3.59 \mathrm{E}-07$ \\
\hline & & 0.99 & 0.0000 & $2.21 \mathrm{E}-08$ & $-1.80 \mathrm{E}-08$ & & $-1.35 \mathrm{E}-11$ & $5.36 \mathrm{E}-13$ & \\
\hline & & 0.98 & -0.0001 & $3.81 \mathrm{E}-08$ & & & $-1.44 \mathrm{E}-11$ & & \\
\hline \multirow{3}{*}{ W05 } & \multirow{3}{*}{$\begin{array}{l}\text { Condenser } \\
\text { Water } \\
\text { Temperature } \\
\text { Reset }\end{array}$} & 0.88 & 0.0056 & $-1.53 E-06$ & $3.58 \mathrm{E}-06$ & $1.64 \mathrm{E}-04$ & $9.16 \mathrm{E}-11$ & $-3.79 \mathrm{E}-10$ & $-3.67 \mathrm{E}-06$ \\
\hline & & 0.61 & 0.0033 & $-1.65 \mathrm{E}-06$ & $3.92 \mathrm{E}-06$ & & $1.23 \mathrm{E}-10$ & $-4.61 \mathrm{E}-10$ & \\
\hline & & 0.46 & 0.0093 & $-1.48 \mathrm{E}-06$ & & & $6.83 \mathrm{E}-11$ & & \\
\hline \multirow{3}{*}{ W06 } & \multirow{3}{*}{$\begin{array}{l}\text { Plant Shut } \\
\text { Down When } \\
\text { There Is No } \\
\text { Load }\end{array}$} & 0.98 & 0.0015 & 5.77E-06 & $-1.86 \mathrm{E}-06$ & $1.45 \mathrm{E}-04$ & $-3.86 \mathrm{E}-10$ & $1.99 \mathrm{E}-10$ & $-1.72 \mathrm{E}-06$ \\
\hline & & 0.98 & 0.0043 & 5.75E-06 & $-1.83 \mathrm{E}-06$ & & $-3.82 E-10$ & $1.84 \mathrm{E}-10$ & \\
\hline & & 0.97 & 0.0005 & $6.00 \mathrm{E}-06$ & & & $-3.79 E-10$ & & \\
\hline \multirow{3}{*}{$\mathrm{CO1}$} & \multirow{3}{*}{ Combo 1} & 0.94 & 0.7595 & $-4.70 \mathrm{E}-05$ & $-2.55 E-05$ & $9.05 \mathrm{E}-04$ & $-1.92 \mathrm{E}-10$ & $-1.46 \mathrm{E}-09$ & $-1.52 \mathrm{E}-05$ \\
\hline & & 0.94 & 0.7626 & $-4.74 \mathrm{E}-05$ & $-2.45 E-05$ & & $-9.78 \mathrm{E}-11$ & $-1.72 \mathrm{E}-09$ & \\
\hline & & 0.73 & 0.5681 & $6.20 \mathrm{E}-07$ & & & $-3.08 \mathrm{E}-09$ & & \\
\hline \multirow{3}{*}{$\mathrm{CO} 2$} & \multirow{3}{*}{ Combo 2} & 0.93 & 0.2684 & $-3.25 \mathrm{E}-05$ & $-1.89 \mathrm{E}-05$ & $1.25 \mathrm{E}-02$ & $-7.75 \mathrm{E}-11$ & $-2.31 E-09$ & $-1.16 \mathrm{E}-04$ \\
\hline & & 0.92 & 0.6061 & $-3.19 E-05$ & $-2.20 \mathrm{E}-05$ & & $-2.21 \mathrm{E}-10$ & $-2.41 E-09$ & \\
\hline & & 0.48 & 0.4025 & $2.03 \mathrm{E}-05$ & & & $-3.52 E-09$ & & \\
\hline \multirow{3}{*}{$\mathrm{CO3}$} & \multirow{3}{*}{ Combo 3} & 0.99 & 0.1888 & $-1.11 \mathrm{E}-05$ & $-1.72 \mathrm{E}-05$ & $9.58 \mathrm{E}-03$ & $-8.05 E-10$ & $-2.19 \mathrm{E}-10$ & $-8.37 \mathrm{E}-05$ \\
\hline & & 0.97 & 0.4647 & $-1.04 \mathrm{E}-05$ & $-2.05 E-05$ & & $-9.96 \mathrm{E}-10$ & $-9.87 E-11$ & \\
\hline & & 0.65 & 0.3479 & $1.55 \mathrm{E}-05$ & & & $-2.52 E-09$ & & \\
\hline \multirow{3}{*}{$\mathrm{CO4}$} & \multirow{3}{*}{ Combo 4} & 0.98 & 0.2130 & $-1.21 \mathrm{E}-05$ & $-1.80 \mathrm{E}-05$ & $6.67 \mathrm{E}-03$ & $-5.20 \mathrm{E}-10$ & $-3.91 \mathrm{E}-10$ & $-5.52 E-05$ \\
\hline & & 0.96 & 0.4144 & $-1.14 \mathrm{E}-05$ & $-2.09 \mathrm{E}-05$ & & $-7.00 \mathrm{E}-10$ & $-1.95 \mathrm{E}-10$ & \\
\hline & & 0.53 & 0.2925 & $1.59 \mathrm{E}-05$ & & & $-2.32 \mathrm{E}-09$ & & \\
\hline
\end{tabular}




\begin{tabular}{|c|c|c|c|c|c|c|c|c|c|}
\hline \multirow[t]{2}{*}{$\#$} & \multirow[t]{2}{*}{ 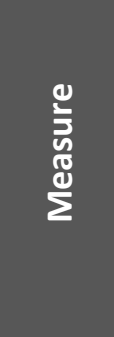 } & \multirow[t]{2}{*}{ ce } & $\begin{array}{l}\text { है } \\
\text { है } \\
\text { है } \\
\text { ठ }\end{array}$ & 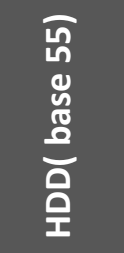 & $\begin{array}{l}50 \\
10 \\
y \\
\frac{0}{0} \\
\frac{0}{0} \\
0\end{array}$ & 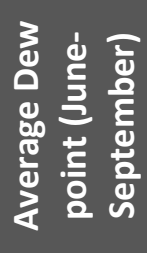 & 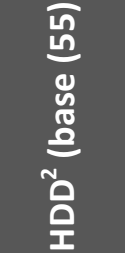 & 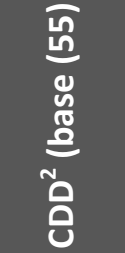 & 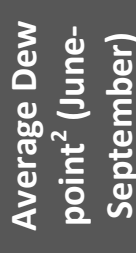 \\
\hline & & & a & b & C & d & e & f & g \\
\hline \multirow{3}{*}{ C05 } & \multirow{3}{*}{ Combo 5} & 0.89 & 0.5251 & $-3.42 \mathrm{E}-05$ & $-1.17 \mathrm{E}-05$ & $3.60 \mathrm{E}-03$ & $-2.27 \mathrm{E}-10$ & $-2.14 \mathrm{E}-09$ & $-2.64 \mathrm{E}-05$ \\
\hline & & 0.88 & 0.6447 & $-3.36 \mathrm{E}-05$ & $-1.38 \mathrm{E}-05$ & & $-3.77 \mathrm{E}-10$ & $-1.90 \mathrm{E}-09$ & \\
\hline & & 0.70 & 0.5034 & $3.39 E-06$ & & & $-2.73 E-09$ & & \\
\hline \multirow{3}{*}{ C06 } & \multirow{3}{*}{ Combo 6} & 0.92 & 0.7063 & $-4.27 \mathrm{E}-05$ & $-2.33 E-05$ & 2.37E-03 & 4.23E-10 & $-1.51 \mathrm{E}-09$ & $-2.68 \mathrm{E}-05$ \\
\hline & & 0.91 & 0.7556 & $-4.29 E-05$ & $-2.31 \mathrm{E}-05$ & & 4.69E-10 & $-1.71 E-09$ & \\
\hline & & 0.60 & 0.5697 & $3.22 \mathrm{E}-06$ & & & $-2.40 \mathrm{E}-09$ & & \\
\hline
\end{tabular}




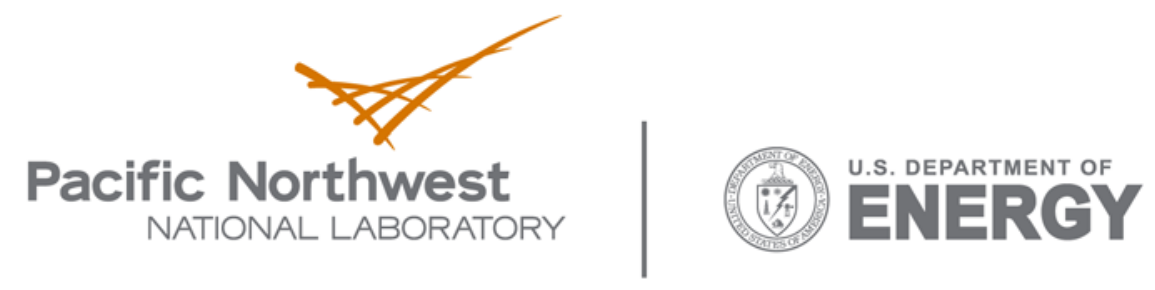

902 Battelle Boulevard

P.O. Box 999

Richland, WA 99352

1-888-375-PNNL (7665)

www.pnl.gov 